\title{
Characterizing the chemistry of yellow-poplar surfaces exposed to different surface energy environments using DCA, DSC, and XPS
}

Michael William Carpenter

West Virginia University

Follow this and additional works at: https://researchrepository.wvu.edu/etd

\section{Recommended Citation}

Carpenter, Michael William, "Characterizing the chemistry of yellow-poplar surfaces exposed to different surface energy environments using DCA, DSC, and XPS" (1999). Graduate Theses, Dissertations, and Problem Reports. 964.

https://researchrepository.wvu.edu/etd/964

This Thesis is protected by copyright and/or related rights. It has been brought to you by the The Research Repository @ WVU with permission from the rights-holder(s). You are free to use this Thesis in any way that is permitted by the copyright and related rights legislation that applies to your use. For other uses you must obtain permission from the rights-holder(s) directly, unless additional rights are indicated by a Creative Commons license in the record and/ or on the work itself. This Thesis has been accepted for inclusion in WVU Graduate Theses, Dissertations, and Problem Reports collection by an authorized administrator of The Research Repository @ WVU. For more information, please contact researchrepository@mail.wvu.edu. 


\title{
CHARACTERIZING THE CHEMISTRY OF YELLOW-POPLAR SURFACES EXPOSED TO DIFFERENT SURFACE ENERGY ENVIRONMENTS USING DCA, DSC, AND XPS.
}

\author{
Michael William Carpenter \\ Master's Thesis submitted to the \\ College of Agriculture, Forestry and Consumer Sciences of \\ West Virginia University \\ in partial fulfillment of the requirements for the degree of \\ MASTER OF SCIENCE
}

in

Forestry

\author{
James P. Armstrong, Ph.D., Chair \\ Lane Wilson, Ph.D. \\ Douglas J. Gardner, Ph.D. \\ Michael P. Wolcott. Ph.D.
}

Department of Wood Science

Morgantown, West Virginia

1999 


\title{
CHARACTERIZING THE CHEMISTRY OF YELLOW-POPLAR SURFACES EXPOSED TO DIFFERENT SURFACE ENERGY ENVIRONMENTS USING DCA, DSC, AND XPS.
}

\author{
by \\ Michael W. Carpenter \\ Committee Chairman: Douglas J. Gardner
}

\begin{abstract}
(ABSTRACT)
The increasing use of powdered instead of liquid resin in some modern wood composite manufacturing facilities requires wood material at significantly higher moisture content to aid in proper adhesion. Higher wood moisture content causes increased steam production during hot-pressing. Increased steam production is of concern because of its possible effects on the glass transition temperature $\left(\mathrm{T}_{\mathrm{g}}\right)$ of wood. Standard Differential scanning calorimetry was utilized to determine the effects of steam pre-conditioning on the $\mathrm{T}_{\mathrm{g}}$ of yellow-poplar sapwood and heartwood at $12 \%$ and FSP (30\%) moisture content. The $\mathrm{T}_{\mathrm{g}}$ values obtained for the sapwood and heartwood compared favorably with those found in the literature. At $30 \%$, the average $\mathrm{T}_{\mathrm{g}}$ was significantly lower than at $12 \%$ moisture content in both sapwood and heartwood. Steam pre-conditioning had no significant effect on the heartwood or sapwood at either moisture content.
\end{abstract}

Yellow-poplar, being a heterogeneous bio-polymer composite, has bulk and surface behavior that is similar to other better understood synthetic polymers. This similarity in behavior has allowed the use of fundamental polymer theory to better explain the molecular orientation of yellow-poplar surfaces in response to different environmental influences. Surface energy changes in extracted and unextracted yellow- 
poplar sapwood and heartwood resulting from exposure to aluminum, teflon, and heat/air surface treatments have been described using dynamic contact angle (DCA), and X-ray photoelectron spectroscopy (XPS) analyses. Results of this study have shown that the surface molecular orientation of yellow-poplar can be controlled by increasing the temperature above the $\mathrm{T}_{\mathrm{g}}$ of lignin while exposing it to either an environment that is higher (aluminum) or lower (teflon) in surface energy. Above the $\mathrm{T}_{\mathrm{g}}$, increases in free volume allows greater molecular mobility that enables increased diffusion of extractives to the surface and reorientation of polymer molecules and/or functional groups. Above the $T_{g}$, the wood with aluminum treatment is greater in surface energy than the control and other surface treatments. The surface energy obtained from teflon treatment at temperatures above the $\mathrm{T}_{\mathrm{g}}$, was lower than heat/air treatment. There was less preferential reorientation evident from all surface treatments with the absence of extractives. The XPS results offered support in describing surfaces abundant in low energy functional groups upon exposure to low energy environments and surfaces more abundant with high energy functional groups upon exposure to high energy environments. 


\section{ACKNOWLEDGEMENTS}

I wish to take this opportunity to express sincere appreciation to Drs. Douglas J. Gardner and Michael P. Wolcott for their untiring patience, valuable assistance, and guidance throughout the laboratory work and preparation of the written thesis. Sincere appreciation is also extended to Dr. Lane Wilson for his many insights and ideas as well as his invaluable help with the XPS portion of this thesis.

A special thanks must be given to my wife, Donna M. Carpenter and to my parents, John W. and Karen D. Carpenter, for their never-ending support in my educational endeavors. Thanks must also be given to Frank Ammons, Daisy Maxon, and Becky Warnke without whom many of the simple but important tasks would not have been accomplished. Additionally, I would like to thank Larry Osborn, Feiping Liu, John Nassar, Doug Knotts, and Michelle Richard-Babbs for their assistance.

The funding for this research was provided by the USDA National Research Initiative Competitive Grant 92-37103-7981 “Molecular response of wood surface to environmental influences." 


\section{TABLE OF CONTENTS}

$\begin{array}{lll}\text { ABSTRACT } & \text { ii }\end{array}$

ACKNOWLEDGEMENTS

LIST OF FIGURES vii

LIST OF TABLES viii

CHAPTER 1: INTRODUCTION 1

1.1 BACKGROUND 1

$\begin{array}{ll}1.2 \text { TECHNICAL OBJECTIVES } & 6\end{array}$

$\begin{array}{ll}1.3 \text { LITERATURE CITED } & 8\end{array}$

CHAPTER 2: DIFFERENTIAL SCANNING CALORIMETRY ANALYSIS OF YELLOW-POPLAR EXPOSED TO STEAM AT 12\% AND FSP MOISTURE CONTENT 9

ABSTRACT 9

2.1 INTRODUCTION 10

2.1.1 Background 11

2.1.2 Technical Objectives $\quad 12$

2.2 MATERIALS AND EXPERIMENTAL PROCEDURES 13

2.2.1 Materials $\quad 13$

2.2.2 Sample Preparation $\quad 13$

2.2.3 Thermal Analysis 14

$\begin{array}{ll}2.3 \text { RESULTS AND DISCUSSION } & 15\end{array}$

$\begin{array}{ll}2.4 \text { CONCLUSIONS } & 21\end{array}$

2.5 LITERATURE CITED 22

CHAPTER 3: ANALYSIS OF THE MOLECULAR ORIENTATION OF YELLOW-POPLAR SURFACES EXPOSED TO ALUMINUM, TEFLON, AND HEAT/AIR ENVIRONMENTS USING DCA AND XPS 23

$\begin{array}{ll}\text { ABSTRACT } & 23\end{array}$

3.1 INTRODUCTION 25

$\begin{array}{ll}3.1 .1 \text { Background } & 25\end{array}$

3.1.2 Technical Objectives $\quad 28$

3.2 LITERATURE REVIE 29

3.2.1 Adhesion Concepts and Theories 29

3.2.2 Chemistry of Wood Surfaces $\quad 33$

$\begin{array}{ll}3.2 .3 \text { Wood Surface Inactivation } & 38\end{array}$

3.2.4 Chemistry of Polymer Surfaces $\quad 40$

3.2.5 Molecular Reorientation of Polymer Surfaces 45

3.2.6 Polymer Theory with Respect to Wood Surfaces 54 
3.2.7 Surface Wettability and DCA Analysis 61

3.2.8 XPS Analysis of Surface Elemental Composition 70

3.3 MATERIALS AND EXPERIMENTAL PROCEDURES 72

3.3.1 Raw Material Selection $\quad 72$

3.3.2 Determination of Extractives Content 73

3.3.3 Flake Sample Preparation 74

3.3.4 Preparation of Extractive-Free Samples 75

3.3.5 Surface Treatment Methods 76

3.3.6 Maximum Moisture Loss Determination 78

3.3.7 Use of DCA Analysis in Measuring Surface Wettability 79

3.3.8 XPS Analysis to Examine Surface Elemental Composition 81

3.3.9 Statistical Design $\quad 81$

3.4 RESULTS AND DISCUSSION 83

3.4.1 Extractive Content of Sapwood and Heartwood 83

3.4.2 Moisture Loss from Surface Treatment 83

3.4.3 Description of Surface Energy Behavior from DCA Analysis 85

3.4.4 Elemental Surface Composition from XPS Analysis 100

3.5 CONCLUSIONS 103

3.6 LITERATURE CITED 107

$\begin{array}{ll}\text { APPENDICES } & 115\end{array}$

Appendix A. Individual Differential Scanning Calorimetry Scans, Heat of Transitions, and Statistical Analysis Results

Appendix A.1 DSC Scans of Yellow-Poplar 116

Appendix A.2 Transition Onset and Ending Values from DSC scans 129

Appendix A.3 Average Heat of Transition Values from DSC scans 131

Appendix A.4 Table of Statistical Analysis Results 133

Appendix B. Dynamic Contact Angle Results, Additional Figures, and Statistical Analysis Results

Appendix B.1 Contact Angle and Surface Energy Results 136

Appendix B.2 Additional Figures of Surface Energy Results 151

Appendix B.3 Tables of Average Surface Energy 175

Appendix B.4 Tables of Statistical Analysis Results 178 


\section{LIST OF FIGURES}

Figure 2.1. A DSC scan of yellow-poplar heartwood at $12 \%$ moisture content without steam pre-conditioning.

Figure 2.2. A DSC scan of yellow-poplar heartwood at $12 \%$ moisture content with steam pre-conditioning

Figure 2.3. A DSC scan of yellow-poplar heartwood at $30 \%$ moisture content without steam pre-conditioning.

Figure 3.1. A schematic representation of the hypothetical chain analogy of the adhesive-bond system adapted from Marra (1983).

Figure 3.2. Maximum moisture loss from surface treatment at different pressing temperatures.

Figure 3.3. Average FSE of unextracted yellow-poplar sapwood exposed to environments of high energy (aluminum), low energy (teflon), and heat/air.

Figure 3.4. Average FSE of unextracted yellow-poplar heartwood exposed to environments of high energy (aluminum), low energy (teflon), and heat/air.

Figure 3.5. Average FSE of extracted yellow-poplar sapwood exposed to environments of high energy (aluminum), low energy (teflon), and heat/air.

Figure 3.6. Average FSE of extracted yellow-poplar heartwood exposed to environments of high energy (aluminum), low energy (teflon), and heat/air.

Figure 3.7. Average FSE of unextracted and extracted yellow-poplar sapwood and heartwood exposed to heat/air surface treatment.

Figure 3.8. Average FSE of unextracted and extracted yellow-poplar sapwood and heartwood exposed to Aluminum surface treatment.

Figure 3.9. Average FSE of unextracted and extracted yellow-poplar sapwood and heartwood exposed to teflon surface treatment. 


\section{LIST OF TABLES}

Table 2.1. Average $\mathrm{T}_{\mathrm{g}}$ and (standard deviation) of yellow-poplar heartwood and sapwood at $12 \%$ and $30 \%$ moisture content with and without steam pre-conditioning.

Table 2.2. Average heat of transition values of yellow-poplar heartwood and sapwood at $12 \%$ and $30 \%$ moisture contents regardless of steam treatment.

Table 3.1. The extractive content in the sapwood and heartwood of yellow-Poplar.

Table 3.2. ANOVA of unextracted and extracted, heartwood and sapwood, final surface energy values.

Table 3.3. Duncan grouping of ANOVA results for final surface energy at $\alpha=0.05$; means with the same letter are not significantly different according to Duncan's New Multiple Range Test.

Table 3.4. Average (standard deviation) FSE results of unextracted yellow-poplar sapwood and heartwood exposed to environments of high energy (aluminum), low energy (teflon), and heat/air.

Table 3.5. Average (standard deviation) FSE results of extracted yellow-poplar sapwood and heartwood exposed to environments of high energy (aluminum), low energy (teflon), and heat/air.

Table 3.6. XPS carbon/oxygen $(\mathrm{C} / \mathrm{O})$ ratios for yellow-poplar sapwood (extracted and unextracted) and yellow-poplar heartwood with aluminum and teflon surface treatments. 


\section{CHAPTER 1}

\section{INTRODUCTION}

\subsection{BACKGROUND}

In a time of conservation and public awareness of the environment's limitations, the wood composite industry has gained wide acceptance because of its economic use of woodworking residues and generally under-utilized tree species. In the past, many tree species would have primarily been under-utilized with the exception of pulp and firewood production. The use of wood composites is an ecologically-sound alternative that can lessen some of the need placed on our non-renewable resources. Non-renewable resources, such as aluminum and steel, could then be allotted in a more conscientious manner to obtain their most beneficial use.

A large percentage of the wood products manufactured, whether solid wood or wood composites, are adhesively-bonded as a stage of production. A recent estimate renders that wood is adhesively-bonded in at least 70\% of its application (Hemingway and Connor 1989). Adhesive bonding in wood composites, though very complex, usually involves the following seven simple steps: 1.) wood is dried to proper moisture content, 2.) the surface is prepared (i.e. adding wax, etc.), 3.) adhesive is applied (i.e. in a blender), 4.) the wood material is consolidated (mat forming), 5.) pressure is applied (often with heat), 6.) time is allowed for adhesive to fully cure (i.e. hot stacking ), 7.) wood composite is allowed to cool to uniform temperature and moisture content (EMC).

The manufacturing processes of wood composites often exposes the bulk and surface of wood to influences from many different environmental conditions. The wood is sometimes 
exposed to harsh but necessary environmental influences such as its initial breakdown from roundwood into more advantageous geometries and sizes, to the exposure of its surfaces to the high temperatures and air flow of a mechanized drying system, or the consolidation of the wood particles, often with an adhesive, under heat and pressure.

Before veneer is peeled from logs in the production of plywood, the logs are often soaked in a vat of hot water or steamed. The manufacturing processes of some oriented strand board plants utilize a similar production step prior to breakdown of the logs into flakes. Heated water is sprayed onto the surfaces of debarked logs as they slowly move through the de-icing decks toward the flaker. The pre-conditioning of logs with heated water in the production methods of two similar but different products introduces a common benefit for machining. The addition of heated water de-ices the logs in the winter months and serves as a natural plasticizer. The heat and moisture plasticizes the amorphous wood polymers (hemicellulose and lignin) by reducing the interchain interactions and, consequently, their rigidity. In other words, the amorphous polymers of wood have less entanglement because of the increase in temperature and are allowed freer movement. Under water-soaked conditions where the amorphous portion of cellulose and hemicelluloses are already softened at room temperature, the properties of lignin places a particularly strong influence on the overall properties of the wood (Salmen 1985). The softening temperature of lignin is strongly influenced by moisture content. The higher the moisture content, the lower the softening temperature or the glass transition temperature $\left(\mathrm{T}_{\mathrm{g}}\right)$ of lignin (Ostberg et al. 1990). Having a lower $\mathrm{T}_{\mathrm{g}}$ can result in less energy being needed in the peeling and flaking of logs.

The flaking operation of OSB manufacture produces flakes of a slightly lower 
moisture content than they had originally as part of the log. Flakes lose moisture as they are cut, by the action of the knife and the exposure of new surfaces, from which evaporation can occur. The knife, as it cuts through the logs, creates friction which in turn creates heat. This additional heat also aids in the removal of moisture from the flakes. However, the moisture that is lost is not nearly enough with the present adhesive technology to prepare the flakes for future adhesion. This need for further drying is met in the drying stage of OSB and other wood composites.

Possibly the most important and least understood operation in wood composite manufacturing is drying. The effects of over-drying or under-drying have a direct impact on all subsequent operations. One important aspect of the drying operation is that, if done properly, it can save on time and costs. Wood material that is too wet requires more resin to have the same level of adhesion than wood of a lower moisture content. But, if the wood material is over-dried (too little moisture), the wood surface can become inactivated which also hinders the strength of the wood-adhesive bond (Hancock 1963). Inactivation is the term given to wood surfaces that exhibit poor adhesion. Over-dried wood surfaces can also result from drying temperatures being too high (above $400{ }^{\circ} \mathrm{F}$ ) and /or drying time that is too long (Christiansen 1990). As the moisture content of wood's surface falls below the fiber saturation point (FSP), the bound water moves to the surface as a vapor. As bound water leaves the surface, it does not provide the cooling effect that the evaporation of free water did. Because the surface is not cooled satisfactorily by the water vapor, the surface temperature begins to increase until surface inactivation occurs (Christiansen 1990). Traditionally, inactivation has been explained as the migration of low energy wood extractives to the surface (Christiansen 1990). However, it 
has also been noticed that the surface energies of extractive-free wood also change as a result of the reorientation of surface functional groups of wood to obtain thermodynamic equilibrium with the surrounding environment (Christiansen 1990). The thermal affects on the surface reorientation are more noticeable at temperatures at or above the $\mathrm{T}_{\mathrm{g}}$ of lignin where increases in molecular mobility occur.

Mat consolidation under heat and pressure, an often utilized manufacturing process of wood composites, exposes the wood surface to environments of rapidly changing temperature and stress. Current mat consolidation theory according to Palardy et al. (1989) involves the following events. Under conventional hot press conditions, heat from each of the press platens converts moisture on or near the mat surface to steam. Within the mat, there are moisture, temperature, and vapor pressure gradients created from both surfaces to its core. Also, horizontal gradients are established from the panel's center to its edges. The temperature and moisture gradients that are created, strongly influence softening and stress relaxation of the wood flakes of the mat during pressing.

In general, the manufacturing process of wood and wood-nonwood composites appears to be straightforward and uncomplicated. However, up close, it is evident that there are many variables present within the manufacturing process. Many of these variables result from the behavior of the wood surface, as it is influenced by it's surrounding environment. In order to produce a strong structural wood product, an understanding of how the wood surface is affected by its environment is necessary. This is especially true when new obstacles present themselves in the future with more frequent bonding of wood with other materials such as synthetic fibers, plastics, and other organic and inorganic materials (Youngquist and Rowell 
1989). The means of understanding how wood surfaces are affected by manufacturing processes, such as those previously mentioned, can be gained through results obtained directly from advanced solid-state analytical techniques combined with knowledge of amorphous polymer theory. This combination offers the ability to relate the surface properties of wood to physical phenomenon such as viscoelasticity, diffusion, and molecular reorientation. 


\subsection{TECHNICAL OBJECTIVES}

This study is aimed at gaining a more thorough understanding of wood surface behavior in response to surrounding environmental influences. The utilization of differential scanning calorimetry (DSC), dynamic contact angle analysis (DCA), and x-ray photoelectron spectroscopy (XPS) can provide the means whereby a better understanding of wood surfaces can be gained.

This thesis is presented in publication format so that each chapter can be read independently of the other chapters. DSC was applied, in chapter 2 , to thermally analyze the bulk of wood to obtain the $\mathrm{T}_{\mathrm{g}}$ of yellow-poplar sapwood and heartwood at $12 \%$ moisture content and FSP (30\%), with and without steam pre-conditioning. Comparisons will be made between the many combinations of sapwood and heartwood at the two moisture contents with and without pre-conditioning the wood to steam. Also, the $T_{g}$ values gained from yellow-poplar sapwood and heartwood at $12 \%$ moisture content will help to determine the temperatures at which surface treatments will be administered in chapter 3 of this study. With knowledge of yellow-poplar's $T_{g}$, the surface treatments can be placed at certain temperatures to utilize the physical and chemical changes that occur in the wood at and above the $T_{g}$. In chapter 3 , the discussion will proceed on to how the molecular orientation of functional groups that comprise yellow-poplar surfaces can reorient in response upon exposure to environments of different surface energies. More specifically, DCA and XPS will be used to discern the ability of the functional groups of yellow-poplar sapwood and heartwood, whether backbone or sidechain, to reorient in response to exposure to a high energy environment (aluminum) and a low energy 
environment (teflon). Also, knowledge will be gained into the role that extractives play in the surface upon exposure to the high and low energy environment. The results of this research will offer insight and ideas for the future of wood and wood composites manufacturing processes. 


\subsection{LITERATURE CITED}

Christiansen, A. W. 1990. How overdrying wood reduces its bonding to phenolformaldehyde adhesives: A critical review of the literature. Part I. Physical responses. Wood and Fiber Science. 22(4) : 441-459.

Hancock, W.V. 1963. Effect of heat treatment on the surface of veneer. Forest Products Journal. 13(2): 81-88.

Hemingway, R.W. and A.H. Conner. 1989. In: Adhesives from renewable resources. ACS Symposium Series 385, Hemingway, R.W., A.H. Conner, Branham, S.J. Eds., American Chemical Society, Washington, D.C.

Ostberg, G., L. Salmen and J. Terlecki. 1990. Softening temperature of moist wood measured by differential scanning calorimetry. Holzforschung. (44) 223-225.

Owen, M.J., T.M. Gentle, T. Orbeck and D.E. Williams. 1988. Dynamic wettability of hydrophobic polymers. In: Polymer Surface Dynamics. J.D. Andrade, Ed. Plenum Press, New York, NY pp. 101-110.

Palardy, R.D., B.A. Haataja, S.M. Shaler, A.D. Williams and T.L. Laufenberg. 1989. Pressing of wood composite panels at moderate temperature and high moisture content. Forest Products Journal. 39(4): 27-32.

Salmen, L. 1985. Viscoelastic properties of in situ lignin under water-saturated conditions. Journal of Material Science. (19) 3090-3096.

Youngquist, J.A., and R.M. Rowell. 1989. Opportunities for combining wood with nonwood materials. In: T.M. Maloney, Ed. Proceedings of the 23rd International Particleboard/Composite Materials Symposium. Washington State University, Pullman, WA. pp. 141-157. 


\title{
CHAPTER 2
}

\section{DIFFERENTIAL SCANNING CALORIMETRY ANALYSIS OF YELLOW-POPLAR EXPOSED TO STEAM AT 12\% AND FSP MOISTURE CONTENT}

\author{
ABSTRACT \\ The manufacture of wood composites often exposes wood to different and \\ sometimes extreme environments. A good example of such an environment is during mat \\ consolidation under heat and pressure. Higher wood moisture content causes increased vapor \\ pressure during hot-pressing. Of special concern is the effect of increased vapor pressure on the \\ softening temperature or $T_{g}$ of wood. The objective of this study was to determine, by standard \\ DSC, the effects of increased vapor pressure on the $T_{g}$ of yellow-poplar sapwood and heartwood, \\ at $12 \%$ and $30 \%$ moisture content. Increased vapor pressure within the wood was simulated by \\ pre-conditioning the wood with steam. The $\mathrm{T}_{\mathrm{g}}$ values obtained for yellow-poplar sapwood and \\ heartwood compare favorably with those found in other studies. At $30 \%$, the average $\mathrm{T}_{\mathrm{g}}$ was \\ significantly lower than at $12 \%$ moisture content in both sapwood and heartwood. Steam pre- \\ conditioning had no statistically significant affect on either the sapwood or heartwood at either \\ moisture content. Average heat of transition values were larger at 12\% than at 30\% moisture \\ content. Less heat of transition occurring with 30\% moisture content resulted from weaker \\ chemical bonding among the primary wood constituents because of water saturation in the wood \\ fibers. The higher heat of transition values were associated with the higher $T_{g}$ values of both \\ sapwood and heartwood at the lower moisture content.
}




\subsection{INTRODUCTION}

The manufacture of wood composites often exposes wood to different and sometimes extreme environments. A particularly good example of such an environment is during mat consolidation under heat and pressure.With the recent upsurge of wood composite manufacturing facilities, especially oriented strand board, comes the use of relatively new technology in wood adhesives. (Wood Technology 1995). A fair amount of the manufacturing facilities are relying on powdered resin systems to supply the necessary level of adhesion in their product. The use of powdered resin instead of the more familiar liquid resins implies that the wood has a higher moisture content upon application. This moisture aids in distribution and adhesion of the resin to the wood before hot-pressing. The extra moisture also lowers the viscosity when the resin gains flow upon the application of heat and pressure. However, excess moisture is not wanted because of the possibility of resin loss occurring at the glue-line.

The presence of higher moisture in the hot-pressing stage of manufacturing often means a higher vapor pressure obtained within the composite mat. The increase in vapor pressure, mainly in the form of steam, subjects the wood to stresses that can affect some of its physical properties and behaviors. Of special concern is the plasticization that occurs within the natural polymers of wood and the effect of the developed steam on the softening temperature of wood. It's effects may not only be limited to that stage of manufacturing but, also to how the wood composite reacts later in its end-use. 


\subsubsection{Background}

Wood is a natural polymeric composite primarily composed of varying amounts of cellulose, hemicellulose, and lignin. These three polymers in situ in wood display both amorphous and crystalline physical and mechanical properties. The presence of both amorphous and crystalline forms in the chemical structure of wood reveals it as both a viscous and an elastic material. Wood is commonly referred to as being a viscoelastic material. At low temperatures, viscoelastic materials are glassy, hard and brittle. As the temperature is increased, viscoelastic materials undergo a glass-rubber transition or, what is sometimes called, softening. The temperature at which this softening occurs is designated as the softening temperature or glass transition temperature $\left(\mathrm{T}_{\mathrm{g}}\right)$.

The $\mathrm{T}_{\mathrm{g}}$ has been defined as the temperature of onset of extensive molecular motion that is long-range and coordinated (Billmeyer 1984; Sperling 1986). Many thermal analysis techniques are available for determining the $\mathrm{T}_{\mathrm{g}}$ of visco-elastic materials. Some of the most useful thermal analysis techniques are standard differential scanning calorimetry (DSC), modulated differential scanning calorimetry (MDSC), differential thermal analysis (DTA), dynamic mechanical thermal analysis (DMTA), and thermogravimetric analysis. (Nguyen et al. 1980; Kelley et al. 1987).

Thermal analysis, such as DSC, involves the measuring of heat flux as a function of temperature while a substance is subjected to a controlled temperature program (Sperling 1986). DSC has been utilized to investigate, with respect to temperature, the thermal properties of wood (Nguyen et al. 1980, 1982, 1983; Nguyen 1982, Ostberg et al. 1990; Kelley et al. 1987). It is known that wood exhibits two $\mathrm{T}_{\mathrm{g}}$ 's that correspond with the two amorphous polymer components of wood (Gunnells et al. 1994). However, according to Irvine (1984), a 
secondary transition may also exist in the amorphous portions of cellulose. Hemicellulose of wood has a $\mathrm{T}_{\mathrm{g}}$ in the range of -23 and $200{ }^{\circ} \mathrm{C}$ (Kelley et al. 1987) and lignin has a $\mathrm{T}_{\mathrm{g}}$ in the range of 60 and $200{ }^{\circ} \mathrm{C}$ (Salmen 1984). Irvine (1984) reported the $\mathrm{T}_{\mathrm{g}}$ of in situ lignin for various water-saturated wood species to occur within a temperature range of 60 to $90{ }^{\circ} \mathrm{C}$. The $\mathrm{T}_{\mathrm{g}}$ depends on the moisture content of the wood as well as the method used to detect it (Kelley et al. 1987; Salmen 1984; Irvine 1984).

\subsubsection{Technical Objectives}

In this study, standard DSC is utilized to thermally analyze the effect on the $\mathrm{T}_{\mathrm{g}}$ of wood caused by increased vapor pressure in the hot-pressing stage of some wood composite manufacturing processes. Steam pre-conditioning of yellow-poplar sapwood and heartwood, at two moisture contents, is done to simulate the results of increased vapor pressure. The two moisture contents are $12 \%$ and $30 \%$. Any differences that occur in the heat of transitions for the different conditions will be noted and discussed. Comparisons will be made to reveal the effects of moisture content, sapwood as opposed to heartwood, and the effects of steam pre-conditioning on the $\mathrm{T}_{\mathrm{g}}$ of wood. 


\subsection{MATERIALS AND EXPERIMENTAL PROCEDURES}

\subsubsection{Materials}

The sapwood and heartwood of yellow-poplar (Liriodendron tulipifera) were the materials utilized in this study. The wood was obtained from a tree with no outward signs of defect or disease, grown in an even-aged stand of Appalachian hardwoods. The sapwood portion of the yellow-poplar wood was separated from what was distinctly heartwood. The heartwood has considerably more extractives present that gives the wood a green appearance. Only the straight-grained and evenly-colored wood was chosen for further sample preparation.

\subsubsection{Sample Preparation}

Sapwood and heartwood blocks of wood were disk-flaked into flakes of roughly the same size and thickness. These flakes were then further broken down into small particles with the use of a Wiley mill. Only the wood particles that were small enough to be sifted through a 40 mesh sieve but large enough not to sift through a 50 mesh sieve were retained for further treatment. A 40 mesh sieve has openings of a size that 40 of them would equal one linear inch. This provided a ground wood sample with particles of a uniform size and without fine wood powder.

A portion of the sapwood and heartwood samples were pre-conditioned with steam in an autoclave. The samples were placed into separate cellulose-based disposable Soxhlet extraction thimbles before exposure to steam at $125^{\circ} \mathrm{C}$ for one hour.

After the steam pre-conditioning, one-half of the "steamed" sapwood and heartwood samples were conditioned to $12 \%$ moisture content, oven-dry basis, and the other half close to 
the fiber saturation point (FSP). The portion of sapwood and heartwood samples that were not exposed to steam were also divided and conditioned to the same two moisture contents. The samples conditioned to $12 \%$ moisture content were batch-conditioned in a humidity controlled cabinet for two weeks at $65 \%$ relative humidity. The dry-bulb temperature was $21^{\circ} \mathrm{C}$ and the wet-bulb temperature was $15^{\circ} \mathrm{C}$. The samples conditioned close to FSP were conditioned in a dessicator bowl with distilled water in the bottom portion instead of desiccant. The dessicator bowl with distilled water provided an environment with a relative humidity of $100 \%$ that would allow the wood samples to approach the FSP. At the end of the two weeks, moisture content samples were taken from the $12 \%$ and FSP samples and the gravimetric method of moisture content determination was performed to indicate whether the desired moisture content had been reached for both. An average moisture content of $30 \%$ was obtained in the FSP samples.

\subsubsection{Thermal Analysis}

Standard DSC analyses were performed with a TA Instruments-Thermal Analyst 2910 system equipped with a $\mathrm{LN}_{2}$ (liquid nitrogen) cooler . The DSC cell was purged constantly with $\mathrm{N}_{2}$ gas at a flow rate of $100 \mathrm{ml} / \mathrm{min}$ while scans were taken. Wood samples ranging in size from $3 \mathrm{mg}$ to $6 \mathrm{mg}$ were hermetically sealed in aluminum pans with the TA Instruments encapsulating press. The samples were scanned from $-25^{\circ} \mathrm{C}$ to $210{ }^{\circ} \mathrm{C}$ with a heating rate of $10^{\circ} \mathrm{C} / \mathrm{min}$. The system was baseline calibrated with a $13.24 \mathrm{mg}$ sample of indium and also heat capacity calibrated with a $4.90 \mathrm{mg}$ sapphire sample. Three samples were scanned at each of the following conditions; heartwood or sapwood, $12 \%$ or $30 \%$ moisture content, with or without steam pre-conditioning. The glass transition temperatures, $\mathrm{T}_{\mathrm{g}}$, were determined with 
the use of a commercially available software package that uses tangent lines to find the onset, inflection, and end of the step transition.

The $\mathrm{T}_{\mathrm{g}}$ results obtained from each DSC scan were compiled and analyzed using a completely randomized analysis of variance (ANOVA) with an equal sample size of three. The ANOVA's were performed with Statistical Analysis Software (SAS) for microcomputers. A general linear model was employed for $\mathrm{T}_{\mathrm{g}}$ to determine the effects of species (sapwood or heartwood), moisture content (12\% or $30 \%)$, steam pre-conditioning, and all possible interactions. The level of statistical significance in $\mathrm{T}_{\mathrm{g}}$ was set at a confidence level of $5 \%(\alpha=$ $0.05)$.

\subsection{RESULTS AND DISCUSSION}

Figures 2.1 through 2.3 contain typical DSC-scans of yellow-poplar heartwood at $12 \%$ and $30 \%$ moisture content with and without steam pre-conditioning. Present in the scans is the heat flow as a solid line and its first derivative as the broken line. The $\mathrm{T}_{\mathrm{g}}$ determined for each of the samples is also included within each of the figures. When viewing the heat flow curves, it is evident that as the temperature nears $100{ }^{\circ} \mathrm{C}$, the boiling point of water, the heat flow decreases at an increasing rate while the derivative heat flow increases at an increasing rate. This decreasing and increasing in the heat flow curves is a result of the hermetically-sealed pans releasing built-up water-vapor pressure. Every scan performed in this study had the same release of water-vapor pressure within the range of 125 to $150{ }^{\circ} \mathrm{C}$. Ostberg et al. (1990) reported the same trouble with sealing the pans hermetically so that there is no water lost during the scan. 


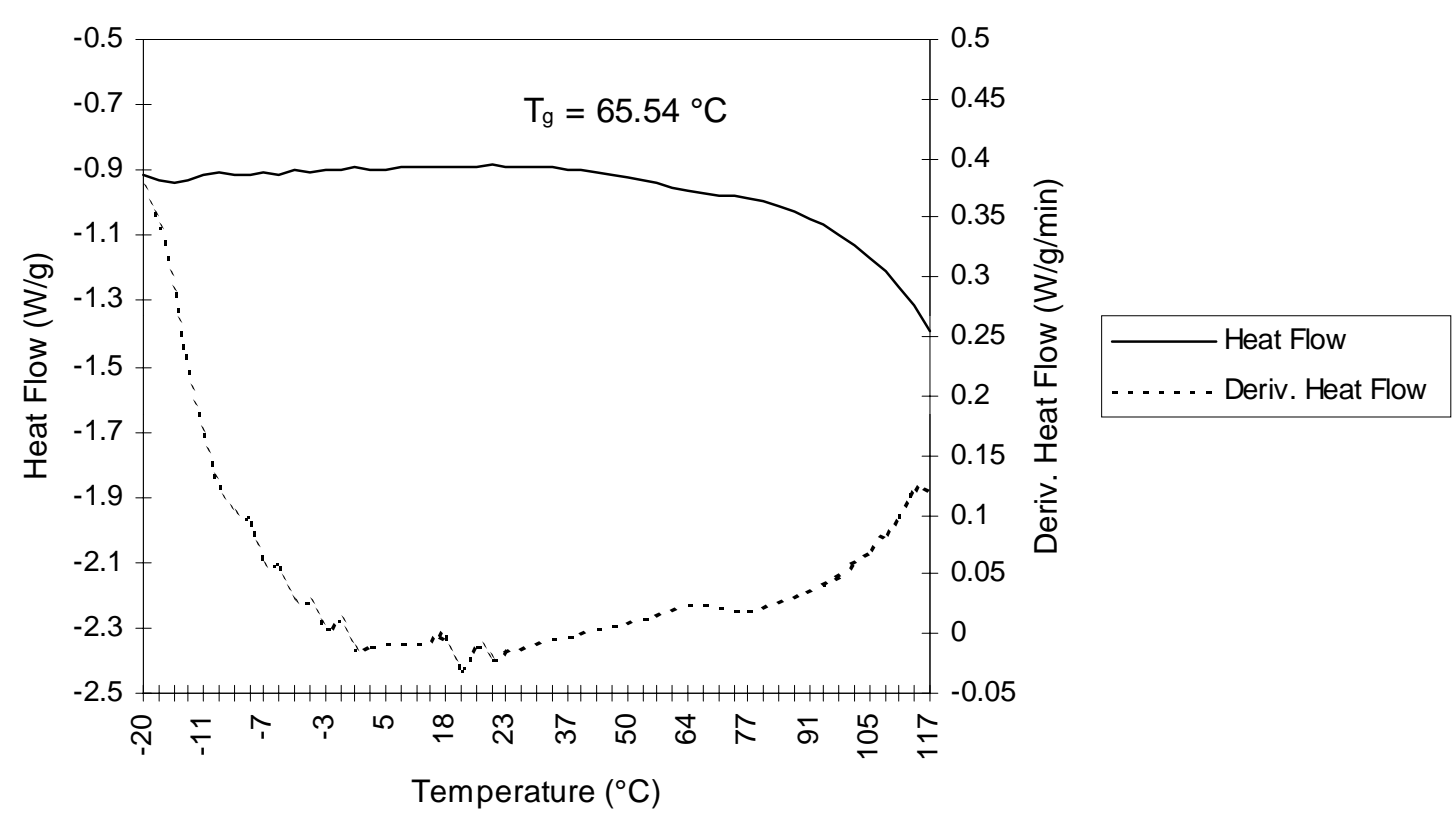

Figure 2.1. A DSC scan of yellow-poplar heartwood at $12 \%$ moisture content without steam pre-conditioning.

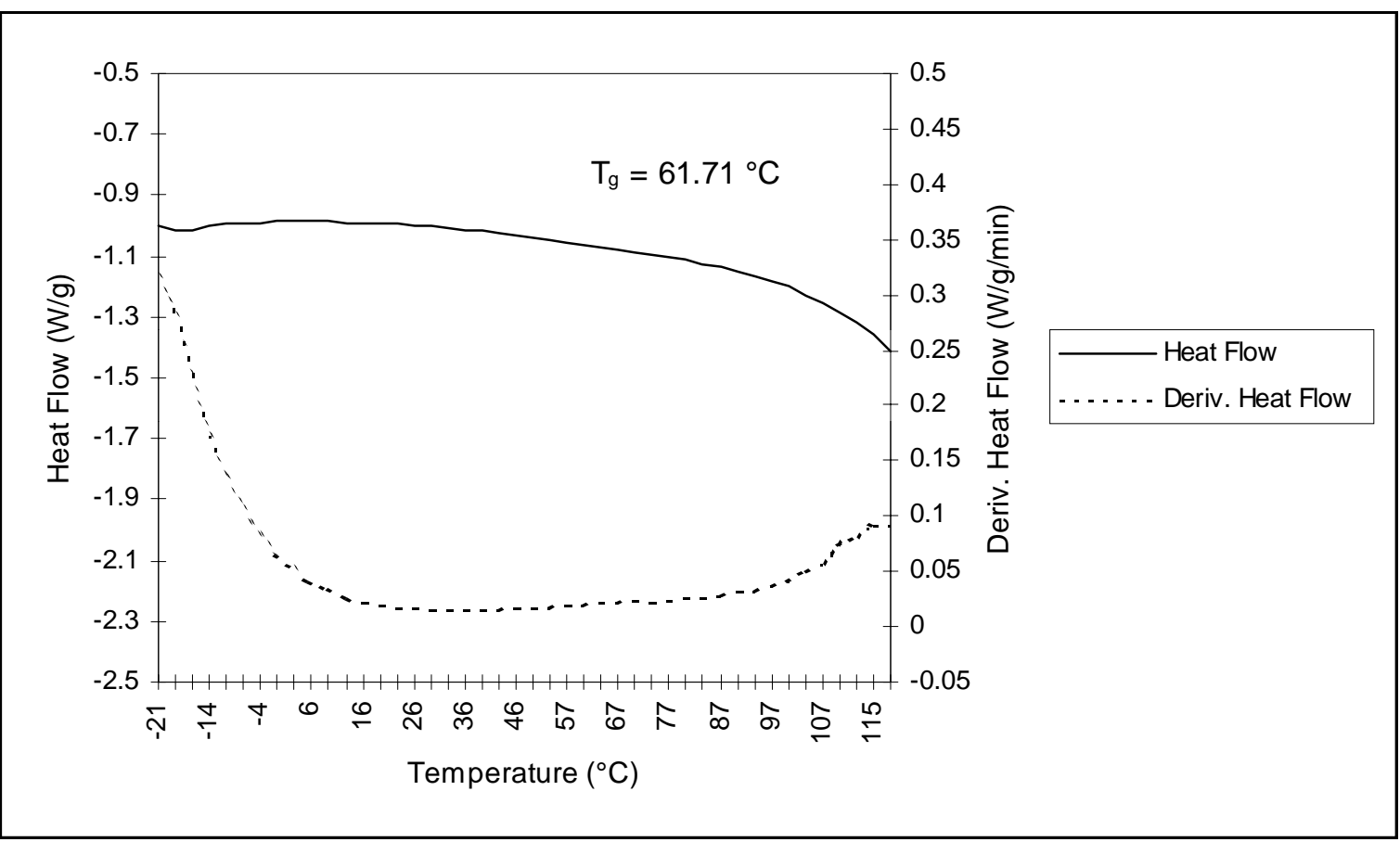

Figure 2.2. A DSC scan of yellow-poplar heartwood at $12 \%$ moisture content with steam pre-conditioning 

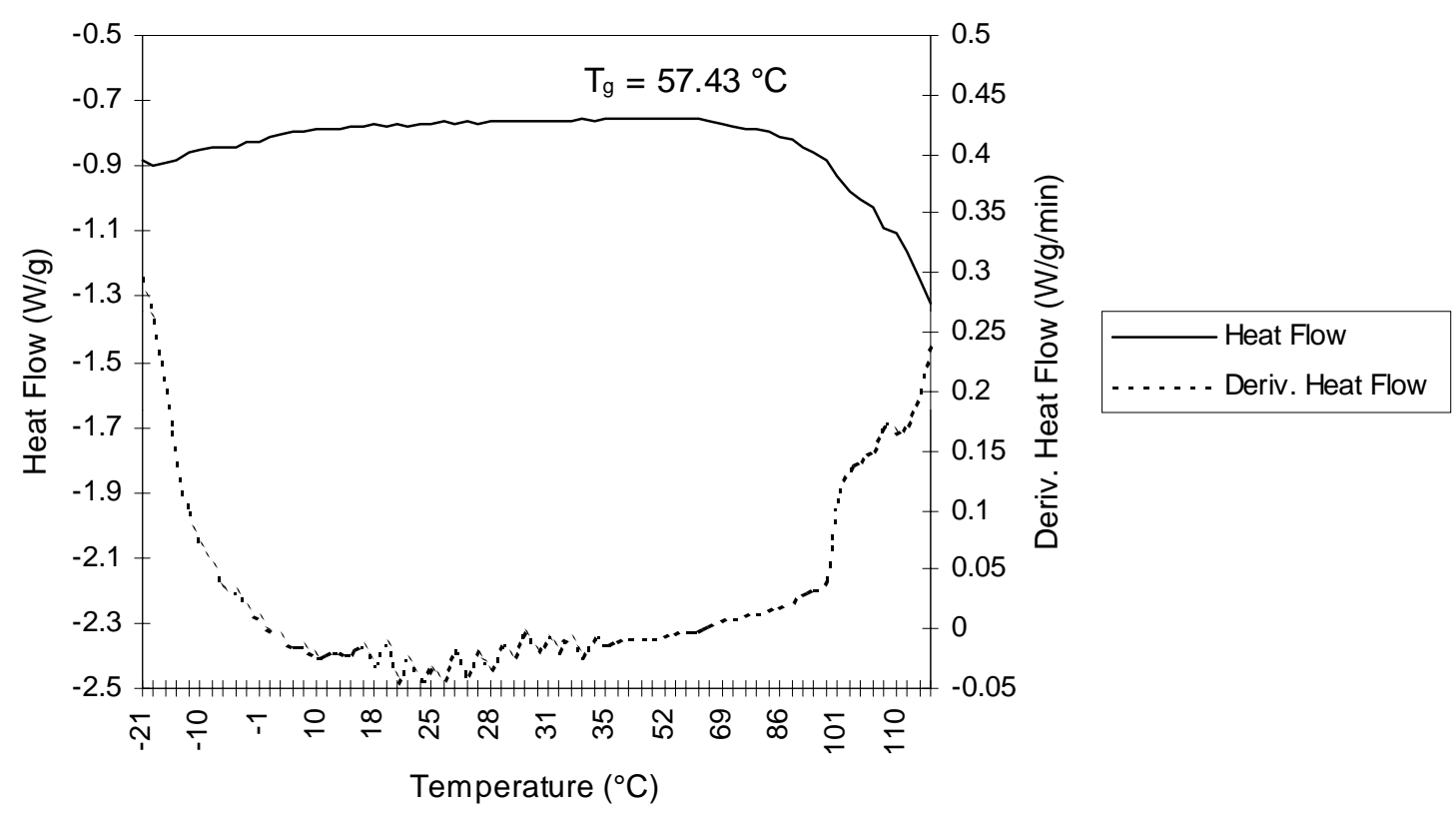

Figure 2.3. A DSC scan of yellow-poplar heartwood at $30 \%$ moisture content without steam pre-conditioning.

All of the individual DSC scans are contained within Appendix A.1. Also, tables containing all individual glass transition onset and ending values along with summarized statistical analysis results are presented in the Appendix as A.2 and A.4 respectively.

Average $T_{g}$ values with their corresponding standard deviations are presented in Table 2.1. Note that in Table 2.1, it is evident that the Average $\mathrm{T}_{\mathrm{g}}$ values at $12 \%$ moisture content are higher than those at $30 \%$. Heartwood at $12 \%$, without steam pre-conditioning, had a $\mathrm{T}_{\mathrm{g}}$ of 62.93 ${ }^{\circ} \mathrm{C}$ as opposed to $58.59{ }^{\circ} \mathrm{C}$ at $30 \%$. This difference also occurred with steam pre-conditioning where heartwood had a $\mathrm{T}_{\mathrm{g}}$ of $63.45^{\circ} \mathrm{C}$ at $12 \%$ and $61.72{ }^{\circ} \mathrm{C}$ at $30 \%$ moisture content. Higher average $\mathrm{T}_{\mathrm{g}}$ values at $12 \%$ moisture content also occurred in sapwood with and without steam preconditioning. The difference is most noticable in comparing the $\mathrm{T}_{\mathrm{g}}\left(67.67^{\circ} \mathrm{C}\right)$ of sapwood at 
$12 \%$ to its $\mathrm{T}_{\mathrm{g}}\left(60.38{ }^{\circ} \mathrm{C}\right)$ at $30 \%$ moisture content without steam pre-conditioning. The ANOVA results support this showing statistical significance of a real difference in $\mathrm{T}_{\mathrm{g}}$ at $12 \%$ and $30 \%$ moisture content. These results indicate the plasticization effect that increased moisture has on wood in lowering its $\mathrm{T}_{\mathrm{g}}$.

Table 2.1. Average $\mathrm{T}_{\mathrm{g}}$ and (standard deviation) of yellow-poplar heartwood and sapwood at $12 \%$ and $30 \%$ moisture content with and without steam pre-conditioning.

\begin{tabular}{||c||c|c|c||}
\cline { 3 - 4 } \multicolumn{1}{c|}{} & \multicolumn{1}{c|}{ Steam $\left({ }^{\circ} \mathbf{C}\right)$} & No Steam $\left({ }^{\circ} \mathbf{C}\right)$ \\
\hline \multirow{3}{*}{ Heartwood } & $\mathbf{1 2 \%}$ & $63.45(5.69)$ & $62.93(3.13)$ \\
\cline { 3 - 4 } & $\mathbf{3 0 \%}$ & $61.72(0.94)$ & $58.59(1.08)$ \\
\hline \hline \multirow{2}{*}{ Sapwood } & $\mathbf{1 2 \%}$ & $67.47(3.43)$ & $67.67(3.08)$ \\
\cline { 2 - 4 } & $\mathbf{3 0 \%}$ & $61.67(2.87)$ & $60.38(1.69)$ \\
\hline
\end{tabular}

The $\mathrm{T}_{\mathrm{g}}$ values obtained for yellow-poplar sapwood and heartwood at $12 \%$ and $30 \%$ moisture content compare favorably with those found in the literature for yellow-poplar and other hardwood species. Gunnells et al. (1994) utilizing DSC, found yellow-poplar sapwood to have a $\mathrm{T}_{\mathrm{g}}$ of $75{ }^{\circ} \mathrm{C}$ at $12 \%$ moisture content and $63{ }^{\circ} \mathrm{C}$ at $31 \%$ moisture content. Gunnells et al. (1994) also revealed red oak (Quercus rubra) to have a $\mathrm{T}_{\mathrm{g}}$ of $68^{\circ} \mathrm{C}$ at $12 \%$ moisture content and $66^{\circ} \mathrm{C}$ at $31 \%$. Ostberg et al. (1990) detected a $\mathrm{T}_{\mathrm{g}}$ of about $68^{\circ} \mathrm{C}$ for birch wood (Betula verrucosa) a structurally similar diffuse-porous hardwood.

At the DSC-temperature range tested only one $\mathrm{T}_{\mathrm{g}}$ was found in each individual scan. Irvine (1984), Kelley et al. (1987), and Ostberg et al. (1990) also found only one thermal transition with the use of DSC and assigned it to that of lignin. However, it is also believed that the observed $\mathrm{T}_{\mathrm{g}}$ of in situ lignin represents the $\mathrm{T}_{\mathrm{g}}$ of the lignin-hemicellulose matrix because of 
the close association of lignin and hemicellulose in wood (Kelley et al. 1987).

There was no statistically-significant difference (at $\alpha=0.05$ ) between the average $\mathrm{T}_{\mathrm{g}}$ of heartwood and sapwood at either moisture content or steam pre-conditioning. Also, steam preconditioning had no statistically-significant effect $(\alpha=0.05)$ on either sapwood or heartwood and at either moisture content. No significant interactions of the main treatment effects were revealed by the ANOVA results either.

Table 2.2 contains average heat of transition values of yellow-poplar sapwood and heartwood at $12 \%$ and $30 \%$ moisture content regardless of steam pre-conditioning. The average heat of transition values with standard deviations of yellow-poplar sapwood and heartwood at both moisture contents with and without steam pre-conditioning are contained in Appendix A.3. Note that in Table 2.2 the average heat of transitions are larger for both heartwood and sapwood at $12 \%$ than they are at $30 \%$ moisture content. Smith and Van Ness (1987) stated that energy in the form of heat is released from the wood resulting in a change in its heat capacity to make-up for the difference between the energy required to break old bonds and the forming of new bonds.

Table 2.2. Average heat of transition values of yellow-poplar heartwood and sapwood at $12 \%$ and $30 \%$ moisture contents regardless of steam treatment.

\begin{tabular}{|c|c|c|}
\hline \multirow[b]{2}{*}{ Sample } & \multicolumn{2}{|c|}{ Moisture Content } \\
\hline & $12 \%$ & $30 \%$ \\
\hline Heartwood & $0.0573(\mathrm{~W} / \mathrm{g})$ & $0.0228(\mathrm{~W} / \mathrm{g})$ \\
\hline Sapwood & $0.0084(\mathrm{~W} / \mathrm{g})$ & $0.0077(\mathrm{~W} / \mathrm{g})$ \\
\hline
\end{tabular}

This difference in energy is recognized as the wood's heat of transition as it is experiencing a 
thermal transition such as its $\mathrm{T}_{\mathrm{g}}$. At $12 \%$ moisture content there is less water within the wood fibers than there is at $30 \%$ which is close to the wood's FSP. Water residing in the fiber cell wall forms hydrogen bonds with the hydroxyl containing natural polymers such as cellulose, hemicelluloses, and lignin. These hydrogen bonds can and often do take the place of possible stronger bonds that could occur between the components of the lignin-hemicellulose matrix and cellulose. With less water molecules being hydrogen bonded in the wood-cell walls at $12 \%$ moisture content, a higher heat of transition occurs resulting from relatively stronger bonds. The higher heat of transitions are associated with the higher $\mathrm{T}_{\mathrm{g}}$ values of both sapwood and heartwood at the lower moisture content. 


\subsection{CONCLUSIONS}

When powdered resins are used in wood composite manufacturing, increased wood moisture is beneficial to adhesion. However, the high temperature and pressure utilized can create excess vapor pressure from the moisture in the wood. This increased vapor pressure may have the potential of influencing some of wood's physical properties. One physical property that is important in the behavior of wood is its softening point or $\mathrm{T}_{\mathrm{g}}$.

The primary goal in this study was to use standard DSC to thermally analyze the effect on the $T_{\mathrm{g}}$ of wood caused by increased vapor pressure in the hot-pressing stage of wood composite manufacturing. Comparisons were made to reveal the effects at $12 \%$ and $30 \%$ moisture content and sapwood as opposed to heartwood.

The $\mathrm{T}_{\mathrm{g}}$ values obtained with DSC for yellow-poplar sapwood and heartwood compare favorably with those found in similar studies. It is evident that at higher moisture contents, the plasticization effects of water within the wood did significantly lower the $T_{g}$ values in both sapwood and heartwood. The steam pre-conditioning had no significant effect on the $T_{\mathrm{g}}$ of either sapwood or heartwood at both $12 \%$ and $30 \%$ moisture content.

Average heat of transition values were larger at $12 \%$ than at $30 \%$ moisture content. Less heat of transition occurring with $30 \%$ moisture content resulted from weaker chemical bonding among the primary wood constituents due to water saturation of the wood fibers. The higher heat of transition values were associated with the higher $T_{g}$ values of both sapwood and heartwood at the lower moisture content. 


\subsection{LITERATURE CITED}

Billmeyer, F. W. 1984. Textbook of Polymer Science. Wiley-Interscience. John Wiley and Sons, Inc. New York.

Gunnells, D. W., D. J. Garner, and M. P. Wolcott. 1993. Temperature dependence of wood surface energy. Wood and Fiber Science. 26(4): 447-455.

Irvine, G. M. 1984. The glass transitions of lignin and hemicellulose and their measurement by different thermal analysis. Tappi 67(5): 118-121.

Kelley, S. S., T. G. Rials, and W. G. Glasser. 1987. Relaxation behavior of the amorphous components of wood. Journal of Material Science. 22: 617-624.

Nguyen, T. 1982. The role of lignin in surface-activated bonding of lignocellulose-characterized by differential scanning calorimetry. Journal of Adhesion. 14: 283-294.

Nguyen, T., E. Zavarin, and E. M. Barrall, II. 1980. Differential scanning calorimetry of hydrogen peroxide and hydrogen peroxide-treated ligno-cellulose. I. Ambient pressure conditions. Thermochin. Acta. 41: 107-116.

Ostberg, G., L. Salmen, and J. Terlecki. 1990. Softening temperature of moist wood measured by differential scanning calorimetry. Holzforschung. 44(3): 223-225.

Parham, R. A. and R. L. Gray. 1984. Formation and structure of wood. In: The Chemistry of Solid Wood. R. M. Rowell, Ed. Advances in Chemistry Series 207. American Chemical Society, Washington D. C.

Salmen, L. 1984. Visco-elastic properties of in situ lignin under water saturated conditions. Journal of Material Science. 19: 3090-3096

Smith, J. M. and H. C. Van Ness. 1987. Introduction to Chemical Engineering Thermodynamics. McGraw-Hill Series in Chemical Engineering. New York.

Sperling, L. H. 1986. Introduction to Physical Polymer Science. Wiley-Interscience. John Wiley and Sons, Inc. New York.

Wood Technology. 1995. Global panel industry increases growth rate. Wood Technology. 122: $35-51$. 


\title{
CHAPTER 3
}

\section{ANALYSIS OF THE MOLECULAR ORIENTATION OF YELLOW-POPLAR SURFACES EXPOSED TO ALUMINUM, TEFLON, AND HEAT/AIR ENVIRONMENTS USING DCA AND XPS}

\begin{abstract}
Yellow-poplar, being a heterogeneous bio-polymer composite, has bulk and surface behavior that is similar to other better understood synthetic polymers. This similarity in behavior has allowed the use of fundamental polymer theory to better explain the molecular orientation of yellow-poplar surfaces in response to different environmental influences. Surface energy changes in extracted and unextracted yellow-poplar sapwood and heartwood resulting from exposure to aluminum, teflon, at heat/air surface treatments have been described using dynamic contact angle (DCA), and X-ray photoelectron spectroscopy (XPS) analyses. Results of this study have shown that the surface molecular orientation of yellow-poplar can be controlled by increasing the temperature above the $\mathrm{T}_{\mathrm{g}}$ of lignin while exposing it to either an environment that is higher (aluminum) or lower (teflon) in surface energy. Above the $\mathrm{T}_{\mathrm{g}}$, increases in free volume allows greater molecular mobility that enables increased diffusion of extractives to the surface and reorientation of polymer molecules and/or functional groups. Above the $\mathrm{T}_{\mathrm{g}}$, the wood with aluminum treatment is greater in surface energy than the control and other surface treatments. The surface energy obtained from teflon treatment at temperatures above the $\mathrm{T}_{\mathrm{g}}$, was lower than heat/air treatment. There was less preferential reorientation evident from all surface treatments with the absence of extractives. The XPS results offered support in describing surfaces abundant
\end{abstract}


in low energy functional groups upon exposure to low energy environments and surfaces more abundant with high energy functional groups upon exposure to high energy environments. 


\subsection{INTRODUCTION}

\subsubsection{Background}

Wood and wood-nonwood composites, being the most abundant and widely used materials in the world, touch virtually everyone. The importance of wood has been displayed over the years in its many uses both as a structural and non-structural, appearance oriented, material. The wood composites industry utilizes wood by breaking it down in some manner into sawn lumber, veneer, or particles and reconstituting it with other materials and/or an adhesive to form a wide range of different products.

Historically, wood composite products have been specialty products produced to have specific mechanical and physical properties as well as geometries that are difficult if not impossible to obtain with solid wood. The different types of wood composites range from those that are primarily made of wood (e.g. particleboard, fiberboard, oriented strand board, laminated veneer lumber, and plywood) to wood in combination with inorganic materials, plastics, natural and synthetic fibers, and other biomass materials.

A high percentage of the wood products manufactured are adhesively-bonded, if not as a stage of production, at some time later in use. A recent estimate renders that wood is adhesively-bonded in at least $70 \%$ of its applications (Hemingway and Connor 1989).

Wood-adhesive bonds, that are stronger than the cohesive strength of the wood and adhesive, are crucial to the performance of wood composites. Weak adhesive bonds frequently reveal themselves as an overall failure in structural composites.

A wood composite can be thought of as being made of two phases separated by an 
interface. The wood-adhesive bond can be viewed as the interface between wood (adherend) and a natural or synthetic polymer (adhesive) material. The interface represents a plane across which molecular forces of attraction, also known as intrinsic adhesion, occur between the wood and polymer material. The interaction of both wood phases at the interface is critical to a strong bond and determines the overall performance of the composite through adhesion. The engineering of all composite materials, wood or synthetic, focuses on the interface between dissimilar materials. The integrity and strength of the bond depends on many interactions between the adherend and adhesive. Interactions of particular importance to the bond are thermodynamic, chemical, and physical in nature. The relative importance of each of the interactions differs in accordance with the materials used as adherend and adhesive. The chemical structure of the wood surface has an effect on both the thermodynamic and physical interactions through spreading and capillary uptake of the liquid adhesive. Also, some adhesives can covalently bond to a wood adherend offering a strong wood-adhesive joint.

The surface chemistry of wood plays an important role in the production of either a weak or a strong bond between adherend and adhesive. Changes in the surface chemistry, especially the surface energy, of wood occur both during the composite consolidation and drying processes. Wood composite manufacturing exposes both the wood and adhesive to environments of rapidly changing temperatures, both during and after the hot-pressing operation. Drying wood often exposes its surface to extreme temperatures and air movement that can also have an adverse affect on adhesion.

Overdrying wood veneers during the plywood manufacturing process has long been a 
cause of low wood surface energy (inactivation). This inactivation can be seen as a surface energy change that is often induced and/or intensified by a natural or manufacturing process that yields a surface that is more difficult to adhesive bond. Traditionally, this inactivation has been explained as the migration of low energy wood extractives to the surface (Christiansen 1990). Some other explanations for surface inactivation of wood have also been offered by Christiansen (1990). According to Christiansen, surface inactivation can also be attributed to the closure of pits located in the cell wall, chemical oxidation and decomposition that can occur on the polymer surface.

It has been observed by Yasuda et al. (1981) and Yasuda et al. $(1991,1992)$ that the surface energy of some synthetic polymers can change as a result of the reorientation of surface functional groups. It may be possible that this reorientation phenomenon is occuring on the wood surface causing, or at least adding to, inactivation over time. It could be that some functional groups of wood reorient to obtain thermodynamic equilibrium with the surrounding environment. Authors such as Gagnon and McCarthy (1984),Gunnells et al. (1994), Yasuda et al. (1981, 1991, 1992) have noted that the thermal effects on the surface reorientation are more noticeable at temperatures equal to or above the glass transition temperature $\left(\mathrm{T}_{\mathrm{g}}\right)$.

To better understand the wood surface and the adhesive bonding process, a fundamental understanding of wood surface behavior based on fundamental polymer theory needs to be developed. In applying amorphous polymer theory, the surface properties of wood can be related to other physical phenomenon such as viscoelasticity, diffusion, and to the chemical structure of wood (Salmen 1984; Kelley et al. 1987; LeFebrve et al. 1989; Wolcott et al. 1994). The wood surface can be viewed as a heterogeneous polymer system composed of 
approximately 40 to $43 \%$ cellulose, 35 to $38 \%$ hemicellulose, 20 to $25 \%$ lignin, and the remaining 3 to $7 \%$ extractives. Hemicelluloses and lignin are amorphous polymers while cellulose is highly crystalline in structure. Because of the differences among the chemical components within the wood, the surface that is created can be a complicated one.

Surface behavior of wood can be described with advanced solid-state analytical techniques. The list of analytical techniques used to study polymer interfaces includes: spectroscopic techniques of magnetic resonance, vibrational infrared absorption, inverse gas chromatography, secondary ion mass spectrometry (SIMS), X-ray photoelectron spectroscopy (XPS) among others (Occhiello et al. 1989; Kamdem and Riedl 1991). One technique that is especially suited to the study of wood surfaces is XPS (Hon 1984). XPS provides information on the chemical composition, the chemical states (bonding and oxidation), and the location of atom types within approximately $5 \mathrm{~nm}$ or less of the wood surface.

Another method which has been extensively used to study the surface of wood is dynamic contact angle analysis $(D C A)$. DCA analysis provides a thermodynamic characterization of solid wood surfaces. The use of XPS in conjunction with DCA analysis can offer a more in-depth view of the state of a surface than DCA analysis alone.

\subsubsection{Technical Objectives}

This research is aimed at gaining a more thorough understanding of wood surface behavior with respect to surrounding environmental influences. More specifically it will describe the molecular orientation and possible reorientation of functional groups comprising yellowpoplar surfaces in response to environmental exposure of different surface energies. 
The specific objectives of this research are:

1.) to discern the ability of the functional groups of yellow-poplar sapwood and heartwood surfaces, whether backbone or sidechain, to reorient in response to exposure to a high energy environment (aluminum) and a low energy environment (teflon);

2.) to determine the role that extractives play in the surface of yellow-poplar sapwood and heartwood upon exposure to the high energy environment and low energy environment.

The objectives will be studied with DCA and XPS as principle tools. However, knowledge gained from Differential Scanning Calorimetry (DSC) about yellow-poplar's $T_{g}$ will also be used. The results of this research will have direct implications for the manufacture of wood composites currently and most importantly in the future.

\subsection{LITERATURE REVIEW}

\subsubsection{Adhesion Concepts and Theories}

Over the years, the concepts and theories of adhesion have evolved from an art to that of a science. However, the evolution is far from complete as new technology and theories are developed to explain the complex phenomenon of adhesion. The theories of adhesive bonding still remain in an indistinct state. Even the famous scientist Debye (1926) treads lightly when offering a theory for adhesive bonding: " the forces between two molecules are supposed to consist of a universal attraction, which increases with diminishing distance until the two molecules touch."

Many researchers and scientists such as Gent and Hamed (1990), Hiemenz (1986), and 
Blomquist (1983) have authored a definition for adhesion. Adhesion can be defined as the state in which two dissimilar surfaces come into contact and are held together by interfacial forces. The interfacial forces may consist of valence forces and/or interlocking action. While adhesion is thought of as being a force that is expressed externally, it is important to note that there is a similar force, known as cohesion, that is expressed internally within a material. Cohesion is often defined as the state in which the particles of a single substance are held together by primary or secondary valence forces. With adhesion, bond formation can take advantage of some of the same forces that hold all substances together, forces that produce cohesion.

An adherend-adhesive-adherend bond system can be thought of as being analogous to a chain that has nine links (Marra 1983).

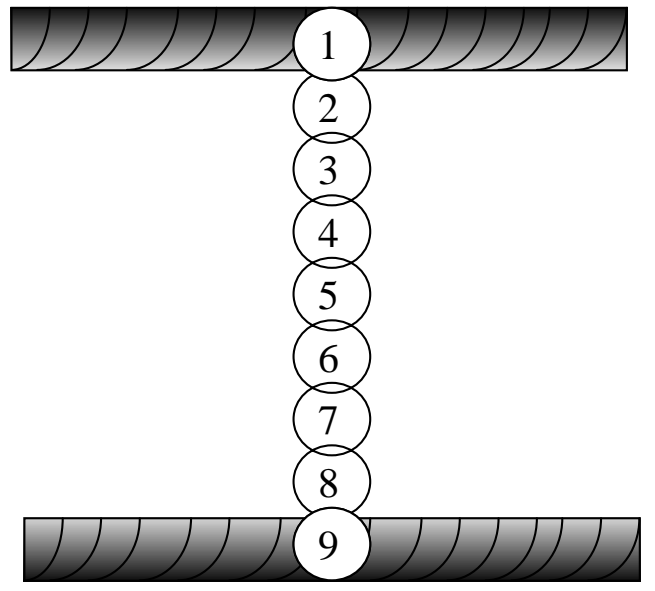

Adherend

Adherend Subsurface

Adherend-Adhesive Interface Intra-adhesive Boundary Layer

Adhesive Intra-adhesive Boundary Layer Adherend-Adhesive Interface Adherend Subsurface Adherend

Figure 3.1. A schematic representation of the hypothetical chain analogy of the adhesive-bond system adapted from Marra (1983). 
In Figure 3.1, each link is representative of a part or specific location within the system. In viewing Figure 3.1, it is evident that links1,8, and 9 are representative of the bulk cohesive strength of the adhesive and the two adherends respectively. Links 2 and 3 are representative of the boundary layers within the adhesive and links 4 and 5 represent the interface between the adhesive and adherend. The two remaining links, 6 and 7, are the contribution that the adherend subsurfaces make to the bond system. The boundary layers within the adhesive, links 2 and 3 , and the adherend subsurfaces, links 6 and 7, offer the most potential for weakness of all the links (Blomquist 1983). The interface between the adhesive and adherend, links 4 and 5, is where the actual adhesive forces exist and adhesion occurs. The failure of any one of the links or locations within the hypothetical chain will cause the whole bond system to fail.

Various theories of adhesion have been postulated that involve the occurrence and interplay of physical and chemical interactions across the adherend-adhesive interface (Subramanian 1984). Three of the theories or mechanisms that might apply to any given adhesive-bond system are mechanical interlocking, diffusion theory, and "specific" adhesion.

Mechanical interlocking requires that the adhesive flows and wets the surface of the solid adherend. With this mechanism, no chemical interaction between the adhesive and adherend is necessary to have a strong bond. The "tendrils" of the adhesive enters into the irregularities and openings on the surface of a solid adherend and harden into mechanical anchors as solidification occurs. Mechanical interlocking may be important in the bonding of materials that are porous or have a rough surface such as textiles and wood products (Gent and Hamed 1983). However, mechanical interlocking can not stand alone as the only mechanism because 
strong adhesive bonds are achieved between surfaces as smooth as optical glass flats (Allen 1987).

The diffusion theory is based on the interpenetration of the long chain molecules within a liquid adhesive into a partially or fully miscible adherend at the molecular level. The extent of the interdiffusion of the adhesive molecules into the adherend is dependent on the free volume of the adherend and the molecular compatibility of the adhesive and adherend. Molecular compatibility is a function of the affinity that is present between the functional groups present in the different polymers within the adhesive and adherend. According to Gent and Hamed (1990) in some cases, the adhesive in contact with a suitable adherend not only interdiffuses but also chemically reacts with one another to form a new chemical entity.

Molecular forces of attraction, also known as specific adhesion, range across a liquid adhesive-solid adherend interface. The adhesive molecules are attracted to specific locations on the adherend surface by primary and secondary bonds. The secondary bonds are known as hydrogen bonds or Van der Waals forces (Sperling 1986). It is conceivable that primary valence forces can form chemical bonds between adhesive and adherend, by either ionic or covalent means (Subramanian 1984). Zavarin (1984) noted that a study by Schur and Levy revealed an improvement in the wet strength of paper products upon oxidation of the pulp with sodium periodate or sodium hypochlorite.

It must be emphasized that in any given adhesive bond more than one or even all of the individual mechanisms could be occurring. This would be highly probable when bonding a wood surface. The wood surface is heterogenous and rough enough to provide a topography that 
facilitates adhesion by mechanical interlocking while offering a polar substrate beneficial for specific adhesion to occur. A fresh wood surface can have an abundance of reactive chemical sites including hydroxyl and carboxyl groups.

\subsubsection{Chemistry of Wood Surfaces}

The chemical composition of wood varies from species to species, tree to tree within the same species, and even within the same tree. The chemical composition of a wood surface often is not the same as the chemical composition of the bulk of the wood. According to Zavarin (1984), the wood surface is a function of the conditions and methods of its formation; the redistribution of extractives after or during formation; the incorporation of foreign materials during and after formation; and the chemical changes in time due to interactions with light, airoxygen, and other physical and chemical reagents.

Wood can be viewed as a heterogeneous bio-polymer composite. The chemical structure of the hardwood cell wall is composed mostly of cellulose (40-45\%) which forms a skeleton of fibers that are surrounded by hemicellulose (20-30\%), functioning as a matrix, and lignin (20$28 \%$ ) as an encrusting material (Sjostrom, 1981). Wood surfaces are characterized by their texture and chemical components exposed there. Wood surfaces are invariably rough in texture due to the anatomy of the wood fibers (Wellons 1983). Differences can exist on the macroscopic level between earlywood and latewood as well as normal wood and reaction wood. On a microscopic level, wood surfaces may range from largely amorphous to densely crystalline. Because strands of polysaccharides (cellulose and hemicellulose) are encased in lignin, most cut 
fiber walls expose a portion of both components, with the amount varying as to where the wall is cut. However, it is more probable that the surface will exhibit a greater amount of polysaccharides. Wood chemical content is $65-75 \%$ polysaccharides and $18-35 \%$ lignin (Pettersen 1984). As a result of wood surfaces being so chemically heterogeneous, the surface is rich in various reactive functional groups. Some of the functional groups of importance are carboxyl (-COOH), hydroxyl(-OH), and carbonyl (C=O) (Johns and Nguyen, 1977). The carboxyl group is composed of a carbonyl and hydroxyl group. Morrison (1987) states that the hydroxyl group within the carboxyl functional group is what actually undergoes nearly every reaction that occurs to it.

Cellulose is a long chain polymer composed of about 7-10,000 $\beta$-D-glucose units in the pyranose form (Goldstein 1991). Cellulose has the formula $\left(\mathrm{C}_{6} \mathrm{H}_{10} \mathrm{O}_{5}\right)_{\mathrm{n}}$ (Morrison 1987). All of the oxygen bridges between glucose units are $\beta(1 \rightarrow 4)$ which form repeating cellobiose units in the cellulose chain. The $\beta$-configuration causes a 180 rotation on alternating glucose units (Goldstein 1991). Cellulose is in the form of stiff linear chains that allows its molecules to line up side-by-side, overlapping each other. The cellulose are thus ribbon-like allowing intermolecular hydrogen bonding and weak van der Waals forces to occur between hydroxyl groups (Goldstein 1991; Pettersen 1984). This structure favors the grouping of individual cellulose chains into bundles that leads to the fibrous state in wood. Hydrogen bonding stabilizes the aggregations in a crystalline structure (Schniewind and Berndt 1991). No branching occurs in the cellulose molecule and all hydroxyl groups within the glucose rings project in the most stable directions (Holum 1990). Hydroxyl groups can participate in bonding either directly as bases and nucleophiles or as hydrogen bonding sites (Morrison 1987). On each glucose unit there are from 
three to six hydroxyl groups available for either inter- or intramolecular hydrogen bonding between the adjacent glucose residues (Skaar 1979; Pettersen 1984). Goldstein (1991) states that each anhydroglucose residue in the cellulose chain has three hydroxyl groups that makes it very hygroscopic such that water can be readily adsorbed or desorbed. This primarily occurs in the amorphous regions where hydroxyls are not involved in interchain bonding.

Crystalline polymers are molecules that are chemically, as well as geometrically, regular in structure (Sperling 1986). Native cellulose within the wood cell wall is only partially crystalline with regions that are disordered or amorphous. Various levels of crystallinity are possible when long chain polymers extend beyond the crystalline regions into amorphous regions. Both partially crystalline and amorphous polymers contain volume in excess of crystalline packing. This excess volume is referred to as free volume (Van Vlack 1982). The presence of free volume can allow diffusion of liquids, smaller more-mobile polymers or molecules, and possible preferential molecular orientation and reorientation. The amount of crystallinity depends on the origin and history of the cellulose, and generally decreases in order from cotton, wood, mercerized cellulose, to regenerated cellulose (Goldstein 1991).

Mercerization is defined as the treatment of cellulose with strong alkali and regenerated cellulose results from treatment with a strong alkali and carbon disulfide (Pettersen 1984). Cellulose is a non-reducing carbohydrate and is insoluble in water despite the fact that it is composed of glucose (Morrison 1987).

Hemicellulose and lignin are also considered to be amorphous within the wood cell wall (Schniewind and Berndt 1991). Hemicelloses are heterogeneous polysaccharides with a branched structure and a low degree of polymerization (100-200) (Riedl and Kamdem 1990; 
Goldstein 1991). They consist mostly of sugars other than glucose. The principle constituent sugars in hardwood hemicelluloses in decreasing abundance are xylose, mannose, glucose, and galactose, with small amounts of rhamnose and arabinose (Goldstein 1991). Most hemicelluloses function as supporting material in the cell walls (Sjostrom 1981). Sjostrom (1981) states that probably no chemical bonds exist between cellulose and hemicellulose but sufficient mutual adhesion is provided by hydrogen bonds and van der Waals forces. However, chemical bonding must exist between hemicelluloses and lignin (Sjostrom 1981; Goldstein 1991).

The chemical composition of lignin suggests that it does not have the attraction potential (hydroxyl groups) of cellulose and hemicellulose (Browning 1975). Lignins are threedimensional network polymers of hydroxy and methyl substituted phenylpropane units with many different linkages between the monomers (Goldstein 1991)The many different linkages as well as being heavily branched leads to a complicated structure that can only be defined by the frequency of occurrence of the various linkages (Sjostrom 1981;Goldstein 1991). Lignin is also not as polar or hygroscopic as cellulose and the hemicelluloses and essentially behaves more like a hydrocarbon (Sjostrom 1981). However, lignin does have some functional groups that are reactive. The reactive functionality is present in the phenolic hydroxyl, benzylic hydroxyl, and carbonyl groups (Sjostrom 1981).

Along with the primary constituents of wood, contaminants can be present in the form of extractives. Extractives are extraneous components that can be separated from the insoluble cell wall by their solubility in water or organic solvents (Goldstein 1991). These extractives are often oleophilic compounds that are low in molecular weight, such as fatty acids and their esters, 
waxes, terpenes (turpentines, resin acids, sterols), mono-and poly saccharides, alkaloids, and aromatic compounds (Back 1991, Nussbaum 1993, Goldstein 1991). Oleophilic compounds tend to be chemically inert and non-polar in nature (Holum 1990).

Wood surfaces are commonly covered with a layer of polar and non-polar extractive (Zavarin 1984; Christiansen 1990). Extractives that have been found in yellow-poplar include alkaloids, sesquiterpenes, and lignans (USDA 1979). Alkaloids are seldom found in temperate zone trees such as yellow-poplar.

All wood surfaces obtained for manufacturing purposes are artificial surfaces such as those produced by sawing or flaking. Several known changes occur to the wood surface over time: oxidation of the surface especially during exposure to high temperatures, migration of extractives to the surface, modification of cellulose/lignin ratio, acidification of the surface (Riedl and Kamdem 1990; Schniewind and Berndt 1991).

The surface energy of a freshly-cut wood surface can decrease from 70 to $40 \mathrm{~mJ} / \mathrm{m}^{2}$ in a matter of weeks. A low surface energy of $40 \mathrm{~mJ} / \mathrm{m}^{2}$ is hydrophobic and more typical of a plasticlike surface. This is a remarkable difference from the freshly-cut hydrophilic surface having an abundance of hydroxyl functional groups. 


\subsubsection{Wood Surface Inactivation}

The chemical composition of a wood surface does not necessarily correspond to the chemical composition of its bulk wood. The chemical composition is a function resulting from the conditions and methods of the surface formation (Zavarin 1984). Within a short period of time, freshly-cut wood surfaces undergo a transformation that has been termed surface inactivation (Back 1991). The rate and amount of inactivation tends to vary on the individual wood species and the temperature it is exposed to whether as a stage of manufacturing or during storage.

From an adhesive bonding standpoint, inactivation has been used to describe a wood surface that exhibits poor bond quality (Christiansen 1990). Most authorities recommend that a wood surface be adhesively bonded as soon as possible after surface preparation to obtain a strong bond (Stumbo 1964). This immediacy in wood-bonding application was simply in response to the common knowledge that fresh surfaces bond more easily than aged surfaces. According to Blomquist (1983), the formation of an adhesive bond depends foremost on the ability of the adhesive to wet and spread on the wood surface. As a general rule, the higher the surface energy of wood, the better it will wet and bond. Fresh Beech surfaces showed an average contact angle of $45^{\circ}$ that results in greater surface energy than an average contact angle of $65^{\circ}$ for aged (one year) beech surfaces (Marian and Stumbo 1962). The relationship between contact angle and surface energy will be discussed more thoroughly in a later section of this literature review. Many studies have reported wood to vary in surface energy from $70 \mathrm{~mJ} / \mathrm{m}^{2}$ of a fresh or activated surface to $40 \mathrm{~mJ} / \mathrm{m}^{2}$ of an aged or inactivated surface (Riedl and Kamdem 1990). 
Numerous inactivation mechanisms have been proposed to explain what occurs to cause inactivation of a wood surface. Summaries of inactivation mechanisms have been compiled by Christiansen (1990) and Back (1991). The list of mechanisms proposed by Christiansen are : 1.) exudation of extractives that hide the surface and lower the wettability; 2.) reorientation of wood surface functional groups which reduces wettability or places for bonding; 3.) chemical interference, such as acidity or reactivity, of extractives that affects the curing of the adhesive; 4 .) oxidation and pyrolysis of wood bonding sites; 5.) irreversible closure of micropores in the cell wall. ). It is most probable that each of the inactivation mechanisms are operative in different situations as well as having the capability of functioning simultaneously.

The list of inactivation mechanisms offered by Back (1991) is similar to that stated above but also mentions a hypothetical realignment of lignin molecules at the wood surface producing a low energy surface. This type of realignment to produce a lower energy surface is similar to changes that occur on other synthetic polymer surfaces (Back 1991).

The principal physical mechanism for inactivation is the migration of extractives to the surface that decreases wettability (Northcott et al. 1959; Gardner et al 1991; Christiansen (1991). The presence of nonpolar extractives reduces the surface energy of wood to that of the extractives (Wellons 1983). Zavarin (1984) adds that surface changes in wood subjected to temperatures below $180{ }^{\circ} \mathrm{C}$ were associated primarily with oxidation. Extractives were found to catalyze the rate of oxidation (Zavarin 1984). A study by Hancock (1963) exposed the effect of heat treatment and extractives on Douglas-fir veneer surfaces. Huang (1994) also studied the effect of heat and extractives on wood surfaces and found that the combined effect of the two results in the loss in wood wettability. Further results of Huang' s study indicated that the heat- 
induced wood wettability loss was not due to the removal of moisture during application of heat. Moisture content does not appear to affect the contribution of extractives to contact angle wettability changes. Therefore, the inactivation theory of hydrophobic extractives, migrating to the wood surface with drying, needs refinement since contact angle increases (losses in wettability) are observed on the wood surface with increased temperatures and no changes in moisture content (Gardner et al. 1996).

\subsubsection{Chemistry of Polymer Surfaces}

The surface chemistry and behavior of a polymer is not necessarily the same as its bulk chemical components. Synthetic polymer surfaces are often more homogeneous in structure and composition than natural polymers and their molecular structures are better understood.

Polymer surfaces are generally chemically-inert, smoother in texture, and have little or no pore structure in comparison to wood (Wellons 1983, Biggs and Fredricks 1994). The absence of pores renders polymer surfaces as non-absorbing. However, polymers are not as uniform in composition as might be thought. The synthetic processes used in manufacturing polymers produce a range of molecular weights resulting in a distribution of varying size molecules (Subramanian 1983). Polymers are large molecules (macromolecules) with long chains formed by the combination of many repeating structural units known as mers (Sperling 1986). Often with the manufacture of polymers, additives such as plasticizers, fillers, and stabilizers are included to perform various functions within the polymer at its end-use (Askeland 1989). Additives can also become unevenly distributed within the polymer and accumulate more abundantly at the surface (Hiemenz 1984). 
The surfaces of polymers, like those of all organic materials, are low in energy in comparison to metals (Wellons 1983). Polymers range in surface energy from a low of $18 \mathrm{~mJ} / \mathrm{m}^{2}$ on teflon (poly-tetraflourethylene) to an average of $31 \mathrm{~mJ} / \mathrm{m}^{2}$ on polyethylene and a relative high of $46 \mathrm{~mJ} / \mathrm{m}^{2}$ on nylon (Wellons 1983). Baszkin et al. (1976) reports that the classic work by Zisman on low energy polymer surfaces revealed that the solid-liquid adhesion is determined by the nature and packing of the solid's surface atoms and is independent of the behavior and arrangements of the underlying molecular structure. The thermodynamics of polymer surfaces were first studied by Fox and Zisman (1950) in the 1950's. Contact angle measurements on monolayers revealed that surface tension was dependent upon the chemical structure of the solid surface.

In the past, surface chemistry assumed a solid surface to be rigid, immobile, and in a state of equilibrium. Such assumptions may be partially correct for solids that are truly rigid, such as metals and ceramics, but inappropriate for most polymers (Andrade 1988). Consequently, the interfacial characteristics of polymers should be viewed as a function of the conditions of the environment in which the polymer exists (Yasuda et al. 1981). Lavielle and Schultz (1985) state that interfacial characteristics of polymers should not be treated as an intrinsic property, but replaced with the concept of potential surface energy. Polymer surface molecules have greater mobility and flexibility of their constitutional units to allow rearrangement in order to accommodate a change of chemical potential in the surrounding environment (Yasuda et al. 1991). The driving force for changes in polymer surfaces is the thermodynamic requirement of the minimization of free energy (Andrade 1988). 
Along with polymer surfaces being dependent on their surrounding environment, they are also effected by temperature and time (Billmeyer 1984, Andrade 1988). Yasuda et al. (1991) investigated the effect of temperature on polymer surfaces and found that the greater mobility of surface molecules allow surface configuration change in response to the surrounding environment at temperatures substantially lower than the $T_{g}$ of the polymer. The $T_{g}$, or what is sometimes called softening temperature, is defined as the temperature that establishes the onset of extensive molecular motion that is long range and coordinated (Billmeyer 1984). One of the findings of great importance included in the study by Yasuda et al. (1991) is that surface transition temperatures, $\mathrm{T}_{\mathrm{s}}$, were reported to be around $15^{\circ} \mathrm{C}$ regardless of the type and $\mathrm{T}_{\mathrm{g}}$ of the four different polymers investigated when the polymer surface is immersed in water. The $\mathrm{T}_{\mathrm{s}}$ for the surface configurational change coincides with the major Drost-Hansen temperature for the change of structural characteristics of vicinal water in contact with a surface. The properties of vicinal water (water in the surface state in contact with a solid surface) differs from its corresponding bulk properties (Etzler and Drost-Hansen 1979).

In the case of a poymer surface within a dry heat environment, the thermal mobility of macromolecules plays the predominant role in surface configurational change, and accordingly the $\mathrm{T}_{\mathrm{s}}$ corresponds to the $\mathrm{T}_{\mathrm{g}}$ of the polymer (Yasuda et al. 1992). An increased rate of surface change, principally within macromolecules, is realized at higher temperatures, especially above the $\mathrm{T}_{\mathrm{g}}$ (Lavielle 1988). This difference in mechanism of surface configurational change between water and dry heat environment emphasizes that the important properties of a polymer surface are interfacial properties rather than simply surface properties. 
Many polymer products having ideal bulk properties have non-ideal surface properties which could restrict their range of application. A polymer surface ages or decays over time, upon exposure to air, as changes to the surface occur (Back 1991). Redistribution of low-molecular weight oleophilic materials to the polymer surface and relaxation of the polymer surface creates the need for pre-treatments such as machining, flaming, electrical (corona) discharge treatment, and chromic acid or plasma etching (Tingey et al.1988, Briggs 1982, Back 1991). These pretreatments modify the polymer surface by increasing the surface energy of a low-energy (hydrophobic) polymer to improve its bonding characteristics (wettability) or make it more receptive to application of ink as a stage in processing (Biggs and Fredricks 1994). Polymer surfaces are inherently non-equilibrium structures and as such exhibit a range of relaxation times under normal conditions and in response to changing environments. Relaxation refers to a time-dependent response to a change in the polymer surface to achieve a new energy state that is closer to equilibrium with a new environment (Andrade 1988). Some correlation is expected between bulk relaxation, such as glass transition within a polymer and relaxation that occurs at the surface (Andrade and Chen 1986). Although it is clear that polymer components adjacent to an interface exhibit different motions and relaxation because of the influence and constraints imposed by the interface.

The time scale for relaxation to occur depends on the intrinsic rigidity of the polymer and the environment in which it is placed (Andrade and Chen 1986). Hydrogels (gel network polymers that are hydrated by water) exhibit relaxation times on the order of a second or less (Yasuda et al. 1981). Hydrogels have highly mobile side chains that make the changes in surface orientation rapid. In contrast to hydrogels, surface relaxation of polymers with more structural 
rigidity, may require days or longer. The results from a study by Ruckenstein and Gourisankar (1985) revealed that the solid-water interfacial free energy of thin films of oxidized fluorocarbon compounds, initially equilibrated in an octane environment, decreased from $50.88 \mathrm{dyne} / \mathrm{cm}$ to an equilibrium value of $26.59 \mathrm{dyn} / \mathrm{cm}$ over a duration of 24 hours. Similarly, the contact angles of water on oxygen-plasma treated polypropylene and glow discharged-polymerized polypropylene increase during storage over several weeks indicating a lower energy surface (Yasuda et al. 1981). The amount of time required for a surface-treated polymer to decay from higher to lower surface energy depends strongly on the degree of crosslinking. Crosslinking density within a polymer is inversely proportional to surface segmental mobility (Lavielle 1988). An extreme case of how crosslinking can effect relaxation time is that oxygen-plasma treated methane polymer ( a tightly-crosslinked network) showed no significant decay even after 200 days (Yasuda et al. 1981).

Abundant research has been focused on the aging or hydrophobic recovery of polymer surfaces after modification to obtain a higher energy surface. Owen et al. (1988) has proposed a thorough list of six possible mechanisms for the hydrophobic (low energy) recovery of a polymer surface:

1.) Reorientation of surface hydrophilic groups away from the surface.

2.) Migration of untreated polymer chains to the surface from within the bulk.

3.) External contamination of the polymer surface.

4.) Changes in surface roughness.

5.) Loss of volatile oxygen-containg species to the atmosphere.

6.) Surface extractive (eg. processing agents) condensation. 
Owen et al. (1988) further claims that the mechanisms, as presented, are in descending order of occurrence. Also, emphasis is given that the first three mechanisms should be considered as being responsible for the hydrophobic recovery of any polymer surface under study. Other research studies add importance to the role that surface contamination caused by diffusion and collection of low molecular weight, hydrophobic processing compounds on the surface and reorientation of the surface molecules assume in polymer surface aging. A study by Tingey et al. (1988) states that many of the polyurethane polymers studied were surface contaminated with impurities that may have origins in processing aids and release agents. These impurities can dramatically alter surface properties of a polymer. Yasuda et al. (1981) reinforces the possibility of reorientation at the surface by stating that wettability introduced by different surface treatments decays with time and can be attributed to the slow burying of hydrophilic functional groups within the polymer matrix.

\subsubsection{Molecular Reorientation of Polymer Surfaces}

Polymer molecules at a surface have greater freedom due to the mobility and flexibility of their constitutional units to rearrange themselves in order to accommodate a change of chemical potential in the surrounding environment (Andrade and Chen 1986, Yasuda et al. 1991). Surface

reorientation has been shown to be present in a diverse group of synthetic polymers from largely hydrophobic polyethylene and polypropylene to inherently hydrophilic hydrogels. Abundant research on polymer surface orientation and reorientation have been done by authors such as Andrade et al. (1979), Ruckenstein and Gourisankar (1985), Lavielle and Schultz (1985), and Yasuda et al (1981, 1991, 1992). 
A polymer surface can restructure or reorient in response to different environments.

When a polymer surface is exposed to an environment of air or vacuum, it will orient its nonpolar chemical components towards the interface, creating a hydrophobic surface, to minimize the free energy. This polymer surface restructuring in response to an air, vacuum, or other highly non-polar environment has been shown utilizing contact angle and X-ray photoelectron spectroscopy (XPS) to occur with many different polymers (Yasuda et al. 1981, Ko et al. 1981, Owen et al. 1988).

Yasuda et al. (1981) utilized contact angle measurement of a water droplet on the surfaces of hydrogels (gelatin with water content of $97.5 \%$, agar with water content of $98.5 \%$ ), oxygenplasma treated polypropylene, oxygen-plasma treated glow-discharged polypropylene, oxygenplasma treated glow-discharged methane polymer exposed to air. They demonstrated reorientation of hydrophilic moieties of select polymer surfaces with different degrees of mobility at the polymer-air interface. The response of hydrogels are of particular importance because they have to be hydrophilic in order to be made. Hydrogels are water-swollen three-dimensional polymer networks that have highly mobile side chains. A hydrogel, that is as much as $98 \%$ water, can show a hydrophobic surface at the hydrogel-air interface in spite of the fact that it is a highly hydrophilic polymer. In the case of hydrogels, the main driving force for the rotation of the molecules at the surface is the strong interaction between water and hydrophilic functional groups of the macromolecule. The hydrogel, agar with water content of $98.5 \%$, exhibited low contact angle (higher surface energy) as opposed to gelatin, consequently revealing that it was not able to reorient to the air environment. Agar has chemical ether bonds that do not allow free rotation of functional groups as freely at room temperature. 
The other polymer surfaces that are naturally lower in surface energy, polypropylene and polymer of methane, were modified to obtain higher surface energy prior to exposure to the air environment. The oxygen-plasma treated polypropylene and glow-discharged polypropylene, upon exposure to air, showed the return to lower surface energy at a much slower rate than the gelatin hydrogel. Polymer of methane used in this study, in the words of Yasuda et al. (1981) had an extremely tight network, thus showed no significant decay in excess of 200 days. This study offered evidence that burying of hydrophilic groups occurs in both hydrophilic and hydrophobic polymer surfaces where there is chemical structure that supports it.

The study by Owen et al. (1988) showed the hydrophobic (low energy) recovery of silicone elastomers, ethylene-propylene (EPR) elastomers, and polytetrafluorethylene exposed to corona discharge. The normally hydrophobic polymers were subjected to corona discharge to oxidize their surfaces to obtain higher surface energy. The use of ESCA showed a marked increase in surface oxygen content resulting from the oxidation of the surface functional groups. It was then shown that the higher surface energy of the polymer decreases after exposure to air. Owen et al. (1988) proposed that the mechanism of the hydrophobic recovery was the reorientation of surface hydrophilic functional groups away from the surface. The oxidized polytetrafluorethylene, commonly known as teflon, did not decay upon exposure to air because only a small amount of oxygen was incorporated into the surface from corona discharge.

When a hydrophobic polymer surface is exposed to an aqueous or highly polar environment, such as water, if given sufficient mobility, it will orient its polar chemical components towards the interface (Andrade et al. 1979, Ruckenstein and Gourisankar 1985, 
Lavielle and Schultz 1985). This reorientation has the effect of creating a surface that is more hydrophilic and higher surface free energy.

The study by Andrade et al. (1979) utilized contact angle measurement at the polymerwater interface to show that the hydrophilic components of polymer surfaces show dominance in interfacial properties. They studied hydrogel polymer systems poly(hydroxyethyl methacrylate) and co-polymers of poly(methoxyethyl methacrylate-hydroxyethyl methacrylate) at varying compositions and equilibrium water contents. The results showed that the hydrophilic component dominates the polymer-water interfacial properties, even at relatively low hydrophilic component compositions.

Ruckenstein and Gourisankar (1985) revealed similar results and conclusions using contact angle methods as well as ESCA to describe surface reorientation of thin "model" films of oxidized fluorocarbon compounds in an aqueous environment. Contact angle measurements were made to estimate instantaneous and equilibrium surface energy properties as well as the time required for the surface to attain its equilibrium wetting characteristics in an aqueous environment. A decrease in contact angle was realized over time, up to 24 hours, accompanied by a continual increase in the width of the water drop's base in contact with the polymer surface. This was confirmation that the water drop was spreading over time as buried polar functional groups within the polymer surface began to reorient themselves to interact with water. The reorientation was confirmed by repetition of contact angle measurement on the surface of the control teflon-FEP. The contact angles remained practically constant over time, at least as long as 96 hours, on the surface of teflon-FEP. The equilibrium values of the individual surface energy components (dispersion and polar) in the aqueous environment differed considerably from 
those of their respective surface energy counterparts in a non-polar environment such as octane or air. The solid-water interfacial free energy of the film, initially equilibrated in an octane environment, decreased from $50.88 \mathrm{dyn} / \mathrm{cm}$ to an equilibrium value of $26.59 \mathrm{dyn} / \mathrm{cm}$ over a duration of 24 hours. The conclusion is made that this change in the polymer-water interfacial energy of such model surfaces can arise only if polar groups which remain buried in its bulk in a non-polar environment like air or octane, reorient toward the surface in a time dependent manner when placed in contact with a strongly-polar aqueous environment. ESCA results add to the conclusion in showing that the outer surface layers contained a fair amount of the polar oxygen atoms capable of reorientation depending on the environment it is placed.

A study by Lavielle and Schultz (1985) also utilized both contact angle measurement and ESCA as well as other analytical techniques to observe surface properties of a polymer in contact with water. The polymer surface studied was a film of polyethylene grafted with small amounts of acrylic acid (1\%). An interesting point made by Lavielle and Schultz (1985) is that acrylic acid-grafted polyethylene presents much better adhesion to aluminum than polyethylene alone, yet the surface energy of the two polymers is almost the same. They mention that this better adhesion has been attributed to reconstruction of the grafted polyethylene surface during contact with the metal at high temperature, leading to preferential orientation of the acrylic groups at the polymer-metal interface. The grafted polyethylene in contact with water exhibited a two step reorientation process at the surface. This two step reorientation process of grafted polyethylene was also identified by Lavielle (1988). In the first step, movements of the macromolecular chains occur. Then, as a second step, the acrylic grafts appear and orient at the surface. Interestingly, the first step of macromolecular motion took place at room temperature $\left(23{ }^{\circ} \mathrm{C}\right)$ 
without any additional heat. Reorientation is particularly pronounced in aqueous solutions, where the polarity is such that a high interfacial free energy driving force is provided to the surface. This driving force can be strong enough for the diffusion or reorientation of polar segments or side chain, functional groups toward the aqueous phase, minimizing the interfacial free energy (Andrade and Chen 1986). The use of ESCA revealed the presence of carboxyl, carbonyl, and hydroxyl groups, after a few days in contact with water, that were initially virtually non-existent.

Molecular mobility within a polymer surface can be increased with elevated temperatures up to and above the polymer's glass transition temperature, $\mathrm{T}_{\mathrm{g}}$. As temperature is increased, the amplitude of vibrational motion becomes greater and the thermal energy becomes roughly comparable to the potential energy barriers to chain segment rotation and translation (Aklonis et al 1972). The $T_{g}$, is defined as the temperature that establishes the onset of extensive molecular motion that is long range and coordinated (Billmeyer 1984). Large scale polymer motion can assume two forms that can both be considered in terms of self diffusion. The chain can alter its overall confirmation or it can move relative to its neighbors (Sperling 1986). Above the $\mathrm{T}_{\mathrm{g}}$, substantially greater increases in free volume allows greater molecular mobility that enables increased diffusion of short chain polymers to the surface and conformational changes of long chains and reorientation of its molecules. An increase in surface temperature considerably accelerates the kinetics of reorientation (Lavielle 1988). Reorientation of surface structure in response to an environment is a relatively slow process in the case of rigid polymers like polyethylene and elevated temperatures are needed to see the effect (Andrade et al. 1979). Lavielle and Schultz (1985) quote an example of the effect of temperature on polymer surface reorientation- "A contact time of one hour at $90{ }^{\circ} \mathrm{C}$ has the same effect on surface energy of 
modified polyethylene as two weeks at $23^{\circ} \mathrm{C}$ ". Studies that utilize changes in temperature, as opposed to isothermal, are often more revealing of surface properties (Jhon and Yuk 1988).

One of the early non-isothermal studies on polymer surface behavior considered the temperature effect on the wettability of oxidized polyethylene films with known surface densities. This study by Baszkin et al. (1976) utilized contact angle measurement of modified (sulfuric acid and potassium chlorate oxidized) polyethylene surfaces to show the temperature dependence of contact angles. The nonpolar polyethylene surface was modified by oxidation into polar surfaces of known density. The chemical oxidation produces polar sites, primarily carbonyls, in the thin superficial layer of the film. The temperature effect on the wettability of oxidized polyethylene surfaces reveal a decrease in free energy at about $85^{\circ} \mathrm{C}$ for different probe liquids employed. At $85^{\circ} \mathrm{C}$, the melting transition temperature of this polymer, a decrease in the surface energy of the oxidized polyethylene films was observed. The decrease in surface energy was interpreted as resulting from the increase in chain mobility leading to the redistribution or reorientation of external polar groups initially located at the solid-air interface.

Another study showing thermal effects done by Jhon and Yuk (1988) revealed the temperature dependence of contact angles on polymer hydrogels of iso and syn-poly (2hydroxyethyl methacrylate) and various mixtures of copolymers with HEMA. A series of alkane probe liquids at various temperatures made it possible to analyze both dispersive and nondispersive interaction and better understand the temperature dependence. The contact angle studies clearly showed the ability of the polymer hydrogel to rearrange the surface structure in response to their environment, and also the temperature dependence of contact angle is observed in the case of hydrogels. 
Two informative studies by Lavielle (1988) and Gagnon and McCarthy (1984) revealed even more about polymer surface reorientation by utilizing elevated temperature and also considering whether reorientation could be reversible and/or cycled in surface energy. The two studies utilized bulk or surface grafted polymers containing both hydrophilic and hydrophobic moities within the surface layer to show that the hydrophilic phase will dominate the interface in a water environment and the hydrophobic phase will dominate in air.

The orientation phenomena of acrylic-acid grafted (1\%) polyethylene, maleic anhydride polypropylene, and polymethylmethacrylate was studied primarily with contact angle measurement, ESCA, and inverse gas chromatography by Lavielle (1988). It is proposed that the reorienting process of the surface involves initial swelling of the acrylic domains by the water diffusing into the film leading to macromolecular chain movement. Macromolecular chain movement completes the first step of a two step restructuring process. The second step involves reorientation of the polar functional groups at the surface. Increased temperature is mentioned as an activator of the reorientation kinetics. The two steps that lead to surface reorientation are attained more rapidly at $30^{\circ} \mathrm{C}$ as increased mobility in the polymer is favored. ESCA investigation as a function of water contact time showed an increasing carboxylic, hydroxyl, and carbonyl group content at the grafted polyethylene surface.

The results of contact angle data obtained with polypropylene were similar to that obtained with grafted polyethylene, thus allowing generalization of the surface restructuring process of reorientation in polyolefines (Lavielle 1988). ESCA also showed similar but better results with relatively more carboxylic groups than grafted polyethylene. In the case of 
polymethylmethacrylate, a hydrogel, mobile side chains are already present so no grafting is necessary to show exceptional reorientation at its surface.

The desired result of complete reversibilty was not realized with the Lavielle (1988) study. They also tried reversibility of the orientation process through heating near the melting point in the presence of nitrogen or through contact with a liquid alkane. In all cases, the contact angle diminishes, but never quite returns to the first value measured. Their explanation was that it would be difficult to imagine that the polymer chain as a whole would return to the same location that it started.

Gagnon and McCarthy (1984) theorized that the process of polar functionality, introduced during polymer surface modification, diffusing away from the surface into the bulk should be reversible under conditions that counteract surface energy minimization. Three polymers, polyethylene, poly(ethylene-co-acrylic acid)(8\% acrylic acid), and Teflon-FEP were chosen to show that it was reversible and could be cycled. These were three non-polar organic polymers containing small amounts of polar functionality. The study used a combination of contact angle measurement, ESCA, and ATR IR data to display that the surface changes were caused by migration of functional groups within the surface. Polyethylene, oxidized with a solution of potassium chlorate and sulfuric acid, teflon-FEP, reduced with a solution of sodium and napthalene, and poly(ethylene-co-acrylic acid) were exposed to varying cycles of heat/air and heat $/ \mathrm{NaOH}$ solution. Heating of oxidized polyethylene at $90{ }^{\circ} \mathrm{C}$, in excess of the $\mathrm{T}_{\mathrm{g}}$ of the polymer, with exposure to air, resulted in the diffusion of polar functional groups into the bulk of the polymer. Heating at a temperature of $85^{\circ} \mathrm{C}$, in conjunction with sodium hydroxide solution, revealed the reversibility of the process. The different environmental influence caused the polar 
functional groups to diffuse out to the interface again. The contact angles of unoxidized polyethylene did not change under the same conditions.

Poly(ethylene-co-acrylic acid), heated at $80^{\circ} \mathrm{C}$, also showed variable surface polarities that can be cycled by heating films in air or aqueous sodium hydroxide. The oxidized teflon-FEP did not display the ability to cycle surface functionality. ESCA and ATR IR reinforced the contact angle results in displaying that the surface changes were caused by migration of functional groups within the surface of both oxidized polyethylene and poly(ethylene-co-acrylic acid).

\subsubsection{Polymer Theory with Respect to Wood Surfaces}

Wood is a heterogeneous bio-polymer composite. Its behavior is similar but more complex than most homogeneous and heterogeneous synthetic polymers. The complexity stems from the many chemical components and their arrangement within the bulk of wood. The difficulty in understanding wood behavior can be analogous to the difficulty in describing or interpreting the behavior of a composite blend of synthetic polymers with both crystalline and amorphous components being present in relatively uncertain quantities. Early scientists and researchers of physical polymer science have had the advantage of being able to first study relationships between chemical structure and the resulting physical properties of simple homogeneous model polymers such as bakelite, nylon, and polyethylene. This simple start laid the groundwork for the depth of knowledge necessary so that one day synthetic polymers would be custom-tailored for their desired application. 
The depth of knowledge within physical polymer science can also be applied in describing the behavior of the bulk and surface of wood. Research studies such as those by Wolcott et al. (1994), Gunnells et al. (1994), Ostberg et al. (1990), Kelley et al. (1987) have applied polymer theory in describing the viscoelastic behavior of wood.

Some of the complexity in understanding wood behavior stems from the presence of both crystalline and amorphous components. Crystalline polymers differ from most other crystalline structures (e.g. metals, semiconductors, and ceramics) in that they are normally only semicrystalline (Askeland 1989). Cellulose in wood is only semi-crystalline. Cellulose also contains amorphous regions as a consequence of its long-chain nature and subsequent entanglements. The presence of crystallinity in polymers depends on the regularity of structure in the polymer and is defined as one that diffracts X-rays and exhibits the first-order transition of melting (Hiemenz 1984; Sperling 1986). The degree of crystallinity and its size and arrangement in a polymer have a profound effect upon the physical and mechanical properties of the polymer (Young and Lovell 1991). Crystalline polymers generally contain appreciable amounts of amorphous materials and when a crystalline polymer is melted, the melt is amorphous (Sperling 1986).

The remaining primary chemical constituents (hemicelluloses and lignin) in wood are amorphous in structure. Amorphous polymers lack the well-defined order associated with crystalline polymers (Sperling 1986). The properties of amorphous polymers, such as the well known polymer glasses and rubbers, have been studied extensively but very little is known about their structure (Young and Lovell 1991). However, it is known that all amorphous polymers assume the characteristics of glasses including hardness, stiffness, and brittleness at sufficiently low temperatures (Billmeyer 1984). 
In general, amorphous polymer theories relate temperature and moisture induced changes in free volume to changes in molecular mobility (Ferry 1980; Billmeyer 1984; Sperling 1986). The state of a polymer depends on it's temperature and amount of time that it is under some form of stress. This is equally true for semi-crystalline or amorphous polymers (Sperling 1986). Moisture content which has such a profound effect on all of woods physical properties can be viewed analogously to a plasticizer that is beneficially placed in many synthetic polymers. Plasticizers are small molecules added to soften a polymer by lowering its $T_{\mathrm{g}}$ or reducing its crystallinity or melting temperature (Sperling 1986).

Wood behaves, like many synthetic polymers, in a viscoelastic manner. This implies that wood displays the behavior of both a fluid (i.e. viscous) and a solid (i.e. elasticity). Viscoelasticity can be thought of as the flow of polymer molecules to a mechanical perturbation (Billmeyer 1984). A phenomenological model is often presented that offers the mechanical analogy of viscoelasticity as a combination of a spring and a dashpot (Aklonis et al 1972). The spring imitates perfectly-elastic behavior and the dashpot represents perfectly-fluid behavior. Elastic strain is produced and recovered instantly. However, the viscous strain is time dependent (Askeland1989). When a strain is applied more rapidly there is less time for viscous flow and the polymer is stronger and less ductile. Conversely, when a stress is applied over a long period of time, substantial viscous flow can occur, even at relatively low temperatures. It is impossible to describe quantitatively the time range which gives rise to each type of behavior because the temperature variable causes all of these ranges to be relative (Aklonis et al 1972).

The temperature dependence of polymer properties is best presented as occurring within five regions of viscoelastic behavior. The first region is known as the glassy region. The chain 
segments are frozen in fixed positions. Hard and brittle are two commonly used terms to describe polymers within the glassy region (Aklonis et al 1972). In the glassy state, large scale molecular motion does not occur. Motion does occur with atoms and small groups of atoms moving against the local restraints of secondary bond forces (Billmeyer 1984). Within this region, there is insufficient thermal energy to overcome potential barriers for rotational and translational motions of segments of the polymer molecules (Aklonis et al 1972).

As temperature is increased, the amplitude of vibrational motion becomes greater and the thermal energy becomes roughly comparable to the potential energy barriers to chain segment rotation and translation (Aklonis et al 1972). At this increased temperature, the polymer is in the second viscoelastic region known as the glass transition region. Within this region the behavior of the polymer changes from a brittle glass to what is best described as a resilient leather. This region can be qualitatively interpreted as the onset of long range and coordinated molecular motion (Sperling 1986; Mark and Kroschwitz 1987). Large scale polymer motion can assume two forms that can both be considered in terms of self diffusion. The chain can alter its overall confirmation or it can move relative to its neighbors (Sperling 1986). Polymer chains can move sideways by simple translation. However, this motion is exceedingly slow for chains that are long and entangled. Sideways diffusion can only occur by many cooperative movements of surrounding chains (Sperling 1986). The most important aspect of this region is the effect that reaching the glass transition temperature, $\mathrm{T}_{\mathrm{g}}$, has on polymer behavior such as decreasing its modulus (Ferry 1980).

With further increases in temperature, the rubbery plateau region is reached where polymers exhibit long-range rubber elasticity. Obtainment of this region is evident when the 
polymer can be stretched as much as several hundred percent and still return to its original length (Sperling 1986). It is known as a plateau region because the polymer's modulus remains relatively constant. In this temperature interval, the short range diffusional motions of polymer chain segments which initially give rise to the $\mathrm{T}_{\mathrm{g}}$ occur very much faster but long-range cooperative motion of chains that would result in translational motions of complete molecules is still restricted (Aklonis et al 1972). The viscoelastic response of linear and crosslinked polymers within the rubbery plateau region are essentially identical.

The fourth viscoelastic region is reached as the temperature of a polymer is increased past its rubbery plateau into the rubbery flow region. Linear polymers that are in the rubbery flow region have exceedingly more large scale molecular motions until whole polymer molecules begin to translate. With higher temperatures, local chain interactions become not high enough in energy to resist molecular flow (Aklonis et al 1972). In a crosslinked polymer, the crosslinks, consisting of primary chemical bonds, do not allow the chains to translate relative to one another. In effect, the crosslinked polymer remains in the rubbery plateau region up to the decomposition temperature of the polymer (Sperling 1986).

The fifth and final viscoelastic region is the liquid flow region. The polymer behaves as the name suggests when subjected to still higher temperatures. The increased thermal energy allows the chains to reptate out through entanglements rapidly and flow as individual molecules (Sperling 1986).

It has been stated by Mark et al. (1984) that the glass transition is the most important single parameter which needs to be known before deciding on the application of non-crystalline 
polymers. The $\mathrm{T}_{\mathrm{g}}$, or what is sometimes called softening temperature, is defined as the onset of extensive molecular motion that is long range and coordinated (Billmeyer 1984).

It is known that wood exhibits two $\mathrm{T}_{\mathrm{g}}$ 's that correspond with the two amorphous polymer components of wood (Gunnells et al. 1994). However, according to Irvine (1984), a secondary transition may also exist in the amorphous portions of cellulose. Billmeyer (1984) states that semi-crystalline polymers also exhibit $\mathrm{T}_{\mathrm{g}}$, though only in the amorphous regions of the polymers. The magnitude of the phenomena associated with $\mathrm{T}_{\mathrm{g}}$ decreases with decreasing amorphous content (Billmeyer 1984). Sperling (1986) adds that Sometimes the $\mathrm{T}_{\mathrm{g}}$ appears masked especially in highly crystalline polymers.

Hemicellulose of wood has a $\mathrm{T}_{\mathrm{g}}$ in the range of -23 and $200{ }^{\circ} \mathrm{C}$ (Kelley et al. 1987) and lignin has a $\mathrm{T}_{\mathrm{g}}$ in the range of 60 and $200{ }^{\circ} \mathrm{C}$ (Salmen 1984). Irvine (1984) reported the $\mathrm{T}_{\mathrm{g}}$ of in situ lignin for various water-saturated wood species to occur within a temperature range of 60 to $90{ }^{\circ} \mathrm{C}$. The $\mathrm{T}_{\mathrm{g}}$ depends on the moisture content of the wood as well as the method used to detect it (Kelley et al. 1987; Salmen 1984; Irvine 1984). The $\mathrm{T}_{\mathrm{g}}$ of synthetic polymers are significantly affected by plasticizers, of which water is of particular importance in wood components (Schniewind and Berndt 1991). The results of the Kelley at al. (1987) study are valuable in showing that the $\mathrm{T}_{\mathrm{g}}$ of in situ lignin and hemicellulose were heavily dependent on moisture content of wood. At the fiber saturation point, both hemicellulose and the amorphous portion of cellulose are well above their $\mathrm{T}_{\mathrm{g}}$, while lignin is still below its $\mathrm{T}_{\mathrm{g}}$. This implies that some of the chemical components of wood are in the rubbery state depending on the moisture content.

At temperatures above the $\mathrm{T}_{\mathrm{g}}$ of amorphous polymers, there is a larger thermal expansion coefficient than below its $\mathrm{T}_{\mathrm{g}}$. This difference can best be explained from a qualitative standpoint 
by using the concepts of occupied and free volume (Mark and Kroschwitz 1987). It can be assumed that occupied volume changes and free volume remains constant at all temperatures below the $T_{g}$, whereas both volume occupied by the molecule and free volume expand with temperatures above the $T_{g}$. The thermal expansion coefficient difference can then be viewed as the expansion coefficient of the free volume above the $T_{\mathrm{g}}$. Free volume can be defined as the difference between the specific volume of the bulk polymer and the volume actually occupied by the molecules excluding others from its area (LeFebvre et al. 1989; Sperling 1986). The free volume may be viewed as the "elbow room" that a molecule requires to undergo rotational and translational motion (Hiemenz 1984). The mobility of polymer molecules is directly related to the amount of free volume at any given temperature (Ferry 1980). Furthermore, it is assumed that free volume is continually redistributed with time and that no local free energy is required for redistribution, thus resulting in random distribution (LeFebvre et al. 1989). This random distribution of free volume allows molecular transport to occur by the movement of diffusing molecules into voids of at least their molecular size.

The molecular mobility resulting from increases in free volume provides the means for polymers to self diffuse or reorient in order to obtain thermodynamic equilibrium. Thermodynamic equilibrium of polymers is most quickly obtained at temperatures above the $\mathrm{T}_{\mathrm{g}}$. Gunnells et al (1994) observed a hydrophobic change in the surface of yellow-poplar and red oak that could be attributed to increased diffusion allowing extractive migration and deposition or limited movement of amorphous polymer segments of wood. The increased diffusion was attributed to increased free volume after reaching temperatures above the $T_{g}$ of lignin. Back (1991) also mentioned the possibility of a hypothetical realignment of lignin molecules at the 
wood surface producing a low energy surface. This type of realignment to produce a lower energy surface is similar to changes that occur on other synthetic polymer surfaces (Back 1991).

\subsubsection{Surface Wettability and DCA Analysis}

The formation of an adhesive bond requires that the adhesive wets, flows, and sets to a solid. Naturally, wetting is important because it has to occur prior to any of the following steps. A broad definition of wetting is the time-dependent process whereby a liquid and solid come into intimate contact (Gent and Hamed 1990). Wetting can involve the spreading of a liquid over a surface, the penetration of a liquid into a porous medium, or the displacement of one liquid by another (Johnson and Dettre 1993). On the molecular level, wetting is a spontaneous motion, driven by the attraction of the polar molecules of the solid surface for the polar molecules of the liquid (Hiemenz 1986). The attractive forces between the molecules can be thought of as free energy. When the liquid and solid are brought in close proximity, the forces are neutralized, and both experience a lower, and therefore more stable, energy level. Collett (1972) states that for any process of wetting, an area of the solid-vapor interface is replaced by an equal area of the solid-liquid interface.

Molecules at a surface, whether liquid or solid, behave differently than molecules in the bulk. One reason for this is that molecules located in the bulk are entirely surrounded by other molecules, all exerting attractive forces on each other in all directions whereas, the molecules at the surface are attracted only inwardly. Therefore surface molecules have unused attractive forces on one side that leads to the existence of surface free energy (Barrow 1979). In a liquid, the inward attraction is working to obtain minimum surface area for a given mass (Hiemenz 
1986). Since the action of reducing surface area is one of tensile forces, the force is called surface tension. The thermodynamic definition of surface tension is the change in Gibbs free energy per unit change in area (Barrow 1979).

A quantity that is closely related to surface tension and can be used to measure it is the contact angle $(\theta)$. The difference between surface tension and contact angle is that surface tension describes the interface between two phases; whereas, contact angle describes the edge of the two-phase boundary where it ends at a third phase (Hiemenz 1986). The contact angle is defined as the angle measured in the liquid that is formed at the junction of three phases such as the solid-liquid-vapor junction (Johnson and Dettre 1993).

Kalnins and Katzenberger (1987) define wettability as the contact angle that a liquid makes when in contact with a solid surface. Herczeg (1965) sums up the study of wettability of wood as providing information about the well-defined physicochemical phenomena of wetting, spreading, capillary penetration, and the surface properties of wood such as its surface free energy. Many early studies of wood wettability such as those by Freeman (1959), Freeman and Wangaard (1960), and Bodig (1962) relied heavily upon empirical results without the application of fundamental knowledge. The Freeman (1959) study stated that glue-bond quality is closely related to $\mathrm{pH}$, specific gravity, and wettability. Freeman and Wangaard (1960) then went on to examine more closely the effect of the wettability on glue-line behavior. The study by Bodig (1962) also related the gluability of wood with its wettability. Marian and Stumbo (1962) found greatly increased wetting (contact) angles on aged beech surfaces and improved wettability with increasing surface roughness. Fresh beech surfaces had an average contact angle of $45^{\circ}$ and surfaces aged one year had an average contact angle of $65^{\circ}$. A smaller contact angle signifies 
greater wettability and a contact angle of $0^{\circ}$ signifies that the liquid spreads freely over the surface and is said to completely wet it (Wellons 1983). When $\theta$ is large, the liquid tends to minimize its area of contact or interaction with the solid. An extreme case is when a liquid is placed on a solid surface with which it has no interaction, the contact angle equals $180^{\circ}$. This indicates a preference of liquid molecules to interact with each other rather than with the solid (Gent and Hamed 1990). Other studies have also shown contact angle increases over time (losses in wettability) such as Gray (1962), Nguyen and Johns (1979), and Gunnells (1992).

The two most commonly used techniques for measuring the contact angle are the sessile drop (static contact angle) and the Wilhelmy plate method. With the static contact angle method, a drop of liquid is placed on a horizontal surface and observed in cross section through a microscope (Herczeg 1965). The relationship between contact angle and the surface tensions for the static contact angle is provided by Young's equation stated below:

$$
\gamma_{\mathrm{sv}}=\gamma_{\mathrm{sl}}+\gamma_{\mathrm{lv}} \cos \theta
$$

where,

$$
\begin{array}{ll}
\gamma_{\mathrm{sv}} & =\text { solid-vapor surface tension } \\
\gamma_{\mathrm{sl}} & =\text { solid-liquid surface tension } \\
\gamma_{\mathrm{lv}} & =\text { liquid-vapor surface tension } \\
\theta & =\text { contact angle }
\end{array}
$$

The primary advantages of the static contact angle method are speed and accuracy (Johnson and Dettre 1993). A disadvantage can be the number of individual measurements that are necessary on a surface to obtain a good estimate of the whole surface. In the past, wood wettability has primarily been measured by the static contact angle method (Gray 1962, Herczeg 1965, and Nguyen and Johns 1979). This does not mean that the static contact angle method is no longer a 
useful method. Zhang et al. (1997) used the static contact angle method in determining the surface tension, adhesive wettability, and bondability of artificially weathered CCA-treated southern pine. Static contact angle method was used along with the Lifshitz-van der Waals/acidbase approach of estimating surface tension. A video camera can also be used with the static contact angle method as Kalnins and Feist (1993) did to determine the increase in wettability of wood with weathering.

The Wilhelmy plate technique involves suspending a thin plate vertically above a liquid. To begin measurement, the bottom edge of the plate is nearly in contact with the surface of the liquid. This is the position of zero force. The liquid is raised until it touches the plate. This is the zero position. The force on the plate is measured as it is cycled slowly up and back down (Johnson and Dettre 1993). The advancing angle is the stable angle as the liquid is raised and the receding angle is the stable angle resulting when the liquid is lowered to its starting position. Johnson and Dettre (1993) also states advantages of the Wilhelmy plate method; 1.) as opposed to static contact angle, it is independent of the person making the measurement 2.) highly reproducible measurements 3.) speed of movement of the three-phase boundary is readily controlled 4.) the sensitivity of the technique is very high.

Dynamic contact angle (DCA) analysis is based on the Wilhelmy plate technique. The principle of how DCA analysis works to arrive at a value for surface wettability is based on measurement by electronic balance of the increased force (weight) resulting from the meniscus formed between the solid surface and the probe liquid. The following equation defines the wetting force as it relates to the liquid surface tension and the contact angle: 


$$
\mathrm{F}=\mathrm{P} \gamma_{\mathrm{LV}} \operatorname{Cos} \theta-\mathrm{V} \rho \mathrm{g}
$$

where,

$$
\begin{array}{ll}
\mathrm{F} & =\text { wetting force } \\
\mathrm{P} & =\text { sample perimeter at the solid/liquid interface } \\
\gamma_{\mathrm{LV}} & =\text { probe liquid surface tension } \\
\theta & =\text { contact angle } \\
\mathrm{V} & =\text { volume of probe liquid } \\
\rho & =\text { probe liquid density } \\
\mathrm{g} & =\text { acceleration due to gravity }\left(9.80 \mathrm{~m} / \mathrm{s}^{2}\right)
\end{array}
$$

Since the probe liquid utilized is of a known surface tension and all of the other variables are known, the contact angle can easily be determined.

For an ideal solid surface, one that is smooth, homogeneous, rigid, and insoluble, the thermodynamic equilibrium condition known as Young's equation, predicts a single contact angle. An example of a surface that is close to being ideal is that of a glass microscope slide. A DCA scan is made up of both advancing and receding curves as the solid is immersed into the probe liquid and then removed at a controlled rate of speed. If the glass microscope slide is clean, the advancing and receding curves of the DCA scan should overlap one another. However, with wood that provides anything but an ideal surface, there are different advancing and receding contact angles (Marmur 1994). The highest contact angle is called advancing and the lowest is called receding. The existence of multiple contact angles is termed contact angle hysteresis. Contact angle hysteresis indicates deviations from the assumptions for Young's equation mentioned above. Surface roughness and heterogeneity, adsorption, absorption, insufficient mobility at the molecular level, and viscous effects operating in the interface all can contribute to hysteresis (Heimenz 1986; Gardner et al. 1991). 
DCA analysis has been successfully used to describe the surfaces of polymers and wood alike. Synthetic fiber surfaces have been studied (Andrade and Chen 1986; Andrade 1988) as well as wood fibers (Young 1978; Klungness 1981). A study by Deng and Abazeri (1998) used the Wilhelmy principle (DCA analysis) on wettability of wood fibers utilizing a group of separate fibers, per DCA scan, instead of singularly. DCA analysis has been used in many studies of wood surfaces (Kalnins and Katzenberger 1987; Gardner et al. 1991; Gunnells et al. 1994; Huang 1994).

Once the contact angle between the wood surface and the probe liquid is known, the surface free energy of the wood surface can be determined. Although the surface energy of a solid can not be measured directly, there are methods to arrive at a good estimation. Five of the most commonly-used approaches of estimating surface energy of a solid are Zisman plot, interaction parameter equation, geometric mean equation, harmonic mean equation, and the Lifshitz-van der Waals/acid-base method.

The Zisman plot, developed using contact angle measurements, is considered to be the first and most widely used method for approximating the surface tension of a solid (Fox and Zisman 1950, Jacob and Berg 1993). The critical surface tension, denoted $\gamma_{c}$ is determined from the extrapolation of a plot of $\cos \theta$ verses surface tension of a homologous series of liquids. Any liquid with a surface tension less than $\gamma_{\mathrm{c}}$ will completely wet the solid surface. The actual value of $\gamma_{c}$ varies with the particular homologous series of liquids used to define it (Gent and Hamed 1990).

The interaction parameter equation as termed by Kalnins and Katzenberger (1987) is a combination of the Girifalco-Good equation with the Young equation. Girifalco and Good 
(1957) derived the following equation utilizing only the London component of surface tension since it is the part that crosses phase boundaries.

$$
\gamma_{S L}=\gamma_{S}+\gamma_{L}-2 \Phi\left(\gamma_{S} \gamma_{L}\right)^{1 / 2}
$$

where:

$$
\begin{array}{ll}
\gamma_{\mathrm{SL}} & =\text { solid-liquid surface tension } \\
\gamma_{\mathrm{S}} & =\text { solid surface tension } \\
\gamma_{\mathrm{L}} & =\text { liquid surface tension } \\
\Phi & =\text { interaction parameter }
\end{array}
$$

The interaction parameter, $\Phi$, ranges from 0.5 - 1.0 and shows that at least half of surface tension can be contributed to London forces (Hiemenz 1986). For simple interfaces, such as wood and water, $\Phi$ is approximately unity (Kalnins and Katzenberger 1987). Stated below is the form of the interaction parameter equation used to provide a reasonable estimation of the surface free energy of a solid wood surface.

$$
\gamma_{S V}=\left(\gamma_{\mathrm{LV}}(1+\operatorname{Cos} \theta)^{2}\right) /\left(4 \Phi^{2}\right)
$$

where:

$$
\begin{array}{ll}
\gamma_{\mathrm{SV}} & =\text { solid surface free energy } \\
\gamma_{\mathrm{LV}} & =\text { liquid surface tension at the liquid-vapor interface } \\
\theta & =\text { contact angle } \\
\Phi & =\text { interaction parameter }
\end{array}
$$

The interaction parameter equation has been used by Gunnells et al. (1994) to show that the surface of wood exhibited a change in the surface energy results similar to a polymer surface undergoing a phase change or glass transition. The surface energy results compared well with 
accompanying standard differential scanning calorimetry determination of the glass transition of lignin that was in the range of literature values from studies by Kelley et al. (1987) and Salmen (1984).

The geometric mean equation, stated below, considers the total surface free energy to be divided into dispersive (non-polar) and polar components:

$$
(1+\operatorname{Cos} \theta) \gamma_{L}=2\left(\gamma_{S}^{d} \gamma_{L}^{d}\right)^{1 / 2}+2\left(\gamma_{s}^{p} \gamma_{L}^{p}\right)^{1 / 2}
$$

where:

$$
\begin{array}{ll}
\gamma_{\mathrm{S}} & =\text { solid surface free energy }(\mathrm{d}=\text { dispersive }, \mathrm{p}=\text { polar }) \\
\gamma_{\mathrm{L}} & =\text { liquid surface tension }(\mathrm{d}=\text { dispersive }, \mathrm{p}=\text { polar }) \\
\theta & =\text { contact angle }
\end{array}
$$

The dispersive components are London forces (Hiemenz 1986). The polar components are surface free energy resulting from dipole-dipole, induced dipole, and hydrogen bonding interactions (Gardner 1996). Two probe liquids with different dispersive and polar components of surface tension are utilized to determine their contact angles with the solid surface. Simultaneous geometric mean equations are solved to arrive at the dispersive and polar components of the solid surface tension. Estimation of total solid surface energy results from the addition of the dispersive and polar components.

The harmonic mean equation developed by $\mathrm{Wu}(1971)$ represented an improvement on the geometric mean equation when characterizing low energy systems. The harmonic mean equation stated below is used in the same manner as geometric mean by solving simultaneous equations to arrive at the total solid surface energy:

$$
(1+\operatorname{Cos} \theta) \gamma_{L}=4\left(\gamma^{d} \gamma_{L}^{d}\right) /\left(\gamma_{S}^{d}+\gamma_{L}^{d}\right)+4\left(\gamma^{p} \gamma^{p}{ }_{L}\right) /\left(\gamma^{p}{ }_{S}+\gamma_{L}^{p}\right)
$$

where: 


$$
\begin{array}{ll}
\gamma_{\mathrm{S}} & =\text { solid surface free energy }(\mathrm{d}=\text { dispersive, } \mathrm{p}=\text { polar }) \\
\gamma_{\mathrm{L}} & =\text { liquid surface tension }(\mathrm{d}=\text { dispersive }, \mathrm{p}=\text { polar }) \\
\theta & =\text { contact angle }
\end{array}
$$

Separation of the polar components into Lewis acid (+) and Lewis base (-) along with consideration of Lifshitz-van der Waals interactions led to another important estimation of solid surface energy. Van Oss et al. (1988) derived the Lifshitz-van der Waals/ acid-base approach presented below:

$$
(1+\operatorname{Cos} \theta) \gamma_{\mathrm{L}}=2\left[\left(\gamma_{\mathrm{S}}^{\mathrm{LW}}{\gamma_{\mathrm{L}}}^{\mathrm{LW}}\right)^{1 / 2}+\left(\gamma_{\mathrm{S}}^{+}+\gamma_{\mathrm{L}}^{-}\right)^{1 / 2}+\left({\gamma_{\mathrm{L}}^{-}}_{\mathrm{L}}^{+}\right)^{1 / 2}\right]
$$

where:

$$
\begin{array}{ll}
\gamma_{\mathrm{S}} & =\text { solid surface free energy } \\
\gamma_{\mathrm{L}} & =\text { liquid surface tension } \\
\theta & =\text { contact angle } \\
\text { LW } & =\text { Lifshitz van der Waals components } \\
+,- & =\text { acid or base components }
\end{array}
$$

Simultaneous equations are also solved with this approach to determine the total solid surface energy. Nonpolar probe liquids (total $\gamma^{\mathrm{LW}}$ ) and polar probe liquids with known electron-acceptor $\gamma^{+}$(acid) and electron-donor $\gamma^{-}$(base) parameters are used to calculate the unknown solid surface energy components (Gardner 1996). Kwok et al. (1994) concluded that the Lifshitz-van der Waals/acid-base approach does not give reasonable and consistent solid surface energy components or solid surface energies from contact angle measurements of flourocarbon FC721, Teflon FEP, and PET. They thought that the approach should be applicable to a variety of solid surfaces. They found the surface energy estimation to be strongly dependent on the liquids used. Gardner (1996) has shown the Lifshitz-van der Waals/acid-base approach to compare favorably if not better than other well established methods with respect to wood surfaces. Gardner (1996) 
reports that the Lifshitz-van der Waals/acid-base approach provides for greater accuracy in calculating wood surface tension components than the geometric-mean and harmonic mean equations because it is based on the contribution of contact angles from five liquids as opposed to two. It was also stated that in some instances the Zisman plot, a widely used method (Gent and Hamed 1990), compared favorably with the results obtained by the Lifshitz-van der Waals/acidbase approach.

\subsubsection{XPS Analysis of Surface Elemental Composition}

The use of X-ray photoelectron spectroscopy (XPS) offers the ability to explore the first few atomic layers of a surface and assign chemical states to the detected atoms. By knowing the chemical states of the detected atoms it is possible to determine the individual chemical elements present (Briggs and Seah 1990; Gardner et al. 1991). The technique determines the kinetic energies of photoelectrons ejected from the inner core of atoms, upon irradiation of the surface of a material with X-rays (Moulder et al 1992).

The samples to be analyzed are placed in an ultrahigh vacuum (UHV) system and exposed to X-rays from either a magnesium or aluminum source. As a result of the exposure to X-ray radiation, photoelectrons are emitted from the sample and are analyzed to determine their binding energy. Their binding energies of the electrons are associated with their appropriate parent atoms and are calculated by the following:

Incident X-ray energy = kinetic energy + binding energy + work function of spectrometer. 
Three spectra or scans are usually obtained for a given sample. A survey scan is performed first that yields binding energy in the range from 0 to $1000 \mathrm{eV}$. The second spectra is the Carbon 1s band which yields binding energy in the range of 280 to $300 \mathrm{eV}$ (Gardner et al 1996). Finally, a third spectra is usually explored that is the Oxygen 1s band with binding energy in the range of 531 to $535 \mathrm{eV}$ (Briggs and Seah 1990). The XPS spectra of an element in a compound differs over a few eVs depending on the nature of its immediate neighbors and the state of chemical combination of atoms (Briggs and Seah 1990). XPS typically probes up to 10 $\mathrm{nm}$ into the sample surface, but can be made more surface sensitive on smooth samples by glancing angle electron detection (Briggs and Seah 1990).

The XPS technique has widely been used for the characterization of chemical groups on the surface of synthetic and natural polymers such as polypropylene, polyethylene, and cellulose (Briggs 1982). Hon (1984), Brewis et al. (1987), Riedl and Kamdem (1990), and Gardner et al. (1991) have all used XPS to characterize the surface chemical groups of solid wood.

Hon (1984) showed, through the use of oxygen-to-carbon ratios from XPS, that yellowpoplar sapwood surfaces are relatively high in carbon-to-carbon and carbon-to-hydrogen bondings that exhibit hydrocarbon characteristics. The same surface characteristics were also shown to exist for lignin. But when a cellulose-rich surface was analyzed, an abundance of oxygen-to-carbon bondings were found. A surface with abundant oxygen-to-carbon bondings is more hydrophilic in nature. Hon (1984) also revealed UV-irradiated wood to have an increased oxygen-to-carbon ratio due to oxidation.

The chemical composition of the surface often does not exhibit the same make-up as the bulk of the wood. According to Zavarin (1984) and others, the wood surface can exhibit 
excessive amounts of extractives resulting from redistribution at or after its formation. Brewis et al. (1987), utilizing XPS, found that the oxygen-to-carbon ratio present on the surface of scots pine varied with the level of extraction. High carbon percentages on wood surfaces have been supported by other XPS studies by Young et al. (1982), Hon (1984), and Gardner et al. (1991). XPS has been used along with DCA analysis by Briggs (1982) and Clark (1977). XPS, when used in conjunction with DCA analysis can provide information on how wood processing and environmental conditioning effects surface energy and chemistry (Gardner et al.1991).

\subsection{MATERIALS AND EXPERIMENTAL PROCEDURES}

\subsubsection{Raw Material Selection}

One 54 year old, 14 inch dbh, yellow-poplar (Liriodendron tulipifera) tree was harvested for this study from a mixed even-age stand of Appalachian hardwoods. This yellow-poplar tree was chosen because of its straight bole, little taper, and no outward signs of defect or disease. Once the tree was felled, the portion below the branches was immediately sawn into six-one foot bolts starting from the top of the butt swell and proceeding toward the crown. The six one-foot bolts had approximately equal volume of heartwood and sapwood present. Each bolt was split longitudinally into halves. From each half bolt, the sapwood was split from the heartwood into rectangular blocks. The rough hewn cut rectangular blocks were then cut along each side with a bandsaw to provide smooth surfaces. Once smooth rectangular blocks were obtained, the blocks were sealed in plastic bags and frozen to preserve their green moisture content. 
As the wood was needed for sample preparation, the blocks of sapwood and heartwood were removed from storage and thawed for flaking. Only the blocks that were defect free, even-colored, and straight grained were kept. Flakes were produced from the blocks of wood with a laboratory scale disk-flaker. The flakes were cut parallel to the tangential face of the block to present the grain-orientation along the longest length of the sample.

\subsubsection{Determination of Extractives Content}

A portion of the sapwood and heartwood flake samples were milled in a small Wiley mill. This ground-wood sample was then sifted with handheld screens to particle size that passes through a 40 mesh and is retained in a 50 mesh screen. Two separate ground-wood samples were obtained for sapwood and heartwood. The samples were then placed in Alundum fritted crucibles before being placed in a Soxhlet extraction unit. The samples were extracted in separate Soxhlet extraction units with an ethyl alcohol-benzene (1:2) mixture for a total of four hours with about six rinses occurring per hour. The sample and crucibles were placed in a filtering flask, attached to a suction flask, and washed with an excess of alcohol to remove the benzene.

The crucibles with sample were then returned to the soxhlet extraction unit and the extraction continued for four more hours with $95 \%$ ethyl alcohol. After the alcohol extraction, the crucibles with sample were again washed as previously described but this time with distilled water. Finally, with the alcohol solvent removed from the samples, one more four hour extraction took place with distilled water. Upon completion of the water extraction, the samples were removed from the crucibles and air-dried. The percentages of total 
extractives were then calculated from the loss in weight due to the extraction and the ovendry weight determination by the gravimetric method.

\subsubsection{Flake Sample Preparation}

The flakes that were obtained from disk flaking were sectioned into samples of $30 \mathrm{~mm}$ in length, $12 \mathrm{~mm}$ in width, and approximately $1 \mathrm{~mm}$ thick. Each flake was measured and sectioned with a razor and a straight edge as a guide. Precautions were taken to not contaminate the flake surface by using medical grade rubber gloves and finger cots.

Enough flake samples were produced of extracted and unextracted sapwood and heartwood to be tested at all surface treatment conditions with DCA and XPS analysis. The flake samples that would not be extracted were next placed in a dark, humidity-controlled cabinet to condition for two weeks to a moisture content of $11 \%$ (oven-dry basis). The conditions in the humidity cabinet were controlled at a relative humidity of $65 \%$. The dry bulb temperature was $20{ }^{\circ} \mathrm{C}$ and the wet bulb temperature was $14^{\circ} \mathrm{C}$. At the end of the two-week period, flake samples were removed from the humidity cabinet for gravimetric moisture content determination. Two weeks proved to be sufficient conditioning time to obtain the desired $11 \%$ moisture content. Once the flake samples were conditioned, they were randomly removed, in groups of four, from the humidity cabinet for surface treament and analysis.

Once extractive-free sapwood and heartwood flake samples were obtained by extraction they were conditioned to the same $11 \%$ moisture content in the humidity-controlled cabinet. The extracted samples were conditioned along with the unextracted samples, however the time that they were conditioning was offset. The conditioning time was offset to assure that the samples 
were not conditioned for a longer amount of time. Once it was determined by the gravimetric method that the extracted samples were properly conditioned, they were removed from conditioning and tested. The extracted samples were DCA or XPS analyzed in the same manner as the previously mentioned unextracted samples.

\subsubsection{Preparation of Extractive-Free Samples}

The yellow-poplar sapwood samples were extracted with acetone separately from the heartwood samples for 48 hours with approximately six acetone rinses occurring per hour. Most of the extractives that are present in wood can be removed by extraction with a solvent such as acetone. Acetone has a low boiling point $\left(56.2^{\circ} \mathrm{C}\right)$ that helps to avoid high temperatures during the extraction that could cause chemical changes in the wood. The following extraction method discussed below was developed by Huang (1994) and found to remove at least $90 \%$ of the benzene-alcohol solubles. Sapwood and heartwood flake samples were pre-cut to the actual testing dimensions before being placed into separate large cellulose-based extraction thimbles. The thimbles with flake samples were then placed in Soxhlet tubes to extract on a Lab-Line Multi-Unit extraction heater. The bottom $500 \mathrm{ml}$. flasks were filled with acetone before connection to the Soxhlet tubes. The bottom flasks and Soxhlet tubes were then connected with the condensers with circulation of room temperature water. Once the extraction was complete, the flake samples were thoroughly rinsed with distilled water until there was no odor of acetone present. The samples were then left to soak overnight in two separate $1000 \mathrm{ml}$ beakers to further 
remove acetone. The washed flake samples were then placed in the humidity-controlled cabinet to condition along with the unextracted samples.

\subsubsection{Surface Treatment Methods}

The flake samples, whether extracted or unextracted, were sanded immediately before surface treatment occurred. The flake samples were sanded with 220 grit industrial sandpaper and then wiped clean with a nylon-bristled brush to remove any debris left from sanding. The samples were sanded to remove the top-most layer of the wood and expose a "fresh" surface.

The extracted and unextracted flake samples to be surface treated were exposed to different surface energy environments. The sample size was four at each treatment condition. The flake samples were subjected to elevated temperatures and "press-dried" against either teflon film (low energy surface) or aluminum caul plates $\left(\mathrm{Al}_{2} \mathrm{O}_{3}\right.$ high energy surface). Teflon provides a low-energy orienting potential in contrast to the high energy orienting potential of

aluminum (surface energy $\left.=500 \mathrm{~mJ} / \mathrm{m}^{2}\right)($ Wellons 1983). The elevated temperatures of 50, 75, 100 , and $150{ }^{\circ} \mathrm{C}$ were obtained with a laboratory-scale, 6 in. by 6 in. Carver Press. The temperature was determined with a digital temperature gauge and held constant throughout the surface treatment. Approximately 5 psig of hydraulic pressure was applied to ensure that the flake surface and aluminum or teflon surfaces made contact.

At each of the four temperatures, the flake samples were press-dried at all four exposure times. The lengths of exposure time were $0.5 \mathrm{~min} ., 1 \mathrm{~min} ., 2 \mathrm{~min}$., and 5 minutes. Prior to any surface treatments, the aluminum caul plates and teflon film(s) were cleaned to 
offer the appropriate surface energy environment.

The aluminum caul plates were sanded with 220 grit industrial sandpaper to remove the layer of oxidation and expose an environment of higher surface energy. The aluminum caul plates were sanded every time and immediately before they were to be used for surface treatment. This was to prevent oxidation from the atmosphere prior to treatment. Also, any residue left on the surface from sanding was removed with lint-free kim-wipes prior to surface treatment use. The aluminum caul plates were an alloy with about $1.2 \%$ magnesium based on its grade.

The teflon film was cleaned with $99.9 \%$ chemically-pure acetone to remove any surface contamination and again to present an environment of the lowest surface energy. Since acetone (or dimethyl ketone) has such a low point of vaporization, it changes from a liquid to its vapor form fast enough not to remain on the teflon surface and adversely-affect the surface treatments. Acetone removes a wide variety of organic compounds (Holum 1990).

Four sets of aluminum caul plates were utilized along with four sets of teflon film. Only one set of aluminum caul plates or teflon film was designated for use at each of the four treatment temperatures. The teflon was a commercially-available brand of structurally pure film.

DCA analysis was used to determine the contact angles of the surface treated samples along with control samples and heat/air "baseline" samples. Sapwood and heartwood control samples, both extracted and unextracted, were tested to use as control values without any of the temperature or surface treatment effects. The sample size for control values was four for each extracted and unextracted sapwood and heartwood. The heat/air samples 
were placed in a forced-air convection oven to simulate the affect of the heat, alone, on the flake surface. All heat/air samples were oven-dried, at each of the four temperatures for the maximum length of time that samples were surface treated, 5 minutes. Five minutes was chosen to reveal the greatest affect that each of the elevated temperatures would have on the flake surfaces. The sample size for the heat/air samples was also four at each treatment condition. The control samples and heat/air samples were sanded with 220 grit industrial sandpaper, prior to testing, in a similar manner that the flake surfaces were sanded before surface treatment. Any debris left from sanding was removed by wiping with a nylon-bristled brush.

XPS analysis was used to determine the elemental composition, primarily the carbon/oxygen $(\mathrm{C} / \mathrm{O})$ ratio, of unextracted yellow-poplar heartwood samples. Angle dependent XPS was used along with analysis perpendicular to the surface to determine the surface elemental composition of yellow-poplar heartwood exposed to aluminum and teflon surface treatment at $150{ }^{\circ} \mathrm{C}$.

\subsubsection{Maximum moisture loss determination}

The maximum amount of moisture loss from the flake samples was determined by drying conditioned samples in the forced-air convection oven at each of the four treatment temperatures. The moisture-loss samples, of sapwood and heartwood, were weighed prior to oven-drying for 5 minutes. After the flake samples were dried in the oven at the different temperatures, they were reweighed and the moisture loss was determined gravimetrically on 
an oven-dry basis. Two samples (replicates) were taken at each combination of flake and temperature to have a good estimation of moisture loss.

\subsubsection{Use of DCA Analysis in Measuring Surface Wettability}

The standard DCA procedure for performing contact angle, $\theta$, analysis as stated by Gardner et al. (1991) was followed. The standard procedure requires the use of thin endcoated flake samples that are suspended from an electronic balance and immersed in a probe liquid of known surface tension at a controlled rate of speed. The flake samples were endcoated with poly (vinyl acetate) to eliminate the uptake of probe liquid by the pores present in the transverse surface of wood. The sole probe liquid used in this study was high performance liquid chromatography (HPLC) grade water. After each DCA scan the used probe liquid was discarded and replaced with fresh liquid and beaker. The surface tension of the probe liquid was found by running an analysis on a clean glass microscope slide. The DCA scan was made up of both advancing and receding contact angles. If the glass microscope slide was thoroughly cleaned with the blue (hottest) portion of a natural gas flame, the advancing and receding portions of the DCA curve should overlap one another.

All of the DCA testing was done parallel to the grain with the probe liquid at $20{ }^{\circ} \mathrm{C}$. The flake samples were immersed in the probe liquid at a rate of $194 \mu \mathrm{m} / \mathrm{sec}$. to a depth of $12 \mathrm{~mm}$. and then returned to the starting position.

It is of utmost importance that any glassware used with DCA be extremely clean, even the slightest amount of contamination can mask the actual results. Because of this, the glassware was first boiled in water and then washed in a solution of distilled water and Fisher 
FL70 detergent before being rinsed out multiple times with distilled water. The same collection of $100 \mathrm{ml}$ beakers were segregated and used for all DCA analyses performed in this study.

The contact angles were measured with a Cahn model 322 DCA analyzer. Prior to any actual testing of flake samples, the electronic balance was calibrated at $0 \mathrm{mg}$ of force and $500 \mathrm{mg}$ with calibration weights. The contact angles were determined from graphs of the advancing and receding wetting force with the assistance of the least squares analysis software (CAHN 1991) of the DCA system.

Once the contact angles were obtained for each individual wood sample, the surface energy of that same sample could be determined. The following equation, offered by Kalnins and Katzenberger (1987), was used to obtain a reasonable estimation of the surface free energy of the solid wood surface

$$
\gamma_{S V}=\left(\gamma_{L V}(1+\operatorname{Cos} \theta)^{2}\right) /\left(4 \Phi^{2}\right)
$$

where:

$$
\begin{array}{ll}
\gamma_{\mathrm{SV}} & =\text { solid surface free energy } \\
\gamma_{\mathrm{LV}} & =\text { liquid surface tension at the liquid-vapor interface } \\
\theta & =\text { contact angle } \\
\Phi & =\text { interaction parameter }
\end{array}
$$

The interaction parameter of wood with pure water has been reported to be close to 1.0 (Kalnins and Katzenberger 1987). The previously mentioned surface free energy equation for solid surfaces was utilized throughout this study to describe both surface treated and untreated flake samples. 


\subsubsection{XPS Analysis to Examine Surface Elemental Composition}

Analysis by X-ray photoelectron spectroscopy was performed using a Vacuum GeneratorMicrotech with a VG-100 AX X-ray analyzer. For each sample, a survey spectrum was obtained as well as high-resolution spectra of the Cls and Ols regions. The XPS spectra were recorded at a vacuum in the range of $10^{-8}$ to $10^{-9}$ Torr using Alk $\alpha$ radiation $(1486.6 \mathrm{eV})$.

Spectra were obtained at an electron take-off angle of $90^{\circ}$ (perpendicular) relative to the sample surface and at a glancing angle of $10^{\circ}$.

The analysis area of the wood samples was approximately $30 \mathrm{~mm}$ in length and $12 \mathrm{~mm}$ in width. Only unextracted yellow-poplar heartwood with exposure to aluminum and teflon surface treatments were analyzed. A \% atom composition ratio of carbon-to-oxygen was calculated for each sample.

\subsubsection{Statistical Design}

Wood that is obtained from trees of the same species, is often assumed to be identical in physical and chemical structure. This is far from the truth. Interestingly, wood obtained from different parts of the same tree is only similar in structure and characteristics. Sources of variability such as size and length of cellular elements, thickness of cell walls, abundance of vessels, and polysaccharide-to-lignin ratios are critical to the physical behavior of wood. The variability stems from wood being produced from a tree that, while living, was subjected to numerous constantly changing environmental influences. Even materials that are 
homogeneous in structure, as opposed to wood, have an inherent level of variability within them.

The statistical design of this study is a four-factor factorial. The experimental units are chosen at random from the population (the whole tree) and assigned at random to the different treatments. The interest of this study was placed on the set of treatments at the given temperatures and amount of exposure time while attempting to control the extraneous source of variability within the wood flake samples.

A completely randomized Analysis of Variance (ANOVA) with equal sample size was utilized to analyze the initial and final surface energy results. The Anova procedures were performed using the Statistical Analysis System (SAS) software program for microcomputers. It was assumed that there was a significant difference between the initial and final surface energy allowing the use of two individual Anovas. The following General Linear Model (GLM) was employed for both initial and final surface energy to determine the effects of species (heartwood or sapwood), extracted or unextracted, surface treatment (aluminum, teflon, or heat/air), temperature $\left(50,75,100\right.$, or $\left.150{ }^{\circ} \mathrm{C}\right)$, and the interaction between surface treatment and temperature.

$$
\mathrm{y}_{\mathrm{ijkl}}=\mu+\text { Species }_{\mathrm{i}}+\mathrm{Ext}_{\mathrm{j}}+\operatorname{Trt}_{\mathrm{k}}+\operatorname{Temp}_{\mathrm{l}}+(\operatorname{Trt} \mathrm{x} \text { Temp })_{\mathrm{kl}}+\varepsilon_{\mathrm{ijkl}}
$$

where:

$\mathrm{y}=$ surface energy determination from DCA measurement

$\mu=$ mean surface energy value

Species $_{\mathrm{i}}=$ effect of sapwood or heartwood

Ext $_{\mathrm{j}}=$ effect of extracted or unextracted

$\operatorname{Trt}_{\mathrm{k}}=$ effect of surface treatment (aluminum, teflon, or heat/air)

$\mathrm{Temp}_{1}=$ effect of surface treatment temperature $\left(50,75,100,150{ }^{\circ} \mathrm{C}\right)$

$(\text { Trt } \mathrm{x} \text { Temp })_{\mathrm{kl}}=$ effect of interaction between the kth surface treatment and the lth surface treatment temperature 


$$
\varepsilon_{\mathrm{ijkl}}=\text { experimental error associated with } \mathrm{y}_{\mathrm{ijkl}}
$$

The level of statistical significance for the initial and final surface energy results was set at $\alpha=$

0.05. Individual statistical significance between surface treatments and temperature were determined through Duncans’s New Multiple Range comparison test.

\subsection{RESULTS AND DISCUSSION}

\subsubsection{Extractive Content of Sapwood and Heartwood}

The percentage of extractives found in yellow-poplar sapwood and heartwood are presented in Table 3.1. The percentages of 3.5 for sapwood and 5.0 for heartwood compare

Table 3.1. The extractive content in the sapwood and heartwood of yellow-Poplar.

\begin{tabular}{||c|c||}
\hline \multicolumn{2}{|c||}{ \% Extractives Present in Yellow-Poplar } \\
\hline Sapwood & 3.5 \\
\hline Heartwood & 5.0 \\
\hline
\end{tabular}

well with those reported in other studies Gardner et al. (1992) found 2.4\% extractives in yellowpoplar sapwood. Huang (1994) reported 3.24\% extractives in sapwood and $4.78 \%$ in heartwood.

\subsubsection{Moisture Loss from Surface Treatment}

The maximum amount of moisture loss that occurred during the aluminum, teflon, and Heat/air surface treatment is presented in Figure 3.2. This may not be entirely 


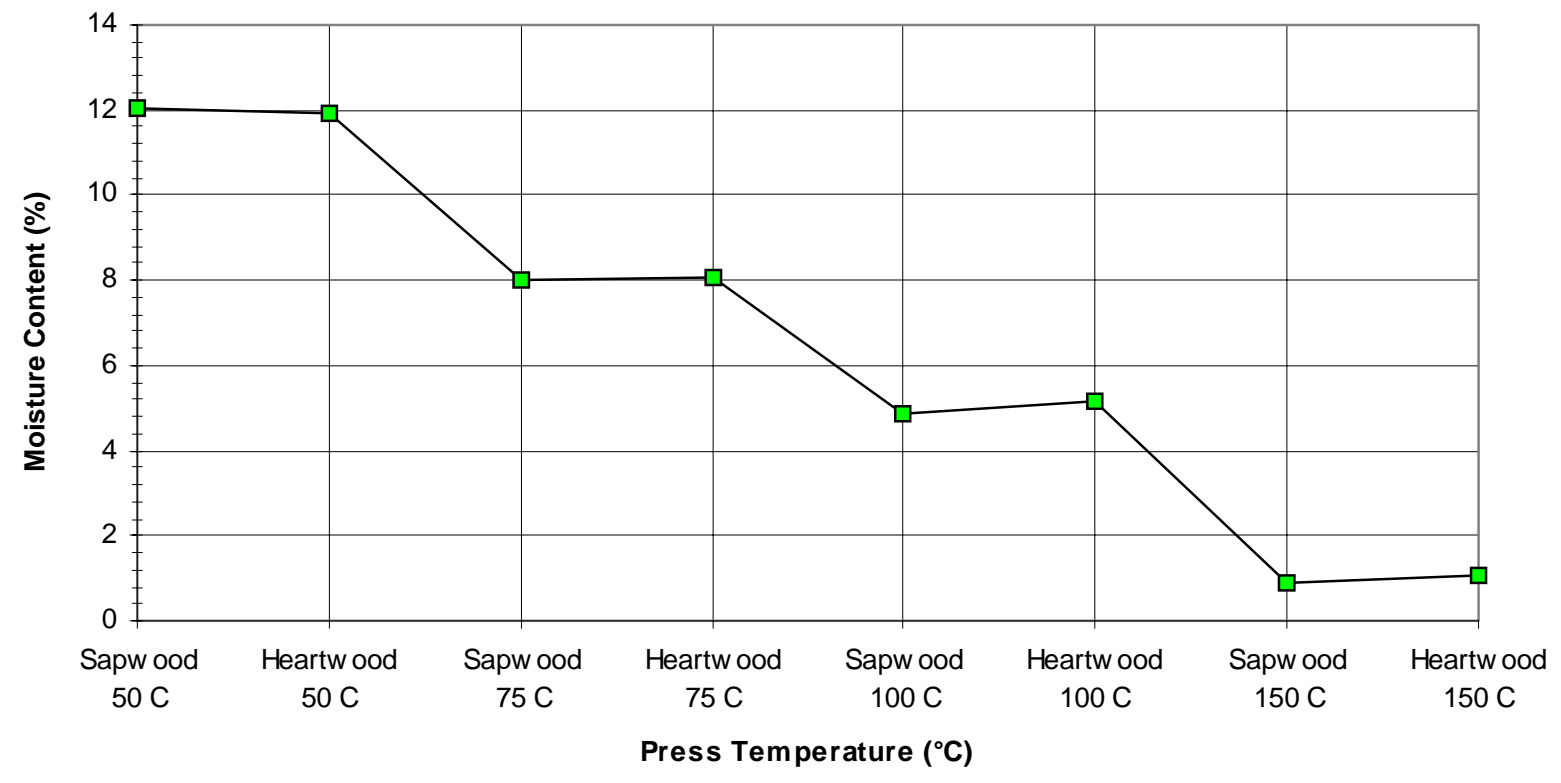

Figure 3.2. Maximum moisture loss from surface treatment at different pressing temperatures.

representative of the actual amount of moisture loss in press-drying. This is because of press-drying not being able to allow the moisture to escape as freely from any of the wood surfaces as it can in the open environment of a convective oven. However, it is apparent that the overall moisture loss from the wood was considerable. From $50{ }^{\circ} \mathrm{C}$ to the maximum surface treatment temperature of $150{ }^{\circ} \mathrm{C}$, the heartwood and sapwood lost more than $10 \%$ moisture content (oven-dry basis). Considering that both heartwood and sapwood were conditioned to $12 \%$ M.C., as much as $83 \%$ of their total moisture could be lost from surface treatment. The sapwood and heartwood both lost about the same amount of moisture and at about the same rate. 


\subsubsection{Description of Surface Energy Behavior from DCA Analysis}

A total of four surface treatment exposure times were utilized in this study. The exposure times were $0.5,1,2$, and 5 minutes. Of the four exposure times, the surface energy results from 0.5 and 5 minutes are given emphasis to represent the extremes of treatment effect. The surface energy results arising from 0.5 and 5 minutes of exposure time will be referred to as initial surface energy (ISE) and final surface energy (FSE), respectively.

After comparing the ISE and FSE results, it was determined that their overall behavior was similar and the discussion could be limited to one of the two. In recognizing this, the decision was made to focus the discussion toward the FSE results. This focus allows more emphasis to be placed on the maximum behavioral response of the wood surface. A summary of the ISE results is included in the Appendix as Table B.8.1.

The ISE and FSE results were analyzed using individual analysis of variances (ANOVA). Also Duncan's New Multiple Range tests were used for comparison of surface treatment and temperature mean results. Anova results for ISE and mean analysis by Duncan's New Multiple Range test are summarized in the Appendix as Tables B.9.1 and B.9.2.

A summary of ANOVA results for FSE are reported in Table 3.2 as P-values. The Pvalue states the probability that if the null hypothesis were true (i.e. the main effects had equal means), a difference in means would be observed as large or larger than that of this study. Statistically-significant differences in means are obtained when the P-value is less than 0.05. 
Table 3.2. ANOVA of unextracted and extracted, heartwood and sapwood, final surface energy values.

\begin{tabular}{|c|c|c|c|c|c|c|}
\hline $\mathrm{M}$ & Source & $\mathrm{DF}$ & SS & MS & F value & $\begin{array}{c}\operatorname{Pr}>F \\
(\alpha=0.05)\end{array}$ \\
\hline $\mathrm{O}$ & Model & 13 & 12014.19 & 924.17 & 57.47 & 0.0001 \\
\hline $\mathrm{D}$ & Error & 178 & 2862.51 & 16.08 & & \\
\hline $\mathrm{E}$ & Corr. Tot. & 191 & 14876.70 & & & \\
\hline $\mathrm{L}$ & \multicolumn{6}{|c|}{$\mathrm{r}^{2}=0.8076 \quad$ C. $\mathrm{V} .=6.4706$} \\
\hline A & Source & $\mathrm{DF}$ & SS & MS & F value & $\begin{array}{c}\operatorname{Pr}>F \\
(\alpha=0.05)\end{array}$ \\
\hline $\mathrm{N}$ & Species & 1 & 1174.08 & 1174.08 & 73.01 & 0.0001 \\
\hline $\mathrm{O}$ & Ext & 1 & 2382.62 & 2382.62 & 148.16 & 0.0001 \\
\hline V & Trt & 2 & 5067.34 & 2533.67 & 157.55 & 0.0001 \\
\hline A & Temp & 3 & 1084.31 & 361.44 & 22.48 & 0.0001 \\
\hline & Trt x Temp & 6 & 2305.84 & 384.31 & 23.90 & 0.0001 \\
\hline
\end{tabular}

The ANOVA of FSE results revealed that all main effects and the interaction between surface treatment and temperature were significantly different. The results of Duncan's test are presented in Table 3.3. The mean sapwood FSE is significantly larger than heartwood. Extracted wood is significantly larger in surface energy than unextracted wood. Aluminum surface treatment resulted in mean FSE that is significantly larger than both heat/air and teflon. Teflon surface treatment resulted in mean FSE that is significantly lower than heat/air. The 
surface treatment temperatures resulted in significantly different mean FSE. The treatment temperature of $50^{\circ} \mathrm{C}$ is significantly larger in surface energy than $75^{\circ} \mathrm{C}$. The treatment temperature of $75^{\circ} \mathrm{C}$ is significantly larger in surface energy than $100^{\circ} \mathrm{C}$ and $150^{\circ} \mathrm{C}$. The treatment temperature of $150^{\circ} \mathrm{C}$ is significantly lower in mean FSE than all other treatment temperatures.

The FSE ANOVA results differed from the ISE results in that data was included for the heat/air surface treatment and all treatment temperatures were significantly different. The insignificantly different ISE means (see Appendix Table B.9.2) present between treatment temperatures of $75^{\circ} \mathrm{C}-100{ }^{\circ} \mathrm{C}$ and $100{ }^{\circ} \mathrm{C}-150{ }^{\circ} \mathrm{C}$ indicates that at the short exposure time the temperature effects were limited by the amount of time necessary for heat to transfer to the wood surface. 
Table 3.3. Duncan grouping of ANOVA results for final surface energy at $\alpha=0.05$; means with the same letter are not significantly different according to Duncan's New Multiple Range Test.

\begin{tabular}{|c|c|c|c|c|}
\hline \multicolumn{2}{|c|}{ Source } & $\mathrm{N}$ & Mean & Duncan Grouping \\
\hline \multirow[t]{2}{*}{ Species } & Sapwood & 96 & 64.45 & A \\
\hline & Heartwood & 96 & 59.50 & B \\
\hline \multirow[t]{2}{*}{ Ext } & Extracted & 96 & 65.49 & A \\
\hline & Unextracted & 96 & 58.49 & B \\
\hline \multirow[t]{3}{*}{ Trt } & Aluminum & 64 & 68.98 & A \\
\hline & Heat/Air & 64 & 60.16 & B \\
\hline & Teflon & 64 & 56.79 & $\mathrm{C}$ \\
\hline \multirow[t]{4}{*}{ Temp } & $50{ }^{\circ} \mathrm{C}$ & 48 & 65.23 & A \\
\hline & $75^{\circ} \mathrm{C}$ & 48 & 62.88 & B \\
\hline & $100{ }^{\circ} \mathrm{C}$ & 48 & 61.01 & $\mathrm{C}$ \\
\hline & $150{ }^{\circ} \mathrm{C}$ & 48 & 58.77 & $\mathrm{D}$ \\
\hline
\end{tabular}

Average FSE results of unextracted yellow-poplar sapwood and heartwood exposed to different surface treatments are presented in Table 3.4. 
Table 3.4. Average (standard deviation) FSE results of unextracted yellow-poplar sapwood and heartwood exposed to environments of high energy (aluminum), low energy (teflon), and heat/air.

\begin{tabular}{|c|c|c|c|c|c|}
\hline & & & ge Final S & Energy (n & \\
\hline & $\begin{array}{l}\text { Treatment } \\
\text { Temperature }\left({ }^{\circ} \mathrm{C}\right)\end{array}$ & Control & Aluminum & Teflon & Heat/Air \\
\hline & 20 & $66.0(2$ & & & \\
\hline $\bar{g}$ & 50 & & $63.4(1.9)$ & $64.9(1.3)$ & $63.4(3.5)$ \\
\hline 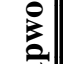 & 75 & & $68.4(3.0)$ & $60.3(0.8)$ & $61.9(1.3)$ \\
\hline $\bar{s}$ & 100 & & $70.1(1.3)$ & $56.0(2.5)$ & $58.2(1.4)$ \\
\hline & 150 & & $69.9(0.7)$ & $51.2(3.6)$ & $54.8(3.9)$ \\
\hline & 20 & $59.6(3$ & & & \\
\hline $\bar{\theta}$ & 50 & & $56.3(2.5)$ & $59.9(2.7)$ & $55.2(7.1)$ \\
\hline$\sum_{=}^{n}$ & 75 & & $67.4(1.3)$ & $55.2(1.5)$ & $54.0(3.8)$ \\
\hline 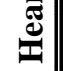 & 100 & & $67.3(2.0)$ & $46.1(2.8)$ & $50.1(6.5)$ \\
\hline & 150 & & $70.0(1.3)$ & $35.2(1.5)$ & $43.7(6.8)$ \\
\hline
\end{tabular}

Average FSE results of unextracted and extracted yellow-poplar sapwood and heartwood exposed to different surface treatments are presented in Figures 3.3 to 3.6. In viewing the Figures, it can be seen that a shaded area is included in the top portion of each. This shaded area is included to denote an imposed "ceiling" on the highest measurable surface energy by the probe liquid utilized. In this study, the probe liquid was HPLC grade water with a surface energy of $72.8 \mathrm{~mJ} / \mathrm{m}^{2}$ at $20^{\circ} \mathrm{C}$

Figure 3.3 contains the average FSE of unextracted yellow-poplar sapwood exposed to environments of high energy (aluminum), low energy (teflon), and heat/air. 


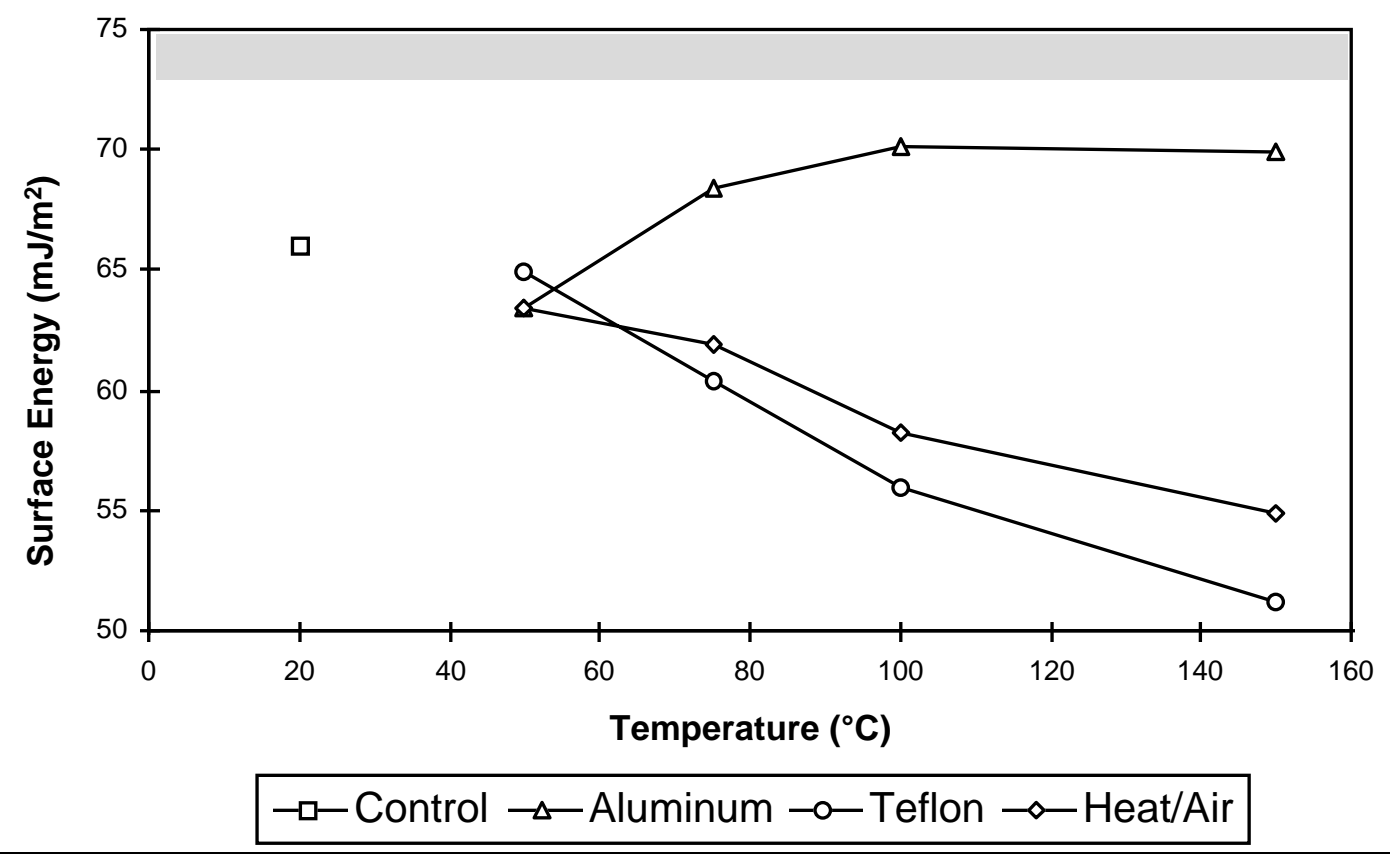

Figure 3.3. Average FSE of unextracted yellow-poplar sapwood exposed to environments of high energy (aluminum), low energy (teflon), and heat/air.

At $50{ }^{\circ} \mathrm{C}$ treatment temperature, all of the average FSE, regardless of surface treatment, are less than the control (fresh) surface energy of $66.0 \mathrm{~mJ} / \mathrm{m}^{2}$. The lowest average FSE, at $50{ }^{\circ} \mathrm{C}$ treatment temperature, was represented by both aluminum and heat/air surface treatments at 63.4 $\mathrm{mJ} / \mathrm{m}^{2}$. In between the two treatment temperatures of $50^{\circ} \mathrm{C}$ and $75^{\circ} \mathrm{C}$, the FSE curve of aluminum surface treated wood increases to a higher surface energy while the teflon surface treatment curve decreases to a lower surface energy than the control. This abrupt change in the surface energy behavior results from the temperature of the wood, especially at its surface, being elevated to and beyond the glass transition temperature $\left(\mathrm{T}_{\mathrm{g}}\right)$ of lignin. At $\mathrm{T}_{\mathrm{g}}$, the free volume and molecular mobility increases within the wood. In unextracted sapwood, this increased free volume and molecular mobility could allow the extractives at the surface to reorient in response 
to either the high energy or low energy environment. The aluminum surface treated wood curve at temperatures above $\mathrm{T}_{\mathrm{g}}$ is greater in surface energy than the control and other surface treatments at all temperatures. In viewing the behavior of the teflon surface treated wood curve at temperatures above $\mathrm{T}_{\mathrm{g}}$, there is a trend of decreasing surface energy with increasing treatment temperature. At $50^{\circ} \mathrm{C}$, the teflon surface treated wood FSE is greater at $64.9 \mathrm{~mJ} / \mathrm{m}^{2}$ than the heat/air treatment but, at temperatures above $\mathrm{T}_{\mathrm{g}}$, the surface energy is always less than the heat/air treatment with a low $51.2 \mathrm{~mJ} / \mathrm{m}^{2}$ at $150^{\circ} \mathrm{C}$. The heat/air surface treated wood curve also exhibits a trend of decreasing surface energy with increasing temperatures. The lower average FSE of heat/air samples represents surface inactivation resulting from the migration and deposition of extractives to the surface and/or reorientation of wood surface molecules (Hemingway 1969; Gunnells et al. 1994). Redistribution of extractives during drying can result in their deposition on the surface in larger amounts (Zavarin 1984). According to Christiansen (1990), exudation of extractives to the surface can lower its wettability and molecular reorientation can involve a loss in bonding sites and wettability.

The overall behavior of FSE curves for all surface treatments of unextracted yellowpoplar heartwood (Figure 3.4), is similar if not identical to that of unextracted sapwood. 


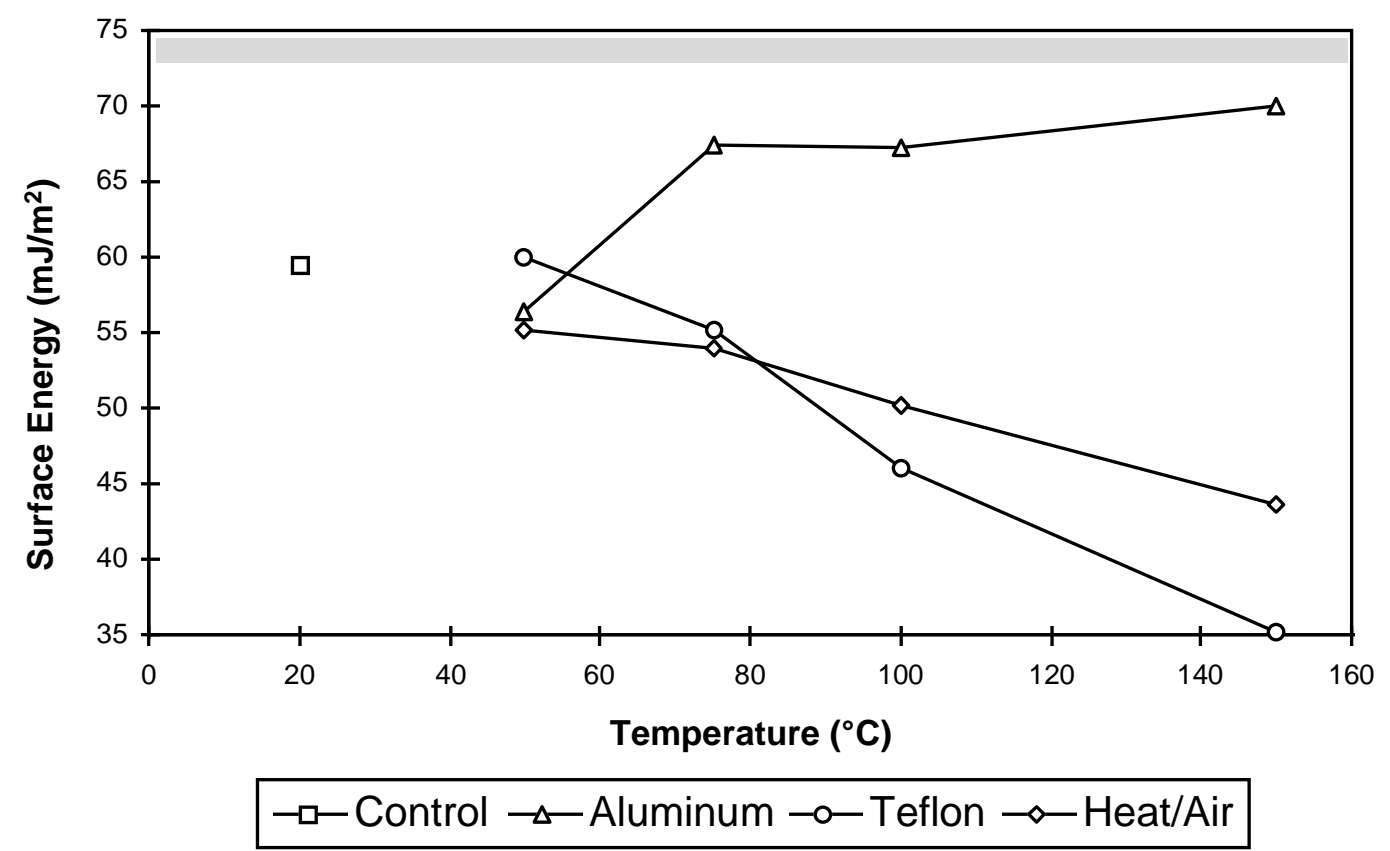

Figure 3.4. Average FSE of unextracted yellow-poplar heartwood exposed to environments of high energy (aluminum), low energy (teflon), and heat/air.

The aluminum surface treated wood curve increases in surface energy while the teflon surface treated wood curve decreases in surface energy as the temperature increases above the $\mathrm{T}_{\mathrm{g}}$ of lignin. The heat/air FSE wood curve also exhibits the decreasing surface energy as treatment temperature increases and is greater in surface energy than the teflon FSE wood curve at $100^{\circ} \mathrm{C}$ and $150^{\circ} \mathrm{C}$.

Figures 3.5 and 3.6 contain the average FSE of extracted yellow-poplar sapwood and heartwood exposed to aluminum, teflon, and heat/air surface treatments. FSE average and standard deviations corresponding to Figures 3.5 and 3.6 are reported in Table 3.5. The overall behavior of FSE curves resulting from all surface treatments in both extracted sapwood and heartwood, are similar but less pronounced in comparison to the unextracted FSE curves 
discussed earlier. However, there are important differences that result from the absence of extractives. The control of both extracted sapwood and heartwood exhibit higher surface energy (see Table 3.5). A surface energy of $72.8 \mathrm{~mJ} / \mathrm{m}^{2}$ (contact angle $=0$ with no variation) in both

Table 3.5. Average (standard deviation) FSE results of extracted yellow-poplar sapwood and heartwood exposed to environments of high energy (aluminum), low energy (teflon), and heat/air.

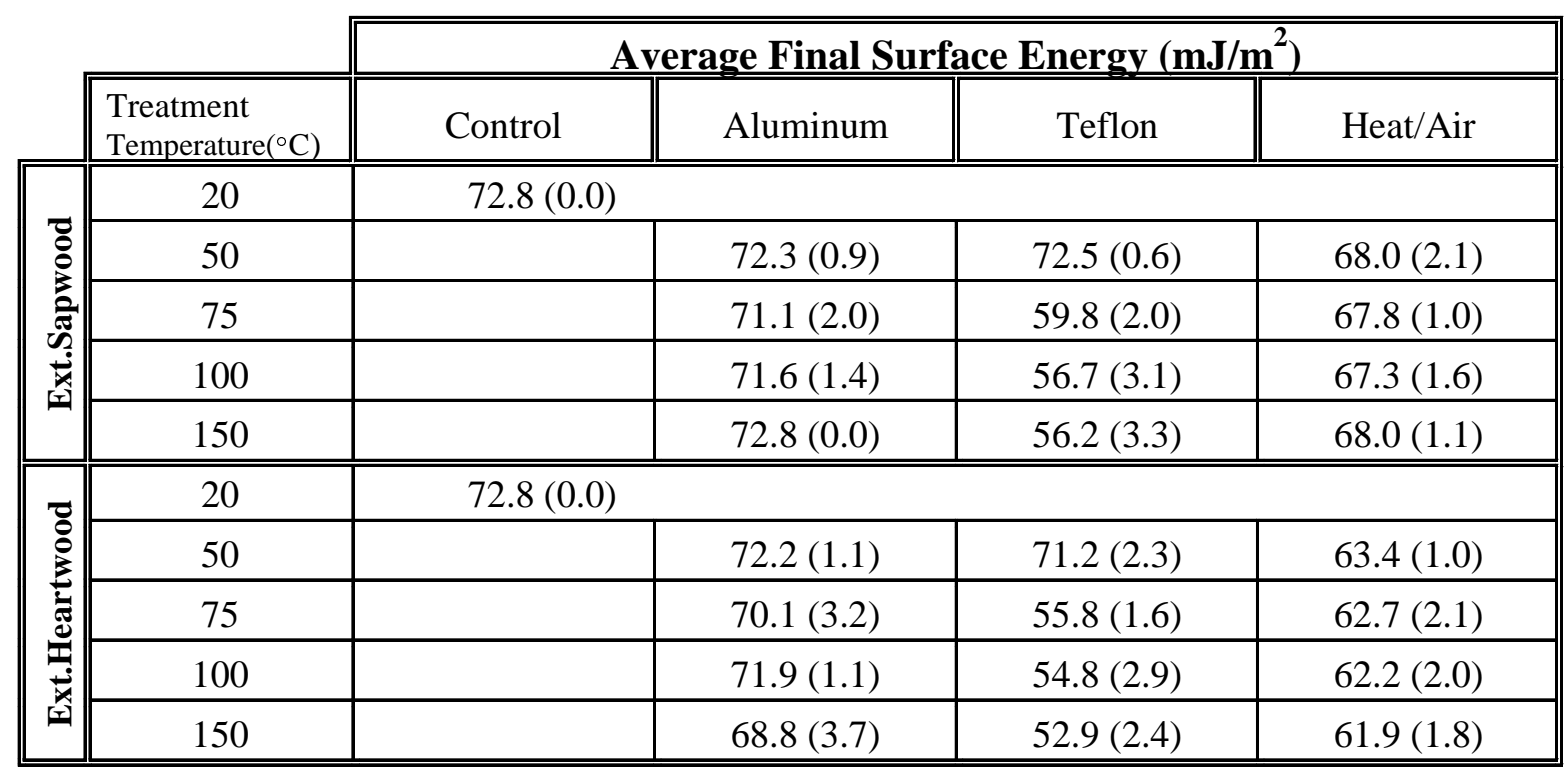

extracted sapwood and heartwood indicated complete wettability of the extracted surface by the probe liquid. In other words, the extracted wood surfaces had a higher surface energy than the probe liquid. Other studies by Chen (1970) and Nguyen and Johns (1979), among others have reported increases in surface energy with the removal of extractives. Also, wood surface treatment FSE curves are higher in surface energy over the entire range of temperatures examined. The placement of extracted sapwood and heartwood FSE curves relative to unextracted sapwood and heartwood can be seen in Figure 3.7. Figure 3.7 contains the average 
FSE curves of extracted and unextracted sapwood and heartwood exposed only to heat/air surface treatment. 


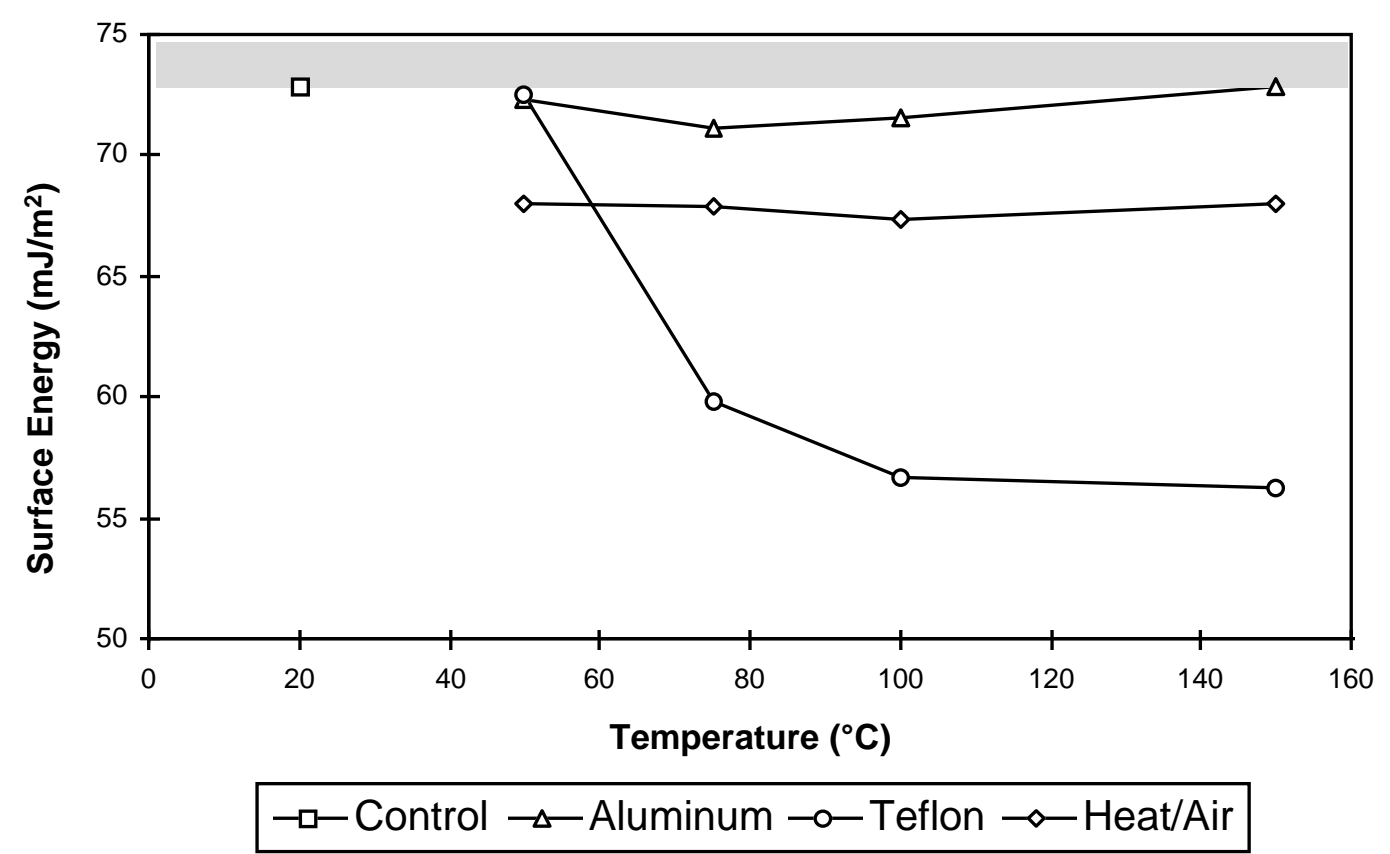

Figure 3.5. Average FSE of extracted yellow-poplar sapwood exposed to environments of high energy (aluminum), low energy (teflon), and heat/air.

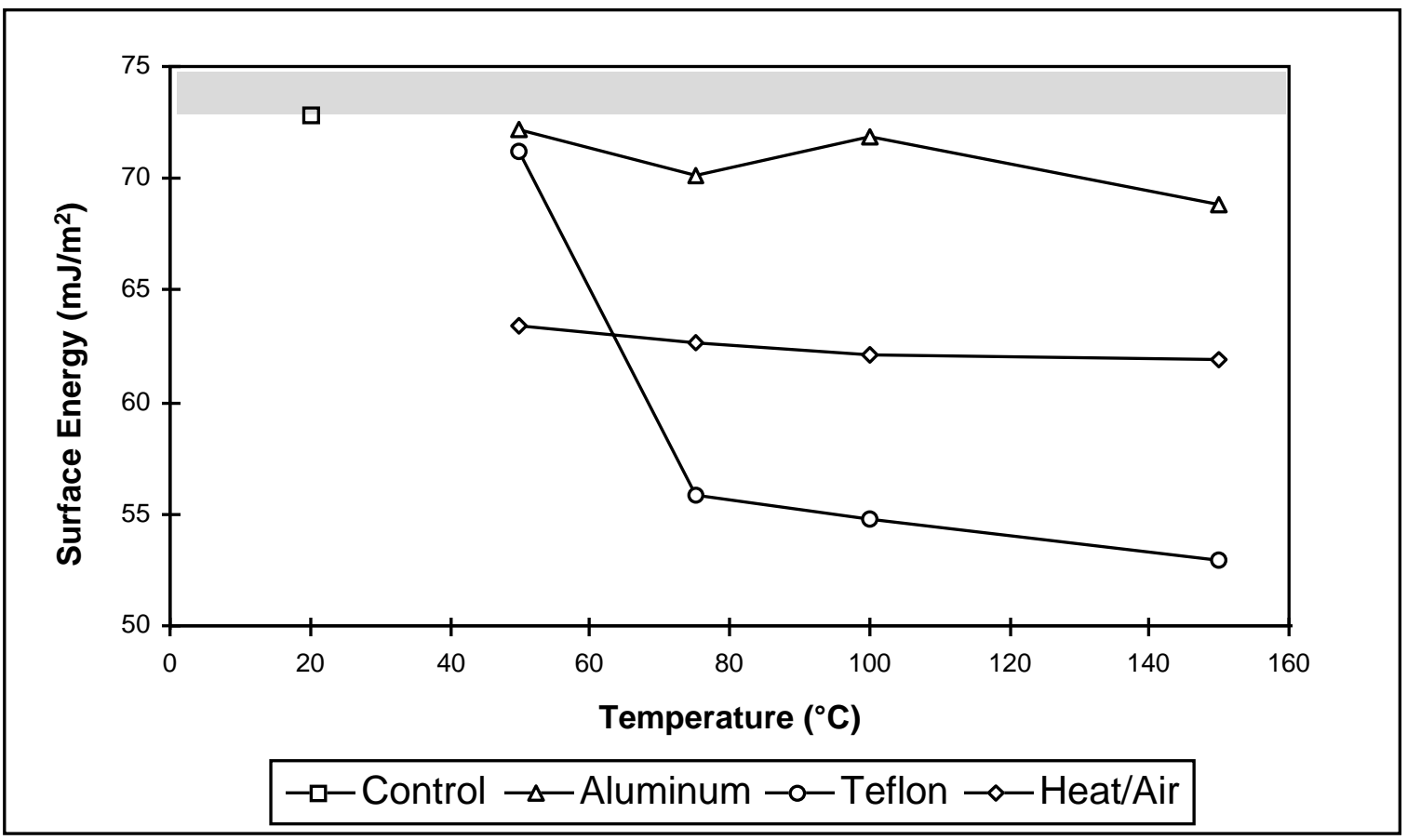

Figure 3.6. Average FSE of extracted yellow-poplar heartwood exposed to environments of high energy (aluminum), low energy (teflon), and heat/air. 
The higher surface energy present in extracted sapwood and heartwood results from the loss of extractives that were composed of low energy functional groups (e.g. aliphatic and/or aromatic). Also, the removal of extractives could present surfaces largely composed of higher

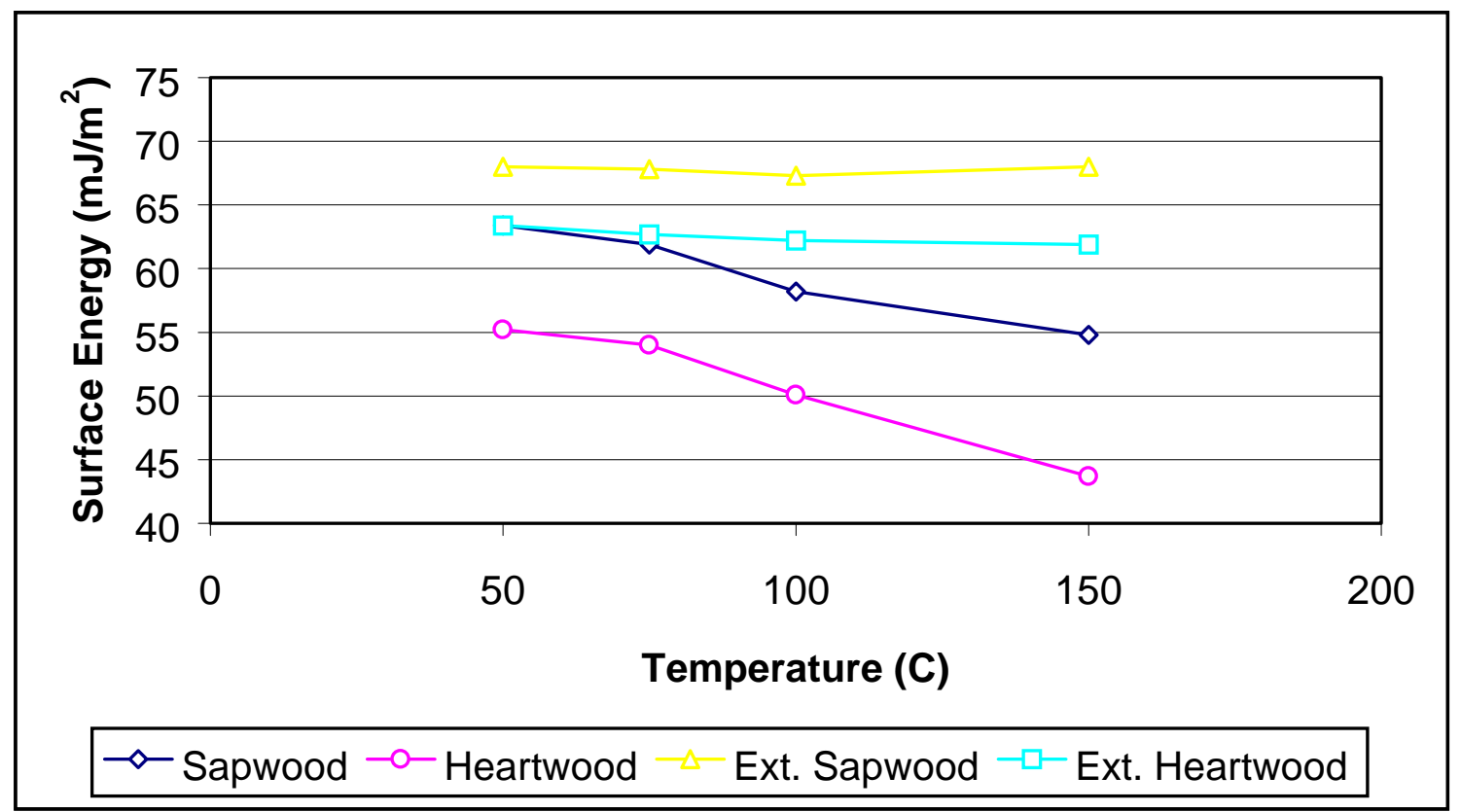

Figure 3.7. Average FSE of unextracted and extracted yellow-poplar sapwood and heartwood exposed to heat/air surface treatment.

energy functional groups (e.g. hydroxyls and carboxyls) present on a surface rich in cellulose, hemicellulose, and lignin.

The FSE curves resulting from heat/air and teflon surface treatments (Figures 3.5 and 3.6) of extracted sapwood and heartwood exhibit similar behavior to that of unextracted FSE curves discussed previously. At temperatures above $\mathrm{T}_{\mathrm{g}}$, the trend of decreasing surface energy with increasing treatment temperature is present. The wood surface energy resulting from teflon surfacetreatment remains lower than heat/air at temperatures above $\mathrm{T}_{\mathrm{g}}$. This lower surface energy response of both extracted sapwood and heartwood from teflon surface treatment reveals 
preferential molecular reorientation greater than the effect of surface inactivation from heat/air. Since the majority of the extractives are not present in extracted sapwood and heartwood, this reorientation must be occurring within the amorphous primary constituents of wood (hemicelluloses and/or lignin). The entire hemicellulose polymer or possibly a branched segment could be reorienting after reaching the $T_{g}$ of lignin. Since lignin is the encrusting long chain polymer in the lignin carbohydrate complex it is less likely to reorient in its entirety but possibly segments or functional groups could.

Figure 3.8 contains the average FSE curves of extracted and unextracted sapwood and heartwood exposed only to aluminum surface treatment. The FSE curves resulting from

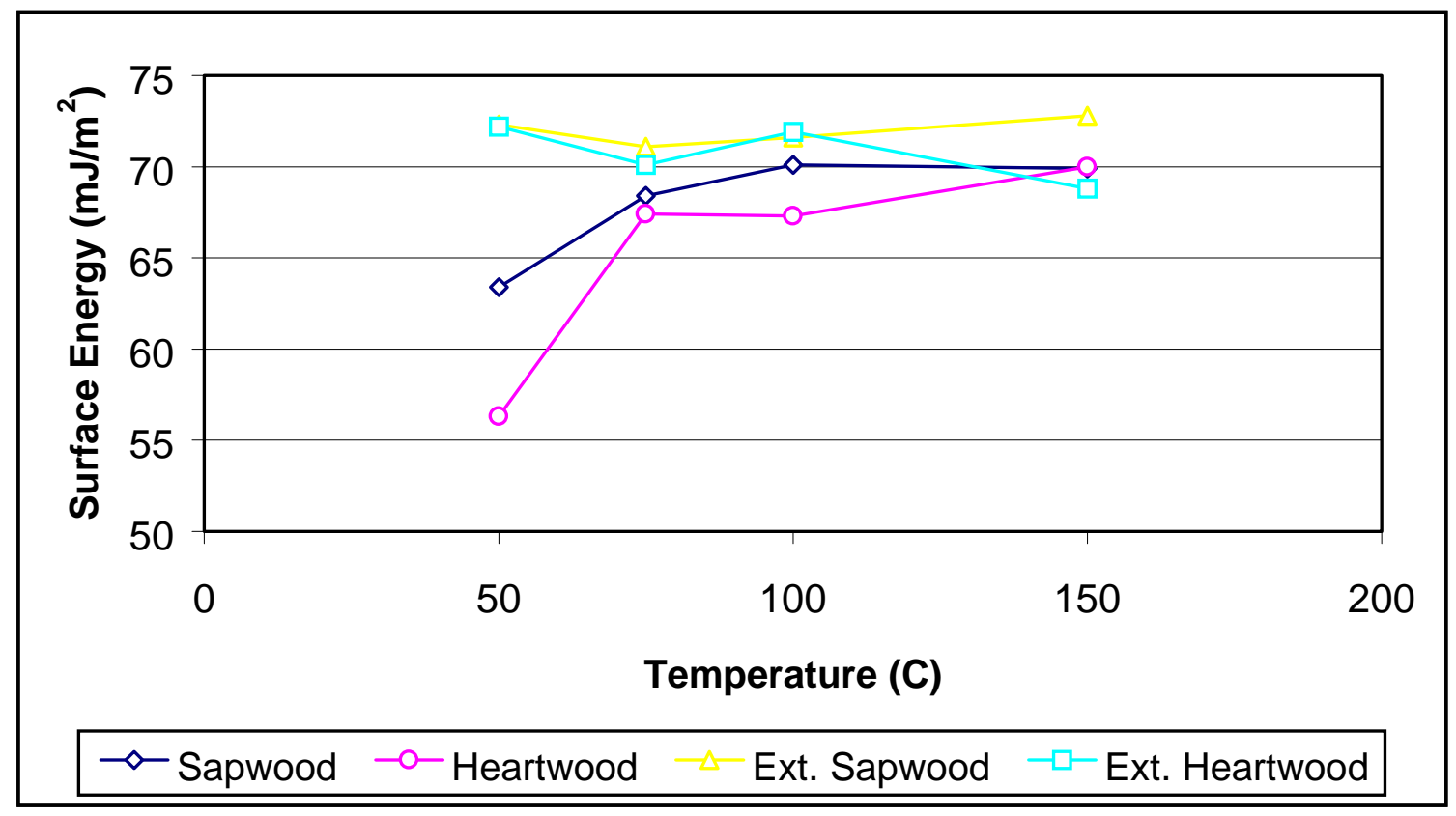

Figure 3.8. Average FSE of unextracted and extracted yellow-poplar sapwood and heartwood exposed to aluminum surface treatment.

aluminum surface treatment of extracted sapwood and heartwood exhibited a more random 
behavior than their unextracted counterparts. There was not any preferential reorientation present in extracted sapwood exposed to aluminum surface treatment until the treatment temperature of $150{ }^{\circ} \mathrm{C}$. Reorientation may have eventually occurred at $75^{\circ} \mathrm{C}$ and $100{ }^{\circ} \mathrm{C}$ treatment temperatures if given a long enough exposure time. Also, an important point is that extracted sapwood obtained an average surface energy of $72.8 \mathrm{~mJ} / \mathrm{m}^{2}$ with a standard deviation of 0 at $150{ }^{\circ} \mathrm{C}$. The actual surface energy of extracted sapwood at $150{ }^{\circ} \mathrm{C}$ may have been higher if it was not limited by the probe liquid utilized.

The extracted heartwood with aluminum surface treatment (Figure 3.8) had the lowest surface energy at $150{ }^{\circ} \mathrm{C}$. This difference in extracted heartwood may have resulted from the migration of some left-over extractives to the surface. The extraction method used to prepare the extracted wood was reported by Huang (1994) to remove at least 90\% of the benzene-alcohol soluble extractives.

Teflon surface treatment was not limited such as aluminum and could show all of its effect. The FSE curves of extracted sapwood and heartwood exposed to teflon surface treatment (Figure 3.9) exhibited less change in surface energy in comparison to unextracted at $100{ }^{\circ} \mathrm{C}$ and $150{ }^{\circ} \mathrm{C}$. Both extracted sapwood and heartwood exhibited very little slope after $\mathrm{T}_{\mathrm{g}}$ had been surpassed in treatment temperature . Whereas, unextracted sapwood and especially heartwood continued to decrease in surface energy with increasing treatment temperature. Unextracted heartwood showed a greater rate of change in comparison to sapwood after increasing above the $\mathrm{T}_{\mathrm{g}}$ of lignin. 


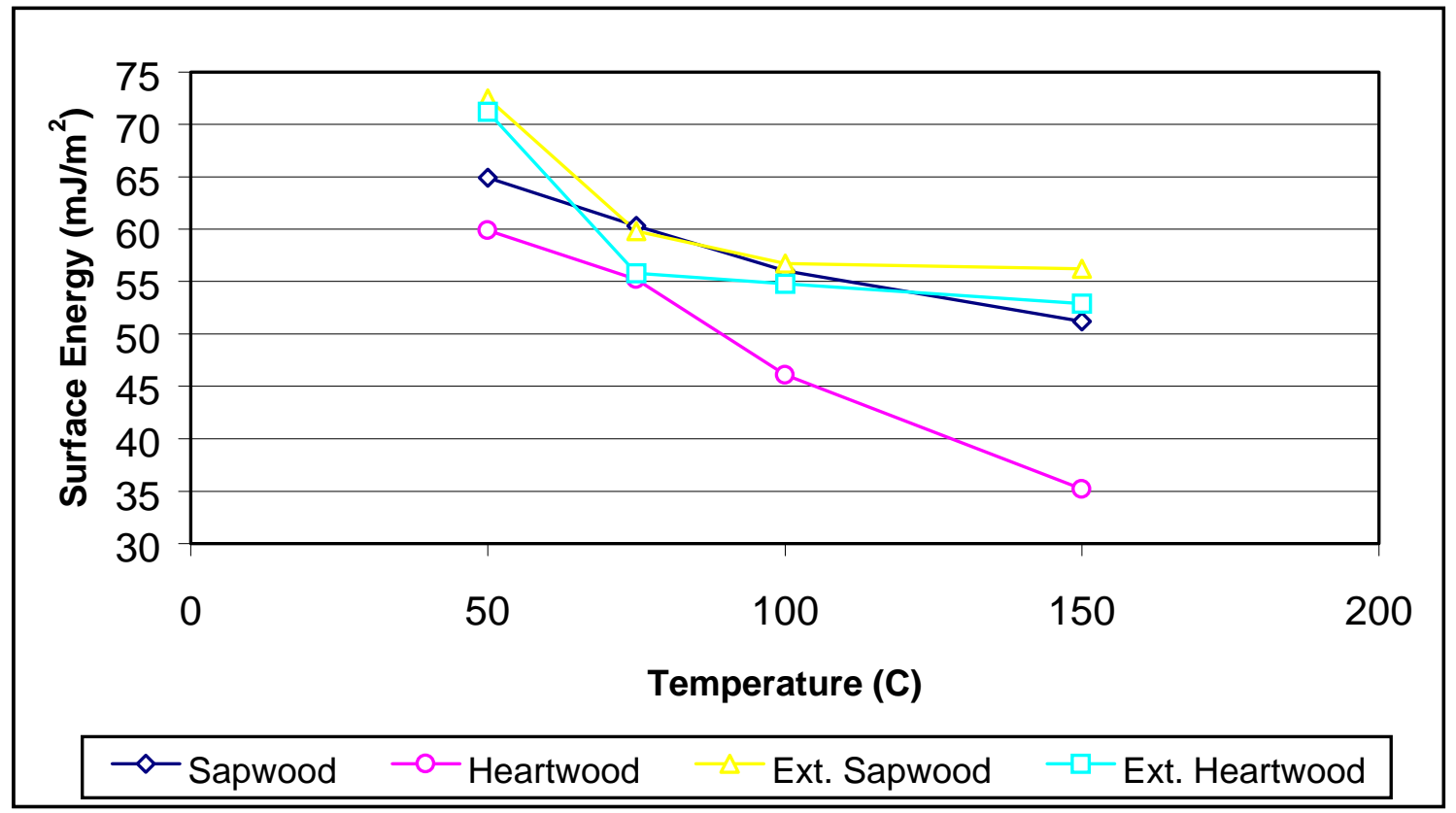

Figure 3.9. Average FSE of unextracted and extracted yellow-poplar sapwood and heartwood exposed to teflon surface treatment.

The difference in rate of change could also be revealing the further diffusion of extractives and short chain chemical components from within the bulk to the surface as free volume and molecular mobility increases. The lowest surface energy $\left(35.2 \mathrm{~mJ} / \mathrm{m}^{2}\right)$ obtained with teflon surface treatment occurred with unextracted heartwood at $150{ }^{\circ} \mathrm{C}$ temperature. Since yellowpoplar heartwood contains a higher percentage of extractives (5.0\%) than sapwood (3.5\%), it can be expected to show the most effect in reorientation in response to its surrounding environment. 


\subsubsection{Elemental Surface Composition from XPS Analysis}

XPS analysis was performed on unextracted yellow-poplar heartwood flakes that were exposed to high energy (aluminum) and low energy (teflon) environments. The XPS analysis was performed perpendicular to the surface and at a glancing angle of $10^{\circ}$. XPS analysis obtained with a glancing angle of $10^{\circ}$ can offer a more representative depiction of the surface elemental composition.

The XPS results are presented below, in Table 3.6, as Carbon/oxygen (C/O) ratios that are present on the surface. A higher $\mathrm{C} / \mathrm{O}$ ratio is indicative of a more hydrophobic surface. This results from the presence of carbon containing functional groups such as methyl, phenyl, and other less polar groups. A higher C/O ratio present on the surface of wood results in a lower surface energy and wettability. A lower $\mathrm{C} / \mathrm{O}$ ratio represents a higher percentage of oxygen containing functional groups, such as hydroxyl or carbonyl groups, that are polar in nature. 
Table 3.6. XPS, perpendicular to surface and with glancing angle, carbon/oxygen $(\mathrm{C} / \mathrm{O})$ ratios from unextracted yellow-poplar heartwood exposed to aluminum and teflon surface treatments.

\begin{tabular}{||l|c||}
\hline \multicolumn{2}{|c||}{ Xample Carbon/Oxygen Ratios } \\
\hline \multicolumn{1}{|c||}{ Camp/O Ratio } \\
\hline $\begin{array}{l}\text { Yellow-poplar heartwood with aluminum } \\
\text { surface treatment (perpendicular XPS) }\end{array}$ & 2.2 \\
\hline $\begin{array}{l}\text { Yellow-poplar heartwood with teflon surface } \\
\text { treatment (perpendicular XPS) }\end{array}$ & 2.0 \\
\hline $\begin{array}{l}\text { Yellow-poplar heartwood with aluminum } \\
\text { surface treatment (glancing angle of } 10^{\circ} \text { ) }\end{array}$ & 2.1 \\
\hline $\begin{array}{l}\text { Yellow-poplar heartwood with teflon surface } \\
\text { treatment (glancing angle of } 10^{\circ} \text { ) }\end{array}$ & 2.3 \\
\hline \hline
\end{tabular}

All of the $\mathrm{C} / \mathrm{O}$ ratios of surface-treated heartwood, given in Table 3.6, are in the range of other yellow-poplar XPS studies by Hon (1984) and Gardner et al. (1991). Hon (1984) found a yellow-poplar sapwood surface to have a relatively higher C/O ratio of 3.7. Gardner et al.(1991) also reported similar C/O ratios of "aged" yellow-poplar sapwood (4.0) and heartwood (5.0). Gardner et al. (1991) associated the aging of the wood surface with a large increase in surface carbon percentages that suggest possible surface modifications by environmental effects such as light or reaction with the atmosphere.

Hon (1984) also presented results that showed the effects of weathering and ultraviolet radiation (UV). Weathered yellow-poplar sapwood surfaces were shown to have a $\mathrm{C} / \mathrm{O}$ ratio of 1.8 and UV irradiated surfaces of 1.6. Hon (1984) suggested that the weathered and UV- 
irradiated wood surfaces resulted from oxidation. The $\mathrm{C} / \mathrm{O}$ results of the weathered and uvirradiated yellow-poplar surfaces reported by Hon (1984) and that of "fresh" yellow-poplar sapwood $(\mathrm{C} / \mathrm{O}=2.4)$ reported by Gardner et al $(1991)$ are the closest in range to those obtained in this study. Some oxidation of the yellow-poplar heartwood surfaces could have occurred in both aluminum and teflon surface treatments. Both surface treatments utilized elevated temperature of $150{ }^{\circ} \mathrm{C}$ for 5 minutes. According to Zavarin (1984) the degradation of wood at moderately elevated temperatures (e.g. $40-160{ }^{\circ} \mathrm{C}$ ) or at short exposure to higher temperatures in the presence of air is composed of pyrolytic and oxidative changes.

The $\mathrm{C} / \mathrm{O}$ ratios revealed by XPS perpendicular to the surface of aluminum (2.2) and teflon (2.0) surface treatment are not as representative of the top surface layer as glancing angle XPS. With perpendicular XPS the depth of electron escape and detection is greater. The perpendicular XPS results suggest that no preferential reorientation occurred. However, in viewing the glancing angle $\mathrm{C} / \mathrm{O}$ ratios, a difference is recognized. The heartwood exposed to aluminum surface treatment had a lower $\mathrm{C} / \mathrm{O}$ ratio than the heartwood exposed to teflon surface treatment, 2.1 and 2.3 respectively. The higher $\mathrm{C} / \mathrm{O}$ ratio of the heartwood, exposed to teflon surface treatment, is indicative of a lower surface energy and less wettability. The XPS results did reveal slight flourine contamination of the wood surface. The amount of contamination was negligible and does not adversely effect the $\mathrm{C} / \mathrm{O}$ ratios obtained. This result supports the occurrence of preferential surface reorientation in yellow-poplar heartwood exposed to low and high energy environments. 


\subsection{CONCLUSIONS}

The wood composites industry utilizes wood by breaking it down in some manner and reconstituting it with other materials and/or an adhesive to form a wide range of useful products. The engineering of all composite materials, wood or synthetic, focuses on the interface between dissimilar materials. The surface chemistry of wood plays an important role in the production of either a weak or strong adhesive bond. Changes in the surface chemistry, especially surface energy, of wood occur during many stages of wood composite manufacturing.

Yellow-poplar, being a heterogeneous bio-polymer composite, has bulk and surface behavior that is similar to other more homogeneous synthetic polymers. Yellow-poplar and wood in general experiences surface energy changes and surface reorientation in response to environmental influences. The surface molecular reorientation of synthetic polymers can be controlled by increasing the temperature above the polymer's $T_{g}$ while exposing it to either an environment that is higher or lower in surface energy. By increasing above $\mathrm{T}_{\mathrm{g}}$, molecular mobility increases as a result of increased free volume, allowing the reorientation of molecules and increased diffusion of smaller chemical entities to the surface. This study has shown the reorientation phenomena to also occur on yellow-poplar surfaces.

The yellow-poplar sapwood and heartwood, whether extracted or unextracted, had similar surface reorientation behavior upon exposure to high energy (aluminum) and a low energy (teflon) environment. However, with the absence of extractives in extracted wood, the behavior was much less pronounced. The results clearly revealed that no preferential surface reorientation was occurring upon exposure to either surface energy environment at 
temperatures below the $\mathrm{T}_{\mathrm{g}}$ of lignin. At temperatures lower than the $\mathrm{T}_{\mathrm{g}}$, there is less free volume and accompanying molecular mobility of the surface molecules. At surface treatment temperatures above the $\mathrm{T}_{\mathrm{g}}$, preferential surface reorientation occurred with exposure to both the high and low energy environments. Above the $\mathrm{T}_{\mathrm{g}}$, increases in free volume allows greater molecular mobility that enables increased diffusion of extractives to the surface and reorientation of polymer molecules.

Above the $T_{g}$, the wood with aluminum surface treatment is greater in surface energy than the control and other surface treatments at all temperatures. There was not any preferential reorientation in extracted wood in response to aluminum treatment with the exception of extracted sapwood showing an increase in surface energy with $150{ }^{\circ} \mathrm{C}$ treatment temperature. The actual surface energy of extracted sapwood may have been greater than determined had it not been limited by the probe liquid utilized.

A lower surface energy results when the wood, whether extracted or unextracted, is exposed to heat/air or teflon surface treatments. The effects of teflon and heat/air surface treatments were not limited such as aluminum and always showed decreasing surface energy with increasing temperature. The behavior resulting from teflon surface treatment is clearly evident, at temperatures above the $\mathrm{T}_{\mathrm{g}}$, where the surface energy was similar or lower than heat/air treatment.

As a result of yellow-poplar having a substantial amount of extractives, especially in the heartwood, the role that extractives play in wood surface reorientation was quite evident. The surface treatments did not have the amount of effect with the extractive-free wood as with the extractives present. The control as well as the FSE curves of extracted wood showed an increase 
in surface energy over the entire range of temperatures examined. The amount of inactivation resulting from heat/air treatment was greater with the presence of extractives. Most importantly, the largest change in surface energy of any surface treatment occurred with unextracted heartwood exposed to teflon surface treatment at $150^{\circ} \mathrm{C}$.

The XPS results revealed, even with some fluorine contamination, that exposure of the unextracted heartwood surface to the low energy environment of teflon presented a surface with greater abundance of low energy functional groups. A greater abundance of high energy functional groups were detected when the wood surface was exposed to the high energy environment of aluminum surface treatment. These XPS results offer further support that wood surface functional groups are preferentially reorienting in response to their environment.

Some insight was gained for further research into the surface chemistry of yellow-poplar and how it changes in response to its physical environment. Benefit could be gained toward a better understanding of the behavior of wood surface chemistry by considering the following:

o A different probe liquid with a higher surface tension should be utilized that could better describe the effect of higher energy surface treatment.

o Determining more precisely the chemical structure of the wood surface after surface treatment to show the actual extent that extractives play in molecular reorientation as opposed to the primary chemical constituents of wood (cellulose, hemicellulose, and lignin). o Determining how much surface inactivation occurred from both aluminum and teflon surface treatments. 
o A difference in amount of heat transfer to the wood surface is present between surface treatments. This difference could be quantified and surface treatment length of exposure could be adjusted to offer better comparison.

o An optimal treatment temperature and length of exposure could be found that could aid in the transfer of knowledge to manufacturing processes of industry. 


\subsection{LITERATURE CITED}

Aklonis, J.J., W.J. MacKnight and M. Shen. 1972. Introduction to polymer viscoelasticity. John Wiley and Sons, New York.

Allen, K.W. 1987. A review of contemporary views of theories of adhesion. Journal of Adhesion. 21:261-277.

Andrade, J.D. 1988. Polymer surface and interface dynamics: An introduction. In Polymer Surface Dynamics. J.D. Andrade, ed. Plenum Press, New York, NY. pp 1-8.

Andrade, J.D. and W.Y. Chen. 1986. Probing polymer and interface dynamics. Surface Interface Analysis. 8:253-256.

Andrade, J.D., S.M. Ra, R.N. King, and D.E. Gregonis. 1979. Contact angles at the solid liquid interface. Journal of Colloid and Interface Science. 72(3):488-494.

Askeland, D.R. 1989. The science and engineering of materials. Wadsworth, Inc. Belmont, California.

Back, E.L. 1991. Oxidative activation of wood surfaces for glue bonding. Forest Products Journal 41(2):30-36.

Barrow, G.M. 1979. Physical Chemistry. Fourth Edition. McGraw-Hill, Inc. New York, NY.

Baszkin, A., M. Nishino, and L. Ter-Minassian-Saraga. 1976. Solid liquid adhesion of oxidized polyethylene films. Effect of temperature. Journal of Colloid and Interface Science 54(3):317-328.

Biggs, D. and R. Fredricks. 1994. A study of wetting tension solutions. Tappi. 77(8):9499.

Billmeyer, F.W. 1984. Textbook of polymer science. Third Edition. John Wiley and Sons, New York, NY.

Blomquist, R.F. 1983. Adhesives - an overview. In: Adhesive Bonding of Wood and Other Structural Materials. Pennsylvania State University, University Park, PA. Ch 1.

Bodig, J. 1962. Wettability related to gluabilities of five philipine mahoganies. Forest Products Journal. 12(6): 265-270. 
Brewis, D.M., J. Comyn, and C, Phanopoulos. 1987. Durability and surface analytical studies of adhesive bonding to wood. Journal of Adhesion. 21: 303-311

Briggs, D. 1982. XPS studies of polymer surface modifications and adhesion mechanisms. Journal of Adhesion.13:287-301.

Briggs, D. and M.P. Seah. 1990. Practical Surface Analysis. Second edition.Vol.1:Auger and X-rayPhotoelectron Spectroscopy. John Wiley and Sons. New York.

Browning, B.L. 1975. The Chemistry of Wood. Robert E. Krieger Publishing Co., Huntington, NY.

CAHN. 1991. CAHN DCA Aplications Software. ATI Analytical Technology Inc., Madison, WI.

Chen, C.M. 1970. Effect of extractive removal on adhesion and wettability of some tropical woods. Forest Products Journal. 20(1):36-40.

Christiansen, A.W. 1990. How over-drying wood reduces its bonding to phenolformaldehyde adhesives: a critical review of the literature. Part I. Physical responses Wood and Fiber Science 22(4):441-459.

Christiansen, A.W. 1991. How overdrying wood reduces its bonding to phenol-formaldehyde adhesives: a critical review of the literature. Part II. Chemical reactions. Wood and Fiber Science 23(1):69-84.

Clark, D.T. 1977. ESCA applied to polymers. Advances in Polymer Science 24:125188.

Collett, B.M. 1972. A review of surface and interfacial adhesion in wood science and related fields. Wood Science and Technology. 6: 1-42.

Debye, P.J.W. 1926. Interatomic and Intermolecular Forces in Adhesion and Cohesion, Edited by Philip Weiss. Elsevier Publishing Co. New York. pp. 1-17.

Deng, Y. and M. Abazeri. 1998. Contact angle measurements of wood fibers in surfactant and polymer solutions. Wood and Fiber Science, 30(2):155-164.

Etzler, F.M. and W. Drost-Hansen. 1979. A role for water in biological rate processes. in Cell-Associated Water. W. Drost-Hansen and J.S. Clegg, eds. Academic Press. New York.

Ferry, J.D. 1980. Viscoelastic properties of polymers. Third Edition. John Wiley and Sons, New York, NY. 
Fox, H.W. and W.A. Zisman. 1950. The spreading of liquids on low energy surfaces. I. Polytetrafluoroethylene. Journal of Colloid Science 5(6):515-531.

Freeman, H.G. 1959. Relation between physical and chemical properties of wood and adhesion. Forest Products Journal. 9(12): 451-458.

Freeman, H.G. and F.F. Wangaard. 1960. Effect of wettability of wood or glueline behavior of two urea resins. Forest Products Journal. 10(6): 311-315.

Gagnon, D.R. and T.J. McCarthy. 1984. Polymer surface reconstruction by diffusion of organic functional groups from and to the surface. Journal of Applied Polymer Science. 29:4335-4340.

Gardner, D.J. 1991. Solid state chemistry of dimensionally stabilized (acetylated) wood. In: Proceedings of the $6^{\text {th }}$ International Symposium on Wood and Pulping Chemistry. Vol. I. pp.345-352.

Gardner, D.J. 1996. Application of the Lifshitz-van der Waals acid-base approach to determine wood surface tension components. Wood and Fiber Science. 28(4):422-428.

Gardner, D.J., J.G. Ostmeyer and T.J. Elder. 1991. Bonding surface activated hardwood flakeboard with phenol-formaldehyde resin. II. Flake surface chemistry. Holzforschung 45(3):215-222.

Gardner, D.J., N.C. Generalla, D.W. Gunnells, and M.P. Wolcott. 1991. Dynamic wettability of wood. Langmuir 7(11):2498-2502.

Gardner, D.J., M.P. Wolcott, L. Wilson, Y. Huang, and M. Carpenter. 1996. Our understanding of wood chemistry in 1995. Pages 29-36 in: Proc. No. 72961995 Wood adhesive Symposium, Forest Product Society.

Gent, A.N. and G.R. Hamed. 1983. Fundamentals of adhesion. In: Adhesive Bonding of Wood and Other Structural Materials. Pennsylvania State University, University Park, PA. Ch 2.

Gent, A.N. and G.R. Hamed. 1990. In: Handbook of Adhesives, third edition, Irving Skeist, ed., Van Nostrand Reinhold Co. New York, NY.

Girifalco, L.A. and R.J. Good. 1957. A theory for the estimation of surface and interfacial energies. I. Derivation and application to interfacial tension. Journal of Physical Chemistry. 61: 904. 
Goldstein, I.S. 1991. Chemical composition of wood. In: Wood structure and composition, Ch.1. Ed. M. Lewin and I.S. Goldstein. International fiber science and technology series;v.11. Marcel Dekker, Inc. New York, NY.

Gray, V.R. 1962. The wettability of wood. Forest Products Journal 6:452-461.

Gunnells, D.W. 1992. Utilizing Dynamic Contact Angle Analysis to Investigate the effects of Environmental Conditions on the Surface of Wood. M.S. Thesis, West Virginia University, WV.

Gunnells, D.W., D.J. Gardner, and M.P. Wolcott. 1994. Temperature dependence of wood surface energy. Wood and Fiber Science 26(4):447-455.

Hancock, W.V. 1963. Effect of heat treatment on the surface of Douglas-fir veneer. Forest Products Journal. 13(2).81-88.

Hemingway, R.W. 1969. Thermal instability of fats relative to surface wettability of yellow birchwood (Betula lutea). Tappi. 52(11): 2149-2155.

Hemingway, R.W. and A. H. Conner. 1989. In: Adhesives from renewable resources. ACS Symposium Series 385, Hemingway, R.W., A.H. Conner, Branham, S.J. Eds., American Chemical Society, Washington, DC.

Herczeg, A. 1965. Wettability of wood. Forest Products Journal 11:499-505.

Hiemenz, P.C. 1984. Polymer Chemistry. Marcel Dekker, Inc. New York, NY

Hiemenz, P.C. 1986. Principles of Colloid and Surface Chemistry. Second Edition. Marcel Dekker, Inc. New York, NY

Holum, J.R. 1990. Fundamentals of general, organic, and biological chemistry. Fourth edition. John Wiley \& Sons, Inc. New York, NY.

Hon, D.S. 1984. ESCA study of oxidized wood surfaces. Journal of Applied Polymer Science. 29(9):2777-2784.

Huang, Y. 1994. A study of the effect of heat on wood wettability using dynamic contact angle analysis. Master's Thesis, West Virginia University, Morgantown, WV.

Irvine, G. M. 1984. The glass transitions of lignin and hemicellulose and their measurement by different thermal analysis. Tappi 67(5): 118-121.

Jacob, B.N. and J.C. Berg. 1993. Zisman analysis of three pulp fiber furnishes. Tappi. 76(2):105-107. 
Jhon, M.S. and S.H. Yuk. 1988. Contact angles at polymer water interfaces. in Polymer Surface Dynamics. J.D. Andrade, ed. Plenum Press, New York, NY. pp 25-44.

Johns, W.E and T. Nguyen. 1977. Peroxyacetic acid bonding of wood. Forest Products Journal. 27(1):17-23.

Johnson, R.E. and R.H. Dettre. 1993. Wetting of low energy surfaces. In: Wettability, J.C. Berg ed. Marcel Dekker, Inc. New York, NY. Ch 1.

Kamdem, D.P. and B. Riedl. 1991. IGC characterization of PMMA grafted onto CTMP fiber. Journal of Wood Chemistry and Technology II(1):57-91.

Kalnins, M.A. and W.C. Feist. 1993. Increase in wettability of wood with weathering. Forest Products Journal. 43(2):55-57

Kalnins, M.A. and C. Katzenberger. 1987. In: Wood and cellulosics : industrial utilization, biotechnology, structure and properties. Kennedy, J.F., Phillips, G.O., Williams, P.W. Eds.; Ellis Horwood, Ltd.; West Sussex, England.

Kelley, S.S., T.G. Rials, and W.G. Glasser. 1987. Relaxation behavior of the amorphous components of wood. Journal of Material Science 22:617-624.

Klungness, J. 1981. Measuring the wetting angle and perimeter of single wood pulp fibers: A modified method. Tappi 64(12):65-66.

Ko, V.C., B.D. Ratner, and A.S. Hoffman. 1981. Characterization of hydrophillichydrophobic polymeric surfaces by contact angle measurements. Journal of Colloid and Interface Science. 82(1):25-37.

Kwok, D.Y., D. Li, and A.W. Neumann. 1994. Evaluation of the Lifshitz-van der Waals / acid-base approach to determine interfacial tensions. Langmuir. 10(4):1323-1328.

Lavielle, L. 1988. Orientation phenomenon at polymer-water interfaces. in Polymer Surface Dynamics. J.D. Andrade, ed. Plenum Press, New York, NY. pp 45-66.

Lavielle, L. and J. Schultz. 1985. Surface properties of graft polyethylene in contact with water. Journal of Colloid and Interface Science. 106(2):438-445.

LeFebrve, D.R., D.W. Dillard and T.C. Ward. 1989. A model for the diffusion of moisture in adhesive joints, Part 1:Equations governing diffusion. Journal of Adhesion 27:1-18. 
Marian, J.E. and D.A. Stumbo. 1962. Adhesion in wood: I and II. Holzforschung $16(5,6): 134-148,165-180$.

Mark, H.F. and J.I. Kroschwitz. 1987. Encyclopedia of polymer science and engineering. John Wiley and Sons, New York, NY.

Mark, J.E., A. Eisenberg, W.W. Graessley, L. Mandelkern, and J.L. Koenig. 1984. Physical properties of polymers. American Chemical Society, Washington, D.C.

Marmur, A. 1994. Thermodynamic aspects of contact angle hysteresis. Advances in Colloid and Interface Science, 50 (1994) 121-141.

Marra, A.A. 1983. Applications of wood bonding. In: Adhesive Bonding of Wood and Other Structural Materials. Pennsylvania State University. University Park, PA. Ch 9.

Moulder, J.F., W.F. Stickle, P.E. Sobol, and K.D. Bomben. 1992. Handbook of X-ray Photoelectron Spectroscopy. Perkin-Elmer Corp. Eden Prairie, MN.

Morrison, R.T. 1987. Organic Chemistry, fifth edition. Allyn and Bacon, Inc. Boston, Mass.

Nguyen, T. and W.E. Johns. 1979. The effects of aging and extraction on the surface free energy of Douglas-fir and redwood. Wood Science and Technology. 13:29-40.

Northcott, P.L., H.G.M. Colbeck, W.V. Hancock, and K.C. Shen. 1959. Undercurecasehardening in plywood. Forest Products Journal. 9(12).

Nussbaum, R.M. 1993. Oxidative activation of wood surfaces by flame treatment. Wood Science and Technology. pp.183-193

Occhiello, E., F. Garbassi, M. Morra and L. Nicolais. 1989. Spectroscopic characterization of interfaces in polymer composites. Composites Science Technology 36:133-151.

Ostberg, G., L. Salmen, and J. Terlecki. 1990. Softening temperature of moist wood measured by differential scanning calorimetry. Holzforschung. 44(3): 223-225.

Owen, M.J., T.M. Gentle, T. Orbeck, and D.E. Williams. 1988. Dynamic wettability of hydrophobic polymers. in Polymer Surface Dynamics. J.D. Andrade, ed. Plenum Press, New York, NY. pp 101-110.

Pettersen, R.C. 1984. The chemical composition of wood. . In: Adhesive Bonding of Wood and Other Structural Materials. Pennsylvania State University., University Park, PA. Ch 2. 
Riedl, B. and P.D. Kamdem. 1990. Some aspects of chemistry teaching and research in wood science. Journal of Chemical Education. 67(7):543-548.

Ruckenstein, E., and S.V. Gourisankar. 1985. Environmentally induced restructuring of polymer surfaces and its influence on their wetting characteristics in an aqueous environment. Journal of Colloid and Interface Science. 107(2):488-502.

Salmen, L. 1984. Visco-elastic properties of in situ lignin under water saturated conditions. Journal of Material Science. 19: 3090-3096

Schniewind, A.P. and H. Berndt. 1991. The composite nature of wood. In: Wood structure and composition, Ch.10. Ed. M. Lewin and I.S. Goldstein. International fiber science and technology series; v.11. Marcel Dekker, Inc. New York, NY.

Sjostrom, E. 1981. Wood Chemistry. Academic Press, Inc. Orlando, FL

Skaar, C. 1979. Moisture sorption hysteresis in wood. Symposium on Wood Moisture Content - Temperature and Humidity Relationships. Virginia Polytechnic Institute. Blacksburg, VA.

Sperling, L. H. 1986. Introduction to Physical Polymer Science. Wiley-Interscience. John Wiley and Sons, Inc. New York.

Stumbo, D.A. 1964. Influence of surface aging prior to gluing on bond strength of Douglas-fir and Redwood. Forest Products Journal. 14(12): 582-588.

Subramanian, R.V. 1983. The adhesive system. In: Adhesive Bonding of Wood and Other Structural Materials. Pennsylvania State University. University Park, PA. Ch.3.

Subramanian, R.V. 1984. Chemistry of adhesion. In: The Chemistry of Solid Wood. Chapter 9. ACS Advances in Chemistry Series 207. R. Rowell, ed. Am. Chem. Soc., Washington, D.C.

Tingey, K.G., J.D. Andrade, C.W. McGary, and R.J. Zdrahala. 1988. Surface analysis of commercial biomedical polymers. in Polymer Surface Dynamics. J.D. Andrade, ed. Plenum Press, New York, NY. pp 153-170.

USDA. 1979. Extractives in Eastern hardwoods; a review. General technical report FPL 18. Forest Products Laboratory, Forest Service, U.S. Department of Agriculture. Madison, WI.

Van Oss, C.J., M.K. Chaudhury and R.J. Good. 1987. Monopolar surfaces. Advances in Colloidal and Interface Science. (28):35. 
Van Vlack, L.H. 1982. Materials for Engineering. Addison-Wesley Publishing Co. Reading, Mass.

Wellons, J.D. 1983. The adherends and their preparation for bonding. In: Adhesive Bonding of Wood and Other Structural Materials. Pennsylvania State University., University Park, PA. Ch 3.

Wolcott, M.P., F.A. Kamke, and D.A. Dillard. 1994. Fundamental aspects of wood deformation pertaining to manufacture of wood-based composites. Wood and Fiber Science. 26(4):496-511.

Wu, S. 1971. Calculation of interfacial tension in polymer systems. Journal of Polymer Science. 34:19-30.

Yasuda, H. and A.K. Sharma. 1981. Effect of orientation and mobility of polymer molecules at surfaces on contact angle and its hysteresis. Journal of Polymer Science: Polymer Physics Edition, 19:1285-1291.

Yasuda, H., E.J. Charlson, and E.M. Charlson, T. Yasuda, M. Miyama, and T. Okuno. 1991. Dynamics of surface property change in response to changes in environmental conditions. Langmuir, 7:2394-2400.

Yasuda T., M. Miyama, and H. Yasuda. 1992. Dynamics of surface property change in response to changes in environmental conditions. 2. Comparisons of changes in air and in liquid water. Langmuir, $8: 1425-1430$.

Young, R.A. 1978. Wettability of wood pulp fibers. Wood and Fiber Science. 8(2):120128.

Young, R.J. and P.A. Lovell. 1991. Introduction to polymers, second ed. Chapman and Hall, New York.

Young, R.A., R.M. Rammon, S.S. Kelley and R.H. Gillespie. 1982. Bond formation by wood surface reactions: Part I. Surface analysis by ESCA. Wood Science 14(3): 110-119.

Zavarin, E. 1984. Activation of wood surface and non-conventional bonding. In: The Chemistry of Solid Wood. Ch. 10. ACS Advances in Chemistry Series 207. R. Rowell, ed. Am. Chem. Soc., Washington, D.C.

Zhang, H.J., D.J. Gardner, J.Z. Wang and Q. Shi. 1997. Surface tension, adhesive wettability, and bondability of artificially weathered CCA-treated southern pine. Forest Products Journal. 47(10):69-72. 


\section{Appendix A.}

This Appendix Contains Individual Differential Scanning Calorimetry Scans, Heat of Transitions,and Statistical Analysis Results. 


\section{Appendix A.1}

Individual Differential Scanning Calorimetry Scans of Yellow-Poplar Sapwood and Heartwood At $12 \%$ and $30 \%$ Moisture Content With and Without Steam Pre-Conditioning. 


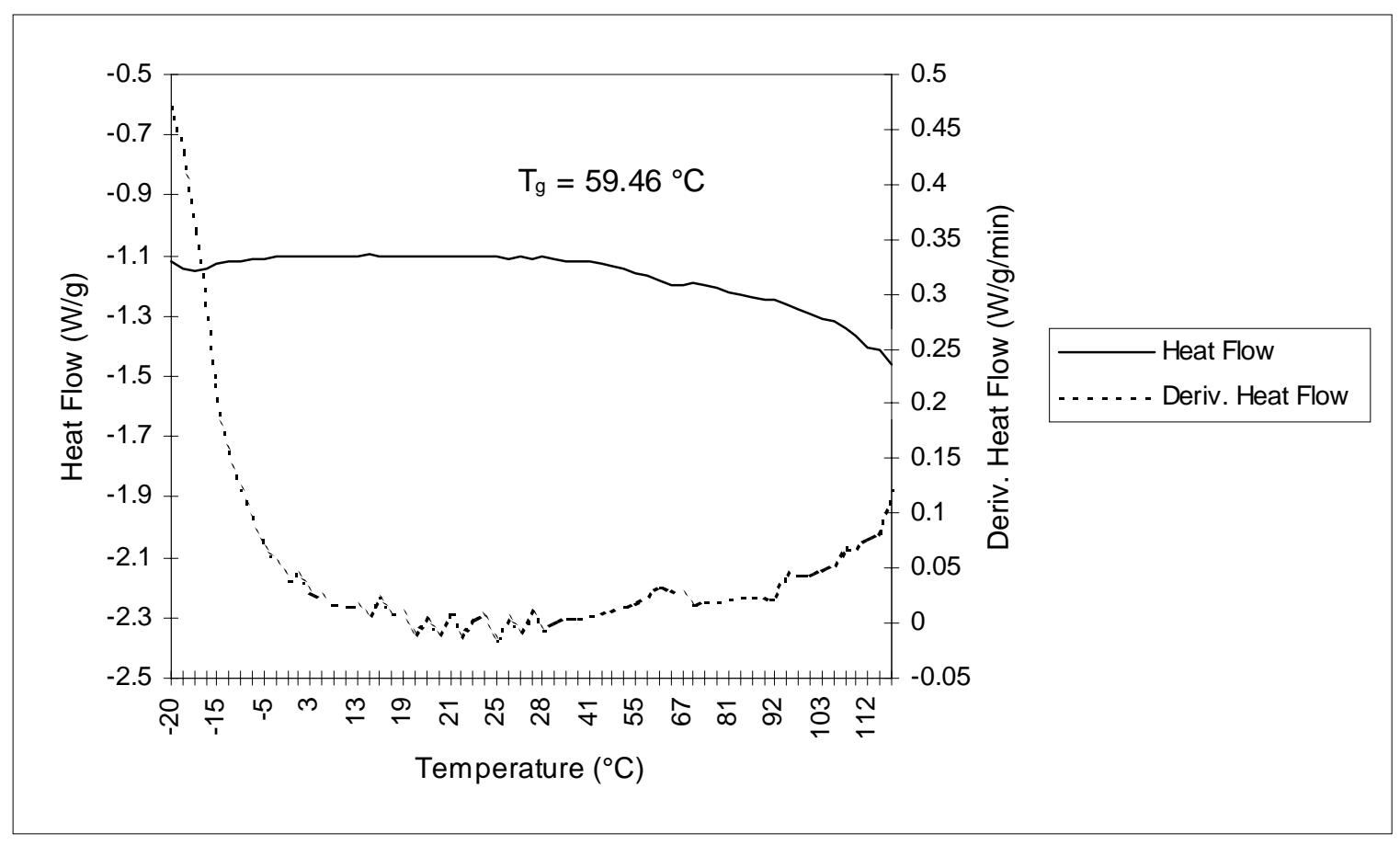

Figure A.1.1. Heat flow and derivative heat flow of yellow-poplar heartwood at $12 \%$ moisture content without steam pre-conditioning.

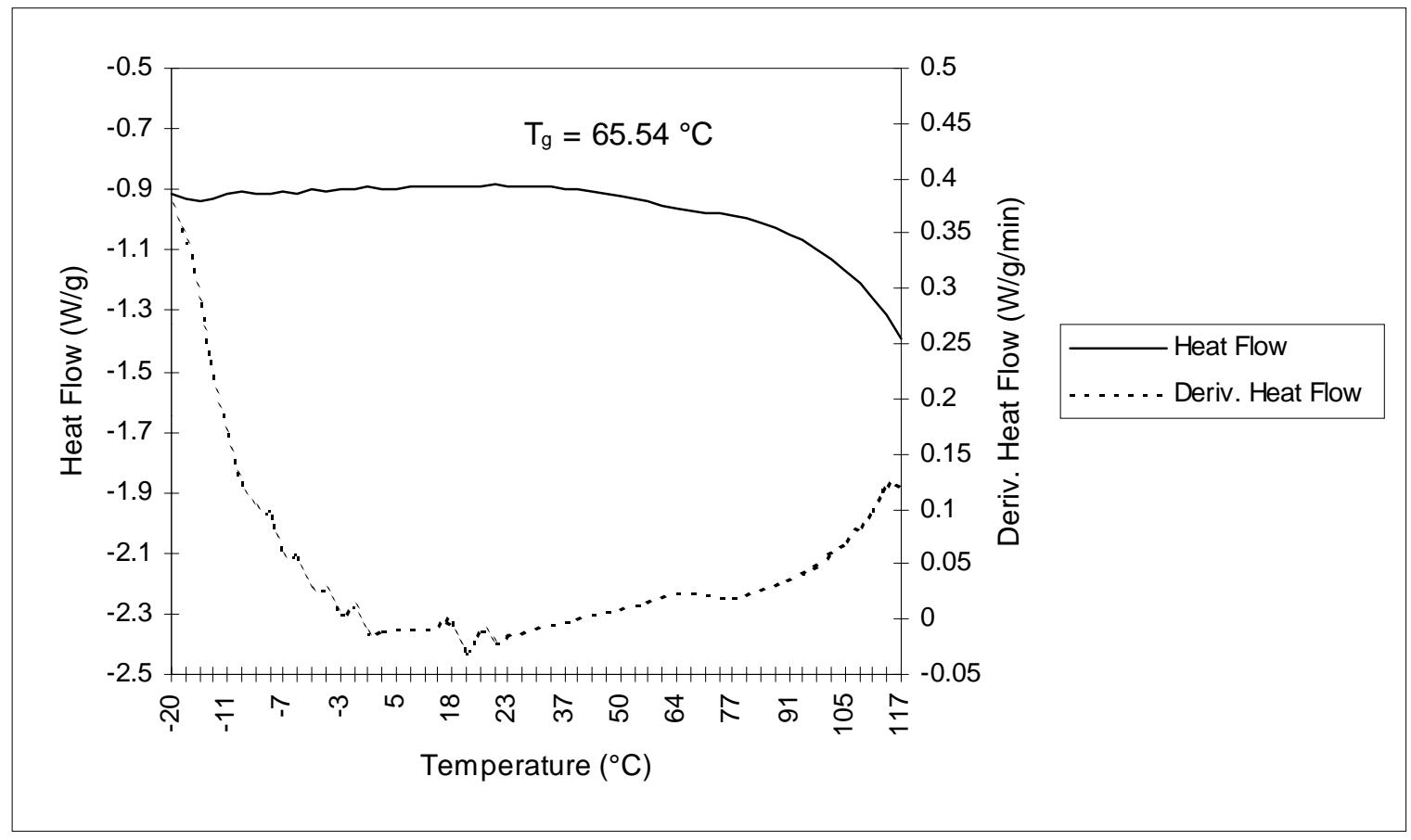

Figure A.1.2. Heat flow and derivative heat flow of yellow-poplar heartwood at $12 \%$ moisture content without steam pre-conditioning. 


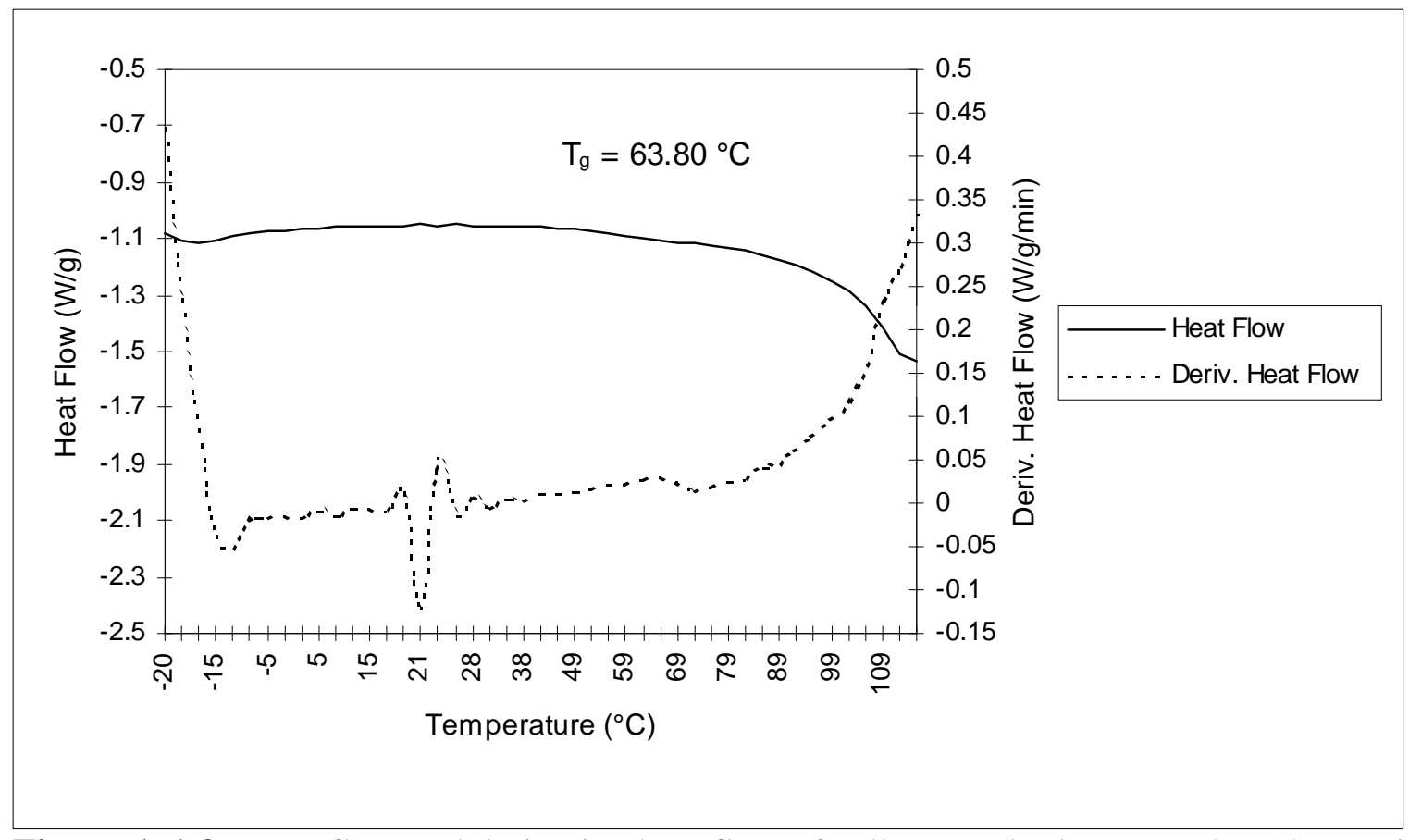

Figure A.1.3. Heat flow and derivative heat flow of yellow-poplar heartwood at $12 \%$ moisture content without steam pre-conditioning.

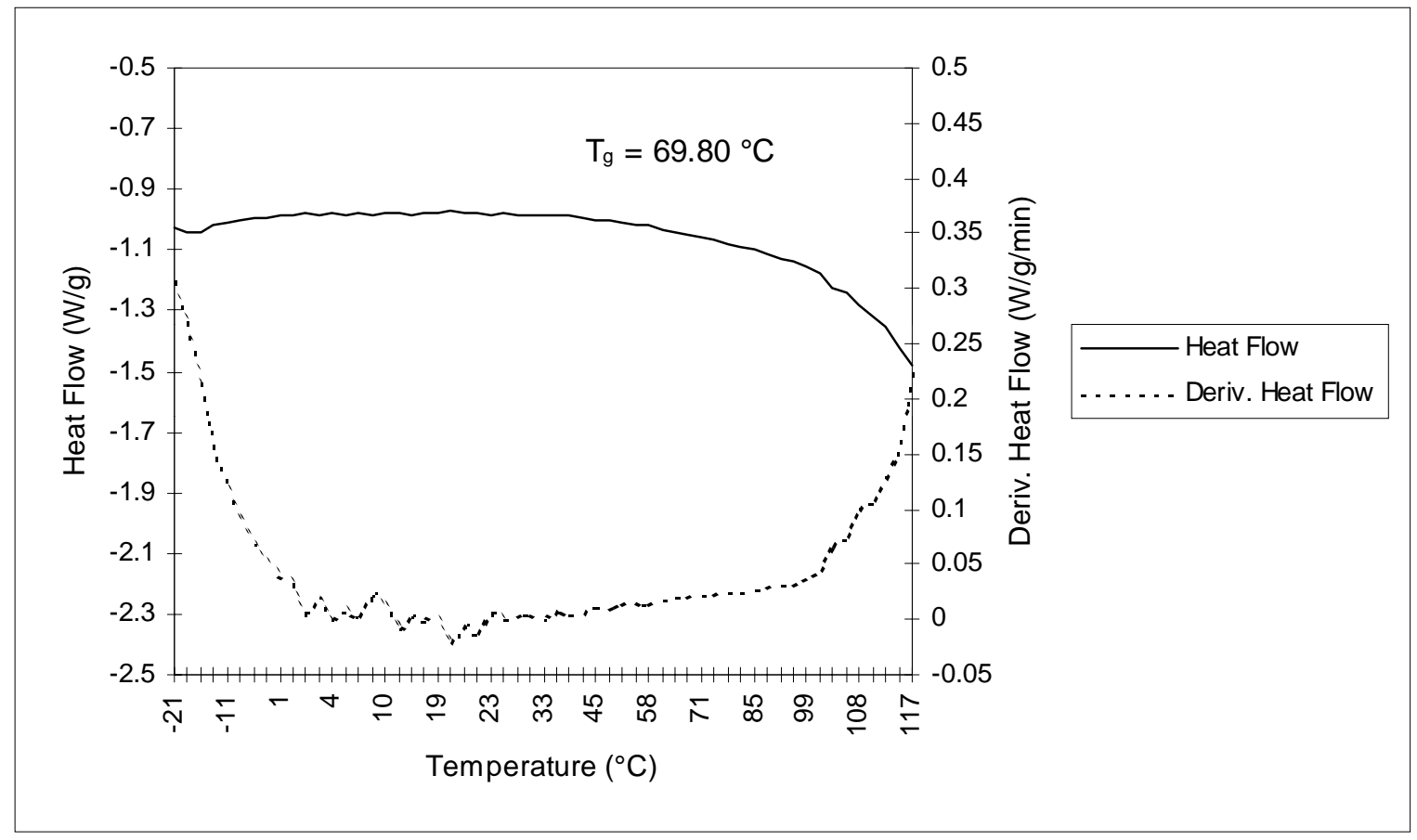

Figure A.1.4. Heat flow and derivative heat flow of yellow-poplar heartwood at $12 \%$ moisture content with steam pre-conditioning. 


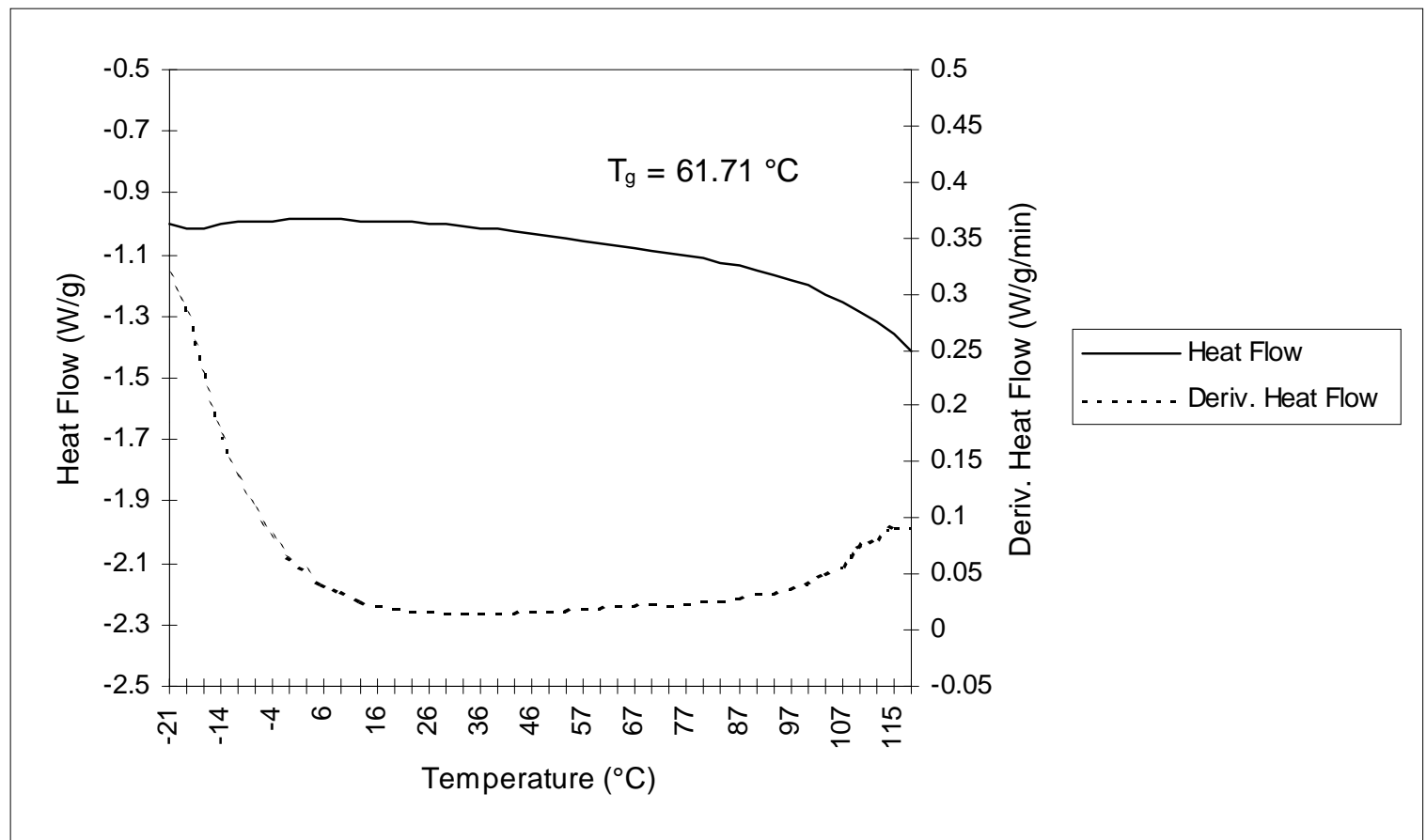

Figure A.1.5. Heat flow and derivative heat flow of yellow-poplar heartwood at $12 \%$ moisture content with steam pre-conditioning.

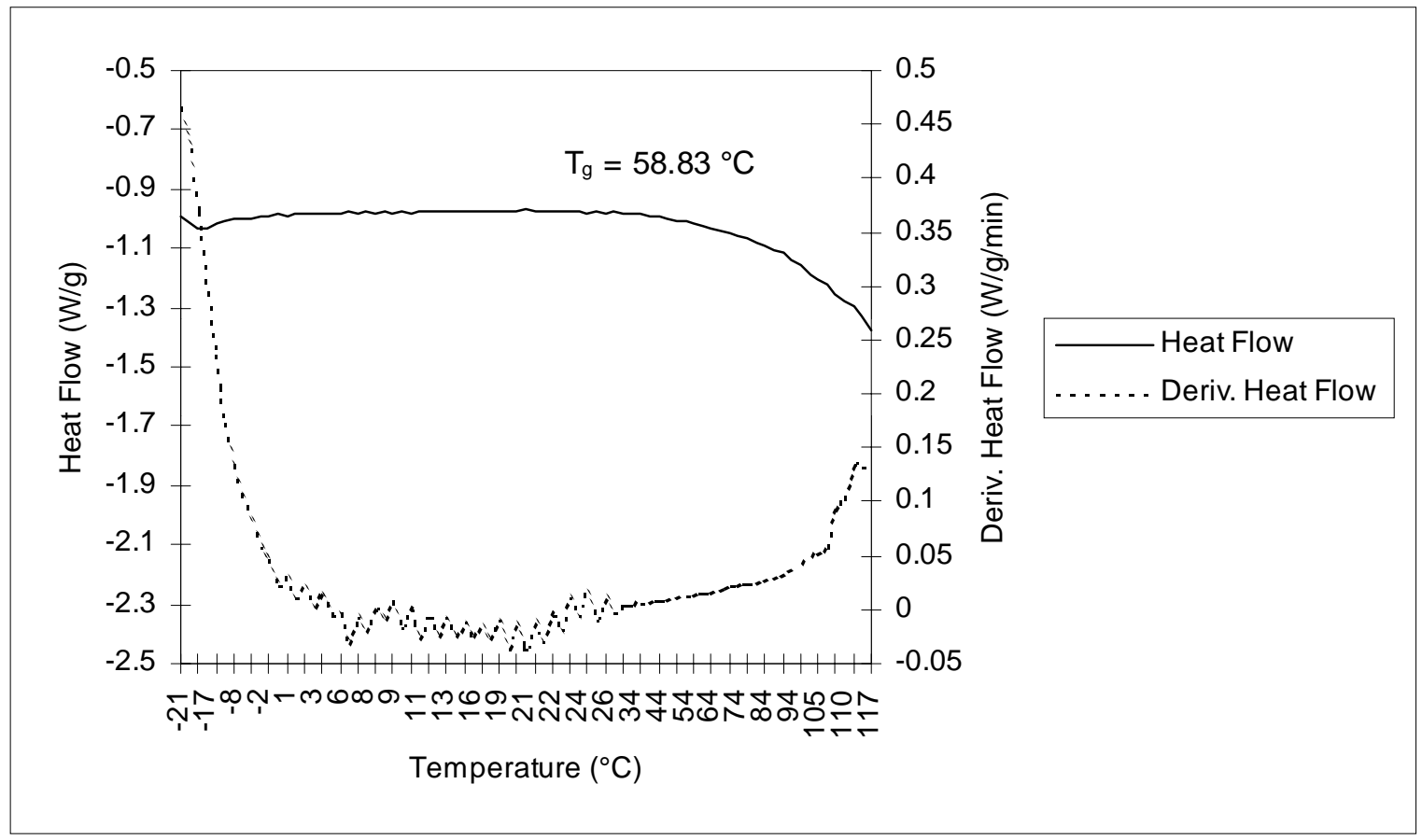

Figure A.1.6. Heat flow and derivative heat flow of yellow-poplar heartwood at $12 \%$ moisture content with steam pre-conditioning. 


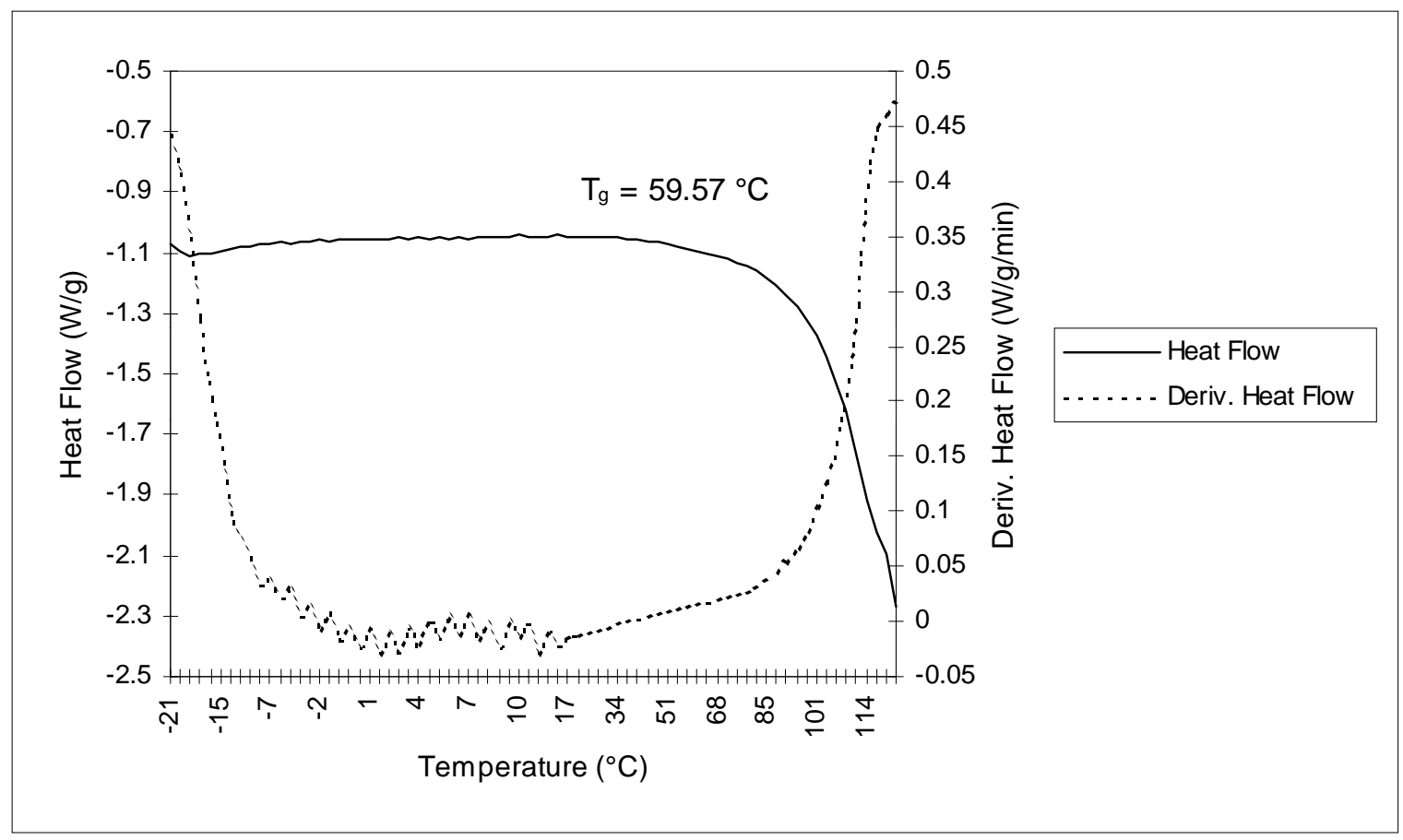

Figure A.1.7. Heat flow and derivative heat flow of yellow-poplar heartwood at $30 \%$ moisture content without steam pre-conditioning.

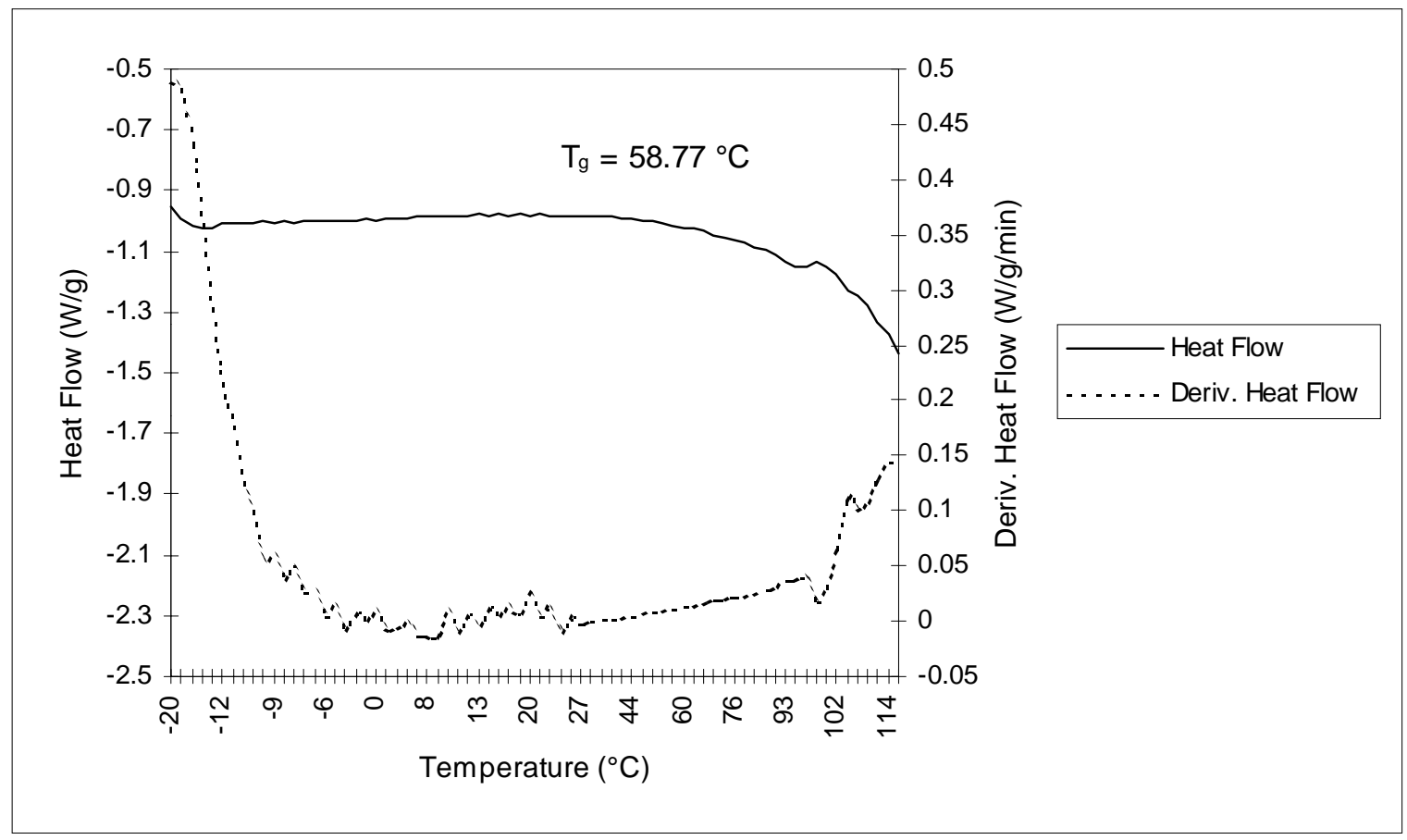

Figure A.1.8. Heat flow and derivative heat flow of yellow-poplar heartwood at $30 \%$ moisture content without steam pre-conditioning. 


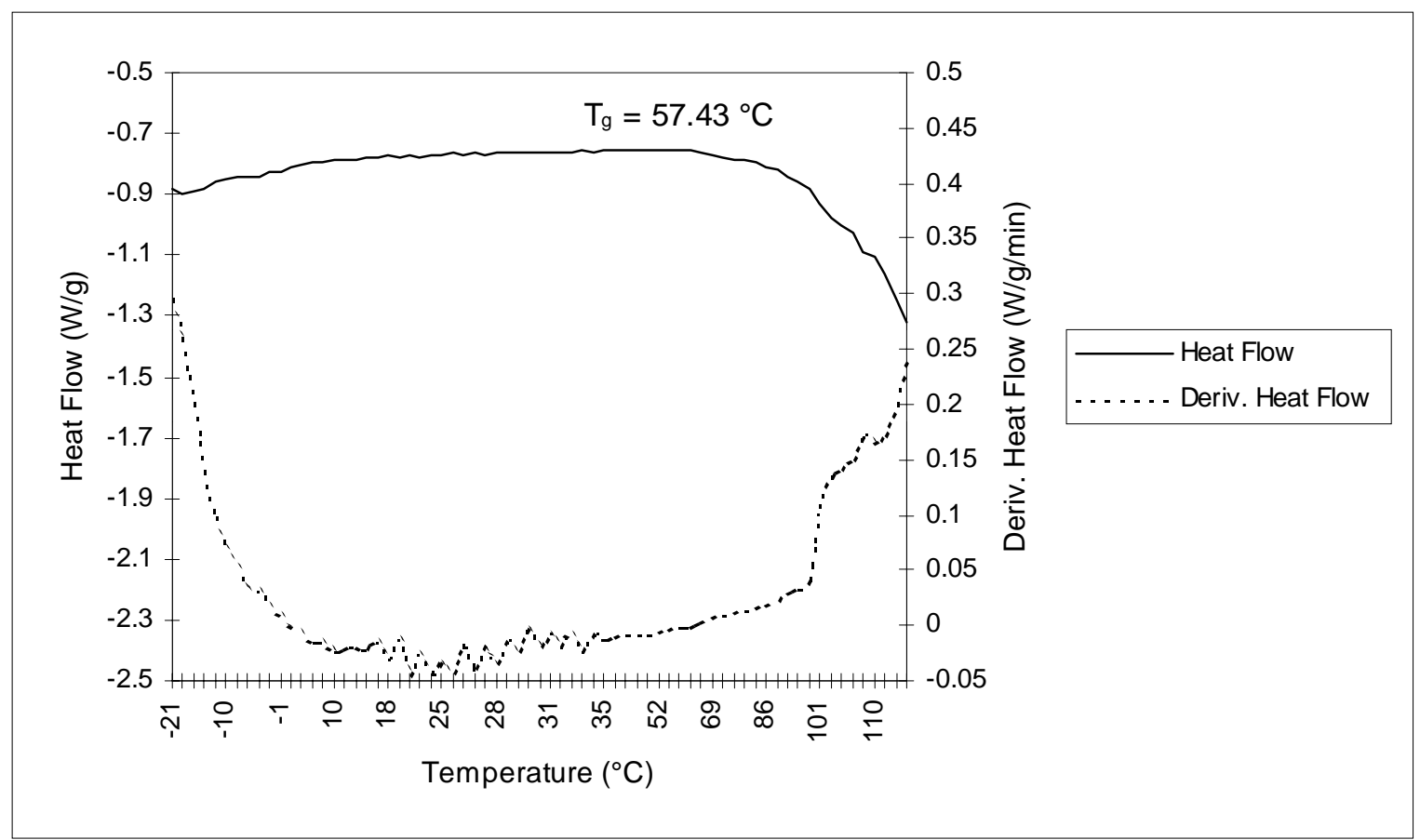

Figure A.1.9. Heat flow and derivative heat flow of yellow-poplar heartwood at $30 \%$ moisture content without steam pre-conditioning.

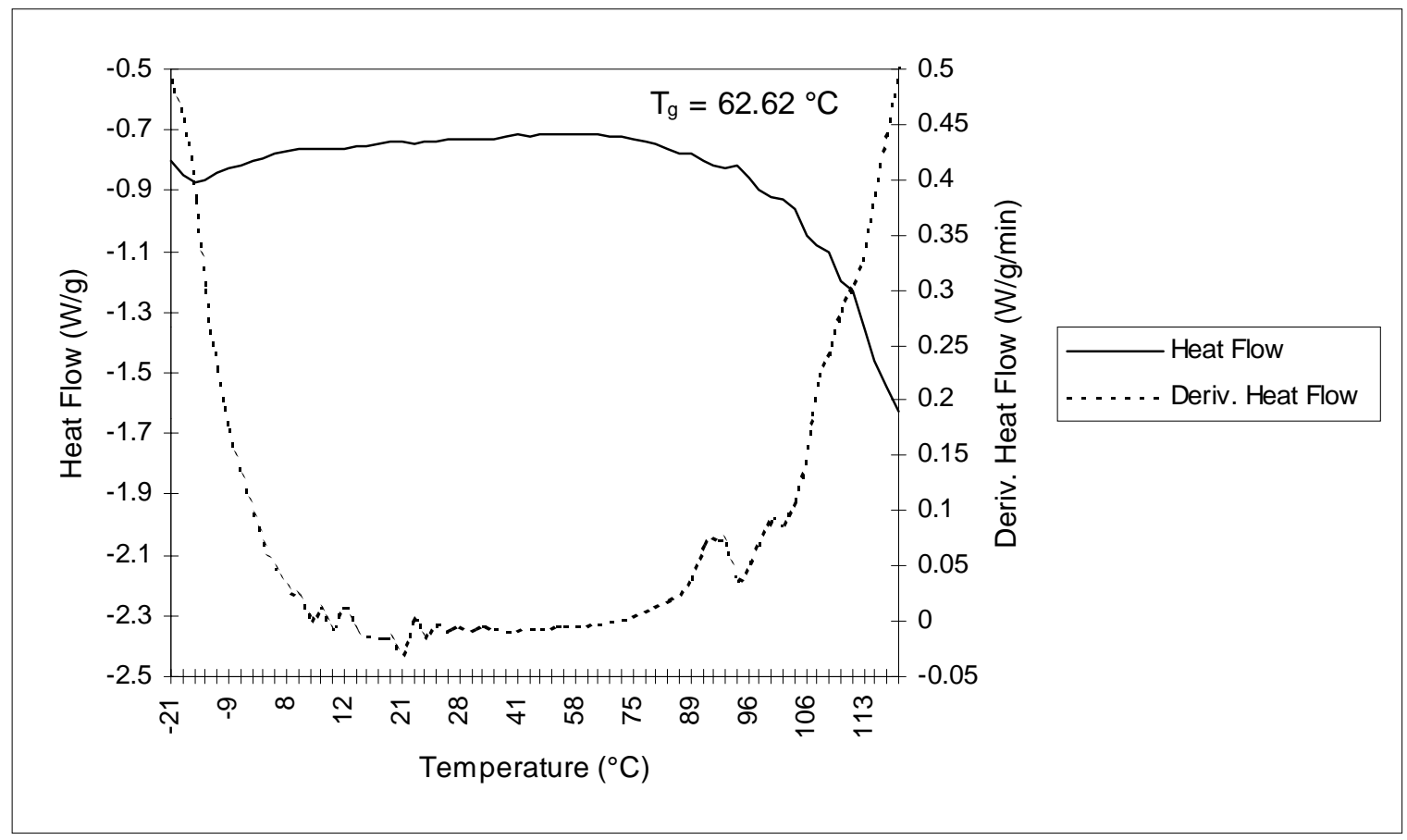

Figure A.1.10. Heat flow and derivative heat flow of yellow-poplar heartwood at 30\% moisture content with steam pre-conditioning. 


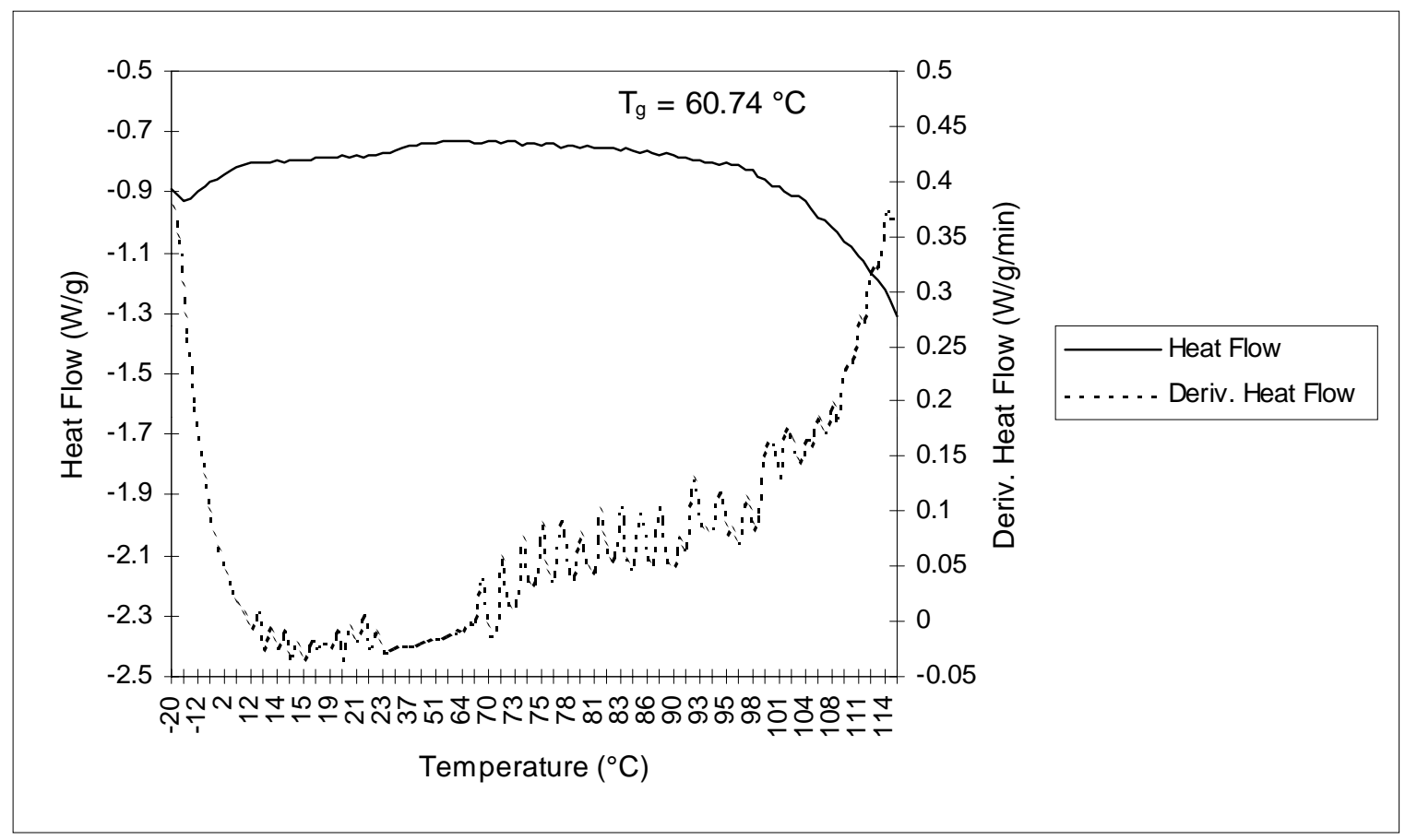

Figure A.1.11. Heat flow and derivative heat flow of yellow-poplar heartwood at 30\% moisture content with steam pre-conditioning.

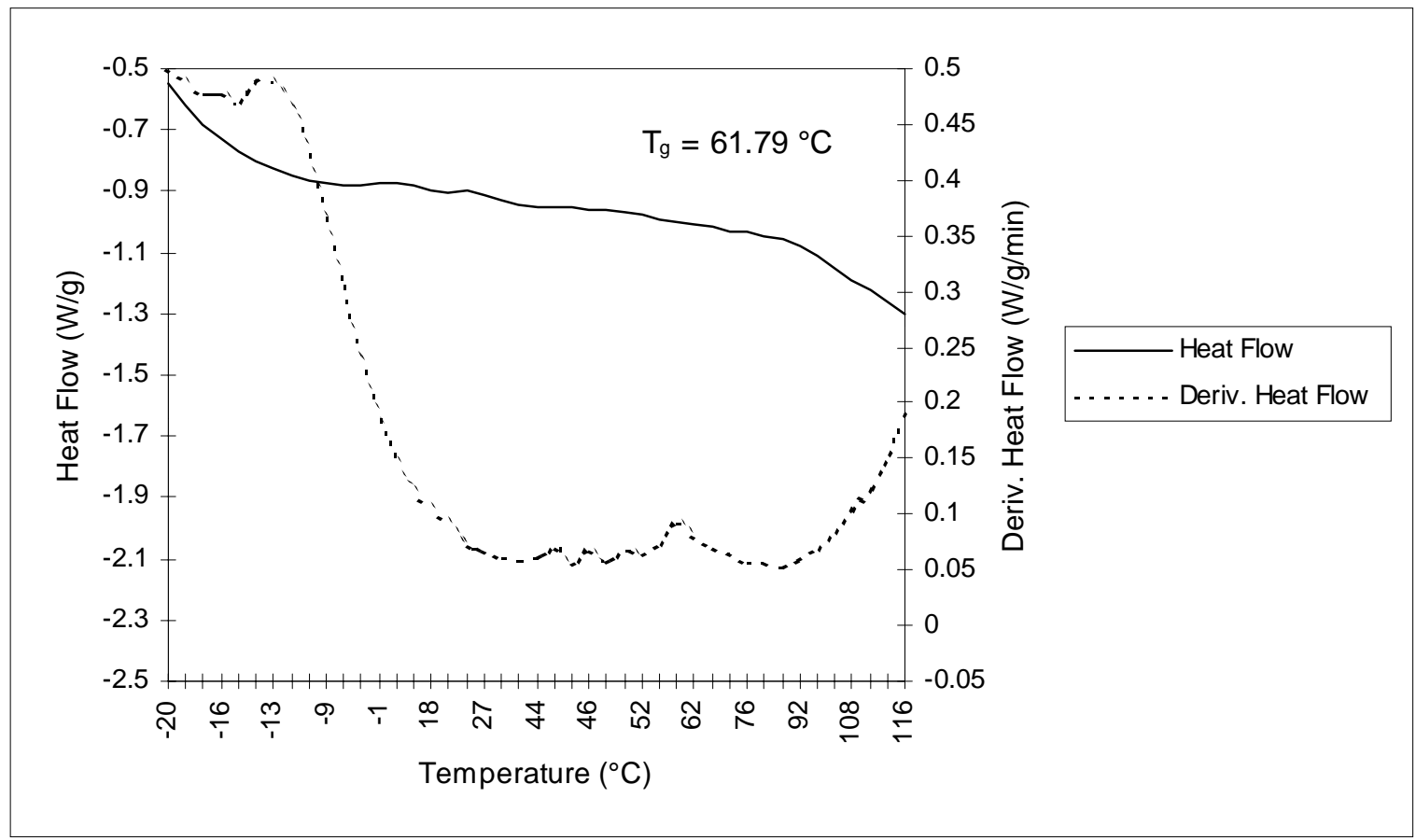

Figure A.1.12. Heat flow and derivative heat flow of yellow-poplar heartwood at 30\% moisture content with steam pre-conditioning. 


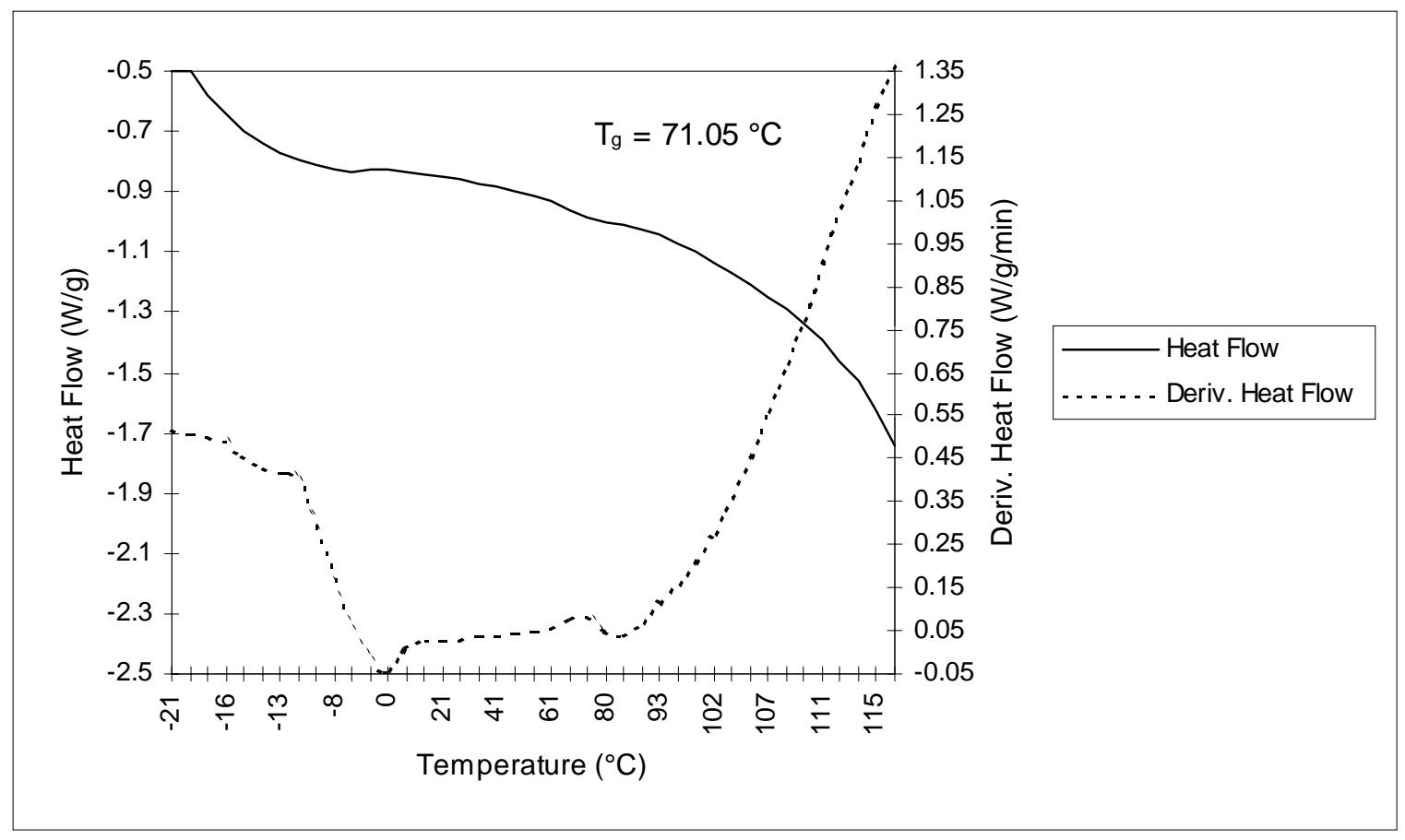

Figure A.1.13. Heat flow and derivative heat flow of yellow-poplar sapwood at $12 \%$ moisture content without steam pre-conditioning.

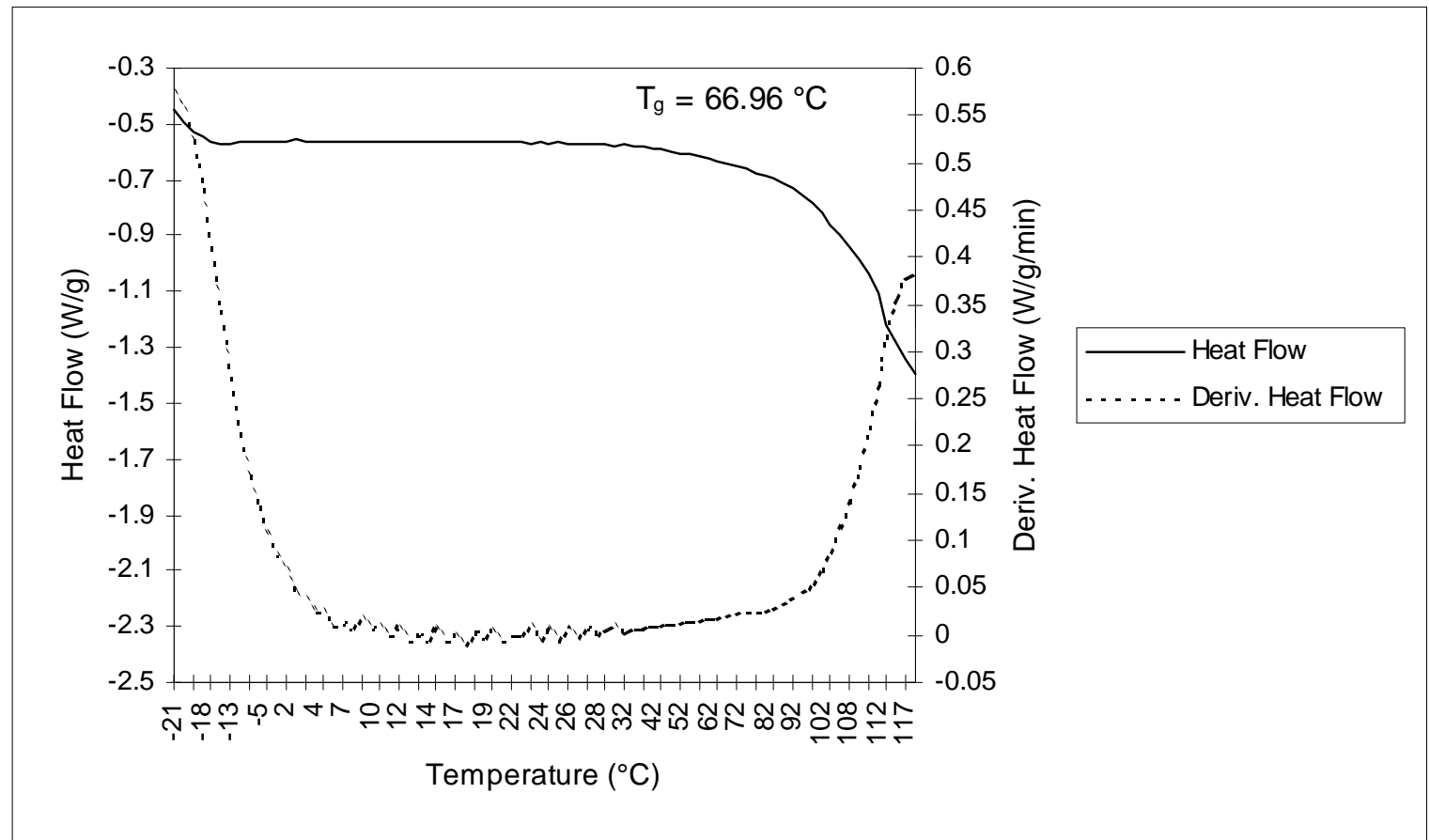

Figure A.1.14. Heat flow and derivative heat flow of yellow-poplar sapwood at $12 \%$ moisture content without steam pre-conditioning. 


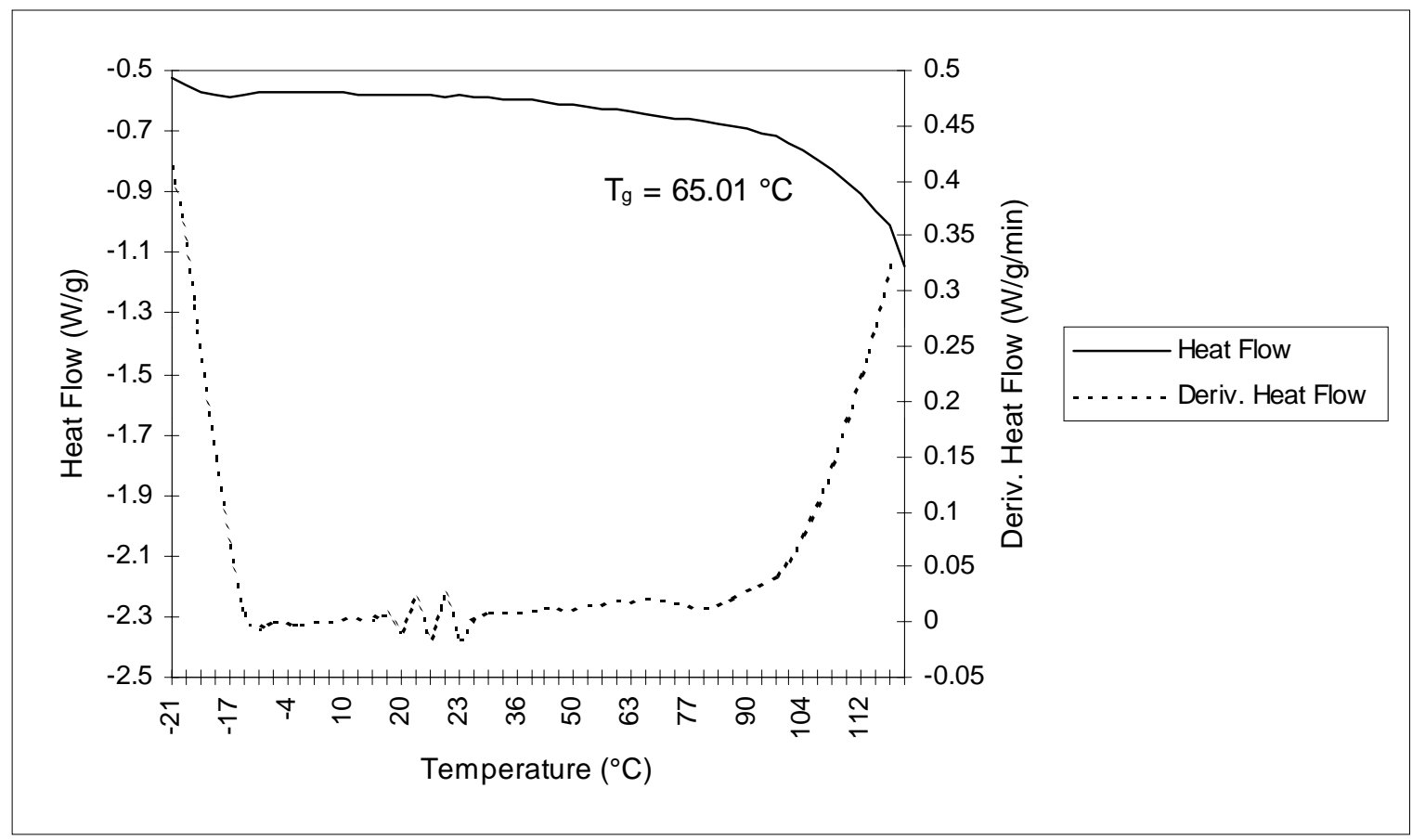

Figure A.1.15. Heat flow and derivative heat flow of yellow-poplar sapwood at $12 \%$ moisture content without steam pre-conditioning.

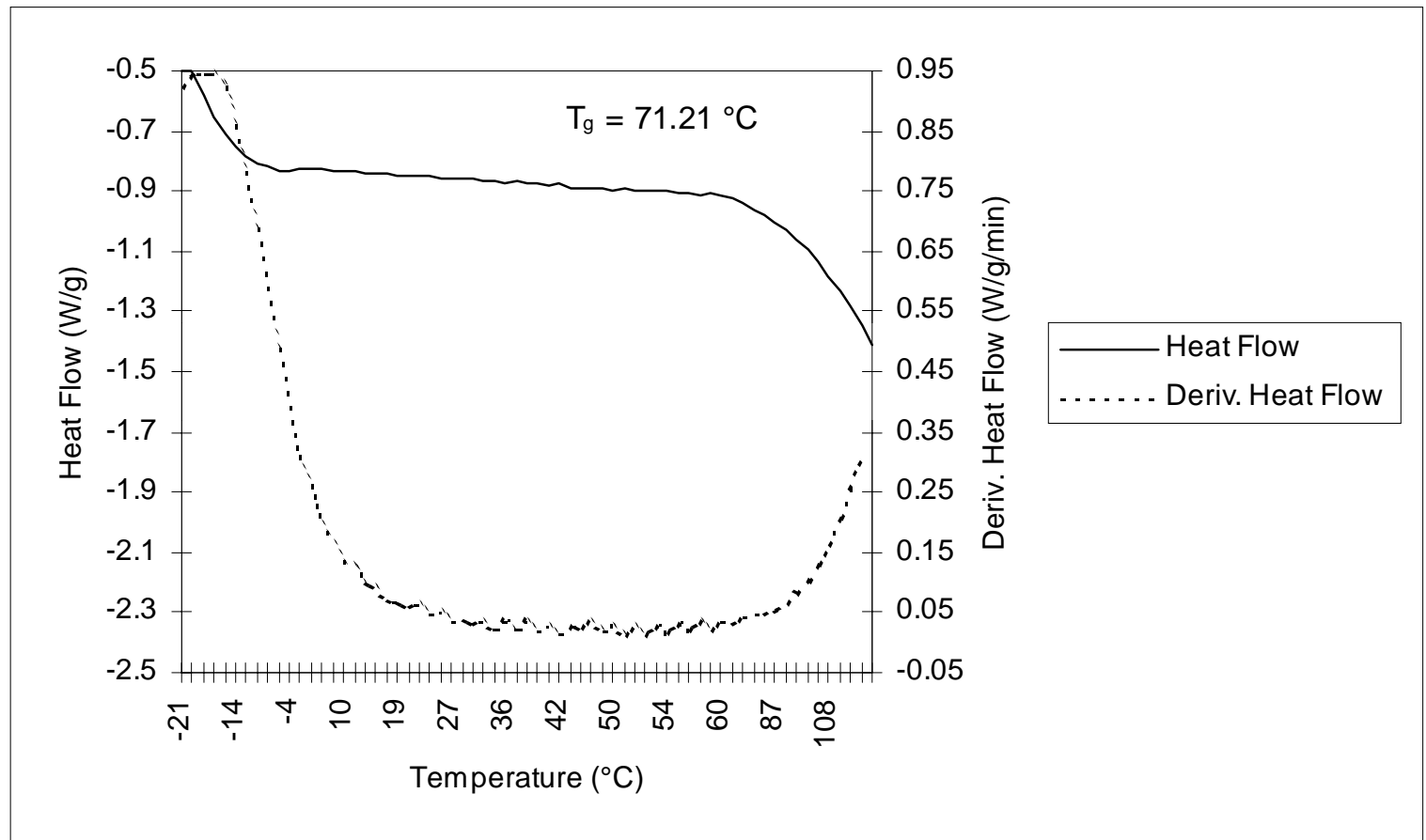

Figure A.1.16. Heat flow and derivative heat flow of yellow-poplar sapwood at $12 \%$ moisture content with steam pre-conditioning. 


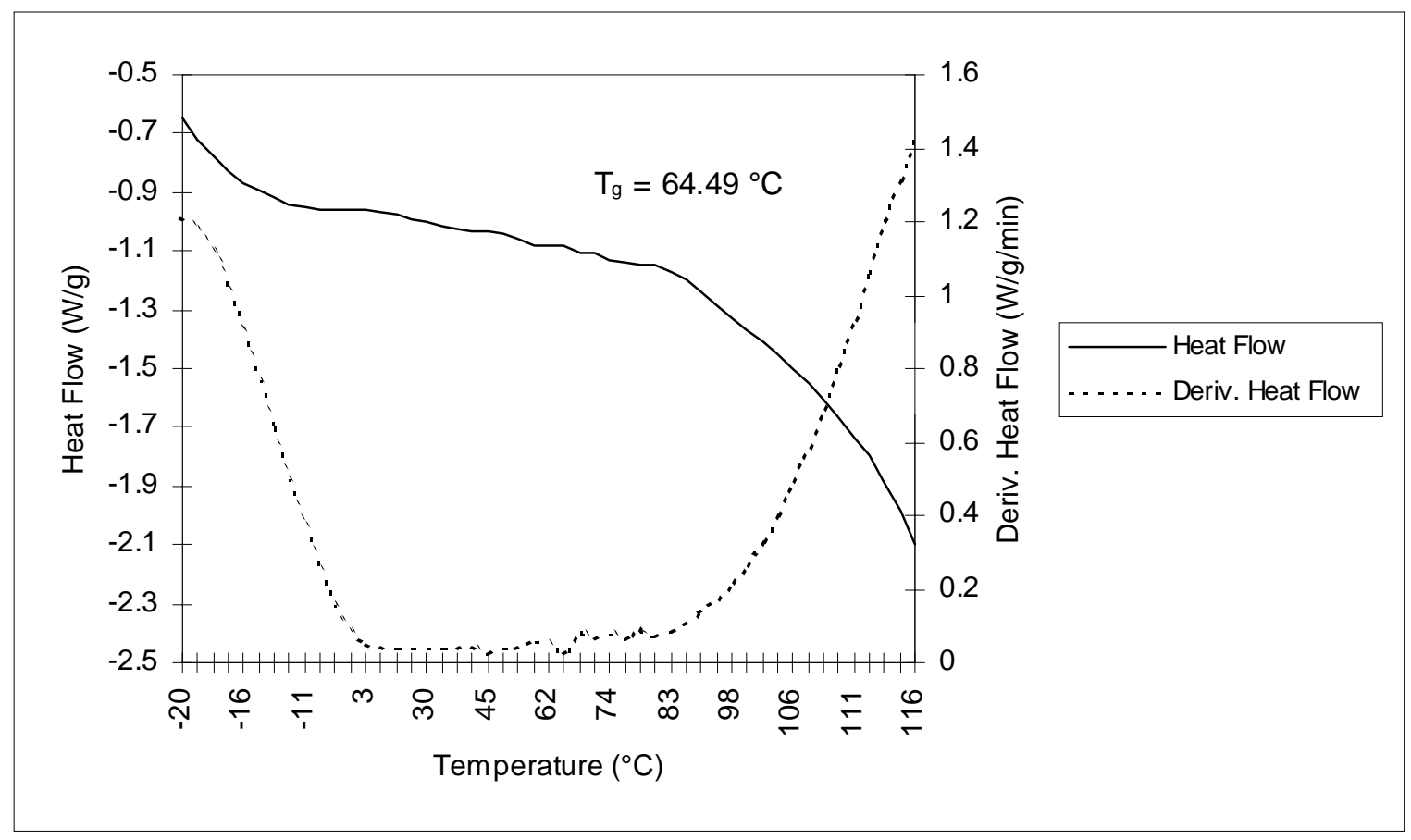

Figure A.1.17. Heat flow and derivative heat flow of yellow-poplar sapwood at $12 \%$ moisture content with steam pre-conditioning.

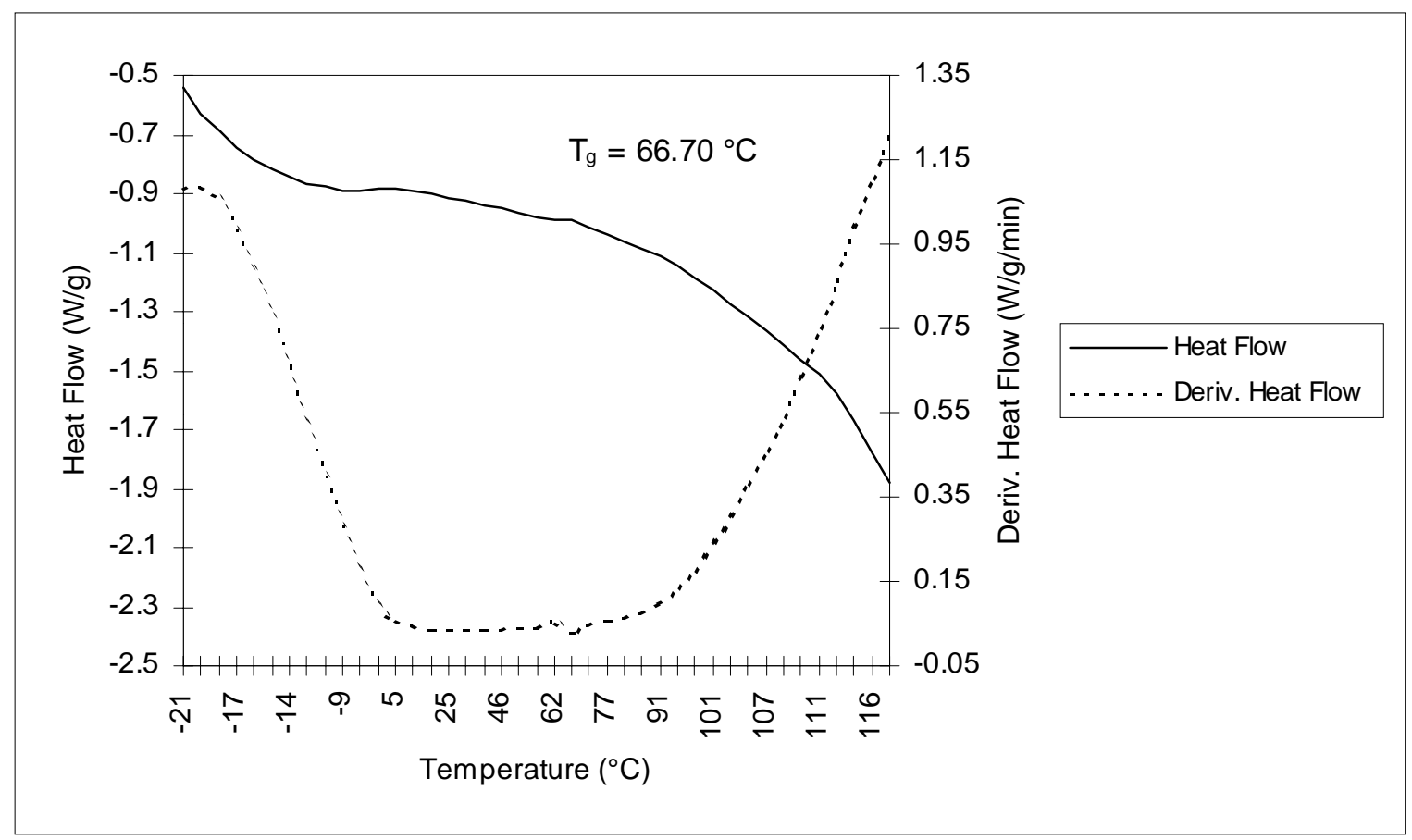

Figure A.1.18. Heat flow and derivative heat flow of yellow-poplar sapwood at $12 \%$ moisture content with steam pre-conditioning. 


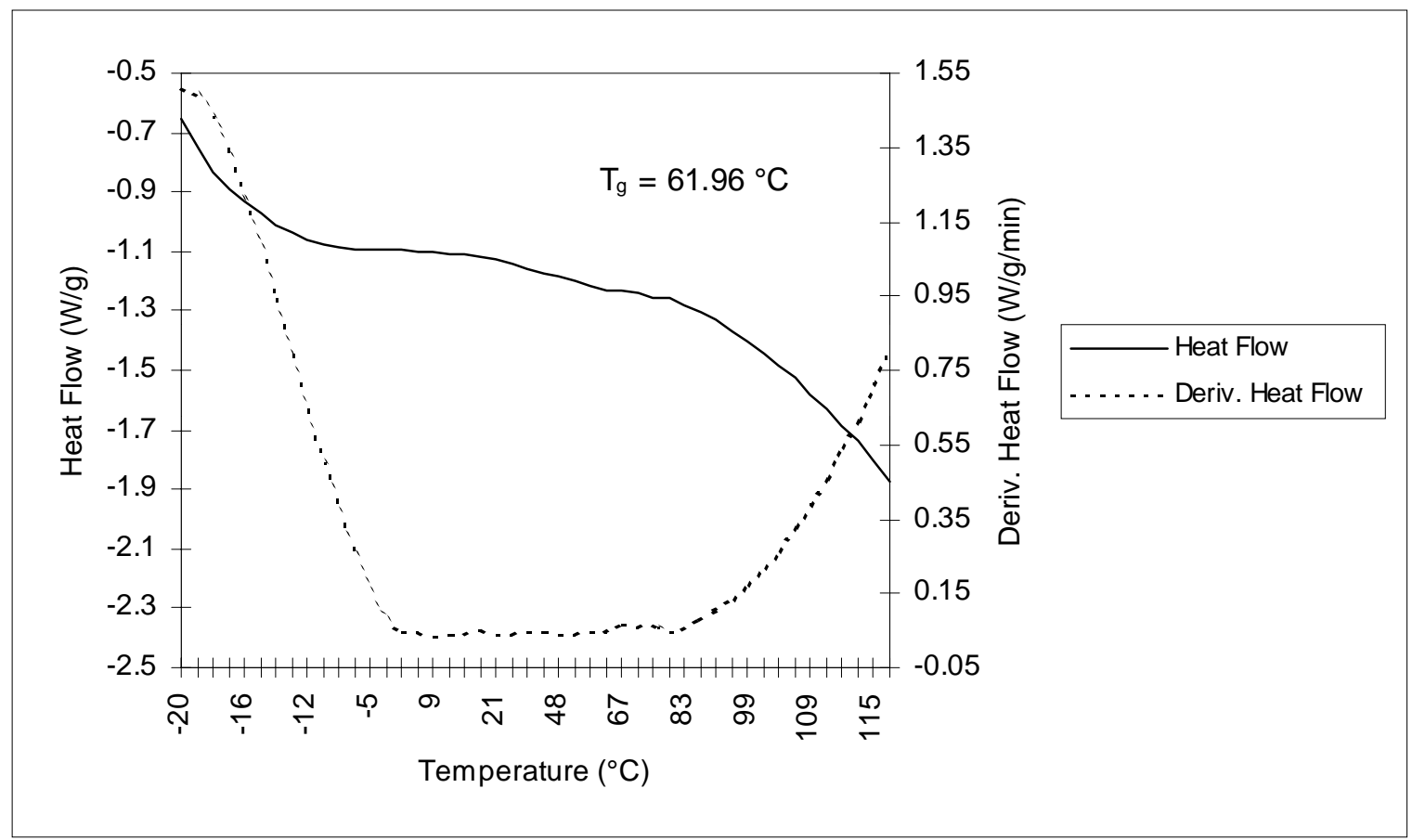

Figure A.1.19. Heat flow and derivative heat flow of yellow-poplar sapwood at $30 \%$ moisture content without steam pre-conditioning.

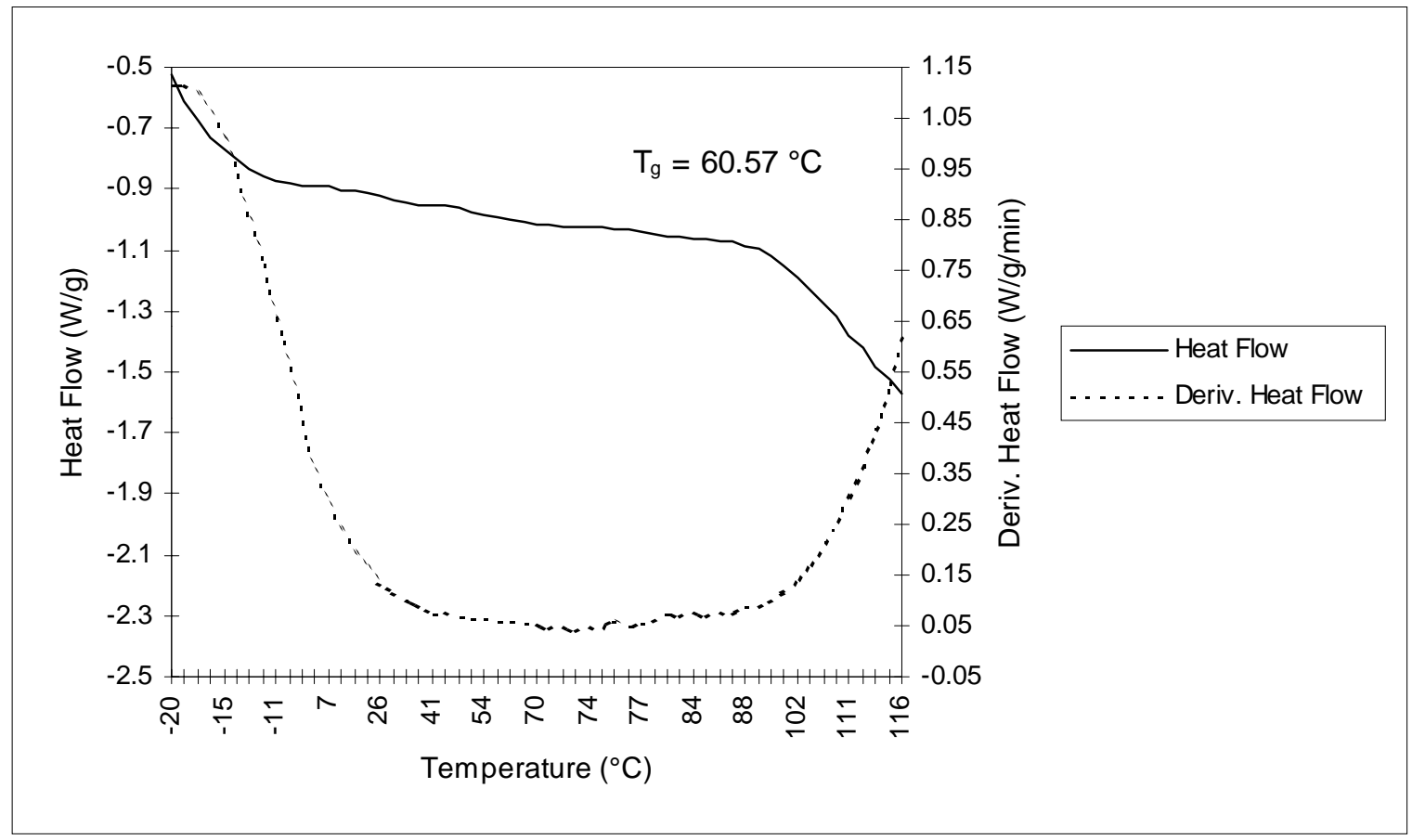

Figure A.1.20. Heat flow and derivative heat flow of yellow-poplar sapwood at $30 \%$ moisture content without steam pre-conditioning. 


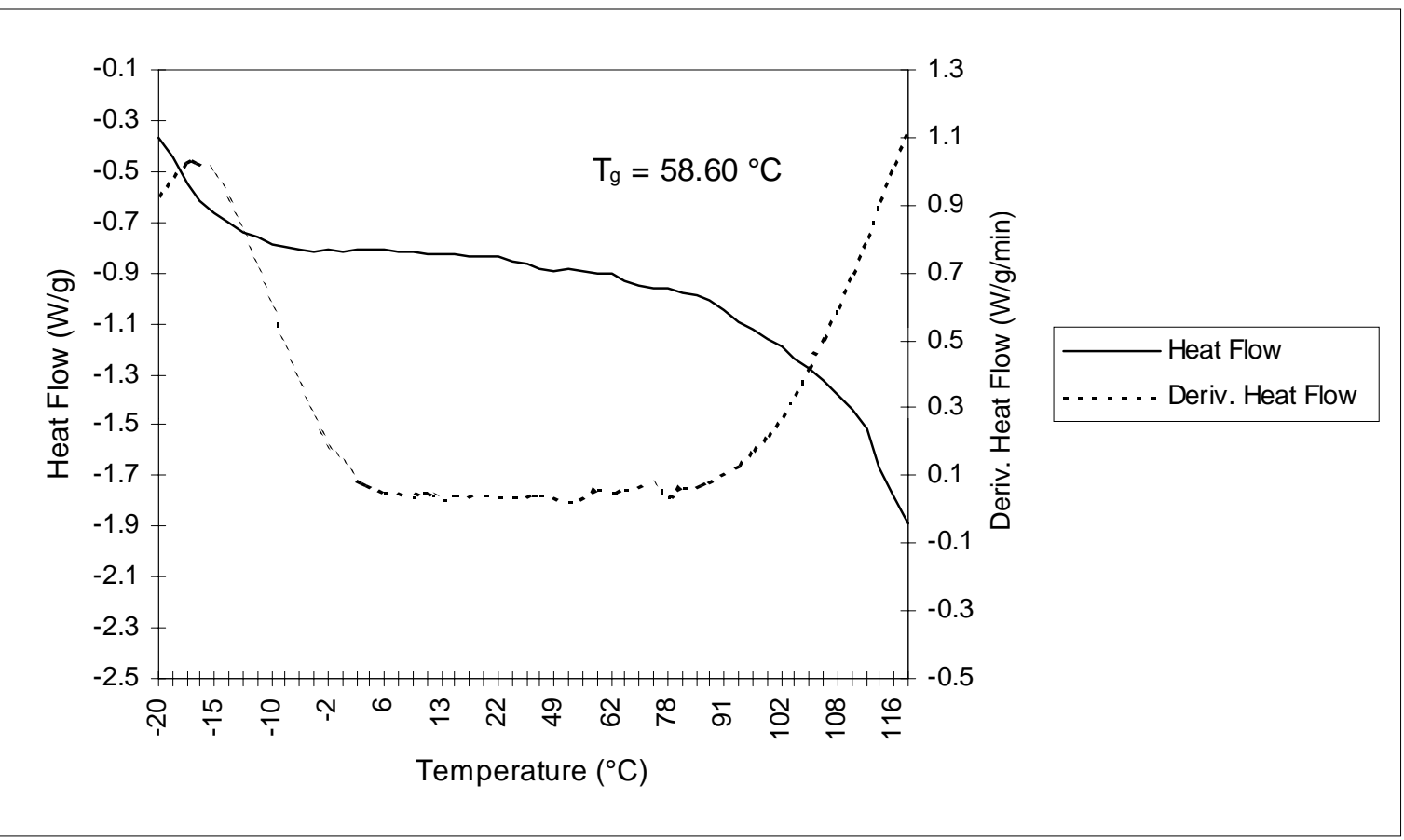

Figure A.1.21. Heat flow and derivative heat flow of yellow-poplar sapwood at $30 \%$ moisture content without steam pre-conditioning.

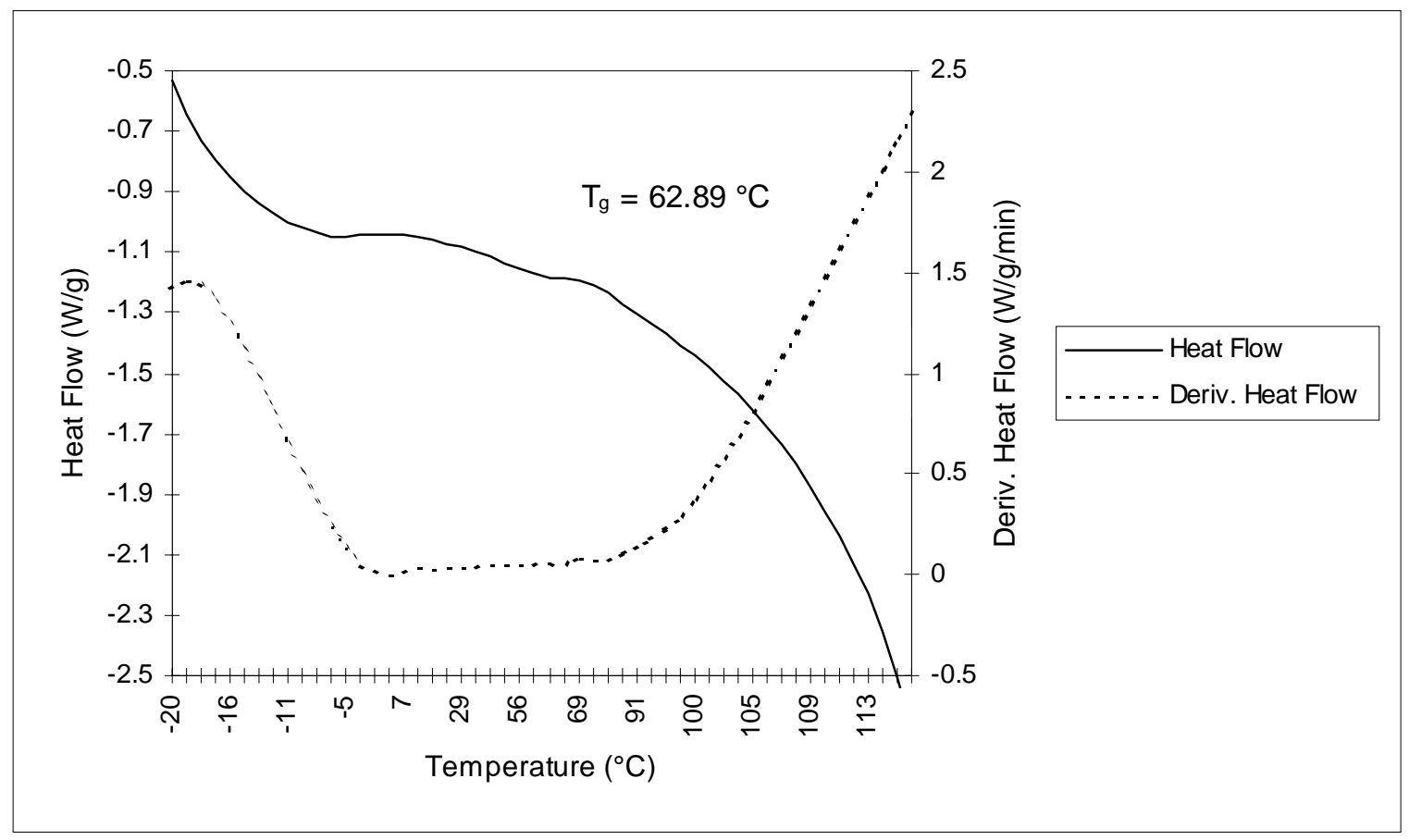

Figure A.1.22. Heat flow and derivative heat flow of yellow-poplar sapwood at $30 \%$ moisture content with steam pre-conditioning. 


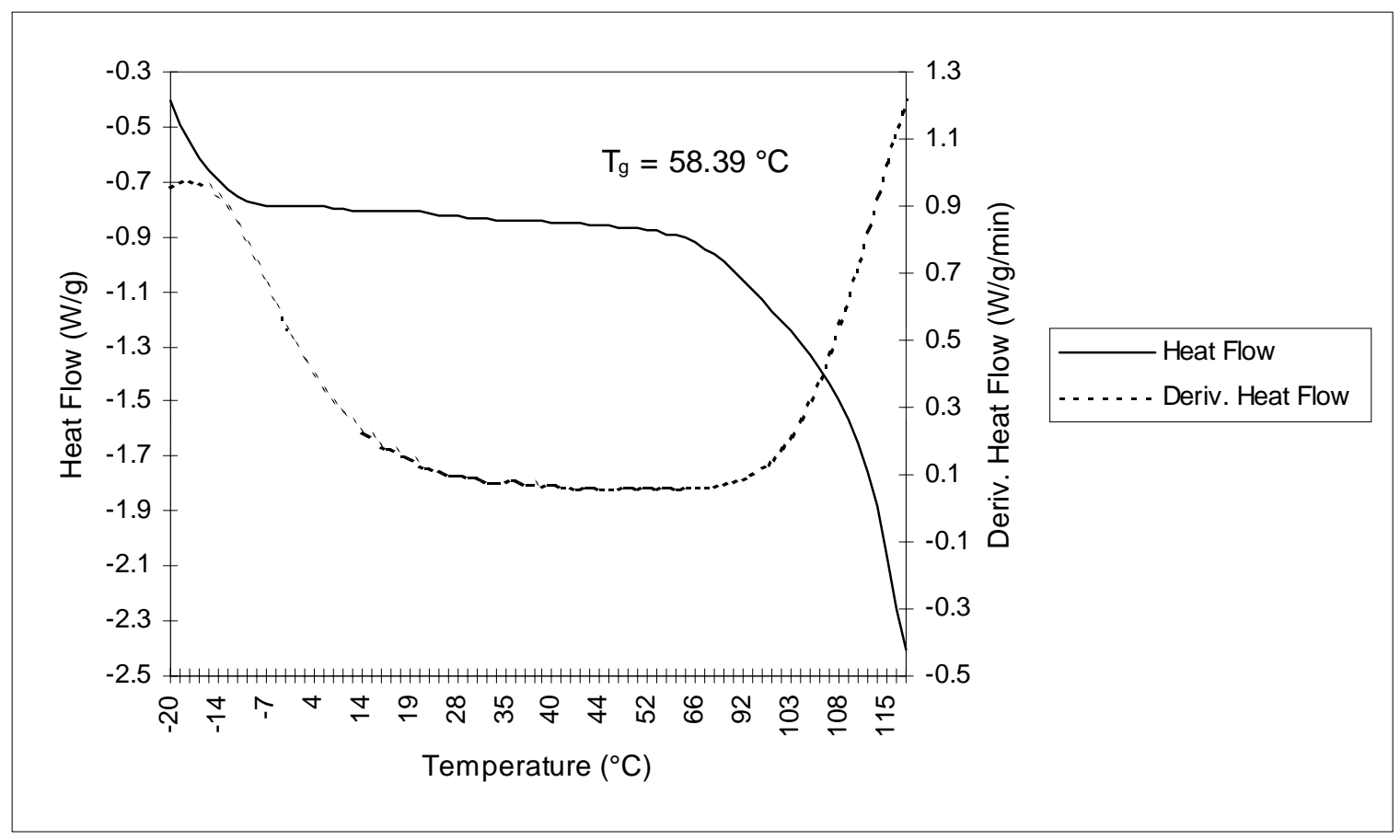

Figure A.1.23. Heat flow and derivative heat flow of yellow-poplar sapwood at $30 \%$ moisture content with steam pre-conditioning.

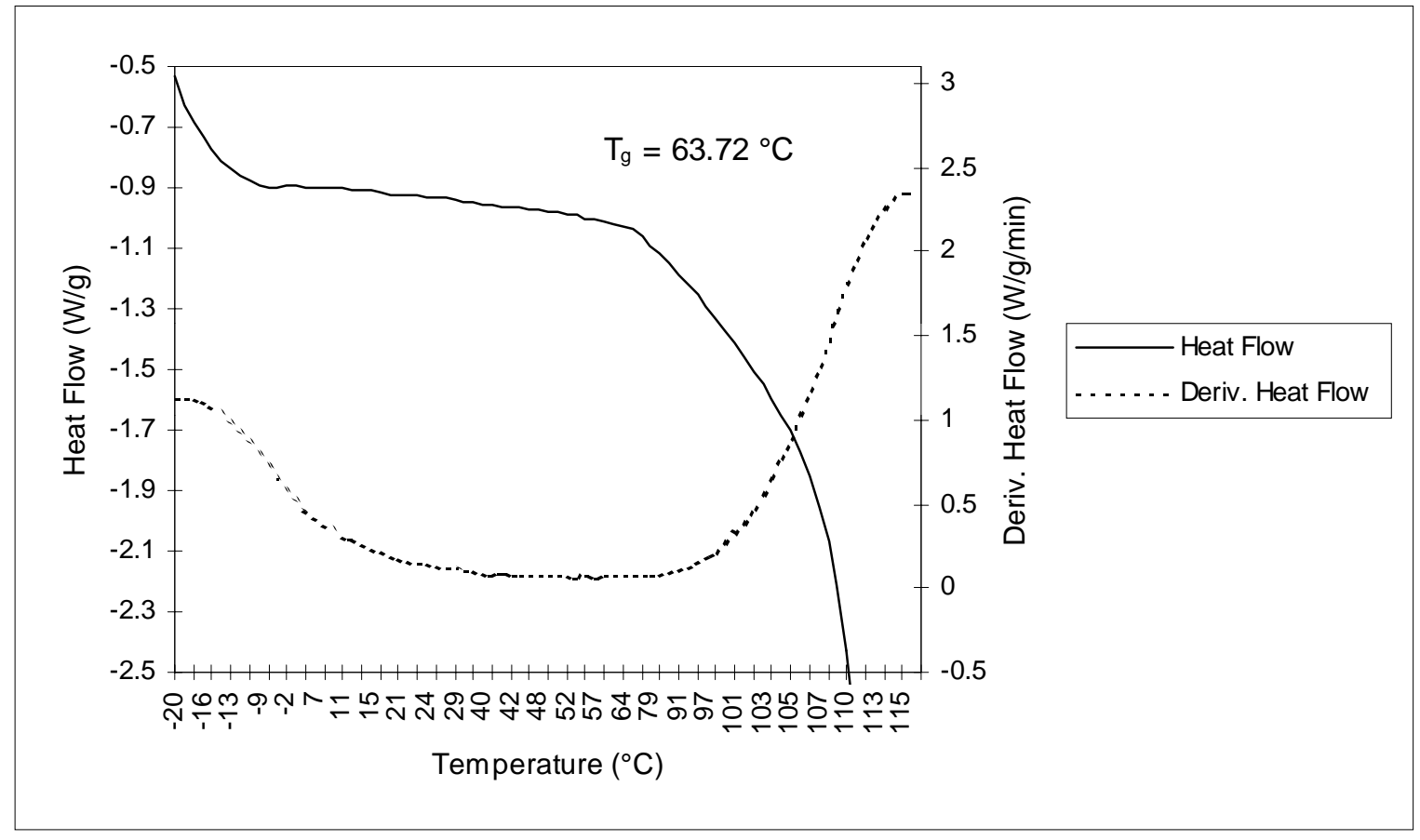

Figure A.1.24. Heat flow and derivative heat flow of yellow-poplar sapwood at $30 \%$ moisture content with steam pre-conditioning. 


\section{Appendix A.2}

Transition Onset and Ending Values From Differential Scanning Calorimetry Scans of Yellow-Poplar Sapwood and Heartwood. 
Table A.2. Transition Onset and Ending Values from Differential Scanning Calorimetry Scans of Yellow-Poplar Sapwood and Heartwood.

\begin{tabular}{|c|c|c|c|c|c|}
\hline $\begin{array}{c}\text { Heartwood (H) } \\
\text { /Sapwood (S) }\end{array}$ & $\begin{array}{c}\text { Moisture } \\
\text { Content }\end{array}$ & $\begin{array}{l}\text { Steam Pre- } \\
\text { Conditioning }\end{array}$ & $\begin{array}{r}\text { Tra } \\
\text { Onset }\left({ }^{\circ} \mathbf{C}\right) \\
\end{array}$ & $\begin{array}{l}\text { tion } \\
\text { Ending }\left({ }^{\circ} \mathbf{C}\right)\end{array}$ & $\mathbf{T}_{\mathbf{g}}\left({ }^{\circ} \mathbf{C}\right)$ \\
\hline$\overline{\mathrm{H}}$ & $12 \%$ & No & 58.26 & 62.71 & 59.46 \\
\hline $\mathrm{H}$ & $12 \%$ & No & 64.10 & 67.23 & 65.54 \\
\hline $\mathrm{H}$ & $12 \%$ & $\mathrm{No}$ & 60.27 & 63.90 & 63.80 \\
\hline $\mathrm{H}$ & $12 \%$ & Yes & 68.10 & 74.89 & 69.80 \\
\hline $\mathrm{H}$ & $12 \%$ & Yes & 54.00 & 63.41 & 61.71 \\
\hline $\mathrm{H}$ & $12 \%$ & Yes & 57.49 & 60.52 & 58.83 \\
\hline $\mathrm{H}$ & $30 \%$ & No & 58.02 & 62.71 & 59.57 \\
\hline $\mathrm{H}$ & $30 \%$ & No & 57.08 & 63.92 & 58.77 \\
\hline $\mathrm{H}$ & $30 \%$ & No & 55.73 & 59.13 & 57.43 \\
\hline $\mathrm{H}$ & $30 \%$ & Yes & 60.84 & 64.69 & 62.62 \\
\hline $\mathrm{H}$ & $30 \%$ & Yes & 57.45 & 61.59 & 60.74 \\
\hline $\mathrm{H}$ & $30 \%$ & Yes & 55.36 & 61.79 & 61.79 \\
\hline$S$ & $12 \%$ & No & 62.68 & 74.14 & 71.05 \\
\hline$S$ & $12 \%$ & No & 64.65 & 66.96 & 66.96 \\
\hline$S$ & $12 \%$ & $\mathrm{No}$ & 63.32 & 70.20 & 65.01 \\
\hline$S$ & $12 \%$ & Yes & 67.81 & 74.61 & 71.21 \\
\hline$S$ & $12 \%$ & Yes & 60.75 & 64.95 & 64.49 \\
\hline$S$ & $12 \%$ & Yes & 62.60 & 70.09 & 66.70 \\
\hline$S$ & $30 \%$ & $\mathrm{No}$ & 55.92 & 62.31 & 61.96 \\
\hline$S$ & $30 \%$ & No & 59.56 & 60.58 & 60.57 \\
\hline$S$ & $30 \%$ & No & 57.54 & 58.60 & 58.60 \\
\hline$S$ & $30 \%$ & Yes & 58.58 & 62.89 & 62.89 \\
\hline$S$ & $30 \%$ & Yes & 57.44 & 58.50 & 58.39 \\
\hline $\mathrm{S}$ & $30 \%$ & Yes & 63.11 & 64.33 & 63.72 \\
\hline
\end{tabular}




\section{Appendix A.3}

Average Heat of Transition Values and (Standard Deviation) of Yellow-Poplar Heartwood and Sapwood at $12 \%$ and 30\% Moisture Content With and Without Steam Pre-Conditioning. 
Table A.3. Average Heat of Transition Values and (Standard Deviation) of Yellow-Poplar Heartwood and Sapwood at 12\% and 30\% Moisture Content With and Without Steam PreConditioning.

\begin{tabular}{||c||c|c|c||}
\cline { 3 - 4 } \multicolumn{1}{c|}{} & \multicolumn{2}{c||}{ Steam } & No Steam \\
\hline \hline \multirow{2}{*}{ Heartwood } & $\mathbf{1 2 \%}$ & $0.0141(0.0145) \mathrm{W} / \mathrm{g}$ & $0.1005(0.0480) \mathrm{W} / \mathrm{g}$ \\
\cline { 3 - 5 } & $\mathbf{3 0 \%}$ & $0.0147(0.0113) \mathrm{W} / \mathrm{g}$ & $0.0309(0.0380) \mathrm{W} / \mathrm{g}$ \\
\hline \hline \multirow{2}{*}{ Sapwood } & $\mathbf{1 2 \%}$ & $0.0102(0.0065) \mathrm{W} / \mathrm{g}$ & $0.0065(0.0056) \mathrm{W} / \mathrm{g}$ \\
\cline { 2 - 4 } & $\mathbf{3 0 \%}$ & $0.0084(0.0045) \mathrm{W} / \mathrm{g}$ & $0.0070(0.0075) \mathrm{W} / \mathrm{g}$ \\
\hline
\end{tabular}




\section{Appendix A.4}

Table of Statistical Analysis Results. 
Table A.4. ANOVA of Glass Transition Temperatures Resulting From Steam Pre-Conditioning Yellow-Poplar Sapwood and Heartwood at 12\% and 30\% Moisture Contents.

\begin{tabular}{|c|c|c|c|c|c|c|}
\hline $\mathrm{M}$ & Source & DF & SS & MS & F value & $\begin{array}{c}\operatorname{Pr}>F \\
(\alpha=0.05)\end{array}$ \\
\hline $\mathrm{O}$ & Model & 7 & 215.24 & 30.75 & 3.21 & 0.0251 \\
\hline $\mathrm{D}$ & Error & 16 & 153.03 & 9.56 & & \\
\hline $\mathrm{E}$ & Corr. Tot. & 23 & 368.28 & & & \\
\hline $\mathrm{L}$ & \multicolumn{6}{|c|}{$\mathrm{r}^{2}=0.5845 \quad$ C. V. $=4.9103$} \\
\hline A & Source & $\mathrm{DF}$ & SS & MS & F value & $\begin{array}{c}\operatorname{Pr}>F \\
(\alpha=0.05)\end{array}$ \\
\hline $\mathrm{N}$ & Species & 1 & 41.32 & 41.32 & 4.32 & 0.0541 \\
\hline $\mathrm{O}$ & M.C. & 1 & 137.81 & 137.81 & 14.41 & 0.0016 \\
\hline $\mathrm{V}$ & Steam & 1 & 8.37 & 8.37 & 0.87 & 0.3636 \\
\hline A & $\begin{array}{l}\text { Species x } \\
\text { M.C. }\end{array}$ & 1 & 18.50 & 18.50 & 1.93 & 0.1834 \\
\hline & $\begin{array}{l}\text { Species x } \\
\text { Steam }\end{array}$ & 1 & 2.45 & 2.45 & 0.26 & 0.6196 \\
\hline & $\begin{array}{l}\text { Steam x } \\
\text { M.C. }\end{array}$ & 1 & 6.33 & 6.33 & 0.66 & 0.4277 \\
\hline & $\begin{array}{l}\text { Species x } \\
\text { M.C. x } \\
\text { Steam }\end{array}$ & 1 & 0.47 & 0.47 & 0.05 & 0.8278 \\
\hline
\end{tabular}




\section{Appendix B}

This Appendix Contains The Individual Dynamic Contact Angle Analysis Results, Additional Surface Energy Figures, And Statistical Analysis Results. 


\section{Appendix B.1}

Individual Contact Angle and Surface Energy Results. 
Table B.1. Individual Contact Angle and Surface Energy Results of Extracted and Unextracted Yellow-Poplar Sapwood and Heartwood Exposed to Different Surface Treatments.

\begin{tabular}{|c|c|c|c|c|c|c|c|c|}
\hline $\begin{array}{c}\text { Sample } \\
\text { No. }\end{array}$ & \begin{tabular}{|} 
Extracted \\
$($ Yes/No $)$
\end{tabular} & $\begin{array}{l}\text { Sapwood/ } \\
\text { Heartwood } \\
\text { ( H / S ) }\end{array}$ & \begin{tabular}{|l|} 
Surface \\
Treatment
\end{tabular} & $\begin{array}{l}\text { Time } \\
\text { (min.) }\end{array}$ & $\begin{array}{l}\text { Temp. } \\
\left({ }^{\circ} \mathrm{C}\right)\end{array}$ & $\begin{array}{l}\text { Contact } \\
\text { Angle } \\
\text { (degrees) }\end{array}$ & $\begin{array}{r}\text { Surface } \\
\text { Energy } \\
(\mathrm{m}\end{array}$ & $\begin{array}{l}\text { Average } \\
\text { Surface } \\
\text { Energy } \\
\left(\mathrm{m}^{\wedge} 2\right)\end{array}$ \\
\hline 1 & No & $S$ & Control & 0 & 20 & 28.54 & 64.22 & 66.01 \\
\hline 2 & $\mathrm{No}$ & $S$ & Control & 0 & 20 & 28.52 & 64.23 & \\
\hline 3 & No & $S$ & Control & 0 & 20 & 20.59 & 68.22 & \\
\hline 4 & No & $S$ & Control & 0 & 20 & 22.54 & 67.35 & \\
\hline 5 & No & $S$ & Aluminum & 0.5 & 50 & 33.66 & 61.11 & 62.43 \\
\hline 6 & No & $S$ & Aluminum & 0.5 & 50 & 34.38 & 60.64 & \\
\hline 7 & No & $S$ & Aluminum & 0.5 & 50 & 33.67 & 61.10 & \\
\hline 8 & No & $S$ & Aluminum & 0.5 & 50 & 23.51 & 66.88 & \\
\hline 9 & No & $S$ & Aluminum & 1 & 50 & 25.89 & 65.68 & 62.91 \\
\hline 10 & No & $S$ & Aluminum & 1 & 50 & 33.69 & 61.09 & \\
\hline 11 & No & $S$ & Aluminum & 1 & 50 & 30.73 & 62.94 & \\
\hline 12 & No & $\mathrm{S}$ & Aluminum & 1 & 50 & 32.32 & 61.96 & \\
\hline 13 & No & $S$ & Aluminum & 2 & 50 & 32.42 & 61.90 & 59.06 \\
\hline 14 & No & $S$ & Aluminum & 2 & 50 & 35.48 & 59.91 & \\
\hline 15 & No & $S$ & Aluminum & 2 & 50 & 37.66 & 58.42 & \\
\hline 16 & $\mathrm{No}$ & $S$ & Aluminum & 2 & 50 & 41.03 & 56.02 & \\
\hline 17 & No & $S$ & Aluminum & 5 & 50 & 33.32 & 61.33 & 63.44 \\
\hline 18 & No & $S$ & Aluminum & 5 & 50 & 26.10 & 65.57 & \\
\hline 19 & No & $S$ & Aluminum & 5 & 50 & 28.31 & 64.35 & \\
\hline 20 & No & $S$ & Aluminum & 5 & 50 & 31.40 & 62.53 & \\
\hline 21 & No & $S$ & Teflon & 0.5 & 50 & 27.63 & 64.74 & 67.13 \\
\hline 22 & $\mathrm{No}$ & $S$ & Teflon & 0.5 & 50 & 24.48 & 66.40 & \\
\hline 23 & No & $S$ & Teflon & 0.5 & 50 & 19.67 & 68.61 & \\
\hline 24 & No & $S$ & Teflon & 0.5 & 50 & 19.28 & 68.77 & \\
\hline 25 & No & $S$ & Teflon & 1 & 50 & 26.32 & 65.45 & 66.01 \\
\hline 26 & No & $S$ & Teflon & 1 & 50 & 26.06 & 65.59 & \\
\hline 27 & $\mathrm{No}$ & $S$ & Teflon & 1 & 50 & 23.24 & 67.01 & \\
\hline 28 & No & $S$ & Teflon & 1 & 50 & 25.25 & 66.01 & \\
\hline 29 & No & $S$ & Teflon & 2 & 50 & 30.39 & 63.14 & 62.60 \\
\hline 30 & No & $S$ & Teflon & 2 & 50 & 35.26 & 60.06 & \\
\hline 31 & No & $S$ & Teflon & 2 & 50 & 26.16 & 65.53 & \\
\hline 32 & No & $\mathrm{S}$ & Teflon & 2 & 50 & 32.78 & 61.67 & \\
\hline 33 & No & $S$ & Teflon & 5 & 50 & 26.52 & 65.34 & 64.88 \\
\hline 34 & No & $S$ & Teflon & 5 & 50 & 30.62 & 63.00 & \\
\hline 35 & No & $\mathrm{S}$ & Teflon & 5 & 50 & 25.83 & 65.71 & \\
\hline 36 & No & $S$ & Teflon & 5 & 50 & 26.27 & 65.48 & \\
\hline
\end{tabular}




\begin{tabular}{|c|c|c|c|c|c|c|c|c|}
\hline 37 & No & $\mathrm{S}$ & Heat/Air & 5 & 50 & 26.07 & 65.58 & 63.42 \\
\hline 38 & No & $\mathrm{S}$ & Heat/Air & 5 & 50 & 24.43 & 66.43 & \\
\hline 39 & No & $S$ & Heat/Air & 5 & 50 & 30.52 & 63.06 & \\
\hline 40 & No & $\mathrm{S}$ & Heat/Air & 5 & 50 & 37.42 & 58.59 & \\
\hline 41 & No & $S$ & Aluminum & 0.5 & 75 & 27.50 & 64.81 & 67.37 \\
\hline 42 & No & $\mathrm{S}$ & Aluminum & 0.5 & 75 & 18.47 & 69.10 & \\
\hline 43 & No & $\mathrm{S}$ & Aluminum & 0.5 & 75 & 22.60 & 67.32 & \\
\hline 44 & No & $\mathrm{S}$ & Aluminum & 0.5 & 75 & 20.51 & 68.26 & \\
\hline 45 & No & $\mathrm{S}$ & Aluminum & 1 & 75 & 23.52 & 66.88 & 67.51 \\
\hline 46 & No & $\mathrm{S}$ & Aluminum & 1 & 75 & 18.72 & 69.00 & \\
\hline 47 & No & $\mathrm{S}$ & Aluminum & 1 & 75 & 20.22 & 68.38 & \\
\hline 48 & No & $S$ & Aluminum & 1 & 75 & 25.72 & 65.77 & \\
\hline 49 & No & $S$ & Aluminum & 2 & 75 & 13.59 & 70.78 & 68.22 \\
\hline 50 & No & $\mathrm{S}$ & Aluminum & 2 & 75 & 23.90 & 66.69 & \\
\hline 51 & No & $\mathrm{S}$ & Aluminum & 2 & 75 & 23.53 & 66.87 & \\
\hline 52 & No & $\mathrm{S}$ & Aluminum & 2 & 75 & 19.84 & 68.54 & \\
\hline 53 & No & $\mathrm{S}$ & Aluminum & 5 & 75 & 5.48 & 72.47 & 68.44 \\
\hline 54 & No & $\mathrm{S}$ & Aluminum & 5 & 75 & 26.46 & 65.37 & \\
\hline 55 & No & $\mathrm{S}$ & Aluminum & 5 & 75 & 21.87 & 67.66 & \\
\hline 56 & No & $S$ & Aluminum & 5 & 75 & 20.51 & 68.26 & \\
\hline 57 & No & $\mathrm{S}$ & Teflon & 0.5 & 75 & 35.76 & 59.72 & 59.09 \\
\hline 58 & No & $S$ & Teflon & 0.5 & 75 & 36.72 & 59.07 & \\
\hline 59 & No & $\mathrm{S}$ & Teflon & 0.5 & 75 & 37.80 & 58.33 & \\
\hline 60 & No & $\mathrm{S}$ & Teflon & 0.5 & 75 & 36.44 & 59.26 & \\
\hline 61 & No & $S$ & Teflon & 1 & 75 & 36.40 & 59.29 & 58.48 \\
\hline 62 & No & $\mathrm{S}$ & Teflon & 1 & 75 & 36.85 & 58.98 & \\
\hline 63 & No & $\mathrm{S}$ & Teflon & 1 & 75 & 40.33 & 56.53 & \\
\hline 64 & No & $\mathrm{S}$ & Teflon & 1 & 75 & 36.63 & 59.13 & \\
\hline 65 & No & $\mathrm{S}$ & Teflon & 2 & 75 & 34.97 & 60.25 & 59.25 \\
\hline 66 & No & $\mathrm{S}$ & Teflon & 2 & 75 & 30.67 & 62.97 & \\
\hline 67 & No & $S$ & Teflon & 2 & 75 & 40.90 & 56.11 & \\
\hline 68 & No & $S$ & Teflon & 2 & 75 & 38.73 & 57.67 & \\
\hline 69 & No & $\mathrm{S}$ & Teflon & 5 & 75 & 34.43 & 60.61 & 60.34 \\
\hline 70 & No & $\mathrm{S}$ & Teflon & 5 & 75 & 35.82 & 59.68 & \\
\hline 71 & No & $S$ & Teflon & 5 & 75 & 35.81 & 59.69 & \\
\hline 72 & No & $\mathrm{S}$ & Teflon & 5 & 75 & 33.21 & 61.40 & \\
\hline 73 & No & $S$ & Heat/Air & 5 & 75 & 34.85 & 60.33 & 61.86 \\
\hline 74 & No & $S$ & Heat/Air & 5 & 75 & 29.83 & 63.47 & \\
\hline 75 & No & $S$ & Heat/Air & 5 & 75 & 33.16 & 61.43 & \\
\hline 76 & No & $\mathrm{S}$ & Heat/Air & 5 & 75 & 31.89 & 62.23 & \\
\hline 77 & No & $\mathrm{S}$ & Aluminum & 0.5 & 100 & 16.73 & 69.75 & 68.75 \\
\hline 78 & No & $\mathrm{S}$ & Aluminum & 0.5 & 100 & 20.53 & 68.25 & \\
\hline 79 & No & $\mathrm{S}$ & Aluminum & 0.5 & 100 & 19.20 & 68.81 & \\
\hline
\end{tabular}




\begin{tabular}{|c|c|c|c|c|c|c|c|c|}
\hline 80 & No & $\mathrm{S}$ & \begin{tabular}{|l|} 
Aluminum \\
\end{tabular} & 0.5 & 100 & 20.63 & 68.21 & \\
\hline 81 & No & $\mathrm{S}$ & Aluminum & 1 & 100 & 18.66 & 69.02 & 68.87 \\
\hline 82 & No & $S$ & Aluminum & 1 & 100 & 19.94 & 68.50 & \\
\hline 83 & No & $S$ & Aluminum & 1 & 100 & 16.01 & 70.00 & \\
\hline 84 & No & $\mathrm{S}$ & Aluminum & 1 & 100 & 21.18 & 67.97 & \\
\hline 85 & No & $\mathrm{S}$ & Aluminum & 2 & 100 & 16.58 & 69.81 & 69.23 \\
\hline 86 & No & $\mathrm{S}$ & Aluminum & 2 & 100 & 17.10 & 69.62 & \\
\hline 87 & No & $S$ & Aluminum & 2 & 100 & 18.91 & 68.92 & \\
\hline 88 & No & $\mathrm{S}$ & Aluminum & 2 & 100 & 19.76 & 68.58 & \\
\hline 89 & No & $\mathrm{S}$ & Aluminum & 5 & 100 & 8.32 & 72.04 & 70.09 \\
\hline 90 & No & $\mathrm{S}$ & Aluminum & 5 & 100 & 16.94 & 69.68 & \\
\hline 91 & No & $\mathrm{S}$ & Aluminum & 5 & 100 & 17.72 & 69.39 & \\
\hline 92 & No & $S$ & Aluminum & 5 & 100 & 18.08 & 69.25 & \\
\hline 93 & No & $\mathrm{S}$ & Teflon & 0.5 & 100 & 33.00 & 61.53 & 61.98 \\
\hline 94 & No & $\mathrm{S}$ & Teflon & 0.5 & 100 & 34.55 & 60.53 & \\
\hline 95 & No & $\mathrm{S}$ & Teflon & 0.5 & 100 & 33.52 & 61.20 & \\
\hline 96 & No & $S$ & Teflon & 0.5 & 100 & 27.73 & 64.68 & \\
\hline 97 & No & $\mathrm{S}$ & Teflon & 1 & 100 & 36.72 & 59.07 & 58.74 \\
\hline 98 & No & $\mathrm{S}$ & Teflon & 1 & 100 & 38.21 & 58.04 & \\
\hline 99 & No & $S$ & Teflon & 1 & 100 & 35.95 & 59.59 & \\
\hline 100 & No & $S$ & Teflon & 1 & 100 & 37.92 & 58.24 & \\
\hline 101 & No & $\mathrm{S}$ & Teflon & 2 & 100 & 39.43 & 57.17 & 55.55 \\
\hline 102 & No & $\mathrm{S}$ & Teflon & 2 & 100 & 45.67 & 52.52 & \\
\hline 103 & No & $\mathrm{S}$ & Teflon & 2 & 100 & 43.50 & 54.18 & \\
\hline 104 & No & $S$ & Teflon & 2 & 100 & 37.78 & 58.34 & \\
\hline 105 & No & $\mathrm{S}$ & Teflon & 5 & 100 & 40.09 & 56.70 & 55.95 \\
\hline 106 & No & $\mathrm{S}$ & Teflon & 5 & 100 & 45.22 & 52.87 & \\
\hline 107 & No & $\mathrm{S}$ & Teflon & 5 & 100 & 41.75 & 55.49 & \\
\hline 108 & No & $\mathrm{S}$ & Teflon & 5 & 100 & 37.18 & 58.76 & \\
\hline 109 & No & $\mathrm{S}$ & Heat/Air & 5 & 100 & 38.82 & 57.61 & 58.20 \\
\hline 110 & No & $\mathrm{S}$ & Heat/Air & 5 & 100 & 34.99 & 60.24 & \\
\hline 111 & No & $\mathrm{S}$ & Heat/Air & 5 & 100 & 39.31 & 57.26 & \\
\hline 112 & No & $S$ & Heat/Air & 5 & 100 & 38.68 & 57.71 & \\
\hline 113 & No & $S$ & Aluminum & 0.5 & 150 & 17.70 & 69.40 & 69.19 \\
\hline 114 & No & $\mathrm{S}$ & Aluminum & 0.5 & 150 & 17.96 & 69.30 & \\
\hline 115 & No & $\mathrm{S}$ & Aluminum & 0.5 & 150 & 20.03 & 68.46 & \\
\hline 116 & No & $\mathrm{S}$ & Aluminum & 0.5 & 150 & 17.17 & 69.59 & \\
\hline 117 & No & $\mathrm{S}$ & Aluminum & 1 & 150 & 19.31 & 68.76 & 68.70 \\
\hline 118 & No & $S$ & Aluminum & 1 & 150 & 18.05 & 69.26 & \\
\hline 119 & No & $\mathrm{S}$ & Aluminum & 1 & 150 & 20.06 & 68.45 & \\
\hline 120 & No & $\mathrm{S}$ & Aluminum & 1 & 150 & 20.34 & 68.33 & \\
\hline 121 & No & $\mathrm{S}$ & Aluminum & 2 & 150 & 17.20 & 69.58 & 68.43 \\
\hline 122 & No & $\mathrm{S}$ & Aluminum & 2 & 150 & 22.51 & 67.36 & \\
\hline
\end{tabular}




\begin{tabular}{|c|c|c|c|c|c|c|c|c|}
\hline 123 & No & $S$ & Aluminum & 2 & 150 & 22.23 & 67.49 & \\
\hline 124 & No & $\mathrm{S}$ & Aluminum & 2 & 150 & 17.94 & 69.30 & \\
\hline 125 & No & $S$ & Aluminum & 5 & 150 & 15.81 & 70.07 & 69.92 \\
\hline 126 & No & $S$ & Aluminum & 5 & 150 & 18.01 & 69.28 & \\
\hline 127 & No & $S$ & Aluminum & 5 & 150 & 13.51 & 70.80 & \\
\hline 128 & No & $\mathrm{S}$ & Aluminum & 5 & 150 & 17.38 & 69.51 & \\
\hline 129 & No & $\mathrm{S}$ & Teflon & 0.5 & 150 & 40.36 & 56.50 & 57.42 \\
\hline 130 & No & $S$ & Teflon & 0.5 & 150 & 38.81 & 57.62 & \\
\hline 131 & No & $\mathrm{S}$ & Teflon & 0.5 & 150 & 37.22 & 58.73 & \\
\hline 132 & No & $\mathrm{S}$ & Teflon & 0.5 & 150 & 39.92 & 56.82 & \\
\hline 133 & No & $\mathrm{S}$ & Teflon & 1 & 150 & 45.27 & 52.83 & 53.95 \\
\hline 134 & No & $\mathrm{S}$ & Teflon & 1 & 150 & 44.82 & 53.18 & \\
\hline 135 & No & $S$ & Teflon & 1 & 150 & 43.30 & 54.33 & \\
\hline 136 & No & $\mathrm{S}$ & Teflon & 1 & 150 & 41.78 & 55.46 & \\
\hline 137 & No & $\mathrm{S}$ & Teflon & 2 & 150 & 46.54 & 51.85 & 51.55 \\
\hline 138 & No & $S$ & Teflon & 2 & 150 & 47.89 & 50.79 & \\
\hline 139 & No & $S$ & Teflon & 2 & 150 & 47.63 & 51.00 & \\
\hline 140 & No & $\mathrm{S}$ & Teflon & 2 & 150 & 45.60 & 52.58 & \\
\hline 141 & No & $\mathrm{S}$ & Teflon & 5 & 150 & 53.14 & 46.58 & 51.23 \\
\hline 142 & No & $S$ & Teflon & 5 & 150 & 44.12 & 53.71 & \\
\hline 143 & No & $S$ & Teflon & 5 & 150 & 48.44 & 50.36 & \\
\hline 144 & No & $S$ & Teflon & 5 & 150 & 43.36 & 54.29 & \\
\hline 145 & No & $\mathrm{S}$ & Heat/Air & 5 & 150 & 37.21 & 58.73 & 54.82 \\
\hline 146 & No & $\mathrm{S}$ & Heat/Air & 5 & 150 & 41.39 & 55.75 & \\
\hline 147 & No & $S$ & Heat/Air & 5 & 150 & 49.70 & 49.36 & \\
\hline 148 & No & $\mathrm{S}$ & Heat/Air & 5 & 150 & 41.82 & 55.44 & \\
\hline 149 & No & $\mathrm{H}$ & Control & 0 & 20 & 32.20 & 62.03 & 59.56 \\
\hline 150 & No & $\mathrm{H}$ & Control & 0 & 20 & 42.38 & 55.02 & \\
\hline 151 & No & $\mathrm{H}$ & Control & 0 & 20 & 35.64 & 59.80 & \\
\hline 152 & No & $\mathrm{H}$ & Control & 0 & 20 & 33.23 & 61.38 & \\
\hline 153 & No & $\mathrm{H}$ & Aluminum & 0.5 & 50 & 45.68 & 52.52 & 53.98 \\
\hline 154 & No & $\mathrm{H}$ & Aluminum & 0.5 & 50 & 40.99 & 56.05 & \\
\hline 155 & No & $\mathrm{H}$ & Aluminum & 0.5 & 50 & 44.82 & 53.18 & \\
\hline 156 & No & $\mathrm{H}$ & Aluminum & 0.5 & 50 & 43.49 & 54.19 & \\
\hline 157 & No & $\mathrm{H}$ & Aluminum & 1 & 50 & 46.00 & 52.27 & 56.10 \\
\hline 158 & No & $\mathrm{H}$ & Aluminum & 1 & 50 & 43.58 & 54.12 & \\
\hline 159 & No & $\mathrm{H}$ & Aluminum & 1 & 50 & 35.03 & 60.21 & \\
\hline 160 & No & $\mathrm{H}$ & Aluminum & 1 & 50 & 38.56 & 57.79 & \\
\hline 161 & No & $\mathrm{H}$ & Aluminum & 2 & 50 & 41.77 & 55.47 & 53.97 \\
\hline 162 & No & $\mathrm{H}$ & Aluminum & 2 & 50 & 41.28 & 55.83 & \\
\hline 163 & No & $\mathrm{H}$ & Aluminum & 2 & 50 & 46.39 & 51.97 & \\
\hline 164 & No & $\mathrm{H}$ & Aluminum & 2 & 50 & 45.56 & 52.61 & \\
\hline 165 & No & $\mathrm{H}$ & Aluminum & 5 & 50 & 41.70 & 55.52 & 56.31 \\
\hline
\end{tabular}




\begin{tabular}{|c|c|c|c|c|c|c|c|c|}
\hline 166 & No & $\mathrm{H}$ & \begin{tabular}{|l|} 
Aluminum \\
\end{tabular} & 5 & 50 & 44.80 & 53.19 & \\
\hline 167 & No & $\mathrm{H}$ & Aluminum & 5 & 50 & 37.57 & 58.49 & \\
\hline 168 & No & $\mathrm{H}$ & Aluminum & 5 & 50 & 38.23 & 58.02 & \\
\hline 169 & No & $\mathrm{H}$ & Teflon & 0.5 & 50 & 27.43 & 64.85 & 66.42 \\
\hline 170 & No & $\mathrm{H}$ & Teflon & 0.5 & 50 & 25.01 & 66.13 & \\
\hline 171 & No & $\mathrm{H}$ & Teflon & 0.5 & 50 & 26.93 & 65.12 & \\
\hline 172 & No & $\mathrm{H}$ & Teflon & 0.5 & 50 & 17.17 & 69.59 & \\
\hline 173 & No & $\mathrm{H}$ & Teflon & 1 & 50 & 28.86 & 64.04 & 62.49 \\
\hline 174 & No & $\mathrm{H}$ & Teflon & 1 & 50 & 28.64 & 64.17 & \\
\hline 175 & No & $\mathrm{H}$ & Teflon & 1 & 50 & 33.35 & 61.31 & \\
\hline 176 & No & $\mathrm{H}$ & Teflon & 1 & 50 & 34.67 & 60.45 & \\
\hline 177 & No & $\mathrm{H}$ & Teflon & 2 & 50 & 43.31 & 54.32 & 57.23 \\
\hline 178 & No & $\mathrm{H}$ & Teflon & 2 & 50 & 37.75 & 58.36 & \\
\hline 179 & No & $\mathrm{H}$ & Teflon & 2 & 50 & 40.68 & 56.27 & \\
\hline 180 & No & $\mathrm{H}$ & Teflon & 2 & 50 & 35.39 & 59.97 & \\
\hline 181 & No & $\mathrm{H}$ & Teflon & 5 & 50 & 34.44 & 60.60 & 59.93 \\
\hline 182 & No & $\mathrm{H}$ & Teflon & 5 & 50 & 33.39 & 61.28 & \\
\hline 183 & No & $\mathrm{H}$ & Teflon & 5 & 50 & 41.06 & 55.99 & \\
\hline 184 & No & $\mathrm{H}$ & Teflon & 5 & 50 & 32.48 & 61.86 & \\
\hline 185 & No & $\mathrm{H}$ & Heat/Air & 5 & 50 & 51.25 & 48.11 & 55.19 \\
\hline 186 & No & $\mathrm{H}$ & Heat/Air & 5 & 50 & 32.03 & 62.14 & \\
\hline 187 & No & $\mathrm{H}$ & Heat/Air & 5 & 50 & 48.87 & 50.02 & \\
\hline 188 & No & $\mathrm{H}$ & Heat/Air & 5 & 50 & 34.60 & 60.49 & \\
\hline 189 & No & $\mathrm{H}$ & Aluminum & 0.5 & 75 & 27.40 & 64.86 & 65.46 \\
\hline 190 & No & $\mathrm{H}$ & Aluminum & 0.5 & 75 & 24.57 & 66.36 & \\
\hline 191 & No & $\mathrm{H}$ & Aluminum & 0.5 & 75 & 26.35 & 65.43 & \\
\hline 192 & No & $\mathrm{H}$ & Aluminum & 0.5 & 75 & 26.84 & 65.17 & \\
\hline 193 & No & $\mathrm{H}$ & Aluminum & 1 & 75 & 22.53 & 67.35 & 65.10 \\
\hline 194 & No & $\mathrm{H}$ & Aluminum & 1 & 75 & 27.87 & 64.60 & \\
\hline 195 & No & $\mathrm{H}$ & Aluminum & 1 & 75 & 29.27 & 63.80 & \\
\hline 196 & No & $\mathrm{H}$ & Aluminum & 1 & 75 & 27.80 & 64.64 & \\
\hline 197 & No & $\mathrm{H}$ & Aluminum & 2 & 75 & 27.83 & 64.62 & 65.42 \\
\hline 198 & No & $\mathrm{H}$ & Aluminum & 2 & 75 & 24.41 & 66.44 & \\
\hline 199 & No & $\mathrm{H}$ & Aluminum & 2 & 75 & 23.28 & 66.99 & \\
\hline 200 & No & $\mathrm{H}$ & Aluminum & 2 & 75 & 29.54 & 63.64 & \\
\hline 201 & No & $\mathrm{H}$ & Aluminum & 5 & 75 & 19.42 & 68.72 & 67.40 \\
\hline 202 & No & $\mathrm{H}$ & Aluminum & 5 & 75 & 23.50 & 66.89 & \\
\hline 203 & No & $\mathrm{H}$ & Aluminum & 5 & 75 & 25.64 & 65.81 & \\
\hline 204 & No & $\mathrm{H}$ & Aluminum & 5 & 75 & 20.69 & 68.18 & \\
\hline 205 & No & $\mathrm{H}$ & Teflon & 0.5 & 75 & 41.24 & 55.86 & 53.08 \\
\hline 206 & No & $\mathrm{H}$ & Teflon & 0.5 & 75 & 46.31 & 52.03 & \\
\hline 207 & No & $\mathrm{H}$ & Teflon & 0.5 & 75 & 45.64 & 52.55 & \\
\hline 208 & No & $\mathrm{H}$ & Teflon & 0.5 & 75 & 46.50 & 51.88 & \\
\hline
\end{tabular}




\begin{tabular}{|c|c|c|c|c|c|c|c|c|}
\hline 209 & No & $\mathrm{H}$ & Teflon & 1 & 75 & 41.91 & 55.37 & 54.83 \\
\hline 210 & No & $\mathrm{H}$ & Teflon & 1 & 75 & 42.89 & 54.64 & \\
\hline 211 & No & $\mathrm{H}$ & Teflon & 1 & 75 & 40.85 & 56.15 & \\
\hline 212 & No & $\mathrm{H}$ & Teflon & 1 & 75 & 44.81 & 53.18 & \\
\hline 213 & No & $\mathrm{H}$ & Teflon & 2 & 75 & 43.10 & 54.48 & 53.76 \\
\hline 214 & No & $\mathrm{H}$ & Teflon & 2 & 75 & 41.34 & 55.79 & \\
\hline 215 & No & $\mathrm{H}$ & Teflon & 2 & 75 & 48.19 & 50.56 & \\
\hline 216 & No & $\mathrm{H}$ & Teflon & 2 & 75 & 43.48 & 54.20 & \\
\hline 217 & No & $\mathrm{H}$ & Teflon & 5 & 75 & 40.05 & 56.73 & 55.15 \\
\hline 218 & No & $\mathrm{H}$ & Teflon & 5 & 75 & 41.59 & 55.61 & \\
\hline 219 & No & $\mathrm{H}$ & Teflon & 5 & 75 & 42.16 & 55.18 & \\
\hline 220 & No & $\mathrm{H}$ & Teflon & 5 & 75 & 44.94 & 53.09 & \\
\hline 221 & No & $\mathrm{H}$ & Heat/Air & 5 & 75 & 42.89 & 54.64 & 54.00 \\
\hline 222 & No & $\mathrm{H}$ & Heat/Air & 5 & 75 & 44.91 & 53.11 & \\
\hline 223 & No & $\mathrm{H}$ & Heat/Air & 5 & 75 & 49.43 & 49.52 & \\
\hline 224 & No & $\mathrm{H}$ & Heat/Air & 5 & 75 & 37.22 & 58.73 & \\
\hline 225 & No & $\mathrm{H}$ & Aluminum & 0.5 & 100 & 21.84 & 67.67 & 66.40 \\
\hline 226 & No & $\mathrm{H}$ & Aluminum & 0.5 & 100 & 27.43 & 64.85 & \\
\hline 227 & No & $\mathrm{H}$ & Aluminum & 0.5 & 100 & 22.51 & 67.36 & \\
\hline 228 & No & $\mathrm{H}$ & Aluminum & 0.5 & 100 & 25.79 & 65.73 & \\
\hline 229 & No & $\mathrm{H}$ & Aluminum & 1 & 100 & 21.82 & 67.68 & 66.13 \\
\hline 230 & No & $\mathrm{H}$ & Aluminum & 1 & 100 & 22.97 & 67.14 & \\
\hline 231 & No & $\mathrm{H}$ & Aluminum & 1 & 100 & 25.80 & 65.72 & \\
\hline 232 & No & $\mathrm{H}$ & Aluminum & 1 & 100 & 28.94 & 63.99 & \\
\hline 233 & No & $\mathrm{H}$ & Aluminum & 2 & 100 & 21.43 & 67.85 & 66.50 \\
\hline 234 & No & $\mathrm{H}$ & Aluminum & 2 & 100 & 22.06 & 67.57 & \\
\hline 235 & No & $\mathrm{H}$ & Aluminum & 2 & 100 & 24.20 & 66.54 & \\
\hline 236 & No & $\mathrm{H}$ & Aluminum & 2 & 100 & 28.84 & 64.05 & \\
\hline 237 & No & $\mathrm{H}$ & Aluminum & 5 & 100 & 24.29 & 66.50 & 67.29 \\
\hline 238 & No & $\mathrm{H}$ & Aluminum & 5 & 100 & 25.47 & 65.90 & \\
\hline 239 & No & $\mathrm{H}$ & Aluminum & 5 & 100 & 24.40 & 66.44 & \\
\hline 240 & No & $\mathrm{H}$ & Aluminum & 5 & 100 & 15.07 & 70.32 & \\
\hline 241 & No & $\mathrm{H}$ & Teflon & 0.5 & 100 & 41.10 & 55.97 & 55.51 \\
\hline 242 & No & $\mathrm{H}$ & Teflon & 0.5 & 100 & 44.36 & 53.53 & \\
\hline 243 & No & $\mathrm{H}$ & Teflon & 0.5 & 100 & 41.42 & 55.73 & \\
\hline 244 & No & $\mathrm{H}$ & Teflon & 0.5 & 100 & 39.93 & 56.82 & \\
\hline 245 & No & $\mathrm{H}$ & Teflon & 1 & 100 & 43.39 & 54.26 & 53.36 \\
\hline 246 & No & $\mathrm{H}$ & Teflon & 1 & 100 & 46.74 & 51.69 & \\
\hline 247 & No & $\mathrm{H}$ & Teflon & 1 & 100 & 43.59 & 54.11 & \\
\hline 248 & No & $\mathrm{H}$ & Teflon & 1 & 100 & 44.54 & 53.39 & \\
\hline 249 & No & $\mathrm{H}$ & Teflon & 2 & 100 & 46.57 & 51.83 & 50.94 \\
\hline 250 & No & $\mathrm{H}$ & Teflon & 2 & 100 & 48.36 & 50.42 & \\
\hline 251 & No & $\mathrm{H}$ & Teflon & 2 & 100 & 44.15 & 53.69 & \\
\hline
\end{tabular}




\begin{tabular}{|c|c|c|c|c|c|c|c|c|}
\hline 252 & No & $\mathrm{H}$ & Teflon & 2 & 100 & 51.60 & 47.83 & \\
\hline 253 & No & $\mathrm{H}$ & Teflon & 5 & 100 & 52.54 & 47.07 & 46.08 \\
\hline 254 & No & $\mathrm{H}$ & Teflon & 5 & 100 & 58.80 & 41.94 & \\
\hline 255 & No & $\mathrm{H}$ & Teflon & 5 & 100 & 52.46 & 47.14 & \\
\hline 256 & No & $\mathrm{H}$ & Teflon & 5 & 100 & 51.16 & 48.19 & \\
\hline 257 & No & $\mathrm{H}$ & Heat/Air & 5 & 100 & 45.54 & 52.62 & 50.12 \\
\hline 258 & No & $\mathrm{H}$ & Heat/Air & 5 & 100 & 60.69 & 40.38 & \\
\hline 259 & No & $\mathrm{H}$ & Heat/Air & 5 & 100 & 43.91 & 53.87 & \\
\hline 260 & No & $\mathrm{H}$ & Heat/Air & 5 & 100 & 44.24 & 53.62 & \\
\hline 261 & No & $\mathrm{H}$ & Aluminum & 0.5 & 150 & 16.84 & 69.71 & 68.37 \\
\hline 262 & No & $\mathrm{H}$ & Aluminum & 0.5 & 150 & 20.97 & 68.06 & \\
\hline 263 & No & $\mathrm{H}$ & Aluminum & 0.5 & 150 & 21.11 & 68.00 & \\
\hline 264 & No & $\mathrm{H}$ & Aluminum & 0.5 & 150 & 21.75 & 67.71 & \\
\hline 265 & No & $\mathrm{H}$ & Aluminum & 1 & 150 & 19.25 & 68.79 & 68.57 \\
\hline 266 & No & $\mathrm{H}$ & Aluminum & 1 & 150 & 18.07 & 69.25 & \\
\hline 267 & No & $\mathrm{H}$ & Aluminum & 1 & 150 & 19.35 & 68.75 & \\
\hline 268 & No & $\mathrm{H}$ & Aluminum & 1 & 150 & 22.23 & 67.49 & \\
\hline 269 & No & $\mathrm{H}$ & Aluminum & 2 & 150 & 18.42 & 69.12 & 68.24 \\
\hline 270 & No & $\mathrm{H}$ & Aluminum & 2 & 150 & 21.70 & 67.73 & \\
\hline 271 & No & $\mathrm{H}$ & Aluminum & 2 & 150 & 22.10 & 67.55 & \\
\hline 272 & No & $\mathrm{H}$ & Aluminum & 2 & 150 & 19.77 & 68.57 & \\
\hline 273 & No & $\mathrm{H}$ & Aluminum & 5 & 150 & 10.40 & 71.61 & 69.99 \\
\hline 274 & No & $\mathrm{H}$ & Aluminum & 5 & 150 & 19.34 & 68.75 & \\
\hline 275 & No & $\mathrm{H}$ & Aluminum & 5 & 150 & 18.45 & 69.11 & \\
\hline 276 & No & $\mathrm{H}$ & Aluminum & 5 & 150 & 14.53 & 70.49 & \\
\hline 277 & No & $\mathrm{H}$ & Teflon & 0.5 & 150 & 53.18 & 46.55 & 48.12 \\
\hline 278 & No & $\mathrm{H}$ & Teflon & 0.5 & 150 & 53.39 & 46.38 & \\
\hline 279 & No & $\mathrm{H}$ & Teflon & 0.5 & 150 & 48.02 & 50.69 & \\
\hline 280 & No & $\mathrm{H}$ & Teflon & 0.5 & 150 & 50.33 & 48.85 & \\
\hline 281 & No & $\mathrm{H}$ & Teflon & 1 & 150 & 52.42 & 47.17 & 44.06 \\
\hline 282 & No & $\mathrm{H}$ & Teflon & 1 & 150 & 55.44 & 44.70 & \\
\hline 283 & No & $\mathrm{H}$ & Teflon & 1 & 150 & 60.24 & 40.75 & \\
\hline 284 & No & $\mathrm{H}$ & Teflon & 1 & 150 & 56.79 & 43.60 & \\
\hline 285 & No & $\mathrm{H}$ & Teflon & 2 & 150 & 60.86 & 40.24 & 41.92 \\
\hline 286 & No & $\mathrm{H}$ & Teflon & 2 & 150 & 60.16 & 40.82 & \\
\hline 287 & No & $\mathrm{H}$ & Teflon & 2 & 150 & 62.23 & 39.11 & \\
\hline 288 & No & $\mathrm{H}$ & Teflon & 2 & 150 & 52.02 & 47.49 & \\
\hline 289 & No & $\mathrm{H}$ & Teflon & 5 & 150 & 64.68 & 37.10 & 35.15 \\
\hline 290 & No & $\mathrm{H}$ & Teflon & 5 & 150 & 68.99 & 33.59 & \\
\hline 291 & No & $\mathrm{H}$ & Teflon & 5 & 150 & 67.42 & 34.86 & \\
\hline 292 & No & $\mathrm{H}$ & Teflon & 5 & 150 & 67.16 & 35.07 & \\
\hline 293 & No & $\mathrm{H}$ & Heat/Air & 5 & 150 & 46.71 & 51.72 & 43.66 \\
\hline 294 & No & $\mathrm{H}$ & Heat/Air & 5 & 150 & 54.64 & 45.36 & \\
\hline
\end{tabular}




\begin{tabular}{|c|c|c|c|c|c|c|c|c|}
\hline 295 & No & $\mathrm{H}$ & Heat/Air & 5 & 150 & 58.37 & 42.30 & \\
\hline 296 & No & $\mathrm{H}$ & Heat/Air & 5 & 150 & 66.93 & 35.26 & \\
\hline 297 & Yes & $S$ & Control & 0 & 20 & 0.00 & 72.80 & 72.80 \\
\hline 298 & Yes & $S$ & Control & 0 & 20 & 0.00 & 72.80 & \\
\hline 299 & Yes & $\mathrm{S}$ & Control & 0 & 20 & 0.00 & 72.80 & \\
\hline 300 & Yes & $\mathrm{S}$ & Control & 0 & 20 & 0.00 & 72.80 & \\
\hline 301 & Yes & $\mathrm{S}$ & Aluminum & 0.5 & 50 & 16.28 & 69.91 & 71.73 \\
\hline 302 & Yes & $S$ & Aluminum & 0.5 & 50 & 0.00 & 72.80 & \\
\hline 303 & Yes & $\mathrm{S}$ & Aluminum & 0.5 & 50 & 11.32 & 71.39 & \\
\hline 304 & Yes & $\mathrm{S}$ & Aluminum & 0.5 & 50 & 0.00 & 72.80 & \\
\hline 305 & Yes & $\mathrm{S}$ & Aluminum & 1 & 50 & 0.00 & 72.80 & 72.69 \\
\hline 306 & Yes & $\mathrm{S}$ & Aluminum & 1 & 50 & 0.00 & 72.80 & \\
\hline 307 & Yes & $S$ & Aluminum & 1 & 50 & 6.44 & 72.34 & \\
\hline 308 & Yes & $\mathrm{S}$ & Aluminum & 1 & 50 & 0.00 & 72.80 & \\
\hline 309 & Yes & $\mathrm{S}$ & Aluminum & 2 & 50 & 0.00 & 72.80 & 72.56 \\
\hline 310 & Yes & $\mathrm{S}$ & Aluminum & 2 & 50 & 9.43 & 71.82 & \\
\hline 311 & Yes & $S$ & Aluminum & 2 & 50 & 0.00 & 72.80 & \\
\hline 312 & Yes & $\mathrm{S}$ & Aluminum & 2 & 50 & 0.00 & 72.80 & \\
\hline 313 & Yes & $\mathrm{S}$ & Aluminum & 5 & 50 & 13.00 & 70.95 & 72.34 \\
\hline 314 & Yes & $S$ & Aluminum & 5 & 50 & 0.00 & 72.80 & \\
\hline 315 & Yes & $S$ & Aluminum & 5 & 50 & 0.00 & 72.80 & \\
\hline 316 & Yes & $\mathrm{S}$ & Aluminum & 5 & 50 & 0.00 & 72.80 & \\
\hline 317 & Yes & $\mathrm{S}$ & Teflon & 0.5 & 50 & 0.00 & 72.80 & 72.27 \\
\hline 318 & Yes & $\mathrm{S}$ & Teflon & 0.5 & 50 & 13.86 & 70.70 & \\
\hline 319 & Yes & $S$ & Teflon & 0.5 & 50 & 0.00 & 72.80 & \\
\hline 320 & Yes & $\mathrm{S}$ & Teflon & 0.5 & 50 & 0.00 & 72.80 & \\
\hline 321 & Yes & $\mathrm{S}$ & Teflon & 1 & 50 & 10.84 & 71.51 & 71.29 \\
\hline 322 & Yes & $S$ & Teflon & 1 & 50 & 0.00 & 72.80 & \\
\hline 323 & Yes & $\mathrm{S}$ & Teflon & 1 & 50 & 20.97 & 68.06 & \\
\hline 324 & Yes & $\mathrm{S}$ & Teflon & 1 & 50 & 0.00 & 72.80 & \\
\hline 325 & Yes & $\mathrm{S}$ & Teflon & 2 & 50 & 0.00 & 72.80 & 72.40 \\
\hline 326 & Yes & $\mathrm{S}$ & Teflon & 2 & 50 & 0.00 & 72.80 & \\
\hline 327 & Yes & $\mathrm{S}$ & Teflon & 2 & 50 & 12.08 & 71.20 & \\
\hline 328 & Yes & $S$ & Teflon & 2 & 50 & 0.00 & 72.80 & \\
\hline 329 & Yes & $\mathrm{S}$ & Teflon & 5 & 50 & 0.00 & 72.80 & 72.50 \\
\hline 330 & Yes & $\mathrm{S}$ & Teflon & 5 & 50 & 0.00 & 72.80 & \\
\hline 331 & Yes & $\mathrm{S}$ & Teflon & 5 & 50 & 10.52 & 71.58 & \\
\hline 332 & Yes & $S$ & Teflon & 5 & 50 & 0.00 & 72.80 & \\
\hline 333 & Yes & $S$ & Heat/Air & 5 & 50 & 21.42 & 67.86 & 68.00 \\
\hline 334 & Yes & $\mathrm{S}$ & Heat/Air & 5 & 50 & 13.21 & 70.89 & \\
\hline 335 & Yes & $\mathrm{S}$ & Heat/Air & 5 & 50 & 22.49 & 67.37 & \\
\hline 336 & Yes & $\mathrm{S}$ & Heat/Air & 5 & 50 & 25.48 & 65.89 & \\
\hline 337 & Yes & $\mathrm{S}$ & Aluminum & 0.5 & 75 & 0.00 & 72.80 & 70.88 \\
\hline
\end{tabular}




\begin{tabular}{|c|c|c|c|c|c|c|c|c|}
\hline 338 & Yes & $\mathrm{S}$ & Aluminum & 0.5 & 75 & 0.00 & 72.80 & \\
\hline 339 & Yes & $S$ & Aluminum & 0.5 & 75 & 25.34 & 65.96 & \\
\hline 340 & Yes & $\mathrm{S}$ & Aluminum & 0.5 & 75 & 8.69 & 71.97 & \\
\hline 341 & Yes & $\mathrm{S}$ & Aluminum & 1 & 75 & 0.00 & 72.80 & 72.64 \\
\hline 342 & Yes & $S$ & Aluminum & 1 & 75 & 0.00 & 72.80 & \\
\hline 343 & Yes & $\mathrm{S}$ & Aluminum & 1 & 75 & 0.00 & 72.80 & \\
\hline 344 & Yes & $\mathrm{S}$ & Aluminum & 1 & 75 & 7.53 & 72.17 & \\
\hline 345 & Yes & $S$ & Aluminum & 2 & 75 & 0.00 & 72.80 & 72.80 \\
\hline 346 & Yes & $\mathrm{S}$ & Aluminum & 2 & 75 & 0.00 & 72.80 & \\
\hline 347 & Yes & $\mathrm{S}$ & Aluminum & 2 & 75 & 0.00 & 72.80 & \\
\hline 348 & Yes & $S$ & Aluminum & 2 & 75 & 0.00 & 72.80 & \\
\hline 349 & Yes & $\mathrm{S}$ & Aluminum & 5 & 75 & 0.00 & 72.80 & 71.07 \\
\hline 350 & Yes & $\mathrm{S}$ & Aluminum & 5 & 75 & 0.00 & 72.80 & \\
\hline 351 & Yes & $S$ & Aluminum & 5 & 75 & 19.22 & 68.80 & \\
\hline 352 & Yes & $\mathrm{S}$ & Aluminum & 5 & 75 & 16.36 & 69.88 & \\
\hline 353 & Yes & $S$ & Teflon & 0.5 & 75 & 19.19 & 68.81 & 68.46 \\
\hline 354 & Yes & $\mathrm{S}$ & Teflon & 0.5 & 75 & 18.94 & 68.91 & \\
\hline 355 & Yes & $S$ & Teflon & 0.5 & 75 & 19.50 & 68.68 & \\
\hline 356 & Yes & $S$ & Teflon & 0.5 & 75 & 22.34 & 67.44 & \\
\hline 357 & Yes & $\mathrm{S}$ & Teflon & 1 & 75 & 31.45 & 62.50 & 65.60 \\
\hline 358 & Yes & $S$ & Teflon & 1 & 75 & 24.07 & 66.61 & \\
\hline 359 & Yes & $\mathrm{S}$ & Teflon & 1 & 75 & 24.50 & 66.39 & \\
\hline 360 & Yes & $\mathrm{S}$ & Teflon & 1 & 75 & 23.50 & 66.89 & \\
\hline 361 & Yes & $\mathrm{S}$ & Teflon & 2 & 75 & 33.38 & 61.29 & 67.31 \\
\hline 362 & Yes & $\mathrm{S}$ & Teflon & 2 & 75 & 24.86 & 66.21 & \\
\hline 363 & Yes & $\mathrm{S}$ & Teflon & 2 & 75 & 18.84 & 68.95 & \\
\hline 364 & Yes & $\mathrm{S}$ & Teflon & 2 & 75 & 0.00 & 72.80 & \\
\hline 365 & Yes & $\mathrm{S}$ & Teflon & 5 & 75 & 34.40 & 60.63 & 59.84 \\
\hline 366 & Yes & $\mathrm{S}$ & Teflon & 5 & 75 & 36.61 & 59.15 & \\
\hline 367 & Yes & $\mathrm{S}$ & Teflon & 5 & 75 & 39.11 & 57.40 & \\
\hline 368 & Yes & $\mathrm{S}$ & Teflon & 5 & 75 & 31.98 & 62.17 & \\
\hline 369 & Yes & $\mathrm{S}$ & Heat/Air & 5 & 75 & 19.14 & 68.83 & 67.84 \\
\hline 370 & Yes & $\mathrm{S}$ & Heat/Air & 5 & 75 & 23.98 & 66.65 & \\
\hline 371 & Yes & $\mathrm{S}$ & Heat/Air & 5 & 75 & 20.18 & 68.40 & \\
\hline 372 & Yes & $\mathrm{S}$ & Heat/Air & 5 & 75 & 22.28 & 67.47 & \\
\hline 373 & Yes & $\mathrm{S}$ & Aluminum & 0.5 & 100 & 22.42 & 67.40 & 70.78 \\
\hline 374 & Yes & $\mathrm{S}$ & Aluminum & 0.5 & 100 & 0.00 & 72.80 & \\
\hline 375 & Yes & $\mathrm{S}$ & Aluminum & 0.5 & 100 & 5.71 & 72.44 & \\
\hline 376 & Yes & $\mathrm{S}$ & Aluminum & 0.5 & 100 & 14.57 & 70.48 & \\
\hline 377 & Yes & $\mathrm{S}$ & Aluminum & 1 & 100 & 13.45 & 70.82 & 69.88 \\
\hline 378 & Yes & $\mathrm{S}$ & Aluminum & 1 & 100 & 23.08 & 67.09 & \\
\hline 379 & Yes & $\mathrm{S}$ & Aluminum & 1 & 100 & 2.65 & 72.72 & \\
\hline 380 & Yes & $\mathrm{S}$ & Aluminum & 1 & 100 & 18.97 & 68.89 & \\
\hline
\end{tabular}




\begin{tabular}{|c|c|c|c|c|c|c|c|c|}
\hline 381 & Yes & $\mathrm{S}$ & Aluminum & 2 & 100 & 0.00 & 72.80 & 71.14 \\
\hline 382 & Yes & $S$ & Aluminum & 2 & 100 & 0.00 & 72.80 & \\
\hline 383 & Yes & $\mathrm{S}$ & Aluminum & 2 & 100 & 17.22 & 69.57 & \\
\hline 384 & Yes & $\mathrm{S}$ & Aluminum & 2 & 100 & 17.70 & 69.39 & \\
\hline 385 & Yes & $S$ & Aluminum & 5 & 100 & 14.06 & 70.64 & 71.58 \\
\hline 386 & Yes & $\mathrm{S}$ & Aluminum & 5 & 100 & 0.00 & 72.80 & \\
\hline 387 & Yes & $\mathrm{S}$ & Aluminum & 5 & 100 & 0.00 & 72.80 & \\
\hline 388 & Yes & $S$ & Aluminum & 5 & 100 & 15.78 & 70.08 & \\
\hline 389 & Yes & $\mathrm{S}$ & Teflon & 0.5 & 100 & 31.20 & 62.65 & 59.85 \\
\hline 390 & Yes & $\mathrm{S}$ & Teflon & 0.5 & 100 & 39.10 & 57.41 & \\
\hline 391 & Yes & $S$ & Teflon & 0.5 & 100 & 33.80 & 61.02 & \\
\hline 392 & Yes & $\mathrm{S}$ & Teflon & 0.5 & 100 & 37.80 & 58.33 & \\
\hline 393 & Yes & $S$ & Teflon & 1 & 100 & 33.24 & 61.38 & 60.27 \\
\hline 394 & Yes & $S$ & Teflon & 1 & 100 & 37.83 & 58.30 & \\
\hline 395 & Yes & $\mathrm{S}$ & Teflon & 1 & 100 & 35.33 & 60.01 & \\
\hline 396 & Yes & $S$ & Teflon & 1 & 100 & 33.24 & 61.38 & \\
\hline 397 & Yes & $\mathrm{S}$ & Teflon & 2 & 100 & 33.84 & 60.99 & 60.68 \\
\hline 398 & Yes & $S$ & Teflon & 2 & 100 & 35.84 & 59.67 & \\
\hline 399 & Yes & $S$ & Teflon & 2 & 100 & 38.10 & 58.12 & \\
\hline 400 & Yes & $\mathrm{S}$ & Teflon & 2 & 100 & 29.02 & 63.95 & \\
\hline 401 & Yes & S & Teflon & 5 & 100 & 44.02 & 53.79 & 56.71 \\
\hline 402 & Yes & $\mathrm{S}$ & Teflon & 5 & 100 & 38.18 & 58.06 & \\
\hline 403 & Yes & $\mathrm{S}$ & Teflon & 5 & 100 & 34.78 & 60.38 & \\
\hline 404 & Yes & $\mathrm{S}$ & Teflon & 5 & 100 & 42.94 & 54.60 & \\
\hline 405 & Yes & $\mathrm{S}$ & Heat/Air & 5 & 100 & 20.24 & 68.38 & 67.33 \\
\hline 406 & Yes & $\mathrm{S}$ & Heat/Air & 5 & 100 & 19.02 & 68.88 & \\
\hline 407 & Yes & $\mathrm{S}$ & Heat/Air & 5 & 100 & 24.16 & 66.57 & \\
\hline 408 & Yes & $\mathrm{S}$ & Heat/Air & 5 & 100 & 26.23 & 65.50 & \\
\hline 409 & Yes & $\mathrm{S}$ & Aluminum & 0.5 & 150 & 0.00 & 72.80 & 72.24 \\
\hline 410 & Yes & $\mathrm{S}$ & Aluminum & 0.5 & 150 & 0.00 & 72.80 & \\
\hline 411 & Yes & $\mathrm{S}$ & Aluminum & 0.5 & 150 & 14.35 & 70.55 & \\
\hline 412 & Yes & $\mathrm{S}$ & Aluminum & 0.5 & 150 & 0.00 & 72.80 & \\
\hline 413 & Yes & $\mathrm{S}$ & Aluminum & 1 & 150 & 0.00 & 72.80 & 71.92 \\
\hline 414 & Yes & $\mathrm{S}$ & Aluminum & 1 & 150 & 0.00 & 72.80 & \\
\hline 415 & Yes & $\mathrm{S}$ & Aluminum & 1 & 150 & 0.00 & 72.80 & \\
\hline 416 & Yes & $\mathrm{S}$ & Aluminum & 1 & 150 & 17.98 & 69.29 & \\
\hline 417 & Yes & $\mathrm{S}$ & Aluminum & 2 & 150 & 0.00 & 72.80 & 71.49 \\
\hline 418 & Yes & $\mathrm{S}$ & Aluminum & 2 & 150 & 0.00 & 72.80 & \\
\hline 419 & Yes & $\mathrm{S}$ & Aluminum & 2 & 150 & 12.94 & 70.96 & \\
\hline 420 & Yes & $\mathrm{S}$ & Aluminum & 2 & 150 & 17.68 & 69.40 & \\
\hline 421 & Yes & $\mathrm{S}$ & Aluminum & 5 & 150 & 0.00 & 72.80 & 72.80 \\
\hline 422 & Yes & $\mathrm{S}$ & Aluminum & 5 & 150 & 0.00 & 72.80 & \\
\hline 423 & Yes & $\mathrm{S}$ & Aluminum & 5 & 150 & 0.00 & 72.80 & \\
\hline
\end{tabular}




\begin{tabular}{|c|c|c|c|c|c|c|c|c|}
\hline 424 & Yes & $\mathrm{S}$ & Aluminum & 5 & 150 & 0.00 & 72.80 & \\
\hline 425 & Yes & $\mathrm{S}$ & Teflon & 0.5 & 150 & 27.07 & 65.04 & 63.39 \\
\hline 426 & Yes & $\mathrm{S}$ & Teflon & 0.5 & 150 & 33.24 & 61.38 & \\
\hline 427 & Yes & $\mathrm{S}$ & Teflon & 0.5 & 150 & 34.03 & 60.87 & \\
\hline 428 & Yes & $\mathrm{S}$ & Teflon & 0.5 & 150 & 24.72 & 66.28 & \\
\hline 429 & Yes & $\mathrm{S}$ & Teflon & 1 & 150 & 23.69 & 66.80 & 66.97 \\
\hline 430 & Yes & $\mathrm{S}$ & Teflon & 1 & 150 & 21.77 & 67.70 & \\
\hline 431 & Yes & $\mathrm{S}$ & Teflon & 1 & 150 & 23.16 & 67.05 & \\
\hline 432 & Yes & $\mathrm{S}$ & Teflon & 1 & 150 & 24.61 & 66.34 & \\
\hline 433 & Yes & $\mathrm{S}$ & Teflon & 2 & 150 & 32.10 & 62.10 & 65.24 \\
\hline 434 & Yes & $\mathrm{S}$ & Teflon & 2 & 150 & 33.13 & 61.45 & \\
\hline 435 & Yes & $\mathrm{S}$ & Teflon & 2 & 150 & 21.77 & 67.70 & \\
\hline 436 & Yes & $\mathrm{S}$ & Teflon & 2 & 150 & 16.78 & 69.73 & \\
\hline 437 & Yes & $\mathrm{S}$ & Teflon & 5 & 150 & 43.56 & 61.07 & 56.20 \\
\hline 438 & Yes & $\mathrm{S}$ & Teflon & 5 & 150 & 42.51 & 54.67 & \\
\hline 439 & Yes & $\mathrm{S}$ & Teflon & 5 & 150 & 42.85 & 54.92 & \\
\hline 440 & Yes & $\mathrm{S}$ & Teflon & 5 & 150 & 33.71 & 54.14 & \\
\hline 441 & Yes & $\mathrm{S}$ & Heat/Air & 5 & 150 & 18.26 & 69.18 & 67.98 \\
\hline 442 & Yes & $\mathrm{S}$ & Heat/Air & 5 & 150 & 21.07 & 68.01 & \\
\hline 443 & Yes & $\mathrm{S}$ & Heat/Air & 5 & 150 & 24.13 & 66.58 & \\
\hline 444 & Yes & $\mathrm{S}$ & Heat/Air & 5 & 150 & 20.79 & 68.14 & \\
\hline 445 & Yes & $\mathrm{H}$ & Control & 0 & 20 & 0.00 & 72.80 & 72.80 \\
\hline 446 & Yes & $\mathrm{H}$ & Control & 0 & 20 & 0.00 & 72.80 & \\
\hline 447 & Yes & $\mathrm{H}$ & Control & 0 & 20 & 0.00 & 72.80 & \\
\hline 448 & Yes & $\mathrm{H}$ & Control & 0 & 20 & 0.00 & 72.80 & \\
\hline 449 & Yes & $\mathrm{H}$ & Aluminum & 0.5 & 50 & 0.00 & 72.80 & 69.23 \\
\hline 450 & Yes & $\mathrm{H}$ & Aluminum & 0.5 & 50 & 13.56 & 70.79 & \\
\hline 451 & Yes & $\mathrm{H}$ & Aluminum & 0.5 & 50 & 34.52 & 60.55 & \\
\hline 452 & Yes & $\mathrm{H}$ & Aluminum & 0.5 & 50 & 0.00 & 72.80 & \\
\hline 453 & Yes & $\mathrm{H}$ & Aluminum & 1 & 50 & 0.00 & 72.80 & 70.98 \\
\hline 454 & Yes & $\mathrm{H}$ & Aluminum & 1 & 50 & 16.96 & 69.67 & \\
\hline 455 & Yes & $\mathrm{H}$ & Aluminum & 1 & 50 & 16.61 & 69.79 & \\
\hline 456 & Yes & $\mathrm{H}$ & Aluminum & 1 & 50 & 10.18 & 71.66 & \\
\hline 457 & Yes & $\mathrm{H}$ & Aluminum & 2 & 50 & 0.00 & 72.80 & 70.89 \\
\hline 458 & Yes & $\mathrm{H}$ & Aluminum & 2 & 50 & 13.79 & 70.72 & \\
\hline 459 & Yes & $\mathrm{H}$ & Aluminum & 2 & 50 & 22.72 & 67.26 & \\
\hline 460 & Yes & $\mathrm{H}$ & Aluminum & 2 & 50 & 0.00 & 72.80 & \\
\hline 461 & Yes & $\mathrm{H}$ & Aluminum & 5 & 50 & 0.00 & 72.80 & 72.16 \\
\hline 462 & Yes & $\mathrm{H}$ & Aluminum & 5 & 50 & 14.66 & 70.45 & \\
\hline 463 & Yes & $\mathrm{H}$ & Aluminum & 5 & 50 & 4.24 & 72.60 & \\
\hline 464 & Yes & $\mathrm{H}$ & Aluminum & 5 & 50 & 0.00 & 72.80 & \\
\hline 465 & Yes & $\mathrm{H}$ & Teflon & 0.5 & 50 & 24.37 & 66.46 & 70.09 \\
\hline 466 & Yes & $\mathrm{H}$ & Teflon & 0.5 & 50 & 0.00 & 72.80 & \\
\hline
\end{tabular}




\begin{tabular}{|c|c|c|c|c|c|c|c|c|}
\hline 467 & Yes & $\mathrm{H}$ & Teflon & 0.5 & 50 & 7.83 & 72.12 & \\
\hline 468 & Yes & $\mathrm{H}$ & Teflon & 0.5 & 50 & 18.79 & 68.97 & \\
\hline 469 & Yes & $\mathrm{H}$ & Teflon & 1 & 50 & 12.83 & 70.99 & 69.23 \\
\hline 470 & Yes & $\mathrm{H}$ & Teflon & 1 & 50 & 23.01 & 67.12 & \\
\hline 471 & Yes & $\mathrm{H}$ & Teflon & 1 & 50 & 16.27 & 69.91 & \\
\hline 472 & Yes & $\mathrm{H}$ & Teflon & 1 & 50 & 18.97 & 68.90 & \\
\hline 473 & Yes & $\mathrm{H}$ & Teflon & 2 & 50 & 16.87 & 69.70 & 69.78 \\
\hline 474 & Yes & $\mathrm{H}$ & Teflon & 2 & 50 & 20.56 & 68.24 & \\
\hline 475 & Yes & $\mathrm{H}$ & Teflon & 2 & 50 & 20.24 & 68.37 & \\
\hline 476 & Yes & $\mathrm{H}$ & Teflon & 2 & 50 & 0.00 & 72.80 & \\
\hline 477 & Yes & $\mathrm{H}$ & Teflon & 5 & 50 & 10.59 & 71.57 & 71.22 \\
\hline 478 & Yes & $\mathrm{H}$ & Teflon & 5 & 50 & 4.12 & 72.61 & \\
\hline 479 & Yes & $\mathrm{H}$ & Teflon & 5 & 50 & 0.00 & 72.80 & \\
\hline 480 & Yes & $\mathrm{H}$ & Teflon & 5 & 50 & 21.32 & 67.90 & \\
\hline 481 & Yes & $\mathrm{H}$ & Heat/Air & 5 & 50 & 27.27 & 64.93 & 63.39 \\
\hline 482 & Yes & $\mathrm{H}$ & Heat/Air & 5 & 50 & 30.40 & 63.14 & \\
\hline 483 & Yes & $\mathrm{H}$ & Heat/Air & 5 & 50 & 31.10 & 62.72 & \\
\hline 484 & Yes & $\mathrm{H}$ & Heat/Air & 5 & 50 & 31.03 & 62.76 & \\
\hline 485 & Yes & $\mathrm{H}$ & Aluminum & 0.5 & 75 & 6.83 & 72.28 & 70.27 \\
\hline 486 & Yes & $\mathrm{H}$ & Aluminum & 0.5 & 75 & 26.94 & 65.11 & \\
\hline 487 & Yes & $\mathrm{H}$ & Aluminum & 0.5 & 75 & 13.26 & 70.87 & \\
\hline 488 & Yes & $\mathrm{H}$ & Aluminum & 0.5 & 75 & 0.00 & 72.80 & \\
\hline 489 & Yes & $\mathrm{H}$ & Aluminum & 1 & 75 & 16.55 & 69.82 & 69.81 \\
\hline 490 & Yes & $\mathrm{H}$ & Aluminum & 1 & 75 & 0.00 & 72.80 & \\
\hline 491 & Yes & $\mathrm{H}$ & Aluminum & 1 & 75 & 15.94 & 70.03 & \\
\hline 492 & Yes & $\mathrm{H}$ & Aluminum & 1 & 75 & 24.10 & 66.59 & \\
\hline 493 & Yes & $\mathrm{H}$ & Aluminum & 2 & 75 & 18.12 & 69.23 & 70.62 \\
\hline 494 & Yes & $\mathrm{H}$ & Aluminum & 2 & 75 & 5.28 & 72.49 & \\
\hline 495 & Yes & $\mathrm{H}$ & Aluminum & 2 & 75 & 0.00 & 72.80 & \\
\hline 496 & Yes & $\mathrm{H}$ & Aluminum & 2 & 75 & 21.24 & 67.94 & \\
\hline 497 & Yes & $\mathrm{H}$ & Aluminum & 5 & 75 & 0.00 & 72.80 & 70.14 \\
\hline 498 & Yes & $\mathrm{H}$ & Aluminum & 5 & 75 & 19.73 & 68.59 & \\
\hline 499 & Yes & $\mathrm{H}$ & Aluminum & 5 & 75 & 24.57 & 66.36 & \\
\hline 500 & Yes & $\mathrm{H}$ & Aluminum & 5 & 75 & 0.00 & 72.80 & \\
\hline 501 & Yes & $\mathrm{H}$ & Teflon & 0.5 & 75 & 21.37 & 67.88 & 63.84 \\
\hline 502 & Yes & $\mathrm{H}$ & Teflon & 0.5 & 75 & 37.29 & 58.68 & \\
\hline 503 & Yes & $\mathrm{H}$ & Teflon & 0.5 & 75 & 23.31 & 66.98 & \\
\hline 504 & Yes & $\mathrm{H}$ & Teflon & 0.5 & 75 & 32.51 & 61.84 & \\
\hline 505 & Yes & $\mathrm{H}$ & Teflon & 1 & 75 & 20.63 & 68.21 & 65.39 \\
\hline 506 & Yes & $\mathrm{H}$ & Teflon & 1 & 75 & 31.96 & 62.18 & \\
\hline 507 & Yes & $\mathrm{H}$ & Teflon & 1 & 75 & 27.21 & 64.97 & \\
\hline 508 & Yes & $\mathrm{H}$ & Teflon & 1 & 75 & 24.84 & 66.22 & \\
\hline 509 & Yes & $\mathrm{H}$ & Teflon & 2 & 75 & 22.68 & 67.28 & 61.05 \\
\hline
\end{tabular}




\begin{tabular}{|c|c|c|c|c|c|c|c|c|}
\hline 510 & Yes & $\mathrm{H}$ & Teflon & 2 & 75 & 28.77 & 64.09 & \\
\hline 511 & Yes & $\mathrm{H}$ & Teflon & 2 & 75 & 36.87 & 58.97 & \\
\hline 512 & Yes & $\mathrm{H}$ & Teflon & 2 & 75 & 43.93 & 53.86 & \\
\hline 513 & Yes & $\mathrm{H}$ & Teflon & 5 & 75 & 38.32 & 57.96 & 55.85 \\
\hline 514 & Yes & $\mathrm{H}$ & Teflon & 5 & 75 & 43.57 & 54.13 & \\
\hline 515 & Yes & $\mathrm{H}$ & Teflon & 5 & 75 & 40.97 & 56.06 & \\
\hline 516 & Yes & $\mathrm{H}$ & Teflon & 5 & 75 & 42.08 & 55.24 & \\
\hline 517 & Yes & $\mathrm{H}$ & Heat/Air & 5 & 75 & 26.58 & 65.31 & 62.67 \\
\hline 518 & Yes & $\mathrm{H}$ & Heat/Air & 5 & 75 & 33.28 & 61.35 & \\
\hline 519 & Yes & $\mathrm{H}$ & Heat/Air & 5 & 75 & 29.99 & 63.38 & \\
\hline 520 & Yes & $\mathrm{H}$ & Heat/Air & 5 & 75 & 34.35 & 60.66 & \\
\hline 521 & Yes & $\mathrm{H}$ & Aluminum & 0.5 & 100 & 14.79 & 70.41 & 66.97 \\
\hline 522 & Yes & $\mathrm{H}$ & Aluminum & 0.5 & 100 & 28.53 & 64.23 & \\
\hline 523 & Yes & $\mathrm{H}$ & Aluminum & 0.5 & 100 & 25.60 & 65.83 & \\
\hline 524 & Yes & $\mathrm{H}$ & Aluminum & 0.5 & 100 & 22.43 & 67.40 & \\
\hline 525 & Yes & $\mathrm{H}$ & Aluminum & 1 & 100 & 24.71 & 66.29 & 66.93 \\
\hline 526 & Yes & $\mathrm{H}$ & Aluminum & 1 & 100 & 24.67 & 66.31 & \\
\hline 527 & Yes & $\mathrm{H}$ & Aluminum & 1 & 100 & 16.31 & 69.90 & \\
\hline 528 & Yes & $\mathrm{H}$ & Aluminum & 1 & 100 & 26.77 & 65.21 & \\
\hline 529 & Yes & $\mathrm{H}$ & Aluminum & 2 & 100 & 0.00 & 72.80 & 71.58 \\
\hline 530 & Yes & $\mathrm{H}$ & Aluminum & 2 & 100 & 17.33 & 69.53 & \\
\hline 531 & Yes & $\mathrm{H}$ & Aluminum & 2 & 100 & 12.19 & 71.17 & \\
\hline 532 & Yes & $\mathrm{H}$ & Aluminum & 2 & 100 & 0.00 & 72.80 & \\
\hline 533 & Yes & $\mathrm{H}$ & Aluminum & 5 & 100 & 0.00 & 72.80 & 71.89 \\
\hline 534 & Yes & $\mathrm{H}$ & Aluminum & 5 & 100 & 0.00 & 72.80 & \\
\hline 535 & Yes & $\mathrm{H}$ & Aluminum & 5 & 100 & 14.23 & 70.58 & \\
\hline 536 & Yes & $\mathrm{H}$ & Aluminum & 5 & 100 & 11.38 & 71.38 & \\
\hline 537 & Yes & $\mathrm{H}$ & Teflon & 0.5 & 100 & 30.67 & 62.97 & 58.99 \\
\hline 538 & Yes & $\mathrm{H}$ & Teflon & 0.5 & 100 & 40.40 & 56.48 & \\
\hline 539 & Yes & $\mathrm{H}$ & Teflon & 0.5 & 100 & 39.86 & 56.87 & \\
\hline 540 & Yes & $\mathrm{H}$ & Teflon & 0.5 & 100 & 35.88 & 59.64 & \\
\hline 541 & Yes & $\mathrm{H}$ & Teflon & 1 & 100 & 38.08 & 58.13 & 58.64 \\
\hline 542 & Yes & $\mathrm{H}$ & Teflon & 1 & 100 & 38.41 & 57.90 & \\
\hline 543 & Yes & $\mathrm{H}$ & Teflon & 1 & 100 & 37.91 & 58.25 & \\
\hline 544 & Yes & $\mathrm{H}$ & Teflon & 1 & 100 & 34.93 & 60.28 & \\
\hline 545 & Yes & $\mathrm{H}$ & Teflon & 2 & 100 & 42.97 & 54.58 & 53.88 \\
\hline 546 & Yes & $\mathrm{H}$ & Teflon & 2 & 100 & 43.36 & 54.29 & \\
\hline 547 & Yes & $\mathrm{H}$ & Teflon & 2 & 100 & 43.93 & 53.86 & \\
\hline 548 & Yes & $\mathrm{H}$ & Teflon & 2 & 100 & 45.33 & 52.79 & \\
\hline 549 & Yes & $\mathrm{H}$ & Teflon & 5 & 100 & 37.36 & 58.63 & 54.76 \\
\hline 550 & Yes & $\mathrm{H}$ & Teflon & 5 & 100 & 46.12 & 52.18 & \\
\hline 551 & Yes & $\mathrm{H}$ & Teflon & 5 & 100 & 42.20 & 55.15 & \\
\hline 552 & Yes & $\mathrm{H}$ & Teflon & 5 & 100 & 44.92 & 53.10 & \\
\hline
\end{tabular}




\begin{tabular}{|c|c|c|c|c|c|c|c|c|}
\hline 553 & Yes & $\mathrm{H}$ & Heat/Air & 5 & 100 & 35.64 & 59.81 & 62.16 \\
\hline 554 & Yes & $\mathrm{H}$ & Heat/Air & 5 & 100 & 30.93 & 62.82 & \\
\hline 555 & Yes & $\mathrm{H}$ & Heat/Air & 5 & 100 & 28.03 & 64.51 & \\
\hline 556 & Yes & $\mathrm{H}$ & Heat/Air & 5 & 100 & 33.02 & 61.52 & \\
\hline 557 & Yes & $\mathrm{H}$ & Aluminum & 0.5 & 150 & 0.00 & 72.80 & 70.13 \\
\hline 558 & Yes & $\mathrm{H}$ & Aluminum & 0.5 & 150 & 22.08 & 67.56 & \\
\hline 559 & Yes & $\mathrm{H}$ & Aluminum & 0.5 & 150 & 11.43 & 71.36 & \\
\hline 560 & Yes & $\mathrm{H}$ & Aluminum & 0.5 & 150 & 19.27 & 68.78 & \\
\hline 561 & Yes & $\mathrm{H}$ & Aluminum & 1 & 150 & 12.60 & 71.06 & 70.37 \\
\hline 562 & Yes & $\mathrm{H}$ & Aluminum & 1 & 150 & 18.41 & 69.12 & \\
\hline 563 & Yes & $\mathrm{H}$ & Aluminum & 1 & 150 & 19.90 & 68.52 & \\
\hline 564 & Yes & $\mathrm{H}$ & Aluminum & 1 & 150 & 0.00 & 72.80 & \\
\hline 565 & Yes & $\mathrm{H}$ & Aluminum & 2 & 150 & 27.27 & 64.93 & 69.29 \\
\hline 566 & Yes & $\mathrm{H}$ & Aluminum & 2 & 150 & 20.89 & 68.09 & \\
\hline 567 & Yes & $\mathrm{H}$ & Aluminum & 2 & 150 & 0.00 & 72.80 & \\
\hline 568 & Yes & $\mathrm{H}$ & Aluminum & 2 & 150 & 11.61 & 71.32 & \\
\hline 569 & Yes & $\mathrm{H}$ & Aluminum & 5 & 150 & 29.90 & 63.43 & 68.78 \\
\hline 570 & Yes & $\mathrm{H}$ & Aluminum & 5 & 150 & 18.65 & 69.03 & \\
\hline 571 & Yes & $\mathrm{H}$ & Aluminum & 5 & 150 & 10.59 & 71.57 & \\
\hline 572 & Yes & $\mathrm{H}$ & Aluminum & 5 & 150 & 12.42 & 71.11 & \\
\hline 573 & Yes & $\mathrm{H}$ & Teflon & 0.5 & 150 & 41.74 & 55.49 & 55.58 \\
\hline 574 & Yes & $\mathrm{H}$ & Teflon & 0.5 & 150 & 39.55 & 57.09 & \\
\hline 575 & Yes & $\mathrm{H}$ & Teflon & 0.5 & 150 & 42.97 & 54.58 & \\
\hline 576 & Yes & $\mathrm{H}$ & Teflon & 0.5 & 150 & 42.17 & 55.18 & \\
\hline 577 & Yes & $\mathrm{H}$ & Teflon & 1 & 150 & 37.80 & 58.33 & 59.60 \\
\hline 578 & Yes & $\mathrm{H}$ & Teflon & 1 & 150 & 35.62 & 59.82 & \\
\hline 579 & Yes & $\mathrm{H}$ & Teflon & 1 & 150 & 38.92 & 57.54 & \\
\hline 580 & Yes & $\mathrm{H}$ & Teflon & 1 & 150 & 31.10 & 62.71 & \\
\hline 581 & Yes & $\mathrm{H}$ & Teflon & 2 & 150 & 35.90 & 59.63 & 61.57 \\
\hline 582 & Yes & $\mathrm{H}$ & Teflon & 2 & 150 & 28.37 & 64.32 & \\
\hline 583 & Yes & $\mathrm{H}$ & Teflon & 2 & 150 & 37.14 & 58.78 & \\
\hline 584 & Yes & $\mathrm{H}$ & Teflon & 2 & 150 & 29.68 & 63.56 & \\
\hline 585 & Yes & $\mathrm{H}$ & Teflon & 5 & 150 & 44.97 & 53.06 & 52.89 \\
\hline 586 & Yes & $\mathrm{H}$ & Teflon & 5 & 150 & 48.52 & 50.30 & \\
\hline 587 & Yes & $\mathrm{H}$ & Teflon & 5 & 150 & 41.05 & 56.00 & \\
\hline 588 & Yes & $\mathrm{H}$ & Teflon & 5 & 150 & 46.07 & 52.21 & \\
\hline 589 & Yes & $\mathrm{H}$ & Heat/Air & 5 & 150 & 29.65 & 63.58 & 61.88 \\
\hline 590 & Yes & $\mathrm{H}$ & Heat/Air & 5 & 150 & 33.04 & 61.51 & \\
\hline 591 & Yes & $\mathrm{H}$ & Heat/Air & 5 & 150 & 36.14 & 59.47 & \\
\hline 592 & Yes & $\mathrm{H}$ & Heat/Air & 5 & 150 & 30.71 & 62.95 & \\
\hline
\end{tabular}




\section{Appendix B.2}

Additional Figures Of Yellow-Poplar Surface Energy Results From Exposure To High Energy, Low Energy, And Heat/Air Environments At Different Temperatures. 


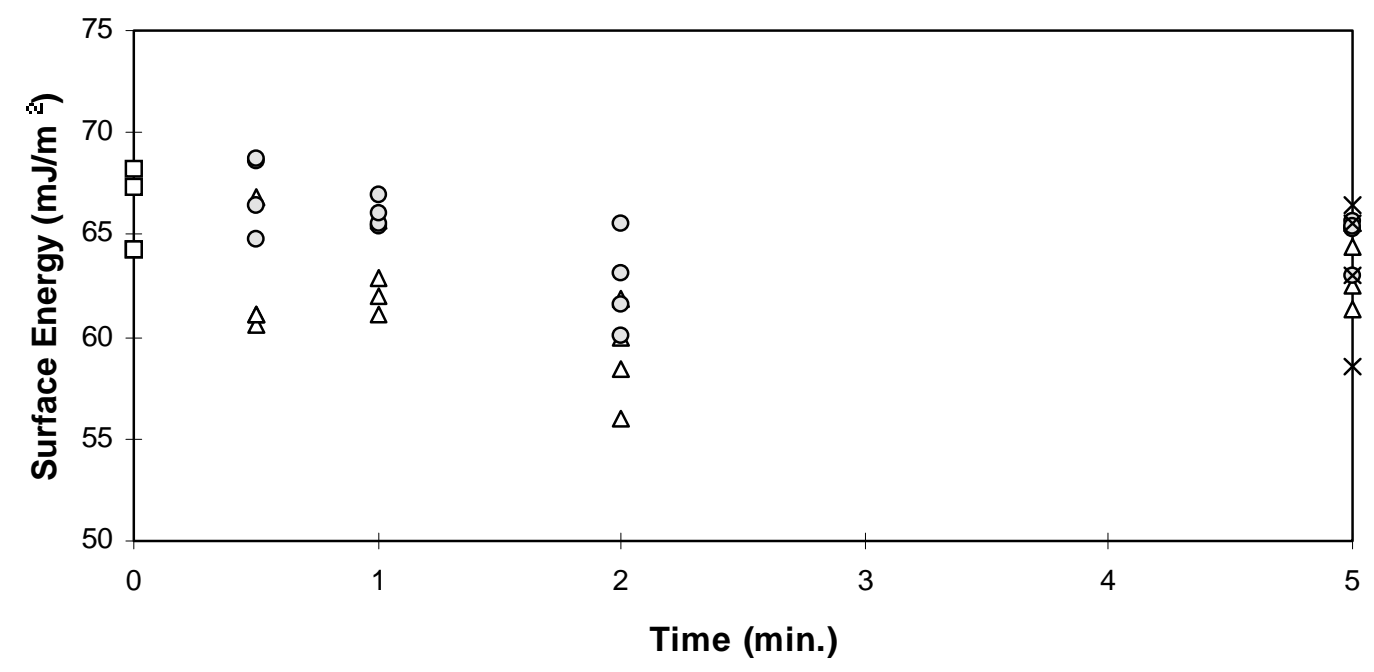

$\square$ Control $\triangle$ Aluminum $\circ$ Teflon $\times$ Heat/Air

Figure B.2.1. Surface energy results of unextracted yellow-poplar sapwood exposed to an environment of high energy (aluminum), low energy (teflon), and heat/air at $50{ }^{\circ} \mathrm{C}$.

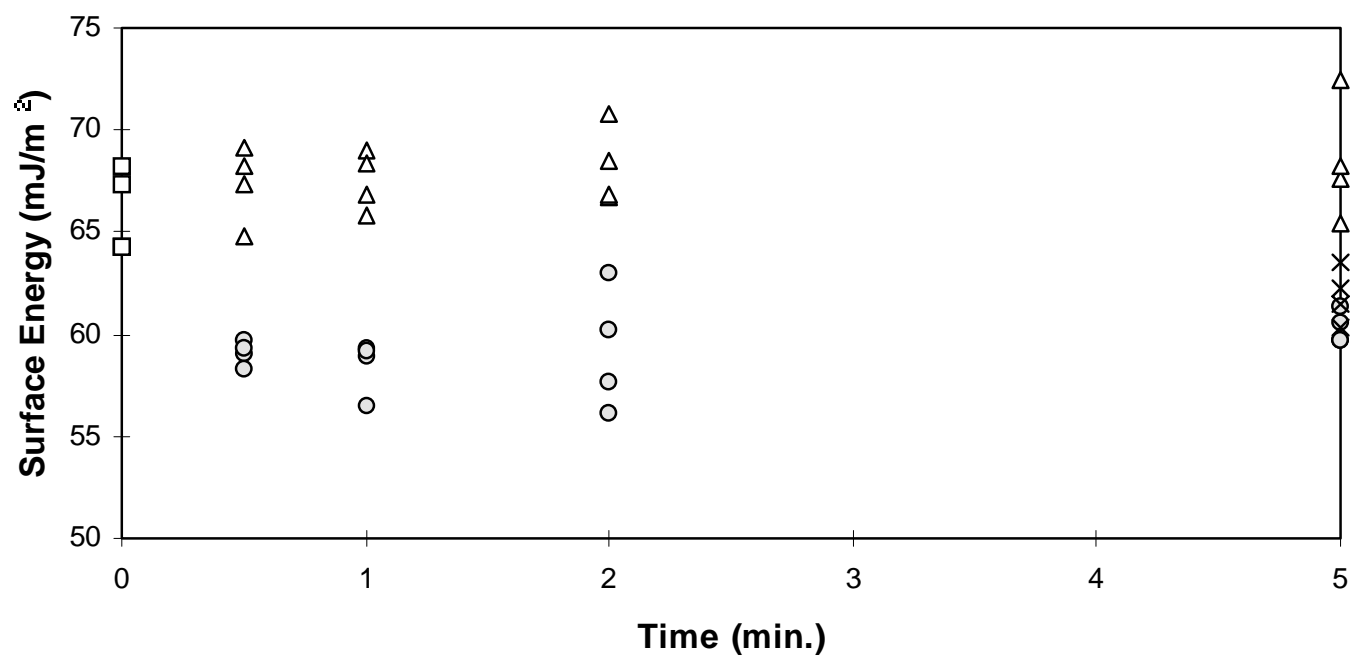

$\square$ Control $\triangle$ Aluminum $\circ$ Teflon $\times$ Heat/Air

Figure B.2.2. Surface energy results of unextracted yellow-poplar sapwood exposed to an environment of high energy (aluminum), low energy (teflon), and heat/air at $75^{\circ} \mathrm{C}$. 


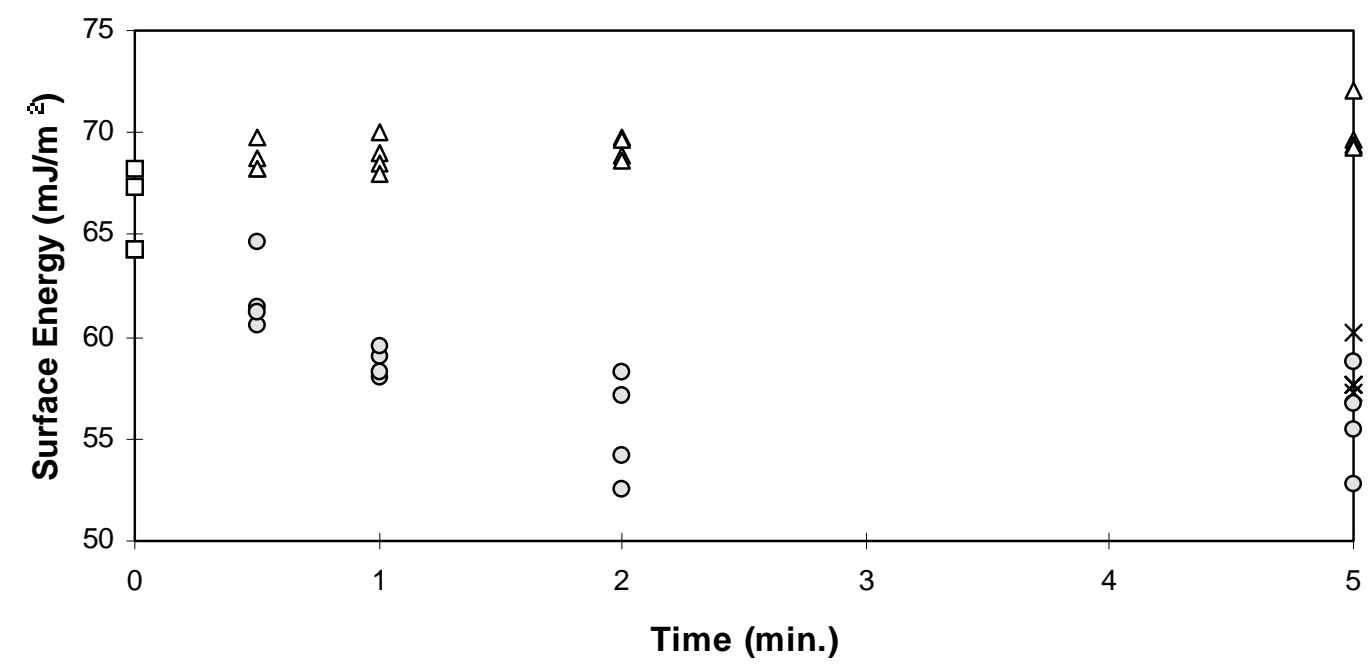

$\square$ Control $\triangle$ Aluminum $\circ$ Teflon $\times$ Heat/Air

Figure B.2.3. Surface energy results of unextracted yellow-poplar sapwood exposed to an environment of high energy (aluminum), low energy (teflon), and heat/air at $100{ }^{\circ} \mathrm{C}$.

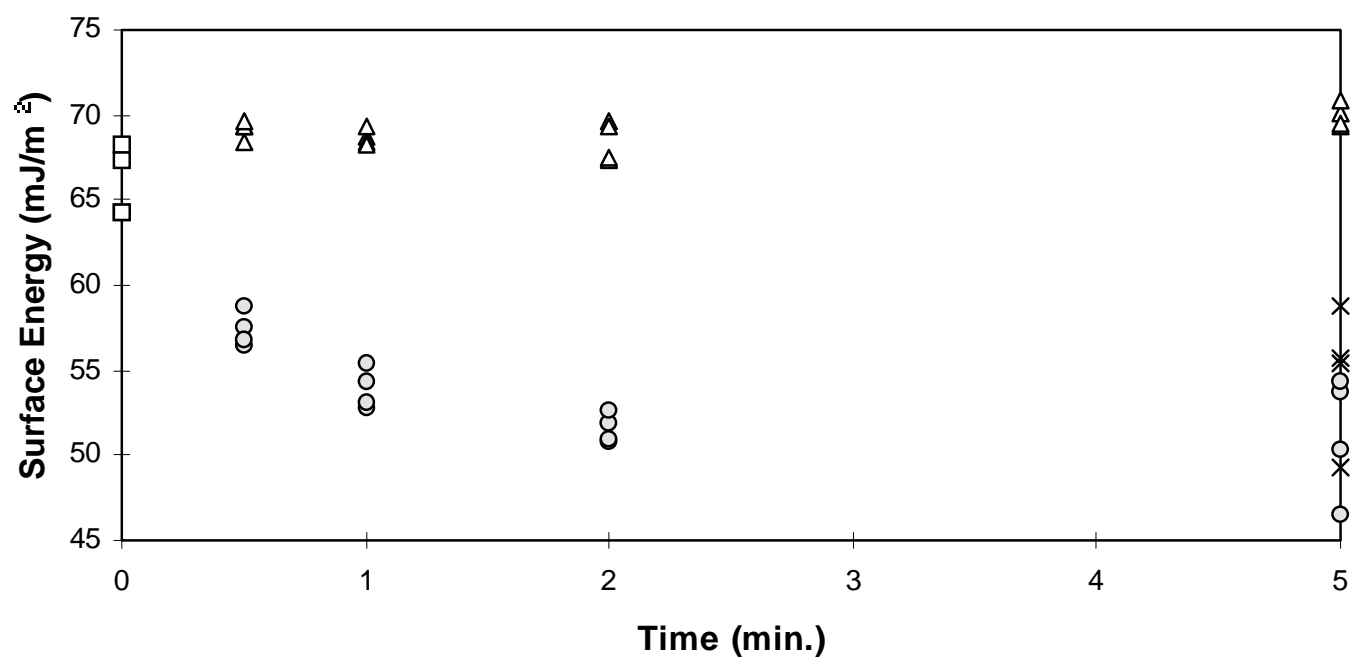

${ }_{\square}$ Control $\triangle$ Aluminum $\circ$ Teflon $\times$ Heat/Air

Figure B.2.4. Surface energy results of unextracted yellow-poplar sapwood exposed to an environment of high energy (aluminum), low energy (teflon), and heat/air at $150{ }^{\circ} \mathrm{C}$. 


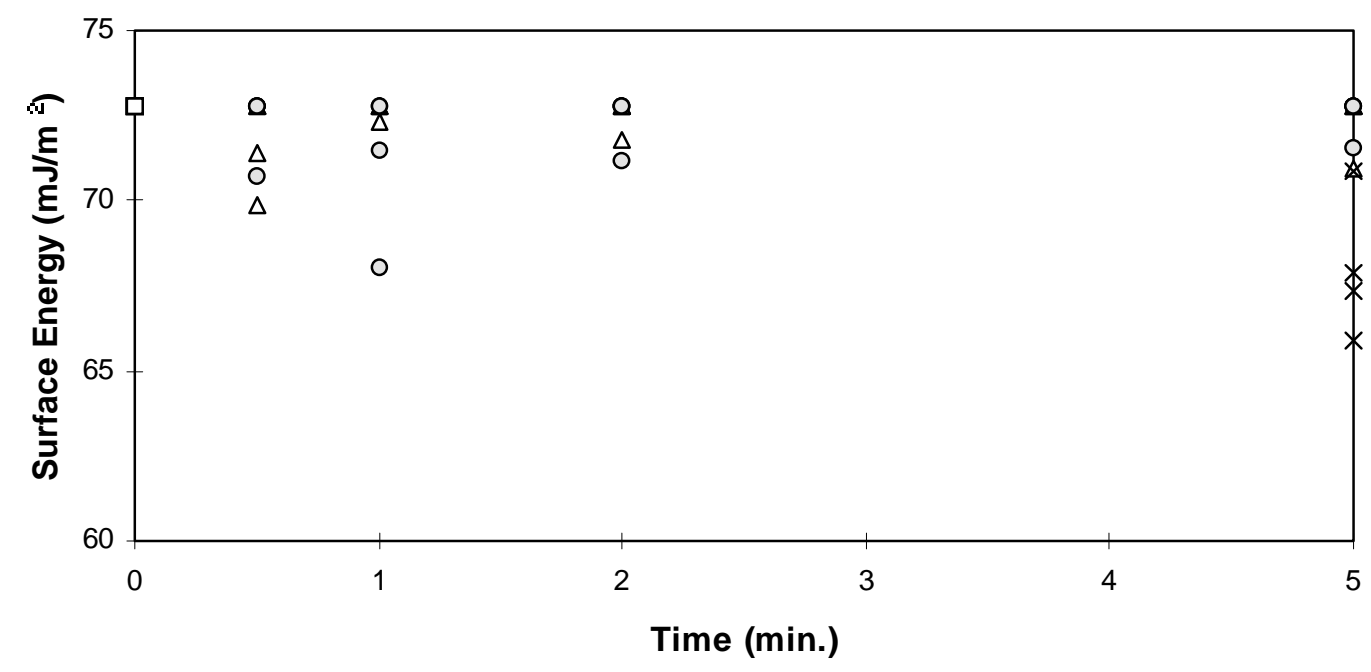

$\square$ Control $\triangle$ Aluminum $\circ$ Teflon $\times$ Heat/Air

Figure B.2.5. Surface energy results of extracted yellow-poplar sapwood exposed to an environment of high energy (aluminum), low energy (teflon), and heat/air at $50{ }^{\circ} \mathrm{C}$.

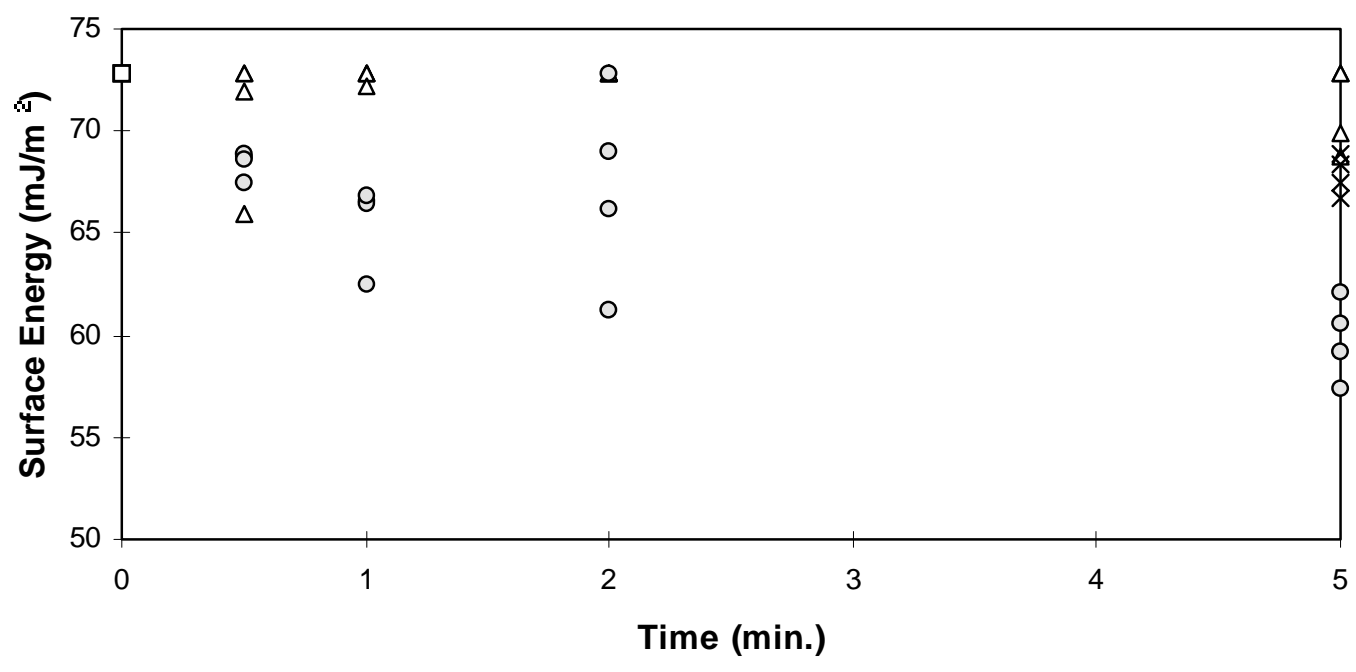

${ }_{\square}$ Control $\triangle$ Aluminum $\circ$ Teflon $\times$ Heat/Air

Figure B.2.6. Surface energy results of extracted yellow-poplar sapwood exposed to an environment of high energy (aluminum), low energy (teflon), and heat/air at $75^{\circ} \mathrm{C}$. 


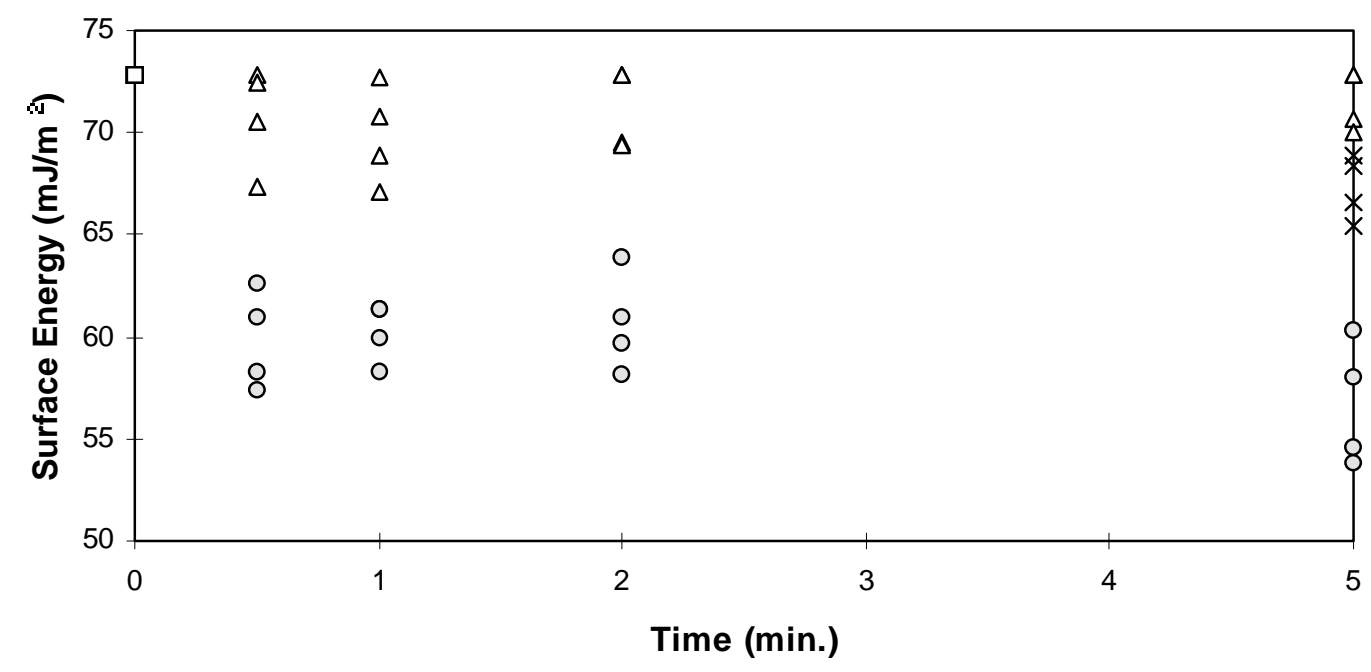

$\square$ Control $\triangle$ Aluminum $\circ$ Teflon $\times$ Heat/Air

Figure B.2.7. Surface energy results of extracted yellow-poplar sapwood exposed to an environment of high energy (aluminum), low energy (teflon), and heat/air at $100{ }^{\circ} \mathrm{C}$.

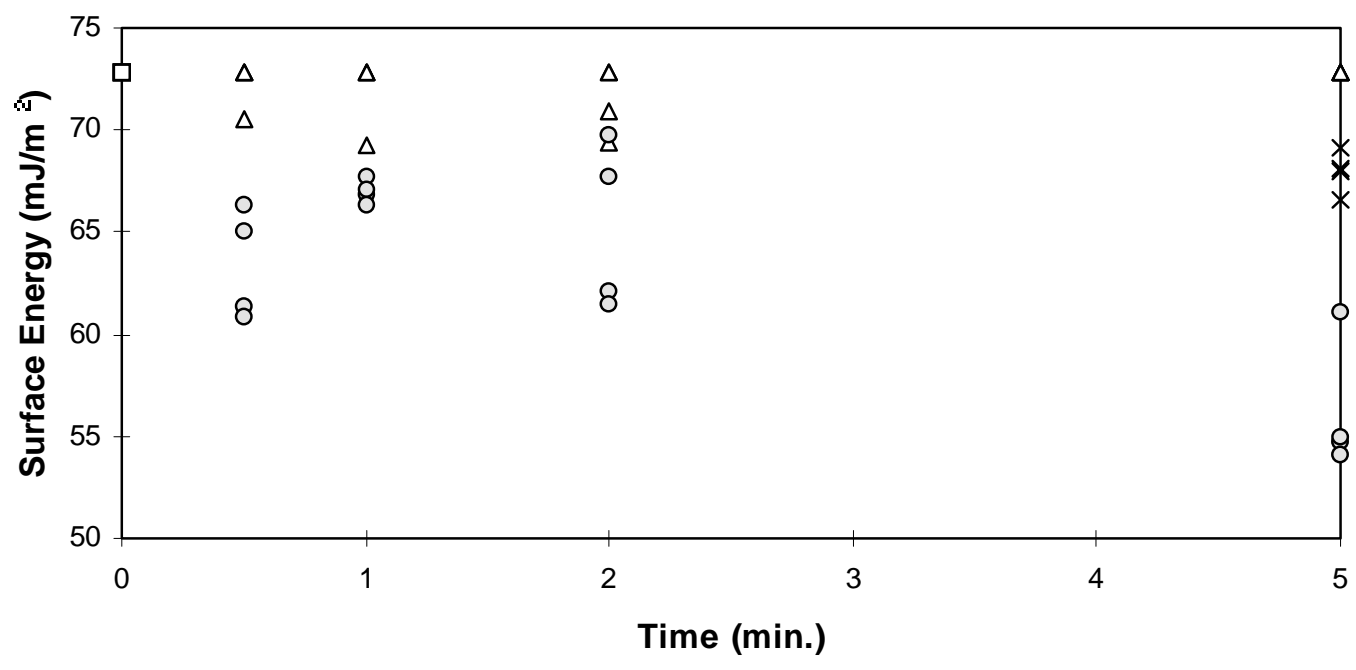

$\square$ Control $\triangle$ Aluminum $\circ$ Teflon $\times$ Heat/Air

Figure B.2.8. Surface energy results of extracted yellow-poplar sapwood exposed to an environment of high energy (aluminum), low energy (teflon), and heat/air at $150{ }^{\circ} \mathrm{C}$. 


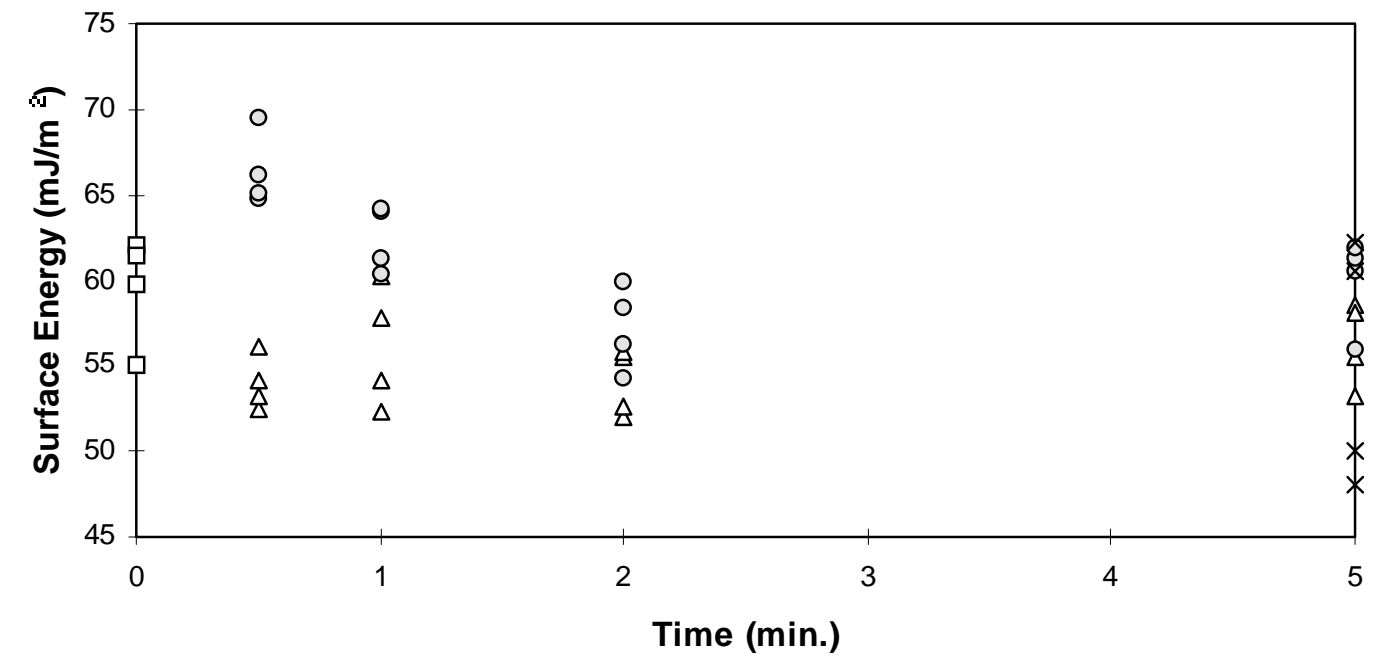

$\square$ Control $\triangle$ Aluminum $\circ$ Teflon $\times$ Heat/Air

Figure B.2.9. Surface energy results of unextracted yellow-poplar heartwood exposed to an environment of high energy (aluminum), low energy (teflon), and heat/air at $50{ }^{\circ} \mathrm{C}$.

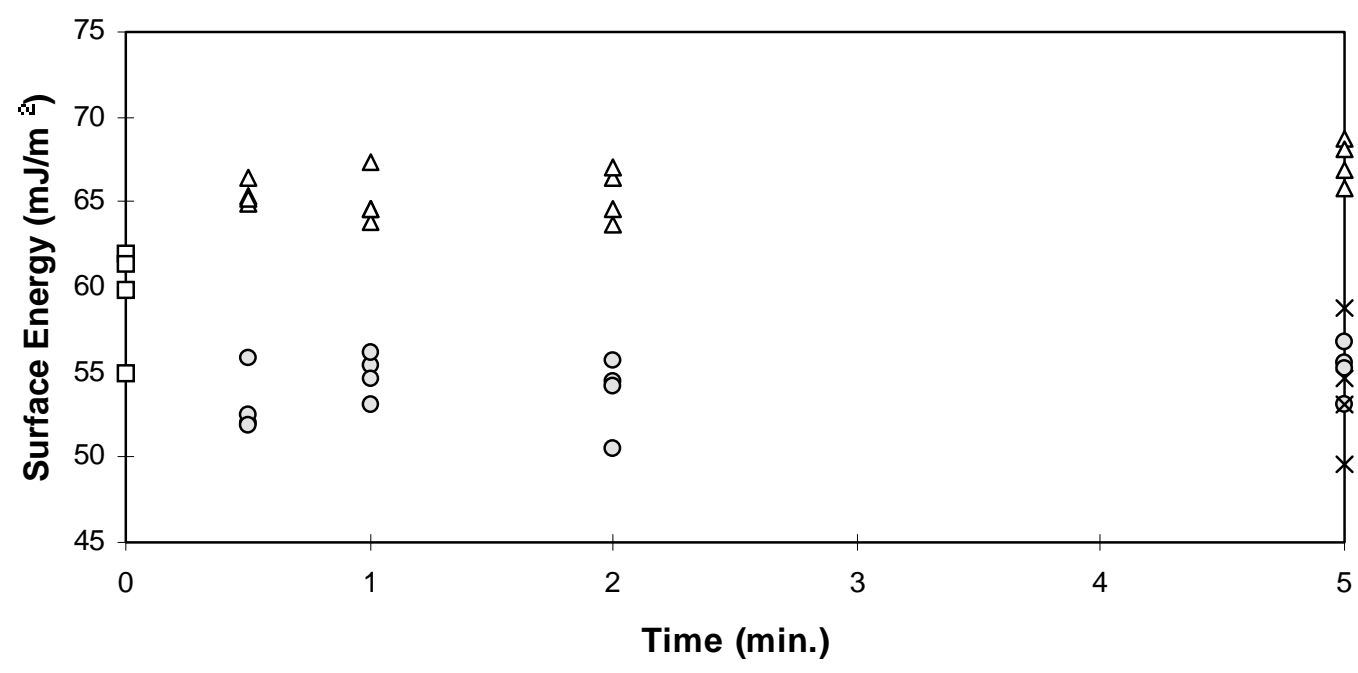

$\square$ Control $\triangle$ Aluminum $\circ$ Teflon $\times$ Heat/Air

Figure B.2.10. Surface energy results of unextracted yellow-poplar heartwood exposed to an environment of high energy (aluminum), low energy (teflon), and heat/air at $75^{\circ} \mathrm{C}$. 


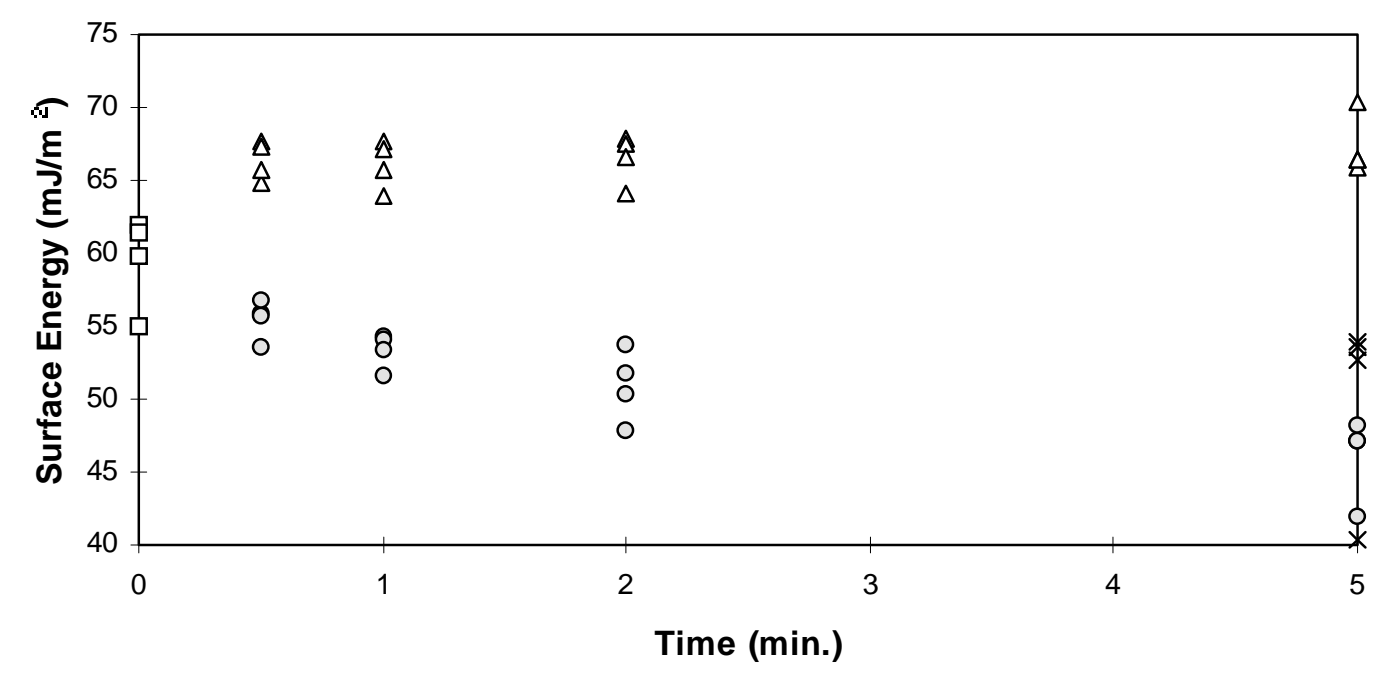

$\square$ Control $\triangle$ Aluminum $\circ$ Teflon $\times$ Heat/Air

Figure B.2.11. Surface energy results of unextracted yellow-poplar heartwood exposed to an environment of high energy (aluminum), low energy (teflon), and heat/air at $100{ }^{\circ} \mathrm{C}$.

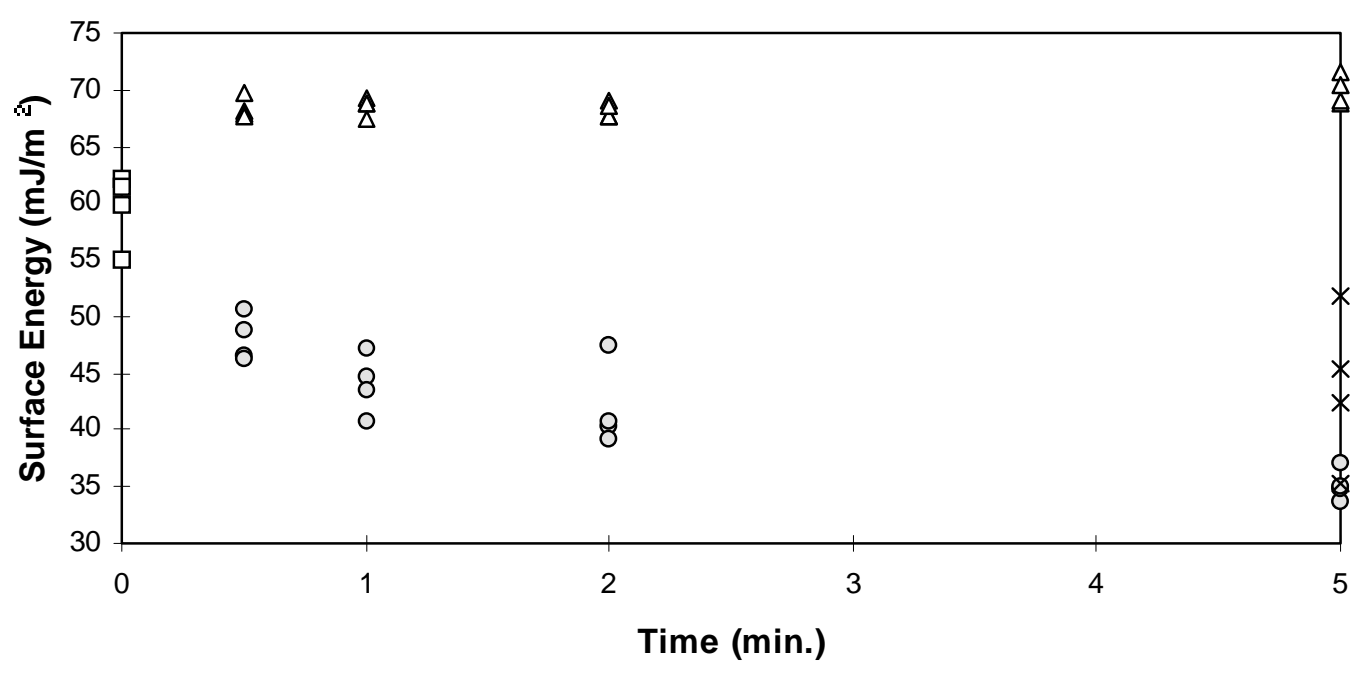

$\square$ Control $\triangle$ Aluminum $\circ$ Teflon $\times$ Heat/Air

Figure B.2.12. Surface energy results of unextracted yellow-poplar heartwood exposed to an environment of high energy (aluminum), low energy (teflon), and heat/air at $150{ }^{\circ} \mathrm{C}$. 


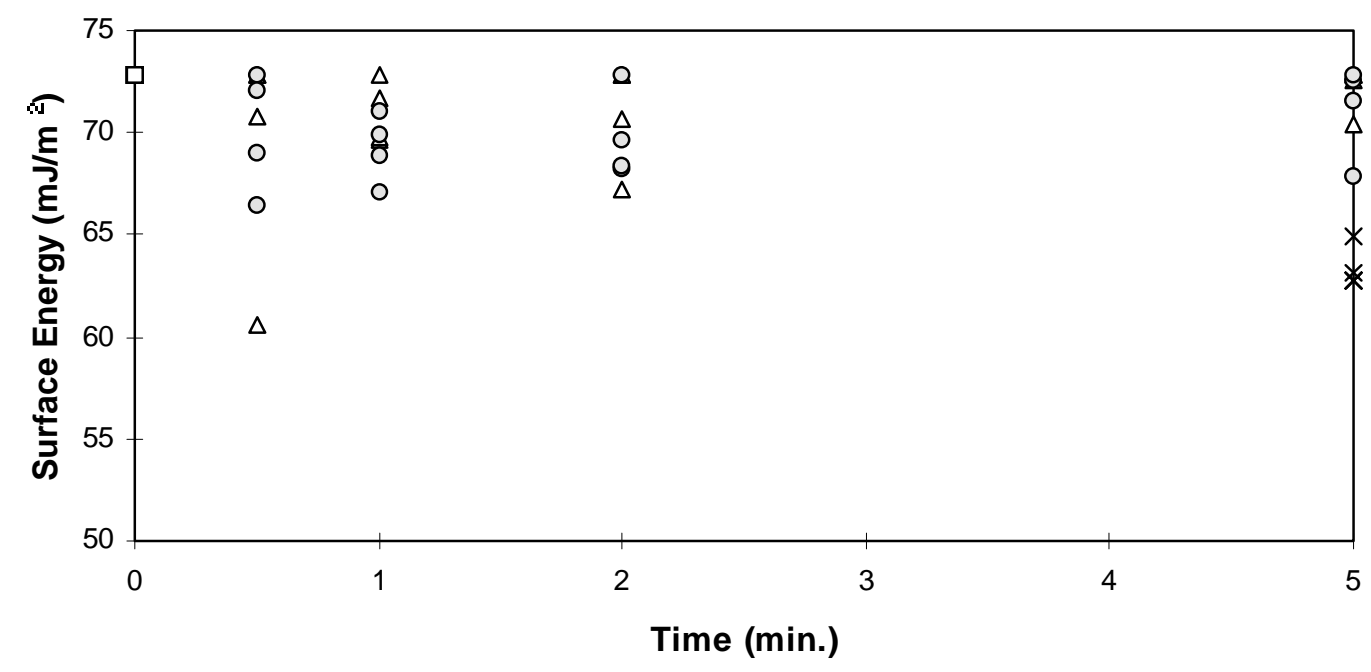

$\square$ Control $\triangle$ Aluminum $\circ$ Teflon $\times$ Heat/Air

Figure B.2.13. Surface energy results of extracted yellow-poplar heartwood exposed to an environment of high energy (aluminum), low energy (teflon), and heat/air at $50{ }^{\circ} \mathrm{C}$.

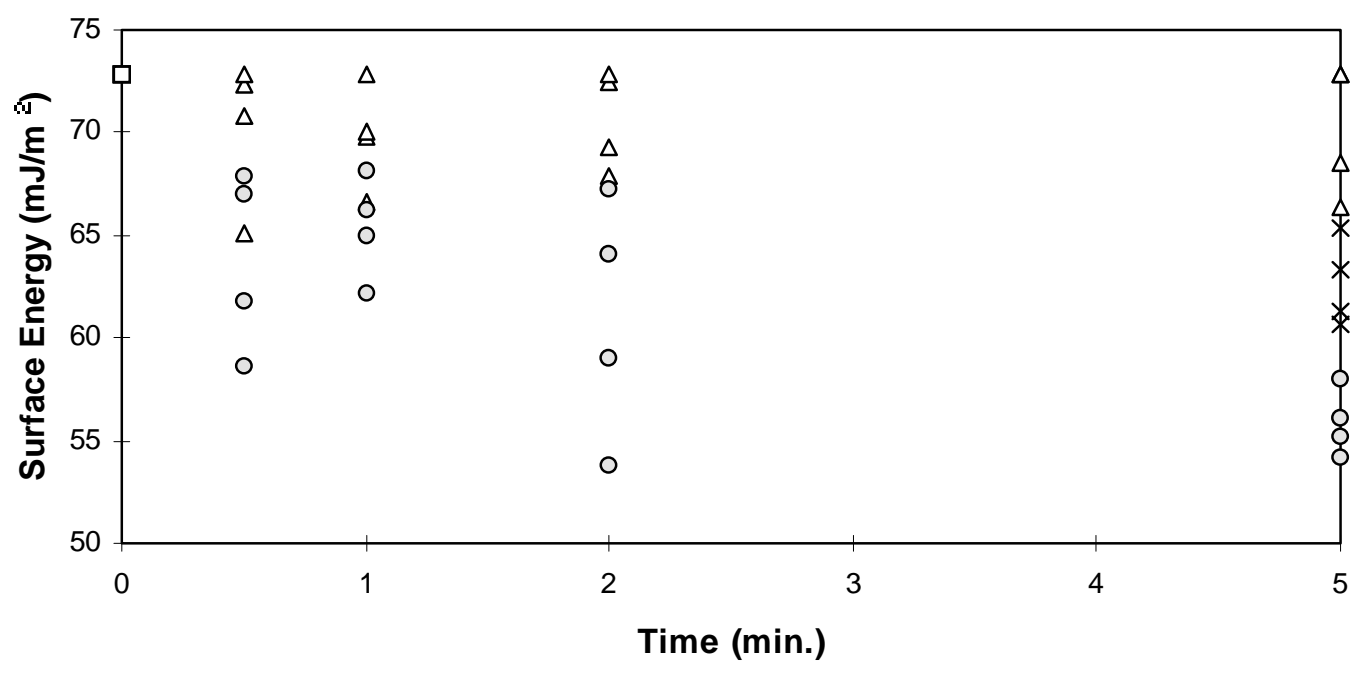

$\square$ Control $\triangle$ Aluminum $\circ$ Teflon $\times$ Heat/Air

Figure B.2.14. Surface energy results of extracted yellow-poplar heartwood exposed to an environment of high energy (aluminum), low energy (teflon), and heat/air at $75^{\circ} \mathrm{C}$. 


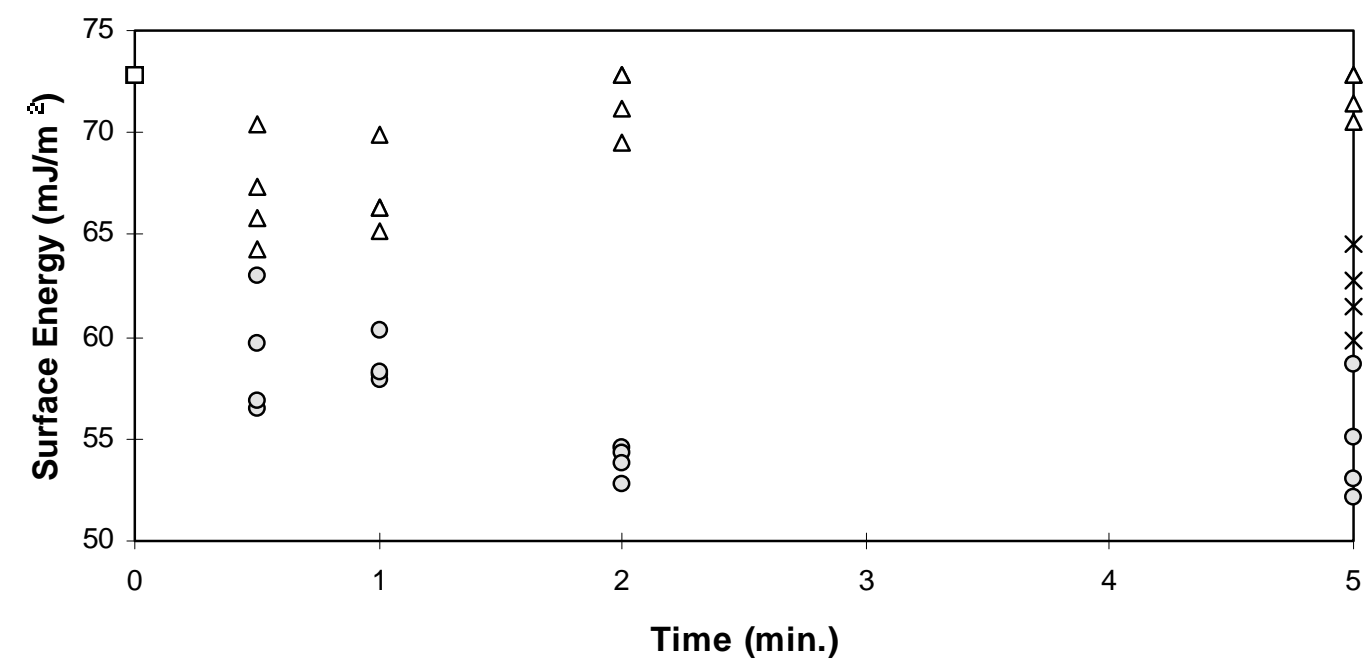

$\square$ Control $\triangle$ Aluminum $\circ$ Teflon $\times$ Heat/Air

Figure B.2.15. Surface energy results of extracted yellow-poplar heartwood exposed to an environment of high energy (aluminum), low energy (teflon), and heat/air at $100{ }^{\circ} \mathrm{C}$.

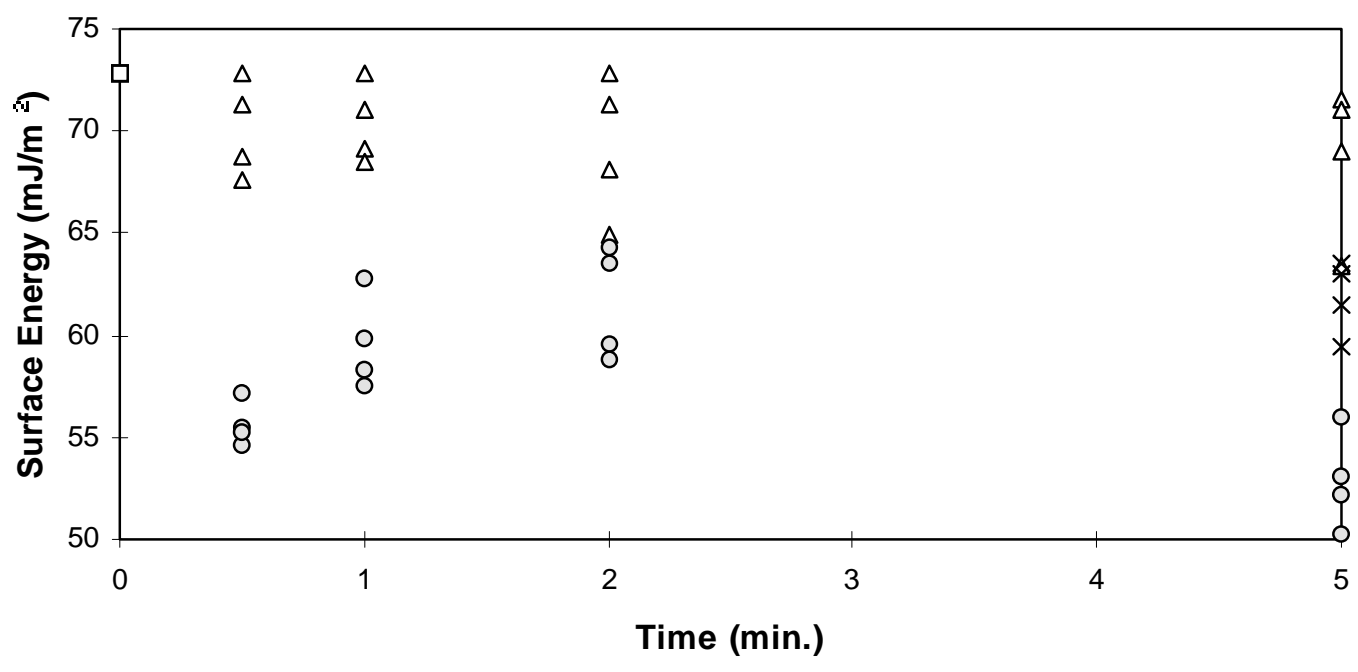

$\square$ Control $\triangle$ Aluminum $\circ$ Teflon $\times$ Heat/Air

Figure B.2.16. Surface energy results of extracted yellow-poplar heartwood exposed to an environment of high energy (aluminum), low energy (teflon), and heat/air at $150{ }^{\circ} \mathrm{C}$. 


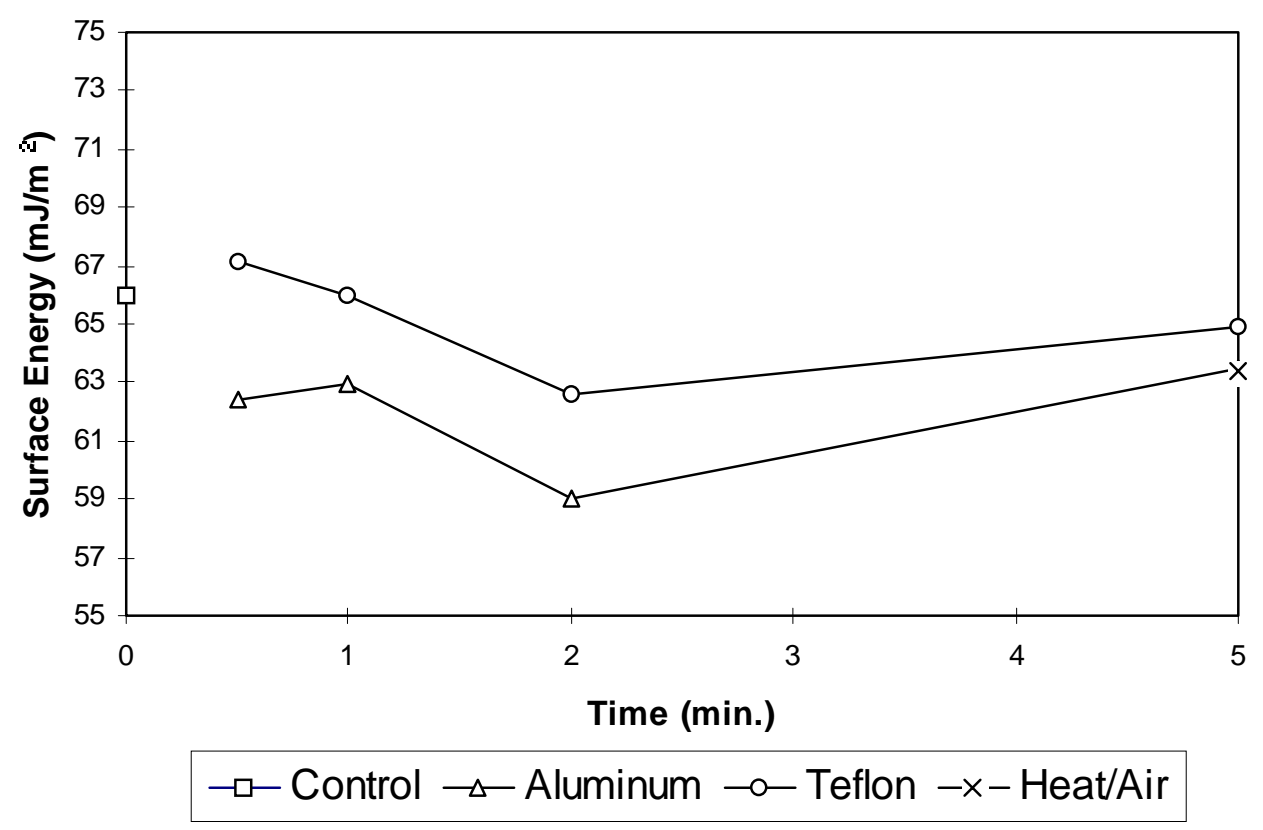

Figure B.2.17. Average surface energy of unextracted yellow-poplar sapwood exposed to an environment of high energy (aluminum), low energy (teflon), and heat/air at $50{ }^{\circ} \mathrm{C}$.

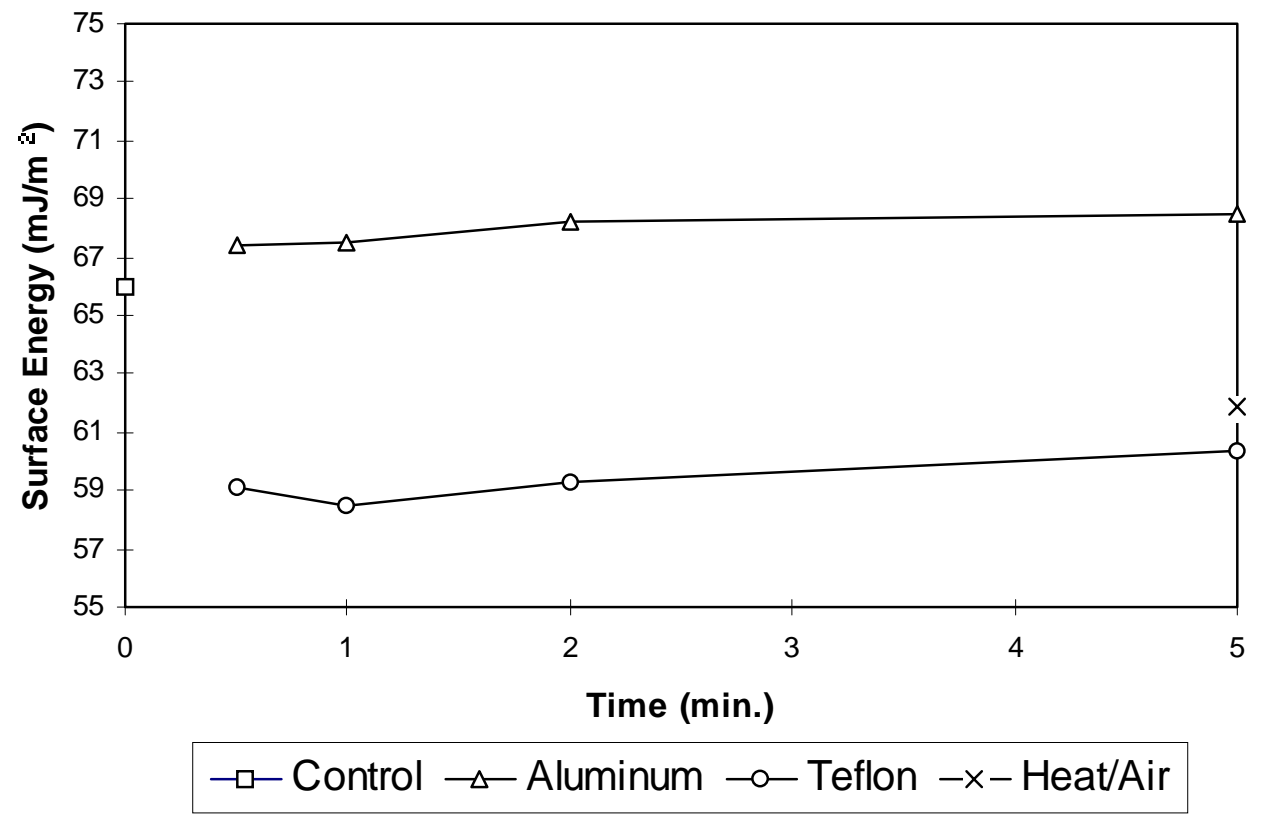

Figure B.2.18. Average surface energy of unextracted yellow-poplar sapwood exposed to an environment of high energy (aluminum), low energy (teflon), and heat/air at $75^{\circ} \mathrm{C}$. 


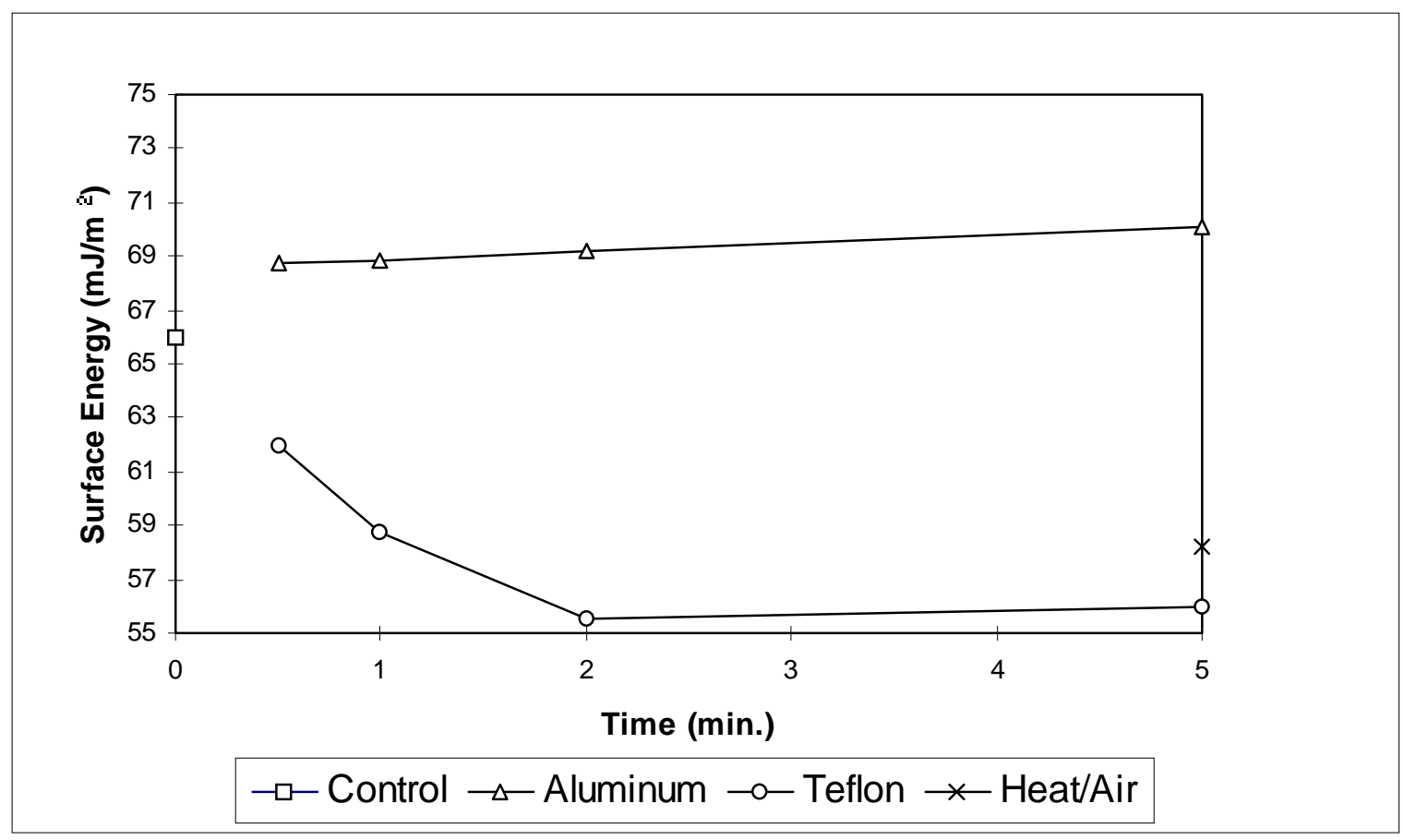

Figure B.2.19. Average surface energy of unextracted yellow-poplar sapwood exposed to an environment of high energy (aluminum), low energy (teflon), and heat/air at $100{ }^{\circ} \mathrm{C}$.

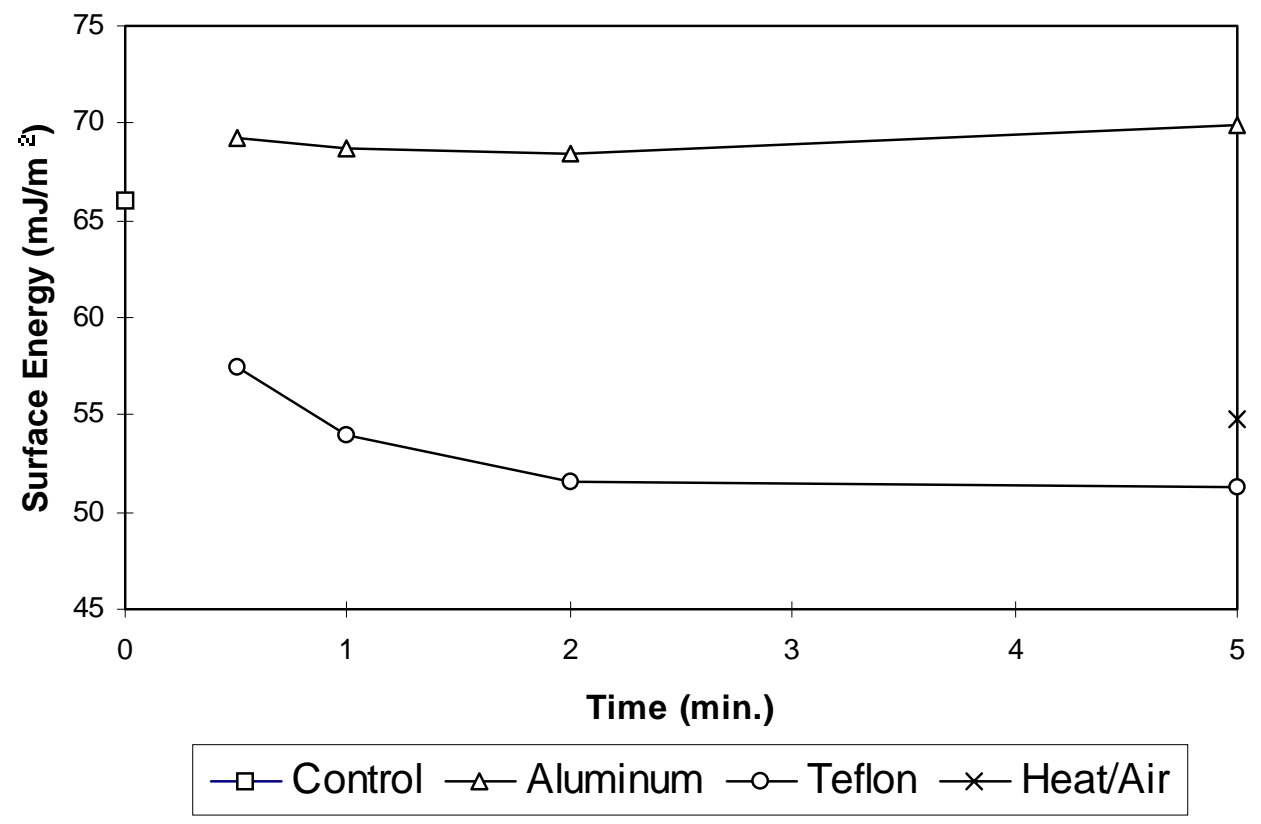

Figure B.2.20. Average surface energy of unextracted yellow-poplar sapwood exposed to an environment of high energy (aluminum), low energy (teflon), and heat/air at $150{ }^{\circ} \mathrm{C}$. 


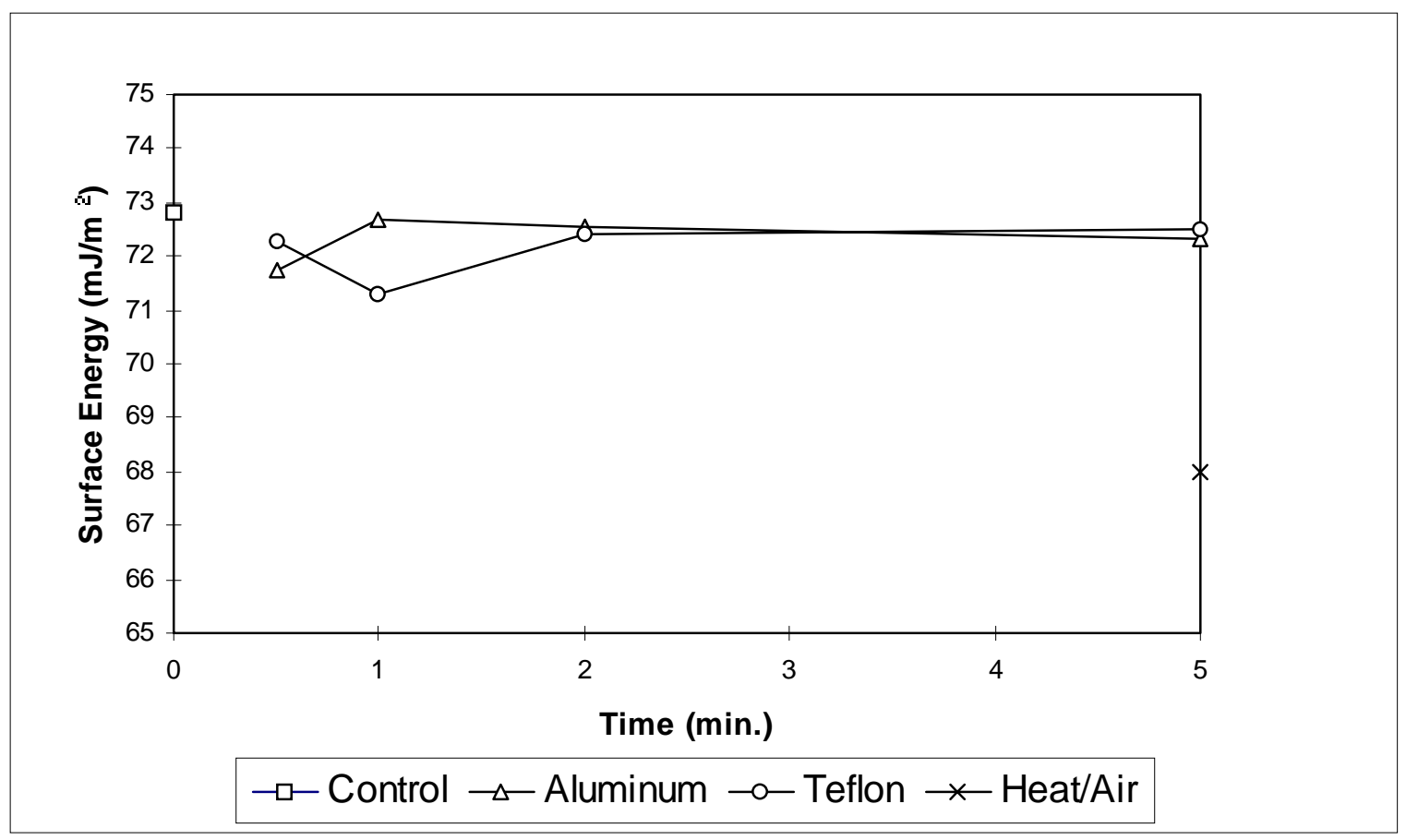

Figure B.2.21. Average surface energy of extracted yellow-poplar sapwood exposed to an environment of high energy (aluminum), low energy (teflon), and heat/air at $50{ }^{\circ} \mathrm{C}$.

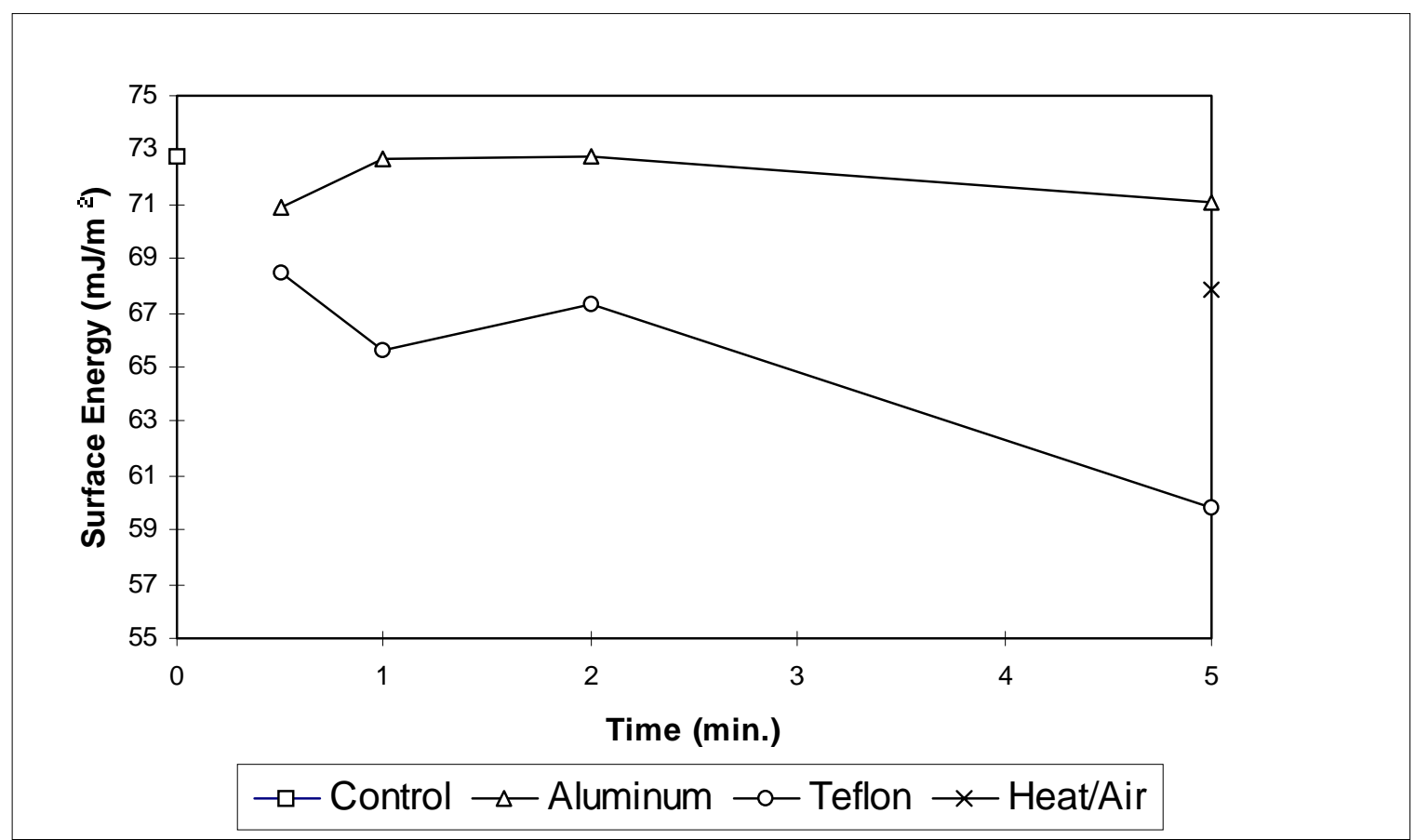

Figure B.2.22. Average surface energy of extracted yellow-poplar sapwood exposed to an environment of high energy (aluminum), low energy (teflon), and heat/air at $75{ }^{\circ} \mathrm{C}$. 


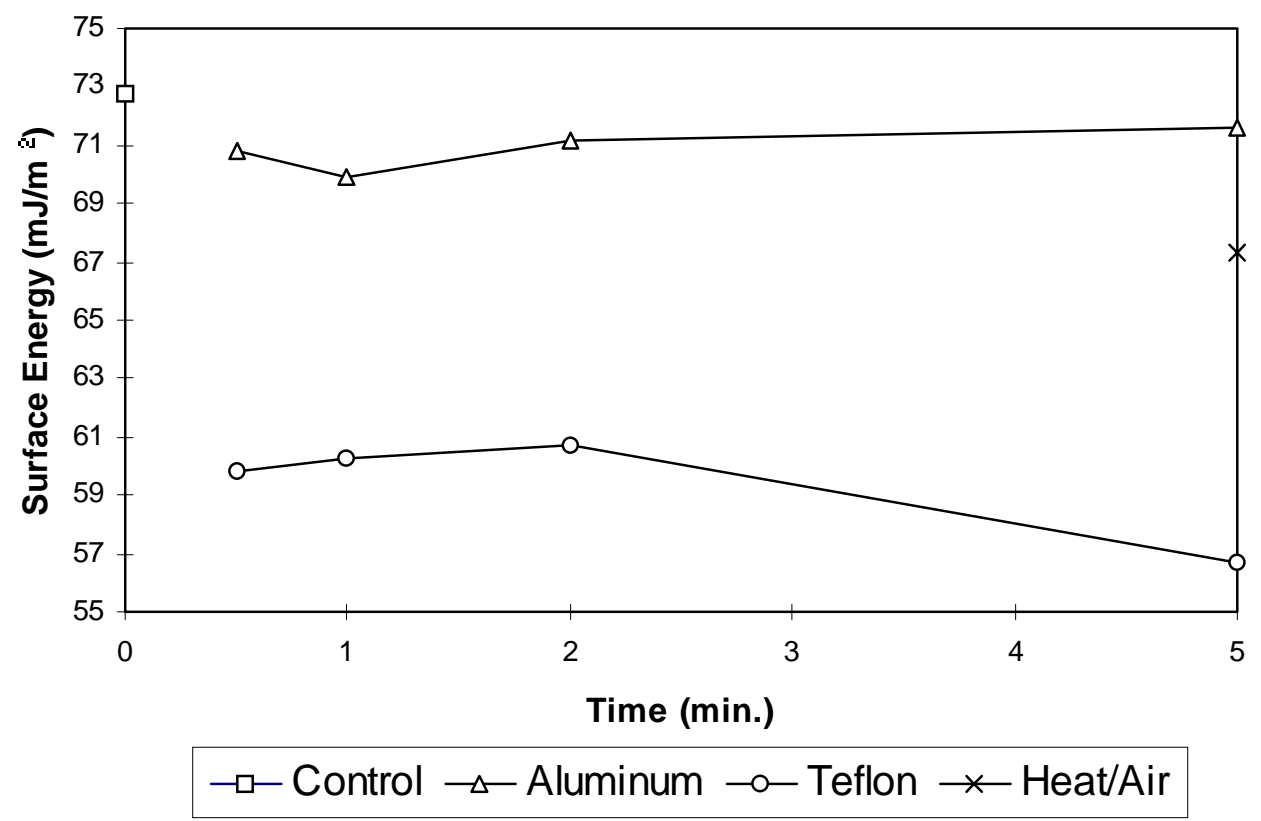

Figure B.2.23. Average surface energy of extracted yellow-poplar sapwood exposed to an environment of high energy (aluminum), low energy (teflon), and heat/air at $100^{\circ} \mathrm{C}$.

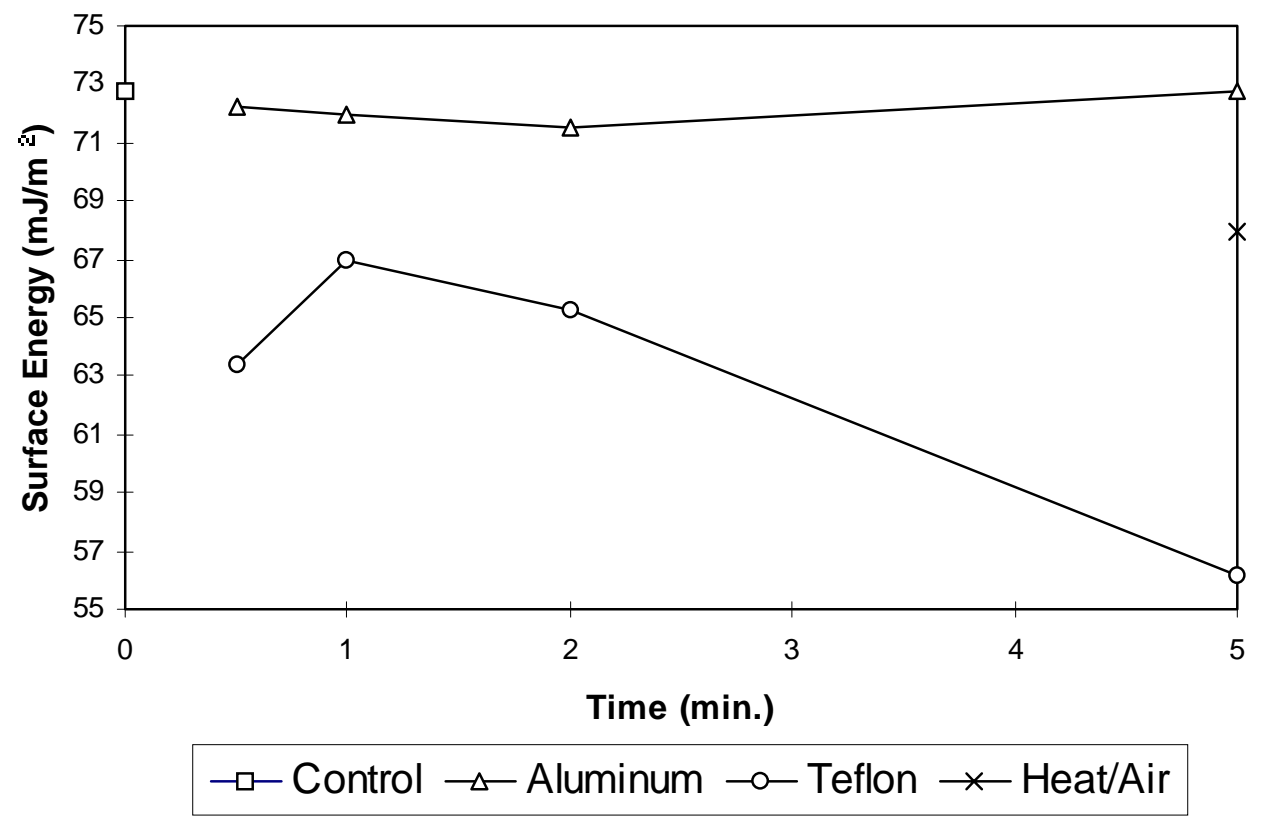

Figure B.2.24. Average surface energy of extracted yellow-poplar sapwood exposed to an environment of high energy (aluminum), low energy (teflon), and heat/air at $150^{\circ} \mathrm{C}$. 


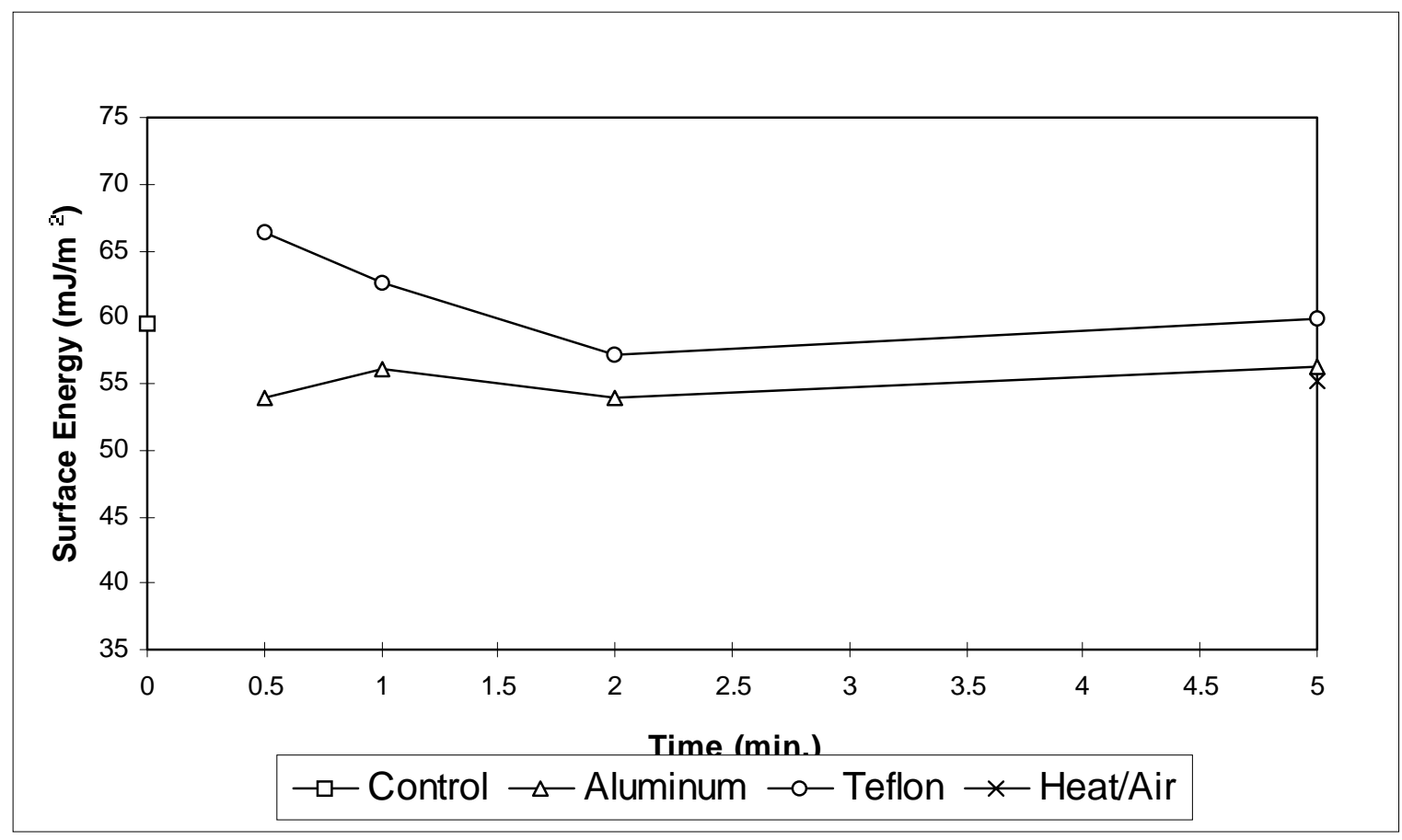

Figure B.2.25. Average surface energy of unextracted yellow-poplar heartwood exposed to an environment of high energy (aluminum), low energy (teflon), and heat/air at $50{ }^{\circ} \mathrm{C}$.

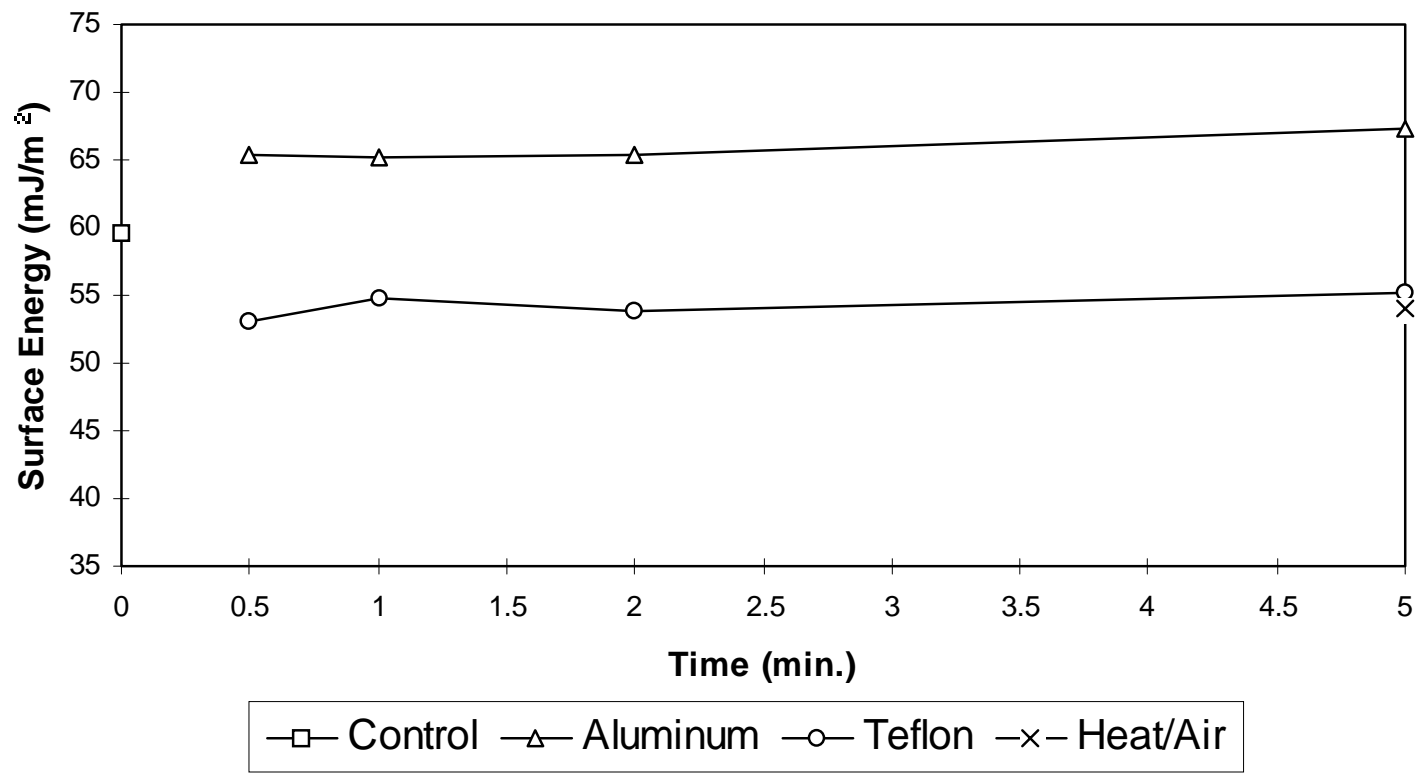

Figure B.2.26. Average surface energy of unextracted yellow-poplar heartwood exposed to an environment of high energy (aluminum), low energy (teflon), and heat/air at $75{ }^{\circ} \mathrm{C}$. 


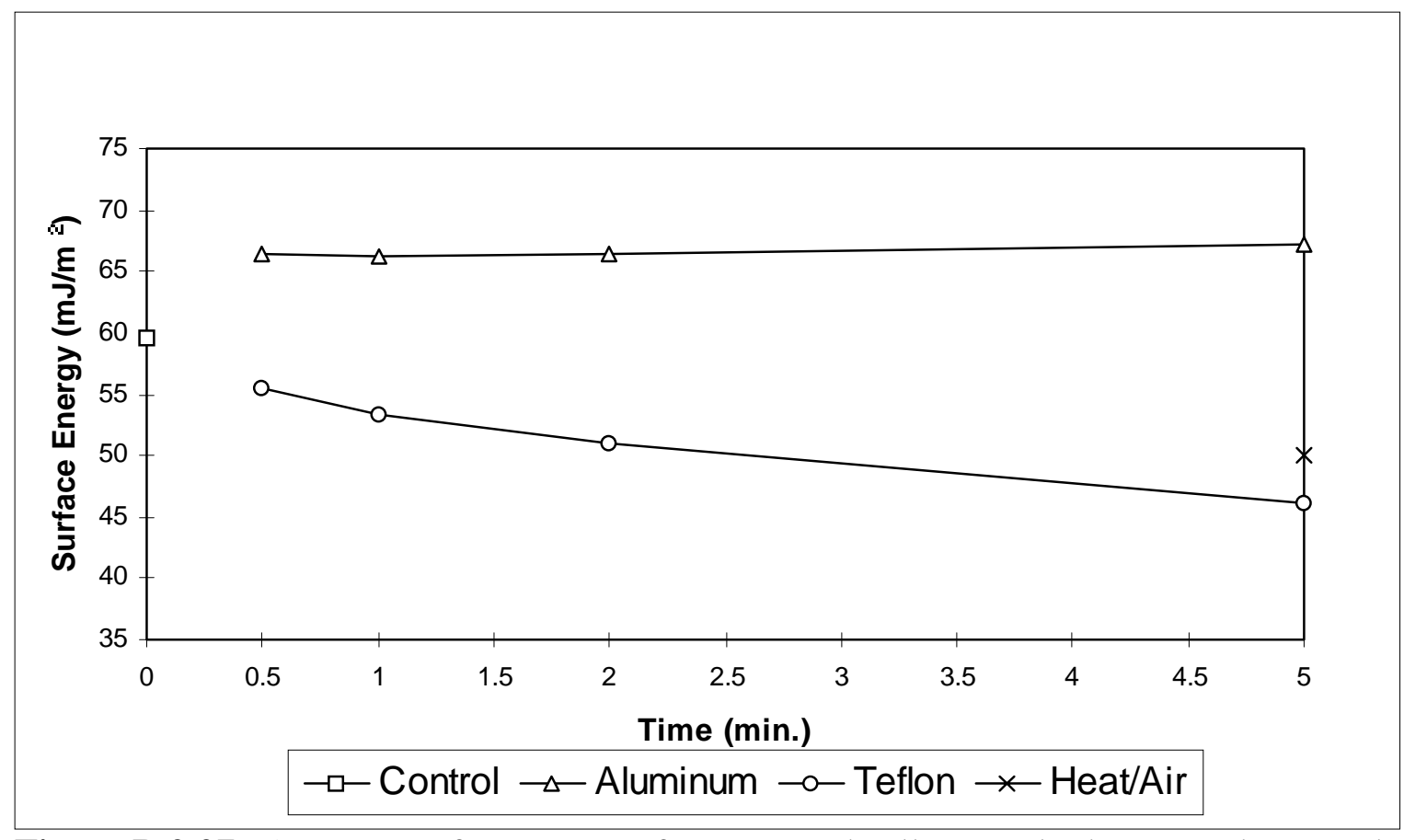

Figure B.2.27. Average surface energy of unextracted yellow-poplar heartwood exposed to an environment of high energy (aluminum), low energy (teflon), and heat/air at $100{ }^{\circ} \mathrm{C}$.

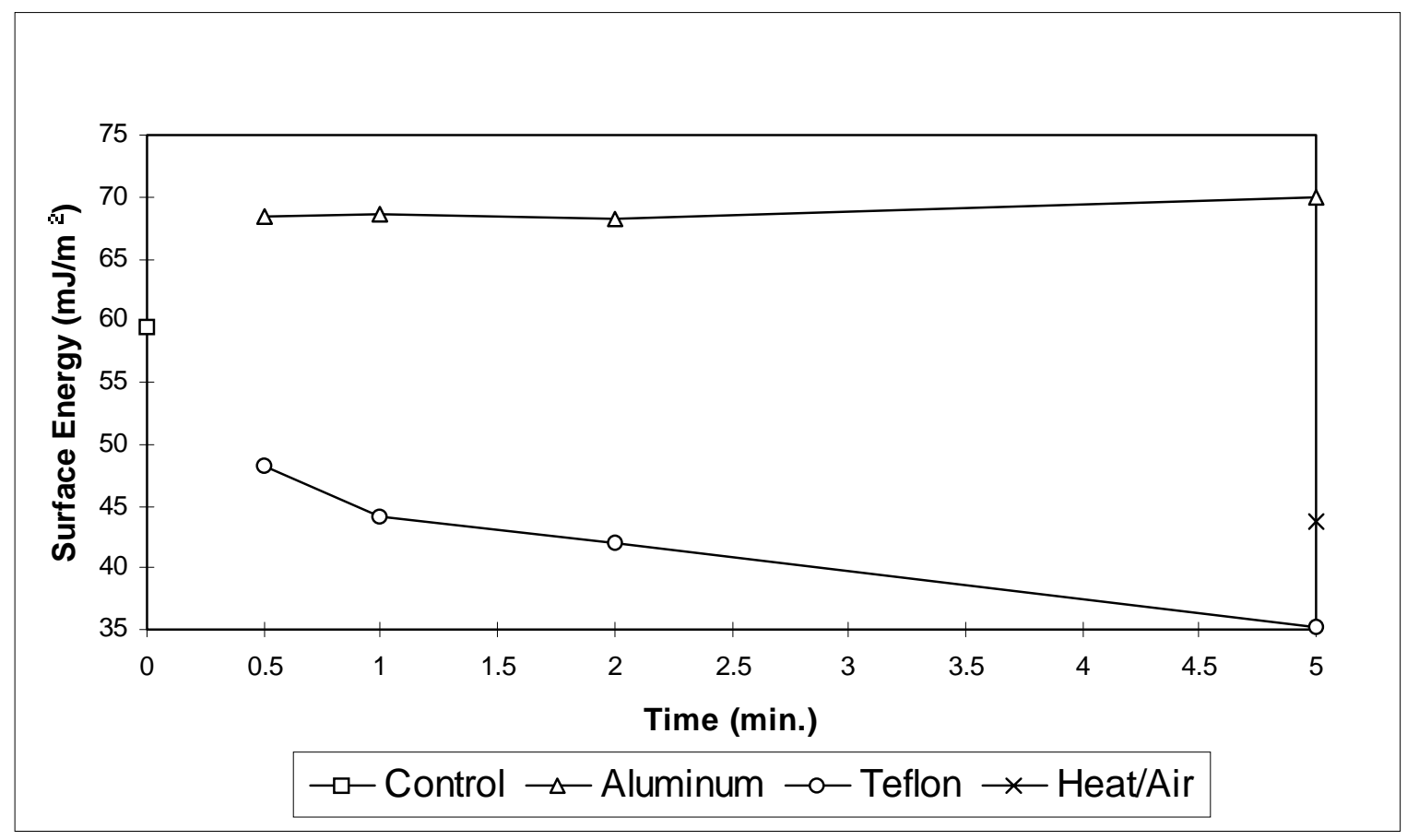

Figure B.2.28. Average surface energy of unextracted yellow-poplar heartwood exposed to an environment of high energy (aluminum), low energy (teflon), and heat/air at $150{ }^{\circ} \mathrm{C}$. 


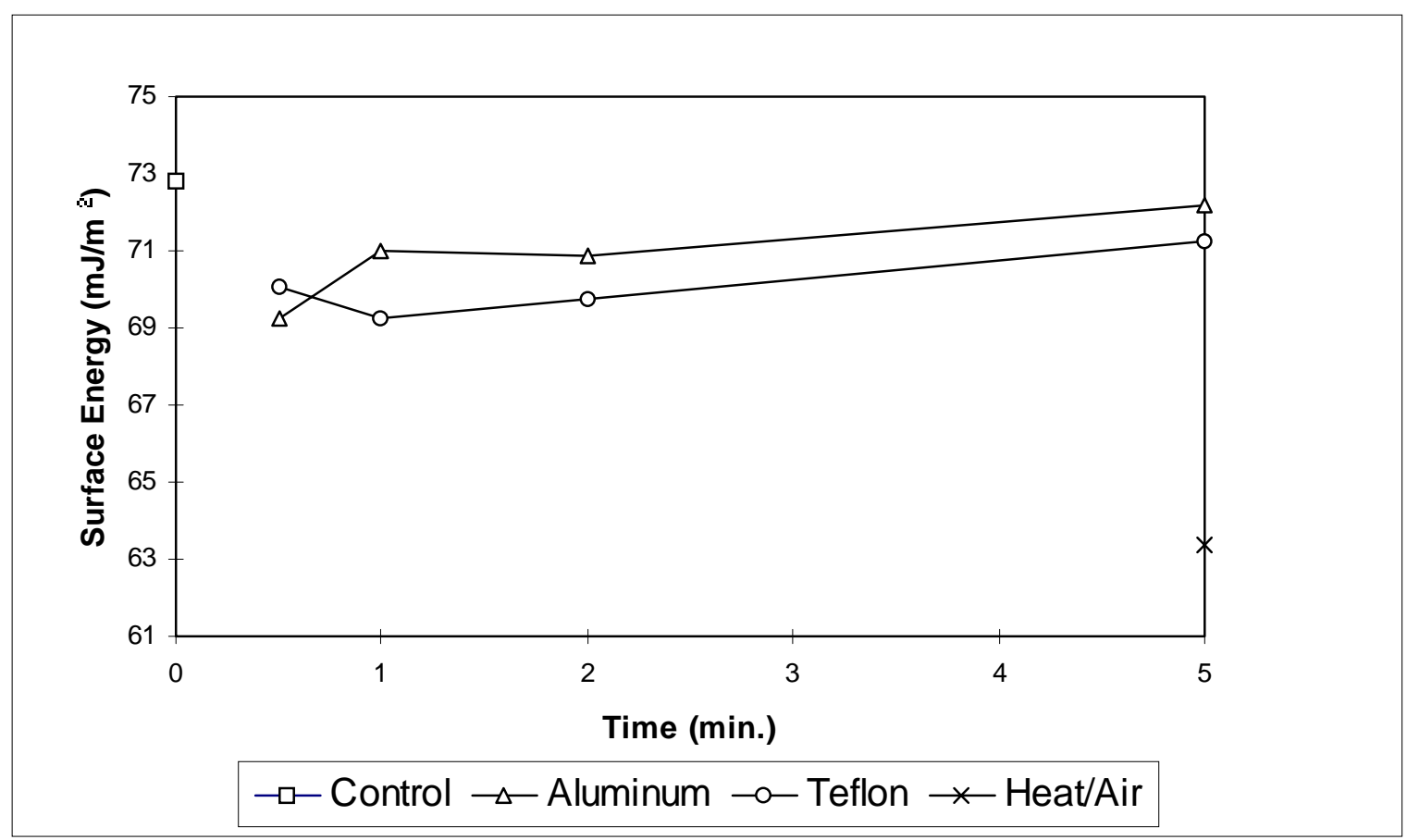

Figure B.2.29. Average surface energy of extracted yellow-poplar heartwood exposed to an environment of high energy (aluminum), low energy (teflon), and heat/air at $50{ }^{\circ} \mathrm{C}$.

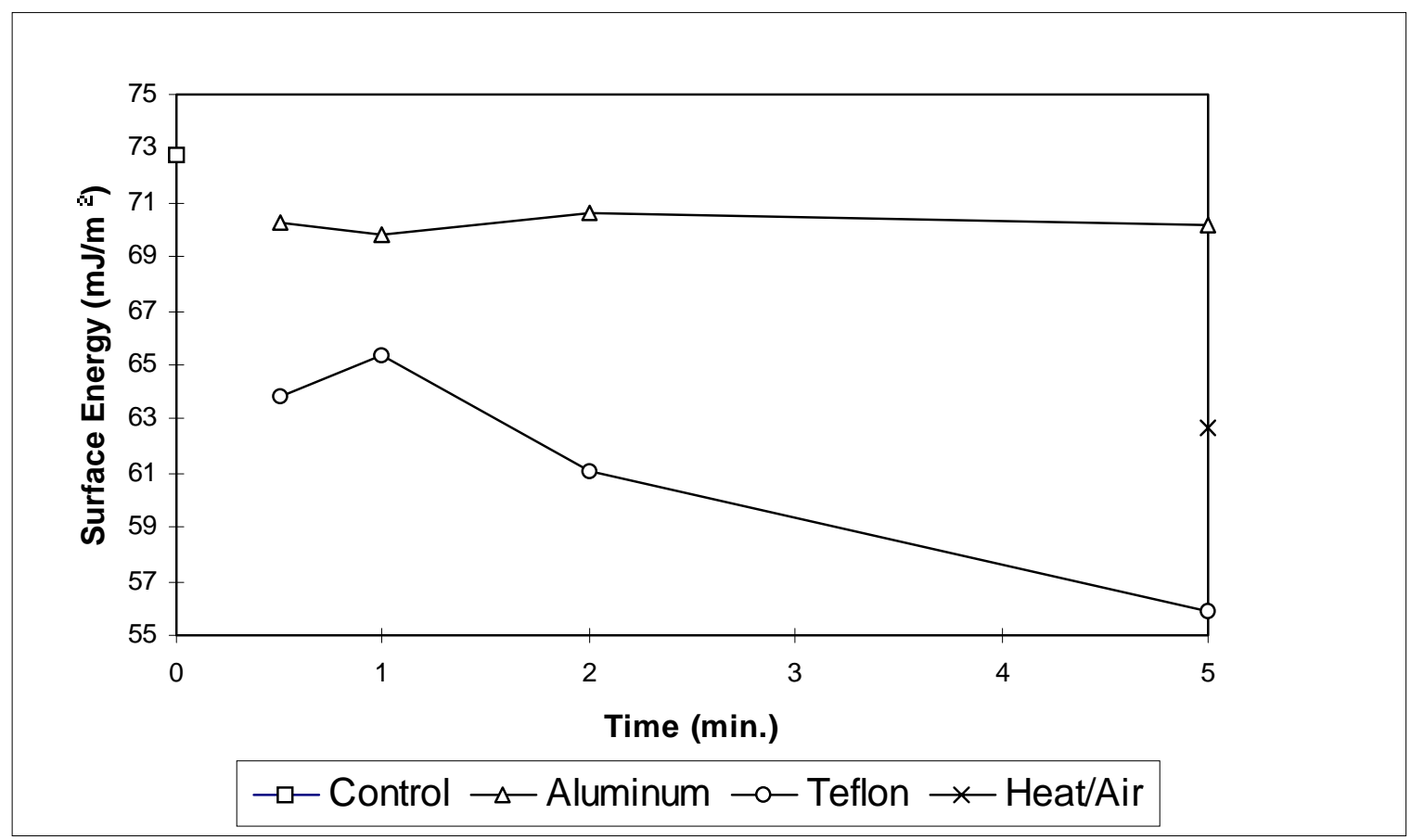

Figure B.2.30. Average surface energy of extracted yellow-poplar heartwood exposed to an environment of high energy (aluminum), low energy (teflon), and heat/air at $75{ }^{\circ} \mathrm{C}$. 


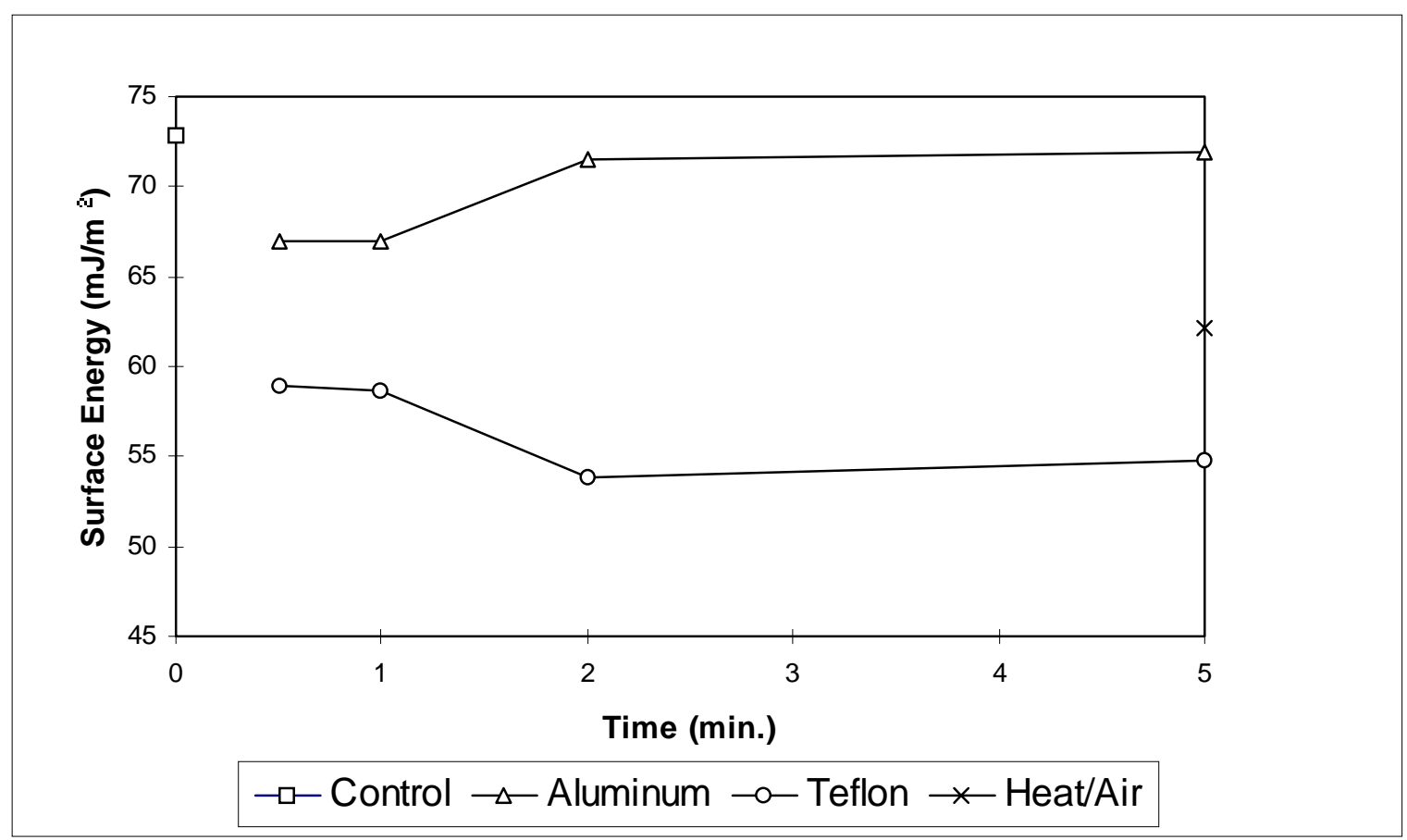

Figure B.2.31. Average surface energy of extracted yellow-poplar heartwood exposed to an environment of high energy (aluminum), low energy (teflon), and heat/air at $100{ }^{\circ} \mathrm{C}$.

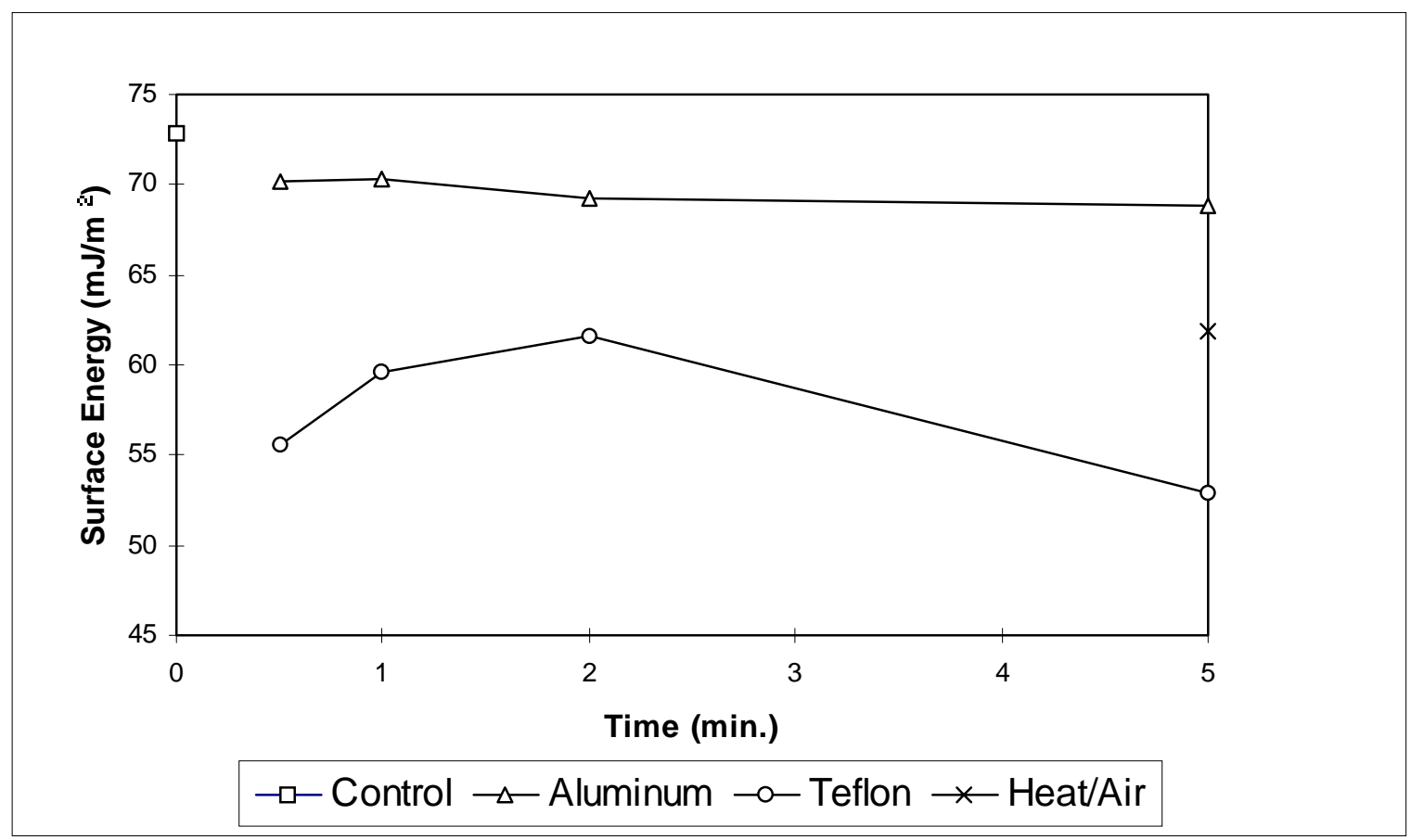

Figure B.2.32. Average surface energy of extracted yellow-poplar heartwood exposed to an environment of high energy (aluminum), low energy (teflon), and heat/air at $150{ }^{\circ} \mathrm{C}$. 


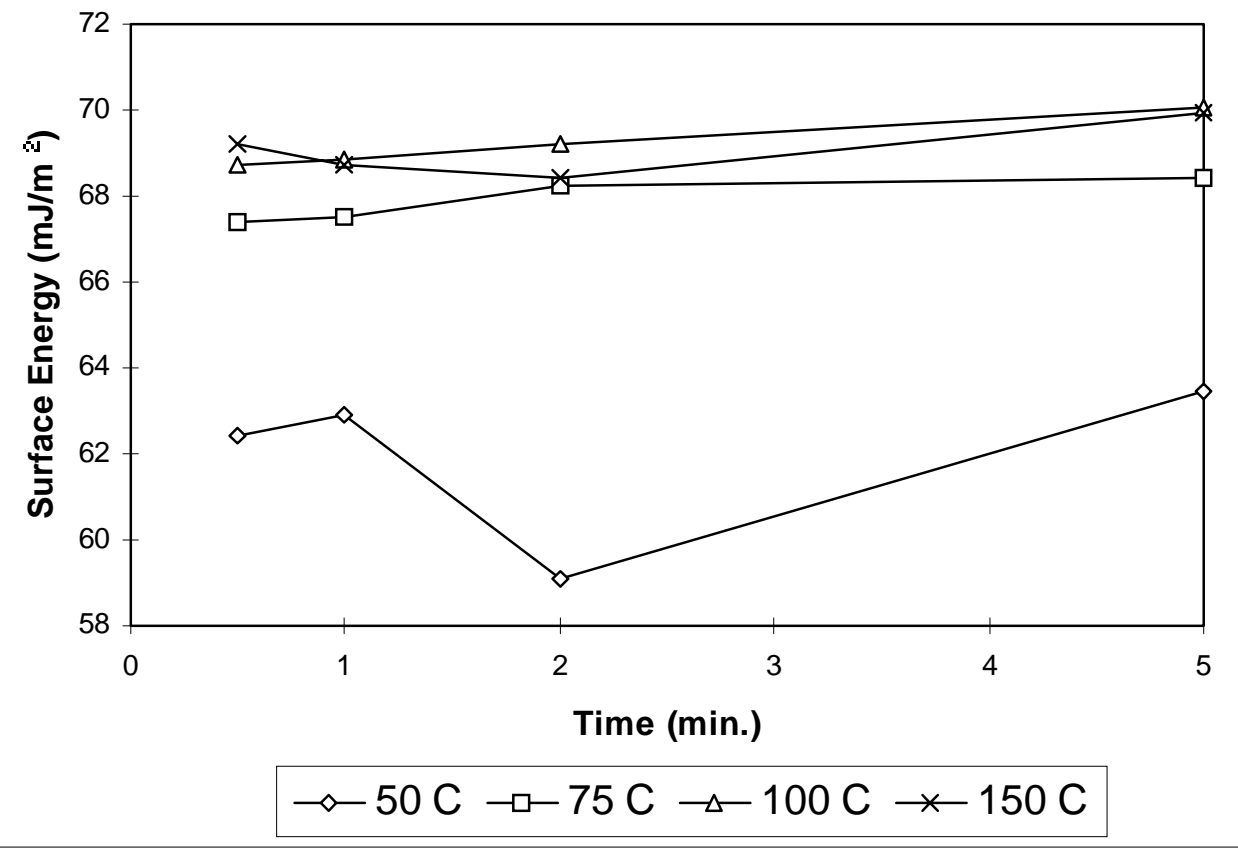

Figure B.2.33. Average surface energy of unextracted yellow-poplar sapwood exposed, at four temperatures, to a high energy environment (aluminum).

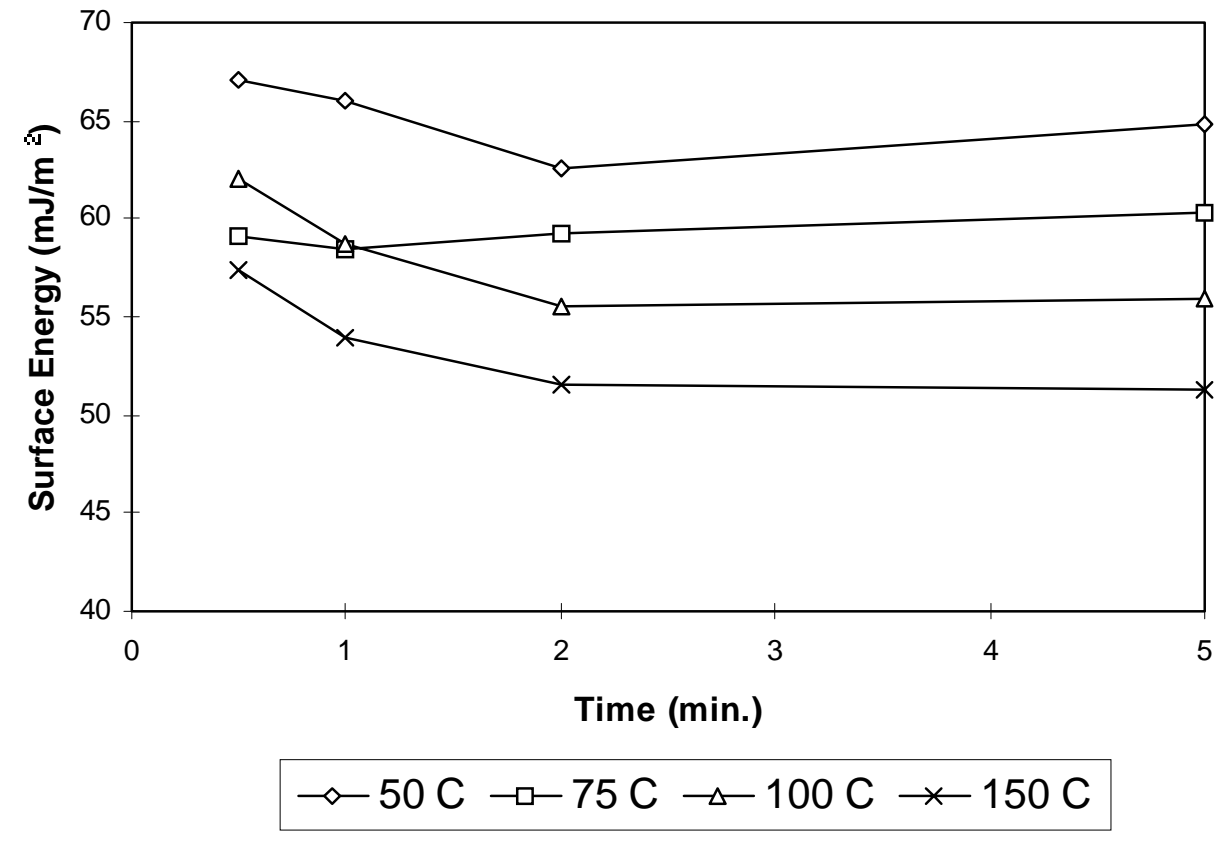

Figure B.2.34. Average surface energy of unextracted yellow-poplar sapwood exposed, at four temperatures, to a low energy environment (teflon). 


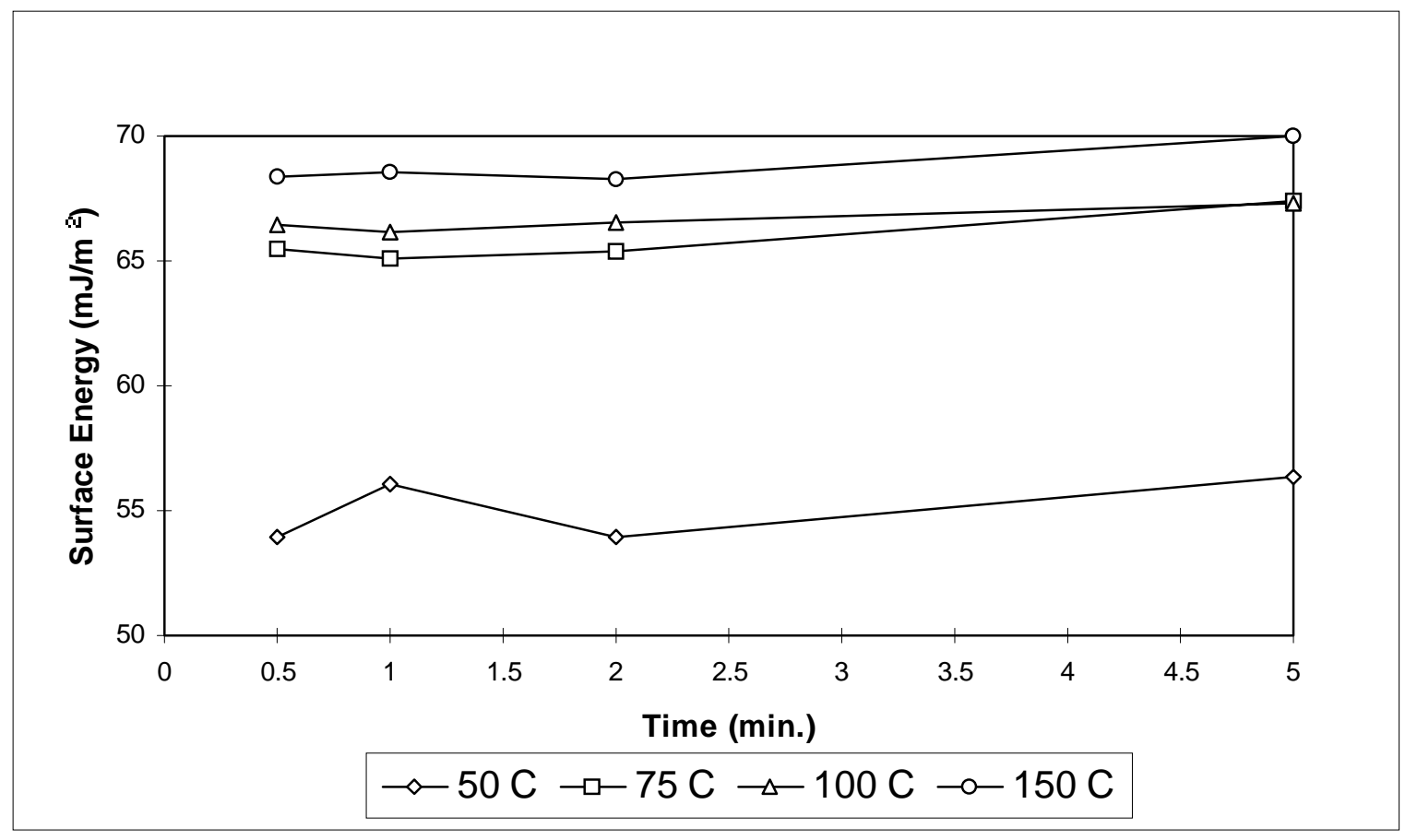

Figure B.2.35. Average surface energy of unextracted yellow-poplar heartwood exposed, at four temperatures, to a high energy environment (aluminum).

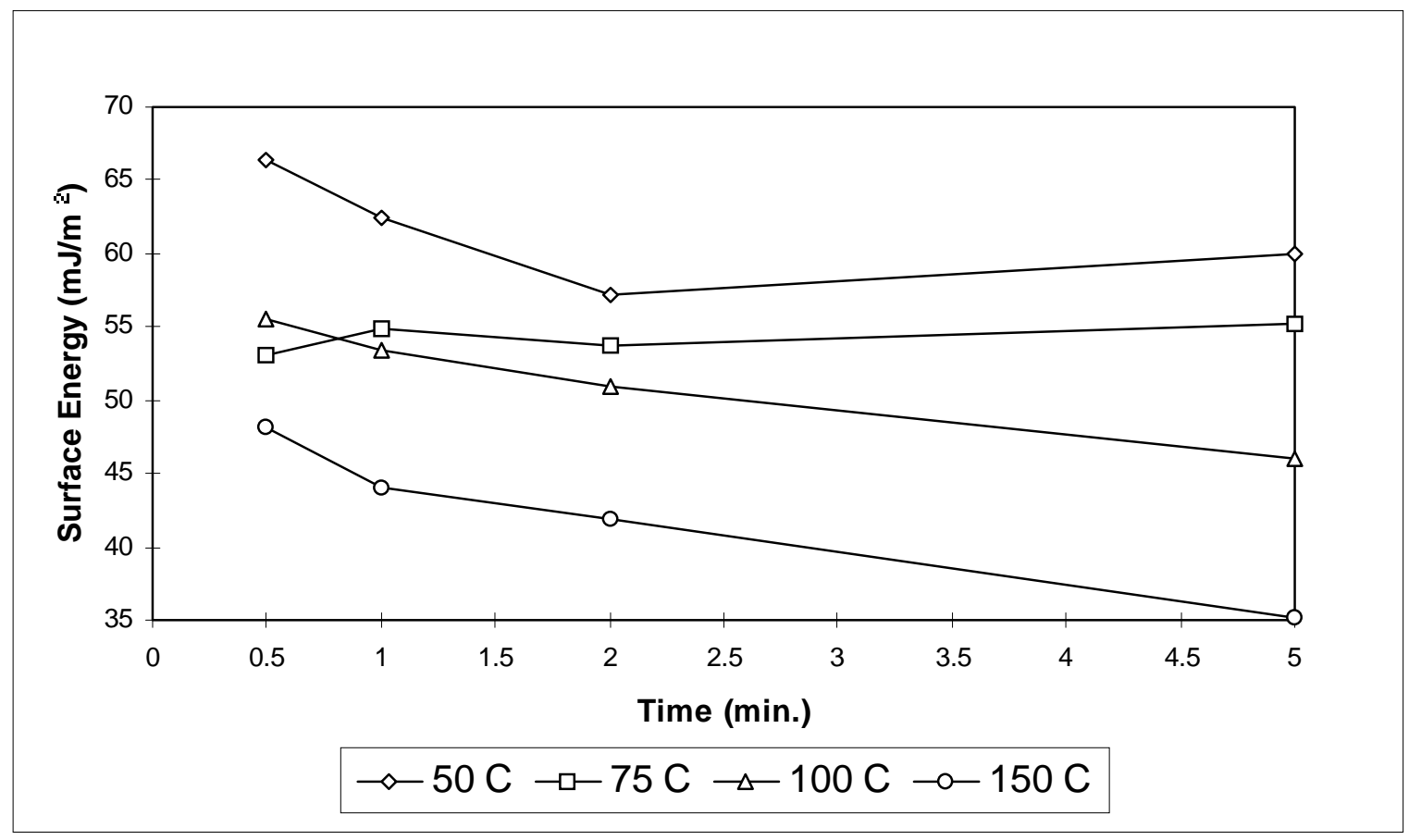

Figure B.2.36. Average surface energy of unextracted yellow-poplar heartwood exposed, at four temperatures, to a low energy environment (teflon). 


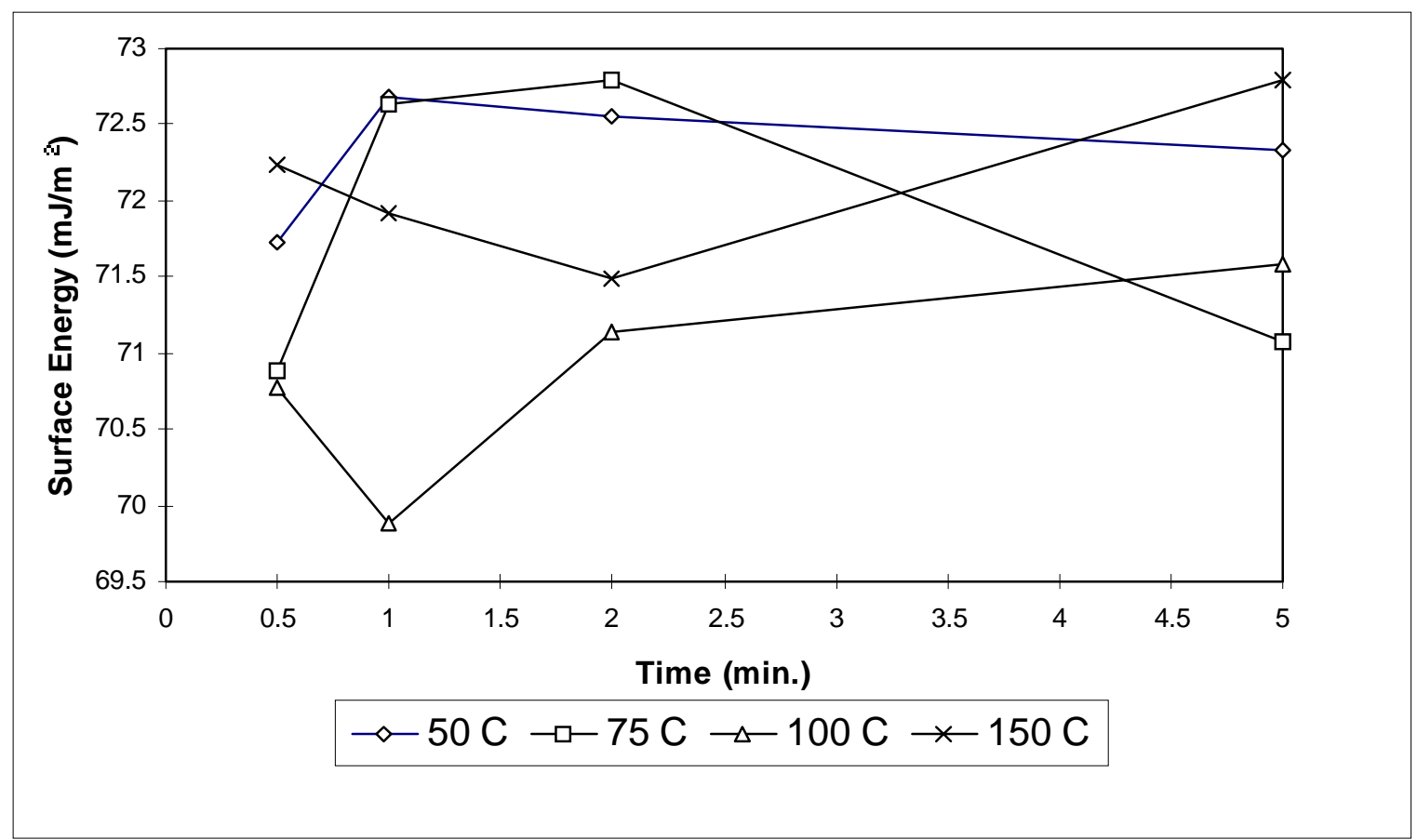

Figure B.2.37. Average surface energy of extracted yellow-poplar sapwood exposed, at four temperatures, to a high energy environment (aluminum).

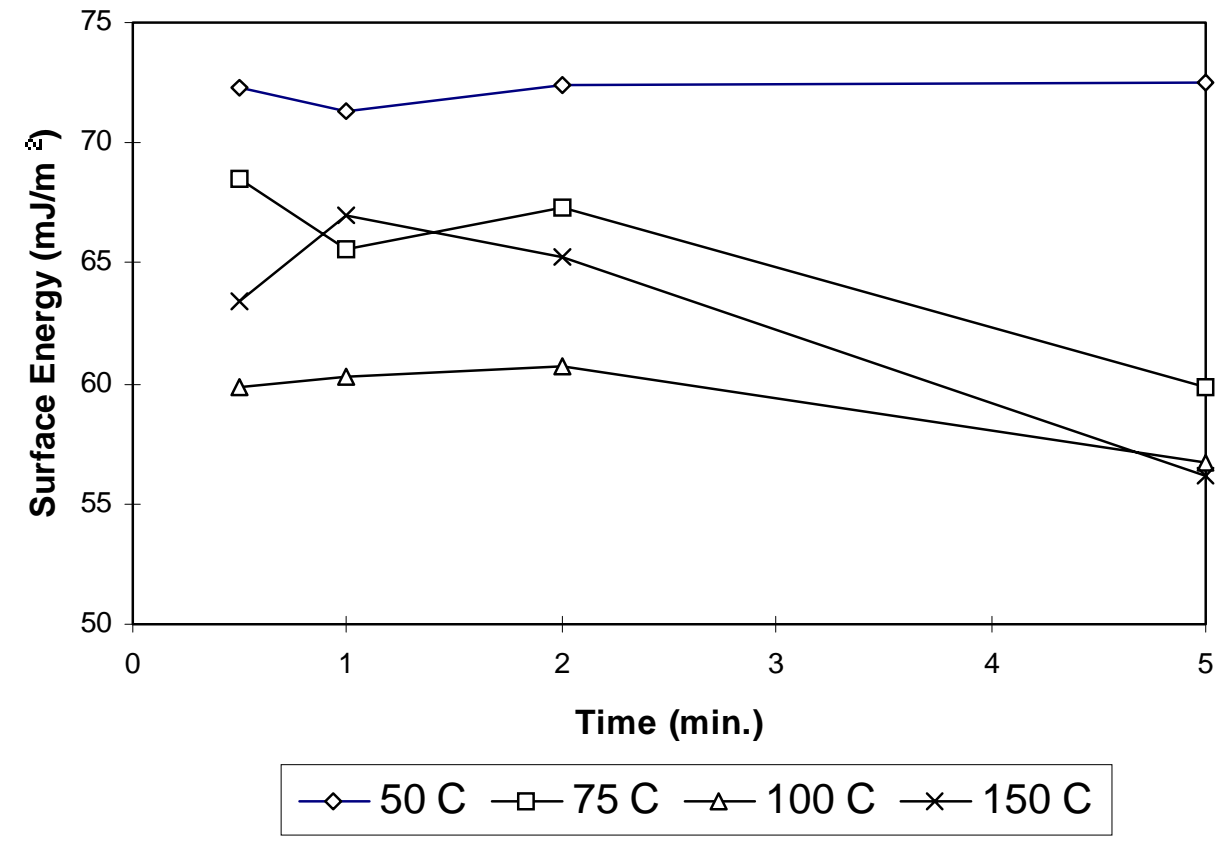

Figure B.2.38. Average surface energy of extracted yellow-poplar sapwood exposed, at four temperatures, to a low energy environment (teflon). 


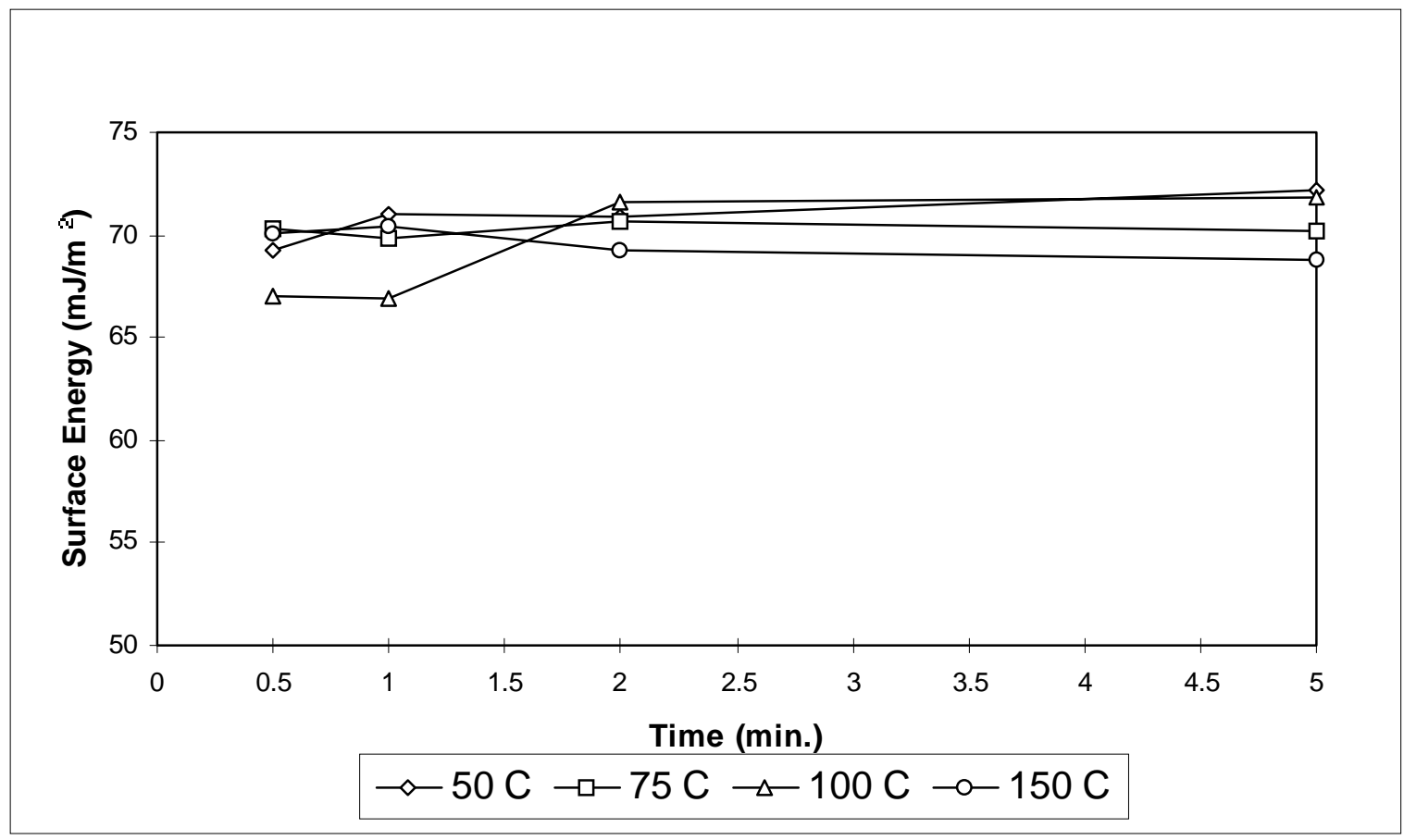

Figure B.2.39. Average surface energy of extracted yellow-poplar heartwood exposed, at four temperatures, to a high energy environment (aluminum).

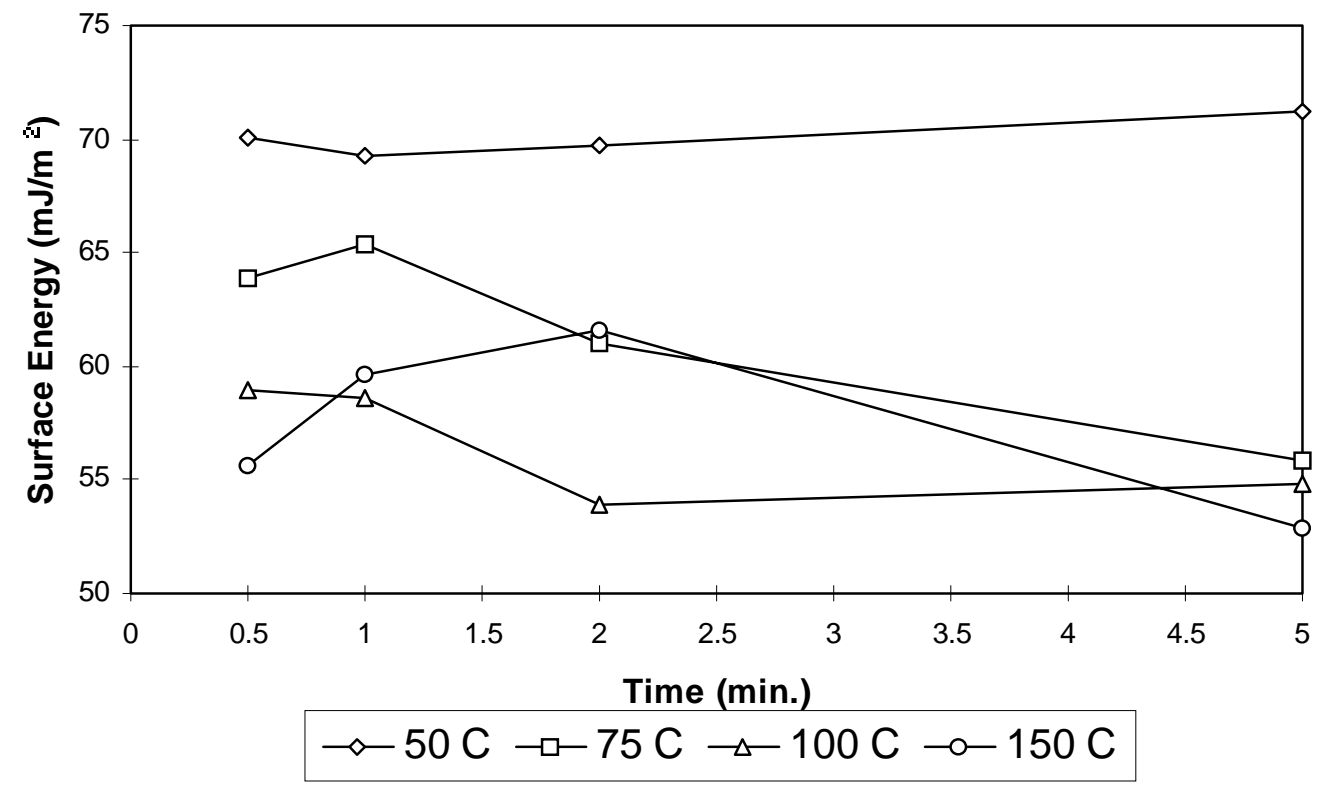

Figure B.2.40. Average surface energy of extracted yellow-poplar heartwood exposed, at four temperatures, to a low energy environment (teflon). 


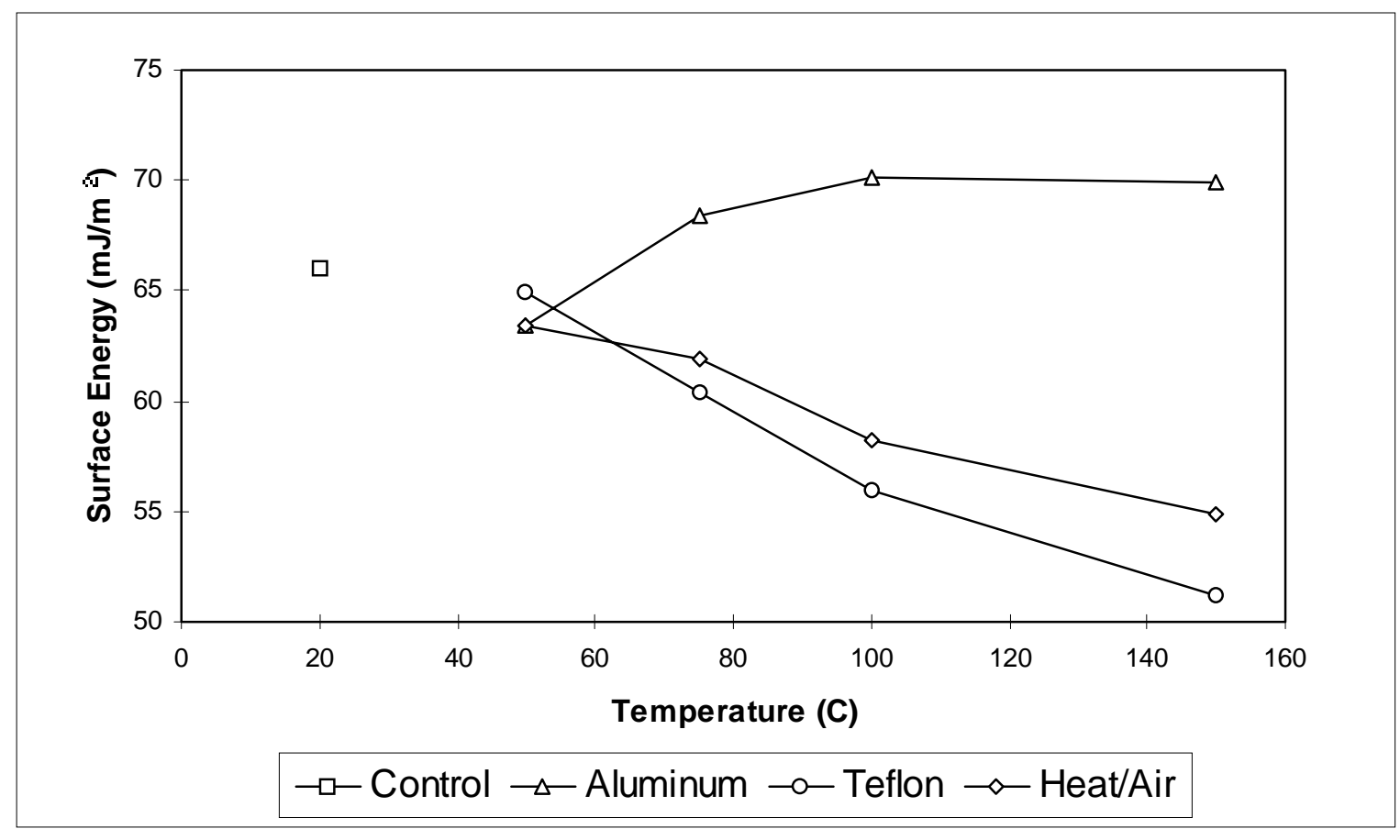

Figure B.2.41. Average surface energy of unextracted yellow-poplar sapwood exposed to environments of high energy (aluminum), low energy (teflon), and heat/air.

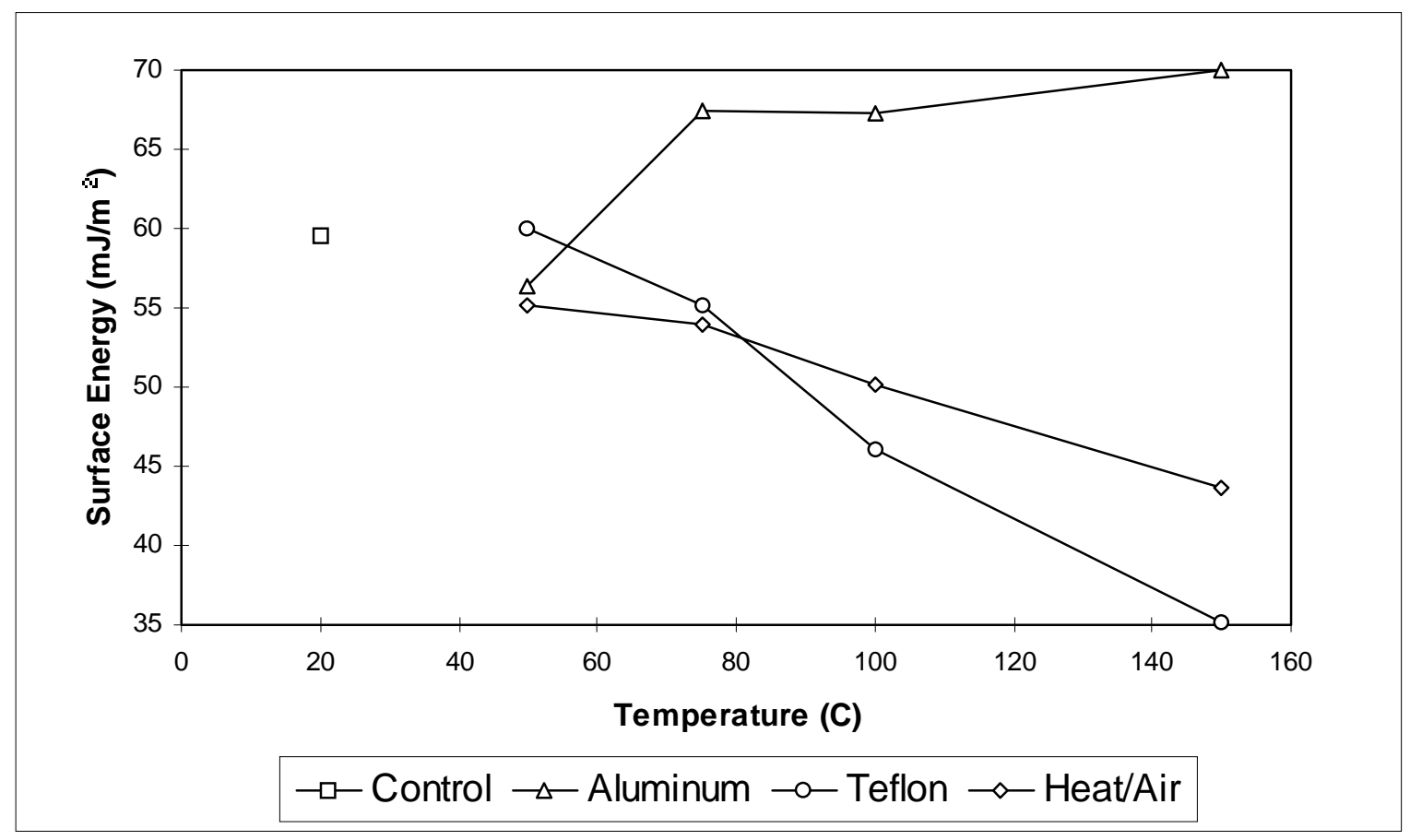

Figure B.2.42. Average surface energy of unextracted yellow-poplar heartwood exposed to environments of high energy (aluminum), low energy (teflon), and heat/air. 


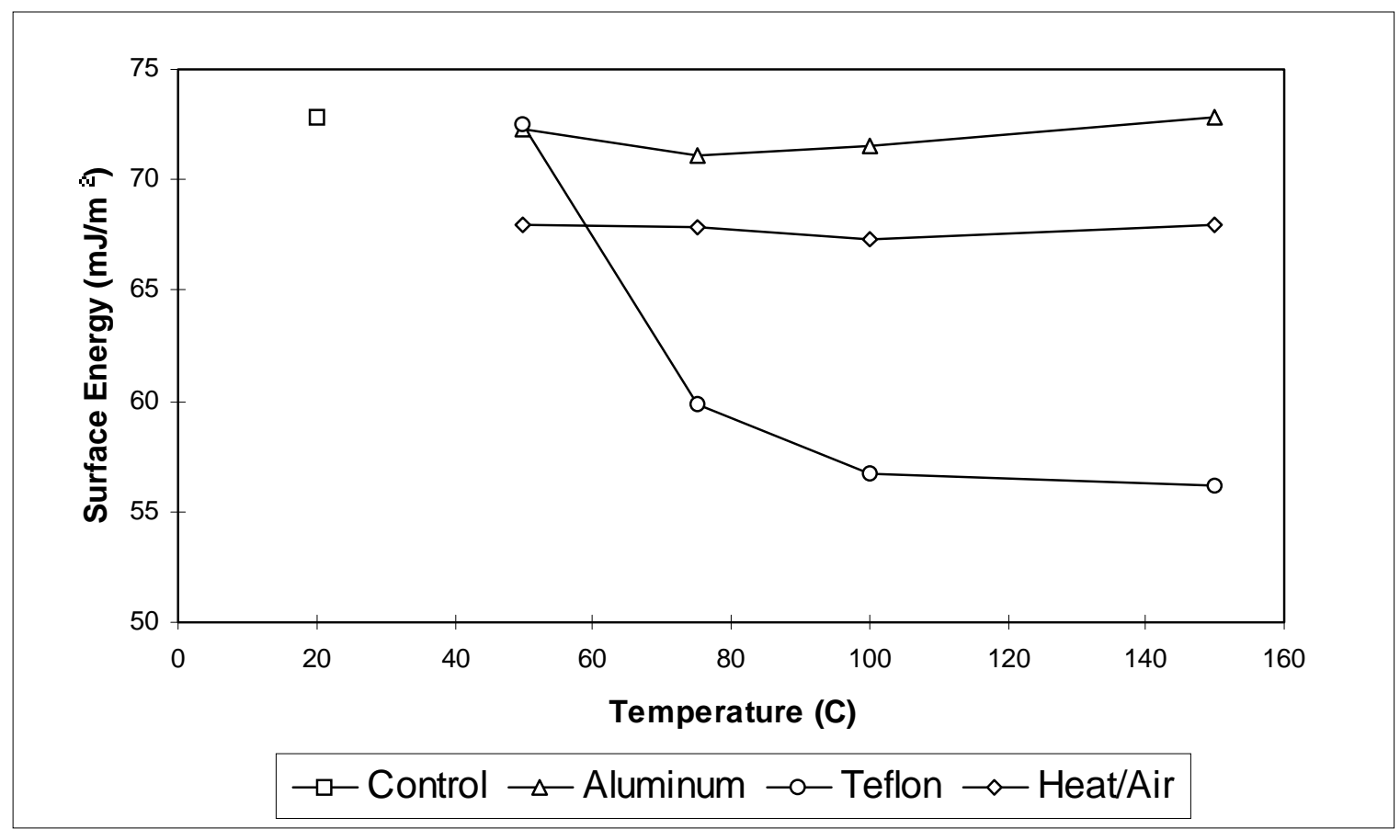

Figure B.2.43. Average surface energy of extracted yellow-poplar sapwood exposed to environments of high energy (aluminum), low energy (teflon), and heat/air.

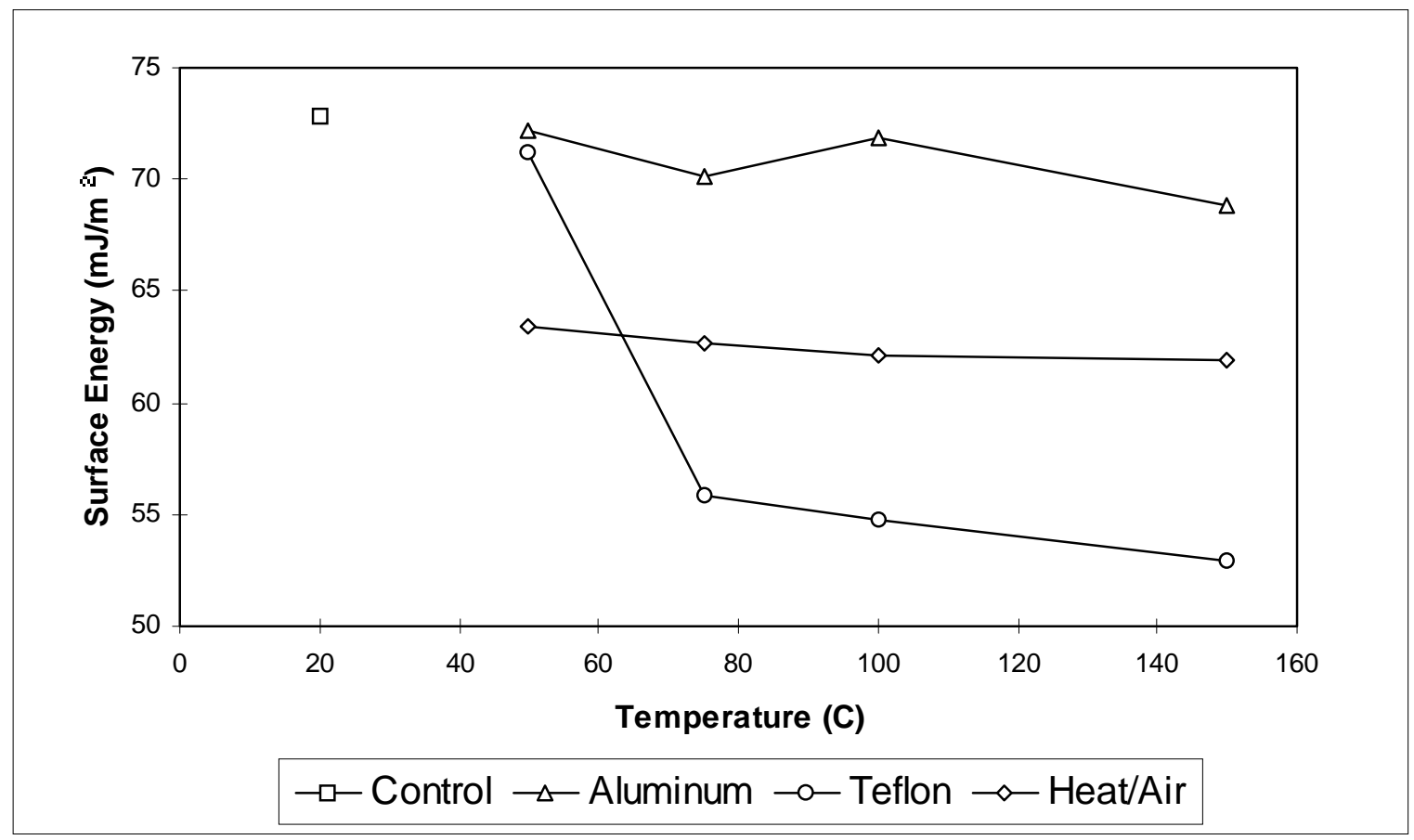

Figure B.2.44. Average surface energy of extracted yellow-poplar heartwood exposed to environments of high energy (aluminum), low energy (teflon), and heat/air. 


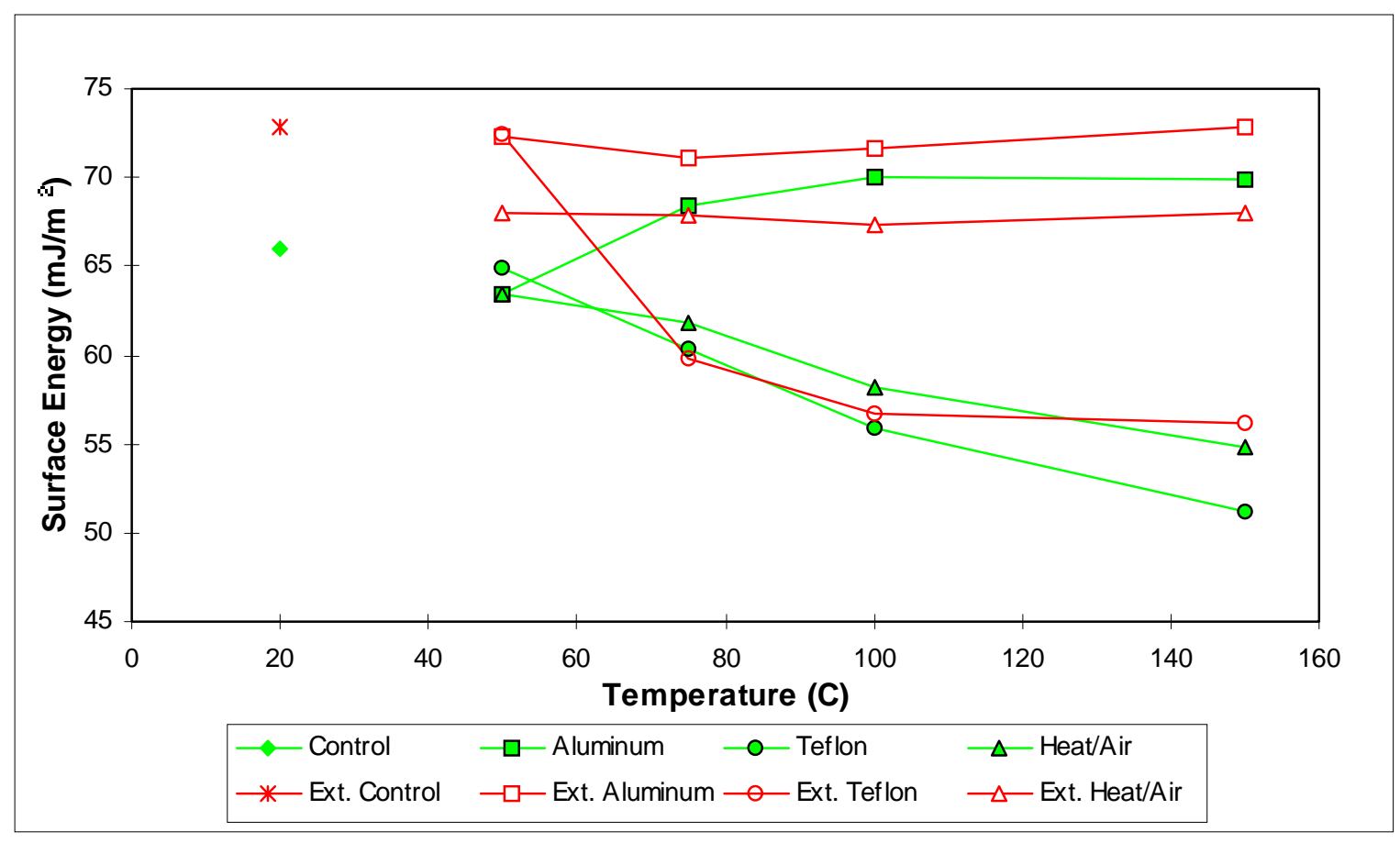

Figure B.2.45. Average surface energy of unextracted and extracted yellow-poplar sapwood exposed to environments of high energy (aluminum), low energy (teflon), and heat/air.

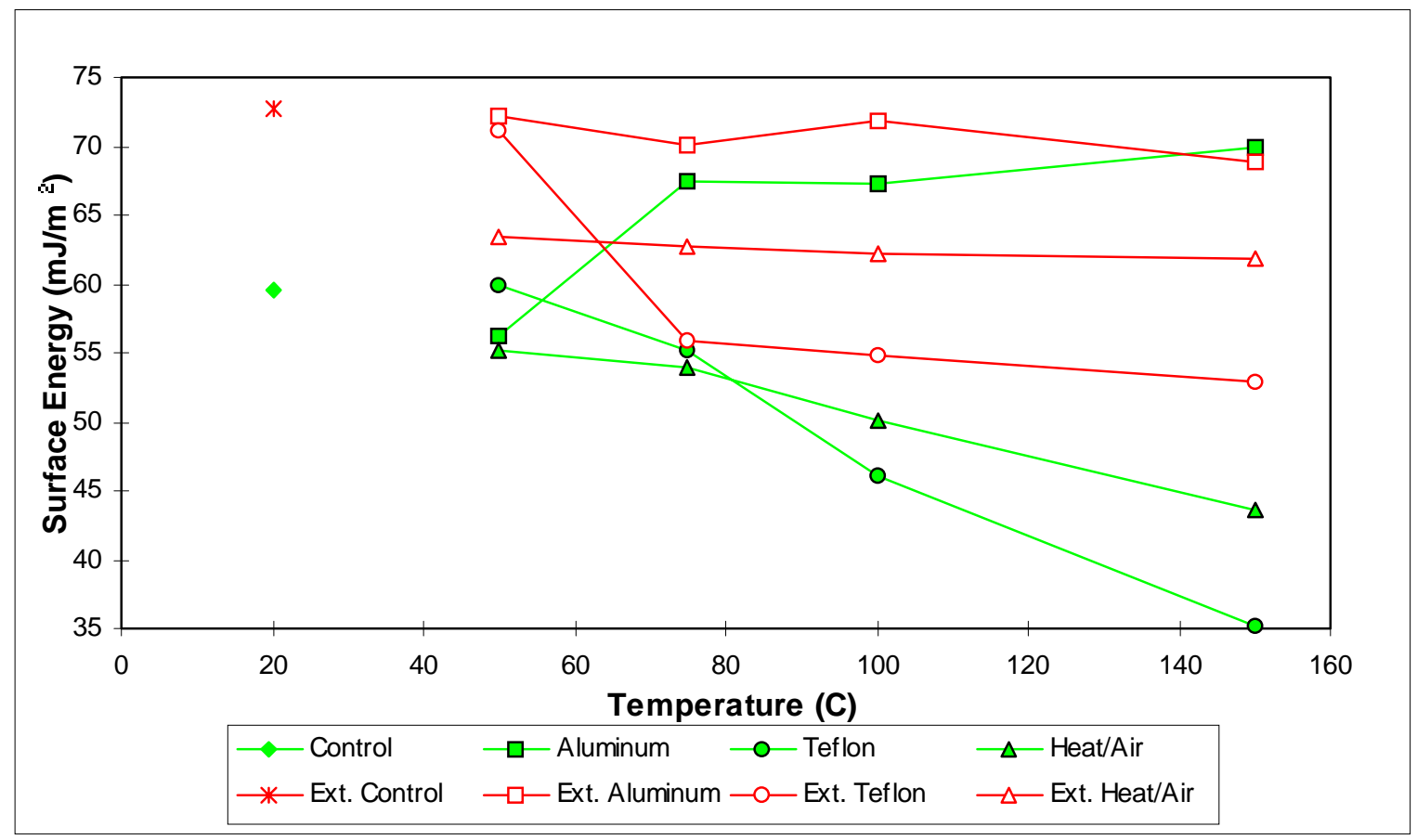

Figure B.2.46. Average surface energy of unextracted and extracted yellow-poplar heartwood exposed to environments of high energy (aluminum), low energy (teflon), and heat/air. 


\section{Appendix B.3}

Tables of Average Initial and Final Surface Energy of Unextracted and Extracted Yellow-Poplar Sapwood And Heartwood. 
Table B.3.1. Average Initial Surface Energy of Unextracted and Extracted Yellow-Poplar Sapwood and Heartwood.

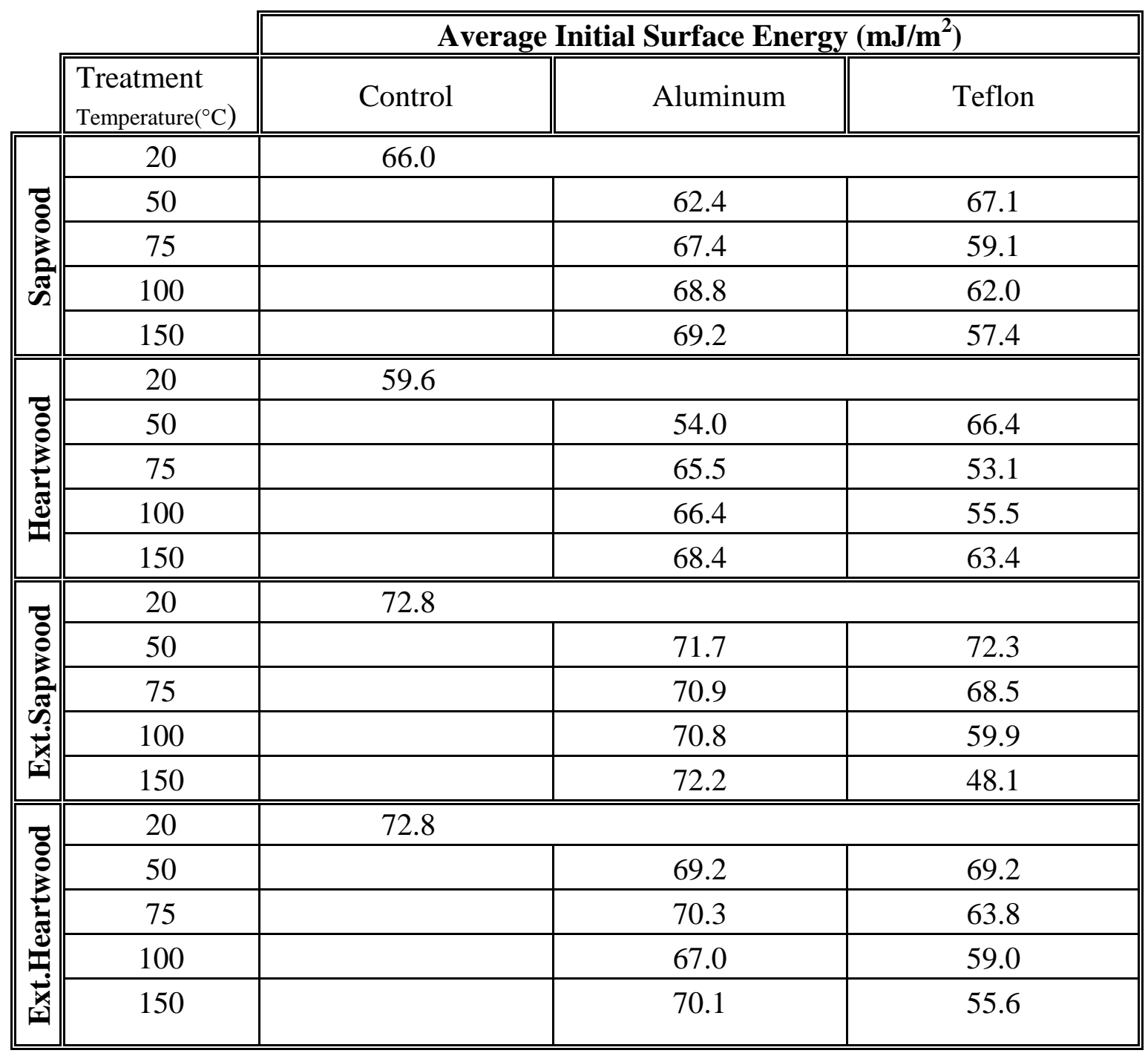


Table B.3.2. Average Final Surface Energy of Unextracted and Extracted Yellow-Poplar Sapwood and Heartwood.

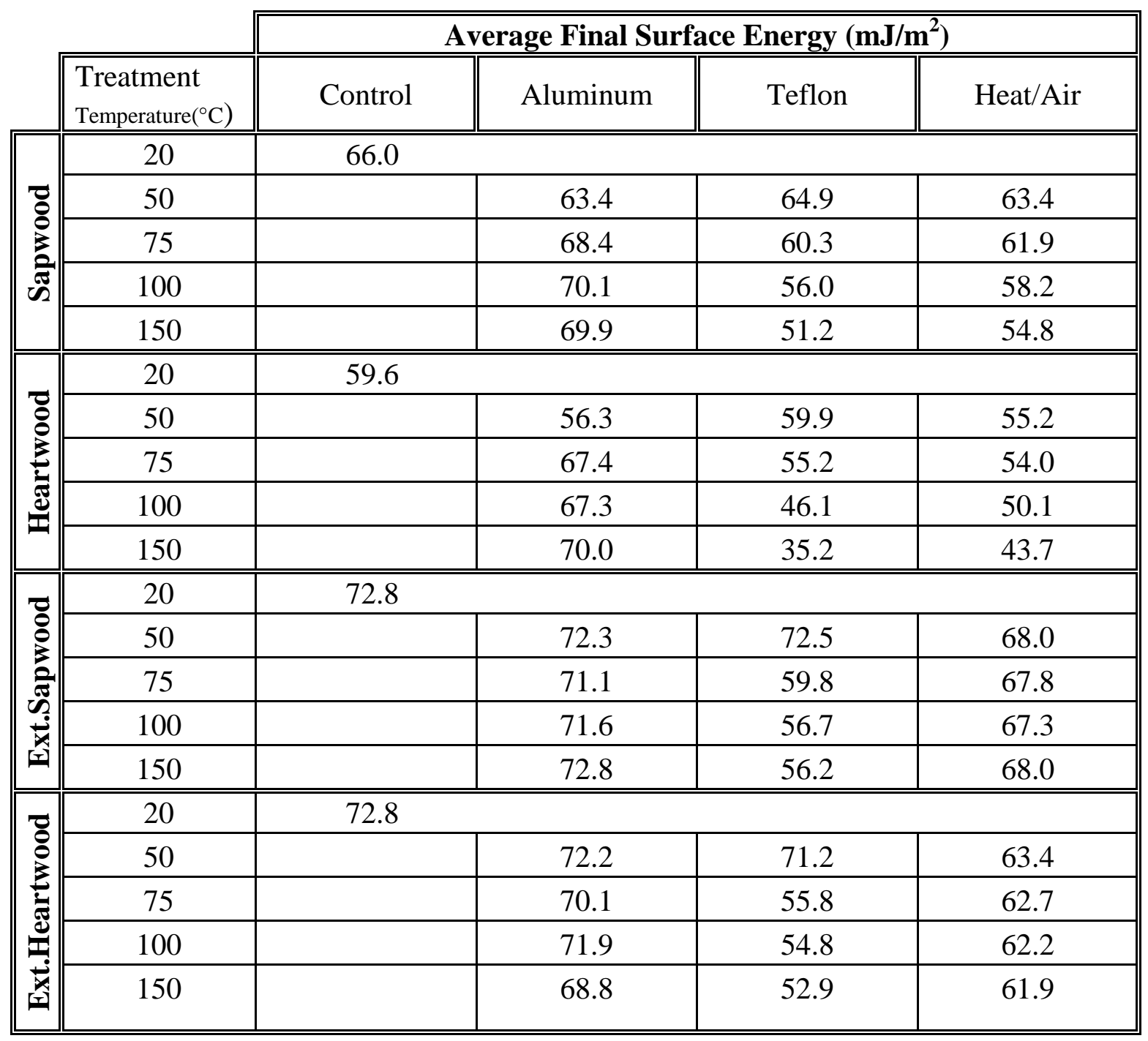




\section{Appendix B.4}

Tables of Statistical Analysis Results For Unextracted and Extracted Yellow-Poplar Sapwood And Heartwood. 
Table B.4.1. ANOVA of unextracted and extracted, heartwood and sapwood, initial surface energy values.

\begin{tabular}{|c|c|c|c|c|c|c|}
\hline M & Source & DF & SS & MS & F value & $\begin{array}{c}\operatorname{Pr}>F \\
(\alpha=0.05)\end{array}$ \\
\hline $\mathrm{O}$ & Model & 9 & 4392.53 & 488.06 & 45.46 & 0.0001 \\
\hline $\mathrm{D}$ & Error & 118 & 1266.85 & 10.74 & & \\
\hline $\mathrm{E}$ & Corr. Tot. & 127 & 5659.38 & & & \\
\hline $\mathrm{L}$ & \multicolumn{6}{|c|}{$\mathrm{r}^{2}=0.7762 \quad$ C. V. $=5.0765$} \\
\hline A & Source & DF & SS & MS & F value & $\begin{array}{c}\operatorname{Pr}>F \\
(\alpha=0.05)\end{array}$ \\
\hline $\mathrm{N}$ & Species & 1 & 458.10 & 458.10 & 42.67 & 0.0001 \\
\hline $\mathrm{O}$ & Ext & 1 & 881.90 & 881.90 & 82.14 & 0.0001 \\
\hline $\mathrm{V}$ & Trt & 1 & 1324.16 & 1324.16 & 123.34 & 0.0001 \\
\hline A & Temp & 3 & 242.06 & 80.69 & 7.52 & 0.0001 \\
\hline & Trt x Temp & 3 & 1486.31 & 495.44 & 46.15 & 0.0001 \\
\hline
\end{tabular}


Table B.4.2. Duncan grouping of initial surface energy; Means with the same letter are not significantly different $(\alpha=0.05)$ according to Duncan's New Multiple Range Test.

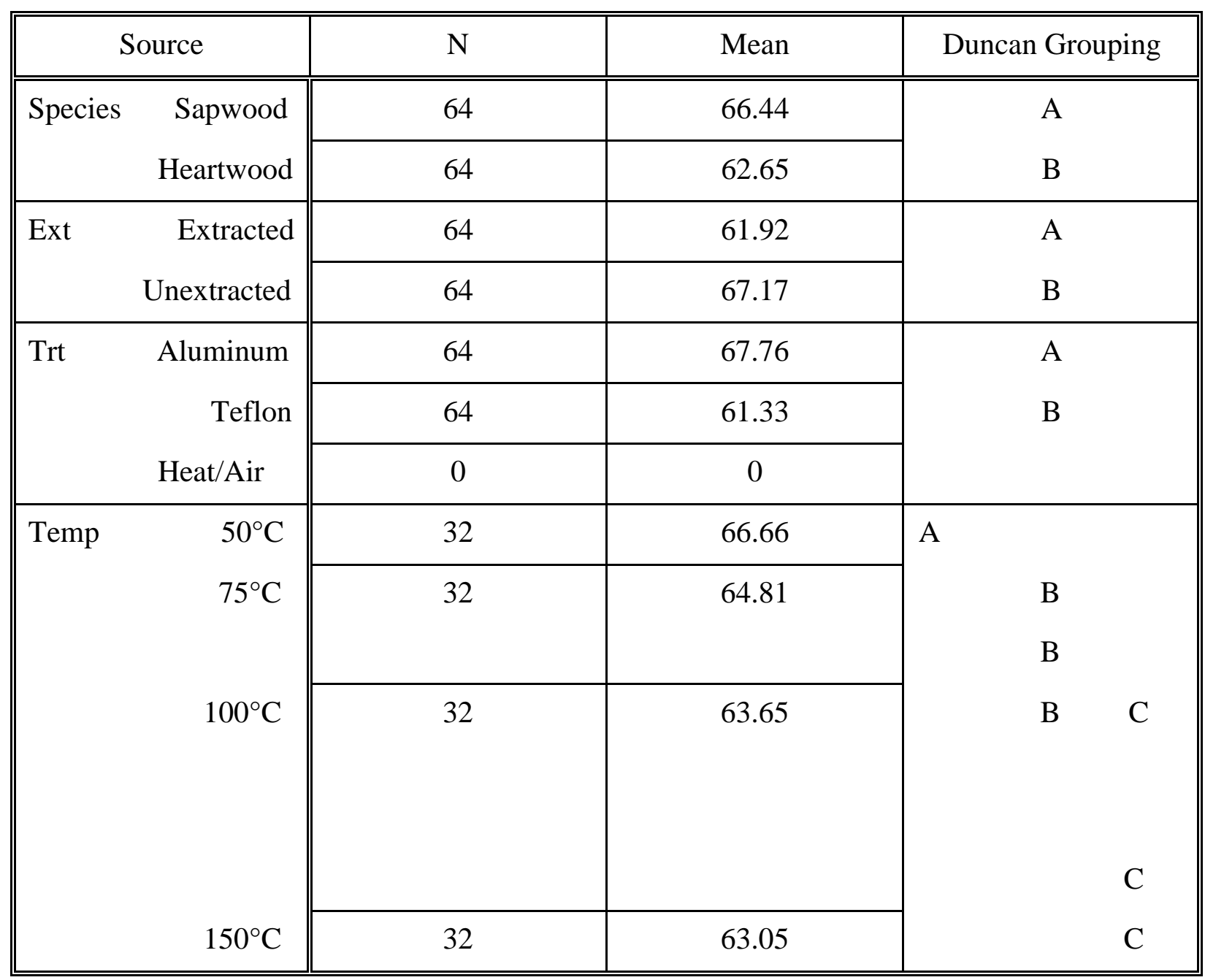


Table B.4.3. ANOVA of unextracted and extracted, heartwood and sapwood, final surface energy values.

\begin{tabular}{|c|c|c|c|c|c|c|}
\hline M & Source & DF & SS & MS & F value & $\begin{array}{c}\operatorname{Pr}>F \\
(\alpha=0.05)\end{array}$ \\
\hline $\mathrm{O}$ & Model & 13 & 12014.19 & 924.17 & 57.47 & 0.0001 \\
\hline $\mathrm{D}$ & Error & 178 & 2862.51 & 16.08 & & \\
\hline E & Corr. Tot. & 191 & 14876.70 & & & \\
\hline $\mathrm{L}$ & \multicolumn{6}{|c|}{$\mathrm{r}^{2}=0.8076 \quad$ C. $\mathrm{V} .=6.4706$} \\
\hline A & Source & DF & SS & MS & F value & $\begin{array}{c}\operatorname{Pr}>F \\
(\alpha=0.05)\end{array}$ \\
\hline $\mathrm{N}$ & Species & 1 & 1174.08 & 1174.08 & 73.01 & 0.0001 \\
\hline $\mathrm{O}$ & Ext & 1 & 2382.62 & 2382.62 & 148.16 & 0.0001 \\
\hline V & Trt & 2 & 5067.34 & 2533.67 & 157.55 & 0.0001 \\
\hline A & Temp & 3 & 1084.31 & 361.44 & 22.48 & 0.0001 \\
\hline & Trt $x$ Temp & 6 & 2305.84 & 384.31 & 23.90 & 0.0001 \\
\hline
\end{tabular}


Table B.4.4. Duncan grouping of final surface energy; Means with the same letter are not significantly different $(\alpha=0.05)$ according to Duncan's New Multiple Range Test.

\begin{tabular}{|c|c|c|c|c|}
\hline \multicolumn{2}{|c|}{ Source } & $\mathrm{N}$ & Mean & Duncan Grouping \\
\hline \multirow[t]{2}{*}{ Species } & Sapwood & 96 & 64.45 & A \\
\hline & Heartwood & 96 & 59.50 & B \\
\hline \multirow[t]{2}{*}{ Ext } & Extracted & 96 & 58.45 & A \\
\hline & Unextracted & 96 & 65.49 & $\mathrm{~B}$ \\
\hline \multirow[t]{3}{*}{ Trt } & Aluminum & 64 & 68.98 & A \\
\hline & Teflon & 64 & 56.79 & $\mathrm{~B}$ \\
\hline & Heat/Air & 64 & 60.16 & $\mathrm{C}$ \\
\hline \multirow[t]{4}{*}{ Temp } & $50^{\circ} \mathrm{C}$ & 48 & 65.23 & A \\
\hline & $75^{\circ} \mathrm{C}$ & 48 & 62.88 & B \\
\hline & $100^{\circ} \mathrm{C}$ & 48 & 61.01 & $\mathrm{C}$ \\
\hline & $150^{\circ} \mathrm{C}$ & 48 & 58.77 & $\mathrm{D}$ \\
\hline
\end{tabular}

